INFLUENCE OF SOLIDIFICATION PARAMETERS ON THE THERMAL CONDUCTIVITY OF CAST A319 ALUMINUM ALLOY

\author{
by \\ Eli Vandersluis \\ B.Eng., Ryerson University, 2014 \\ A thesis \\ presented to Ryerson University \\ in partial fulfillment of the \\ requirements for the degree of \\ Master of Applied Science \\ in the Program of \\ Mechanical and Industrial Engineering \\ Toronto, Ontario, Canada, 2016 \\ C Eli Vandersluis 2016
}




\section{AUTHOR'S DECLARATION}

I hereby declare that I am the sole author of this thesis. This is a true copy of the thesis, including any required final revisions, as accepted by my examiners.

I authorize Ryerson University to lend this thesis to other institutions or individuals for the purpose of scholarly research.

I further authorize Ryerson University to reproduce this thesis by photocopying or by other means, in total or in part, at the request of other institutions or individuals for the purpose of scholarly research.

I understand that my thesis may be made electronically available to the public. 


\title{
ABSTRACT \\ INFLUENCE OF SOLIDIFICATION PARAMETERS ON THE THERMAL CONDUCTIVITY OF CAST A319 ALUMINUM ALLOY
}

\author{
Master of Applied Science, 2016 \\ Eli Vandersluis \\ Mechanical and Industrial Engineering \\ Ryerson University
}

One of the major causes of premature failure in A319 aluminum alloy powertrain components is the accumulation of thermal stresses. Consequently, the engine operating temperature is restricted to prevent large internal temperature gradients in the components, thereby reducing thermal efficiency. The objective of this research was to investigate the influence of solidification parameters on the thermal conductivity of A319 alloy, in an effort to promote uniform temperature distributions in powertrain components. Castings with varying mould preheating temperatures were characterized using thermal analysis, microstructural analysis, mechanical testing, and thermal conductivity measurements via the transient plane source method. The results indicated that increasing solidification rate was associated with two competing phenomena: Whereas finer secondary phases improved conductivity, a finer dendritic structure reduced conductivity. As a result, a critical solidification rate was found to attain maximum thermal conductivity in A319. 


\section{ACKNOWLEDGEMENTS}

I would like to express my deepest gratitude to my supervisor, Professor C. Ravindran, for his ongoing support, guidance, encouragement, and motivation to continually challenge myself during my graduate studies.

I am extremely grateful to Mr. Alan Machin, for his technical knowledge, advice, and assistance with the design and machining of the permanent moulds, the interpretation of results, and many other aspects of this research.

I am thankful to Mr. Jose del Castillo-Sierra, Dr. Anthony Lombardi, Mr. Suleman Ahmad, and Dr. Abdallah Elsayed of the Centre for Near-net-shape Processing of Materials at Ryerson University for their meaningful discussions and assistance with experiments.

I am also thankful to Mr. Joseph Amankrah for technical assistance.

I am grateful to Mr. Thomas Warren of Gamma Foundries Inc. for chemical analysis of samples.

Finally, I would like to thank my family and friends for their essential support and patience during this academic journey. 


\section{TABLE OF CONTENTS}

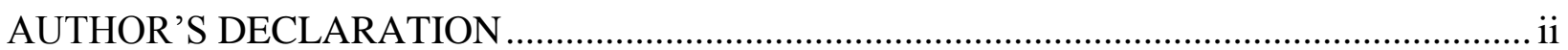

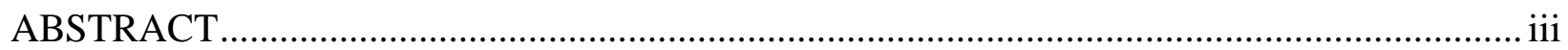

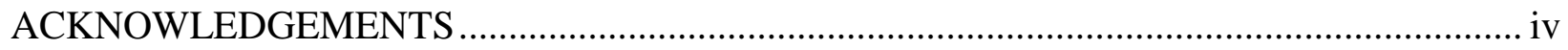

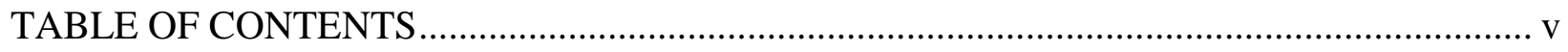

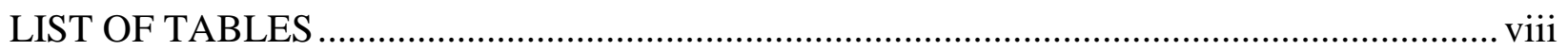

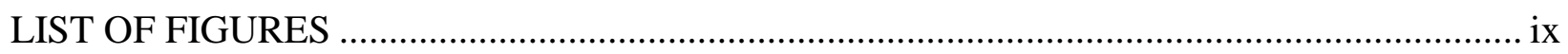

NOMENCLATURE ………………………………............................................... xiv

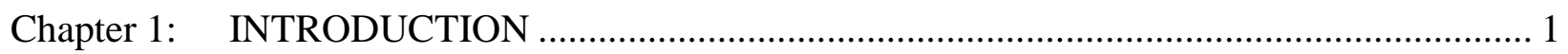

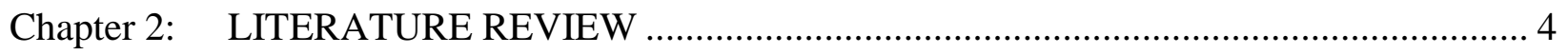

2.1. A319 Aluminum Alloy …………………………............................................... 4

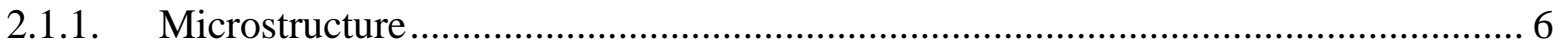

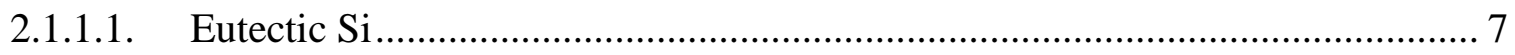

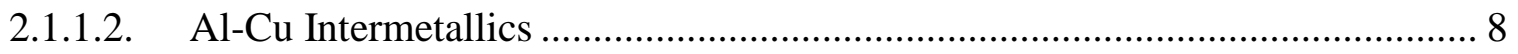

2.1.1.3. Mg-Bearing Intermetallics.................................................................... 9

2.1.1.4. Fe-Bearing Intermetallics ....................................................................... 9

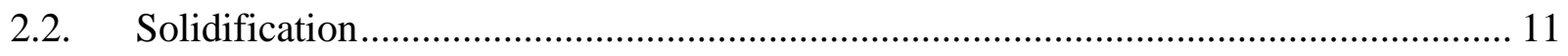

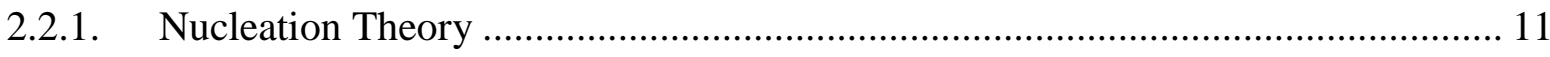

2.2.1.1. Homogeneous Nucleation............................................................................ 12

2.2.1.2. Heterogeneous Nucleation....................................................................... 14

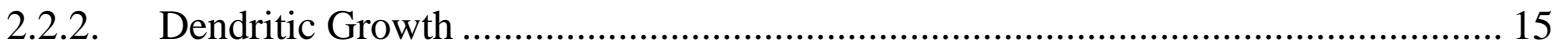

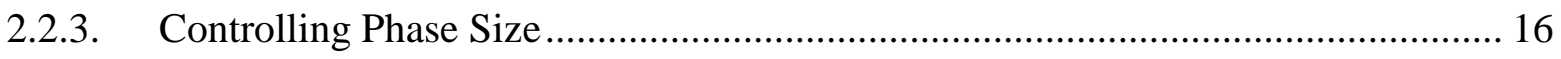

2.2.3.1. Influence on Mechanical Properties ............................................................ 20

2.2.4. Development of A319 Alloy Microstructure …………………………….......... 22 


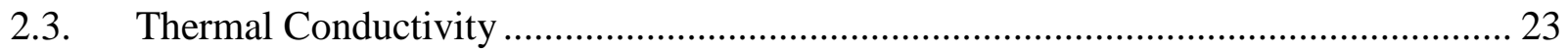

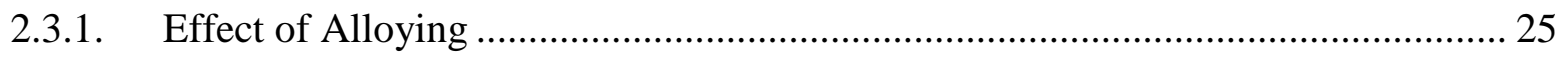

2.3.1.1. Elements in Solid Solution ...................................................................... 26

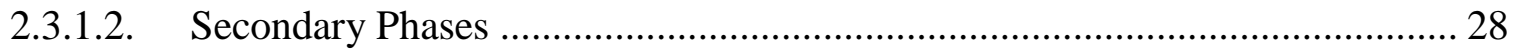

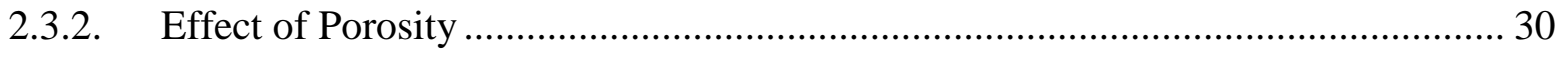

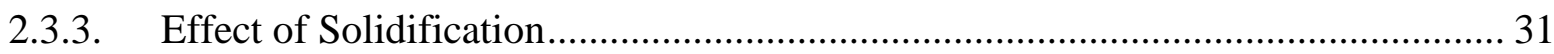

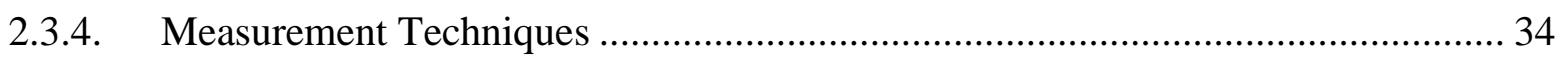

2.3.4.1. Transient Plane Source Technique ……………………………………..... 35

Chapter 3: EXPERIMENTAL PROCEDURE …………………............................................ 40

3.1. Permanent Mould Design .................................................................................. 40

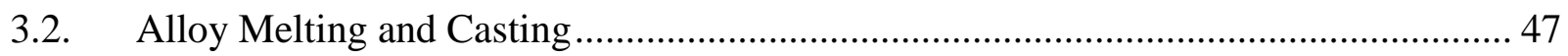

3.2.1. Mould Temperature Control ............................................................................ 48

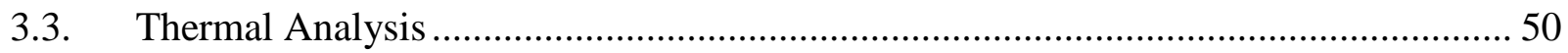

3.4. Sample Sectioning and Preparation ....................................................................... 52

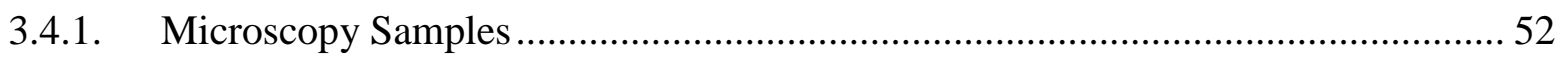

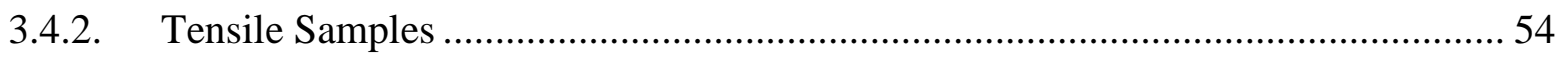

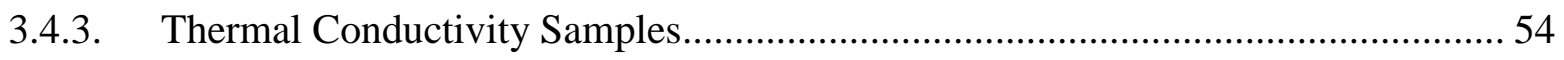

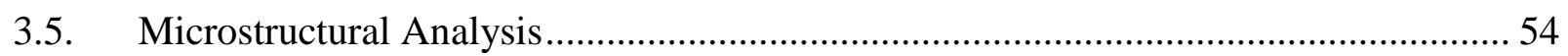

3.5.1. Measurement of Secondary Dendrite Arm Spacing (SDAS) ……………............. 54

3.5.2. Quantitative Image Analysis ............................................................................. 55

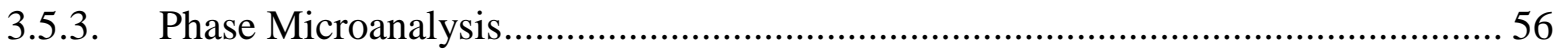

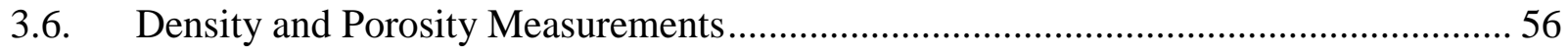

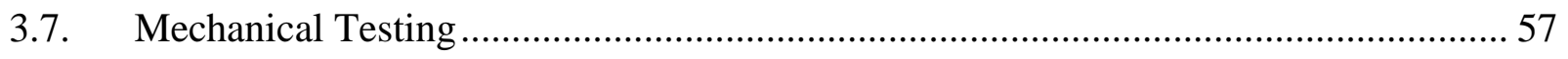

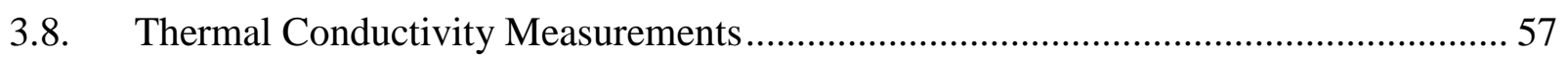

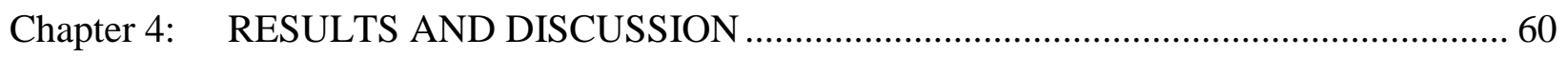




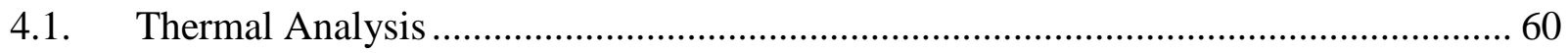

4.1.1. Relationships between Solidification Parameters .................................................... 65

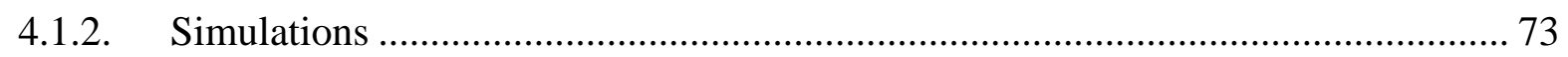

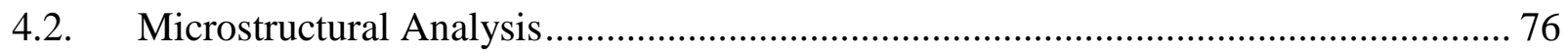

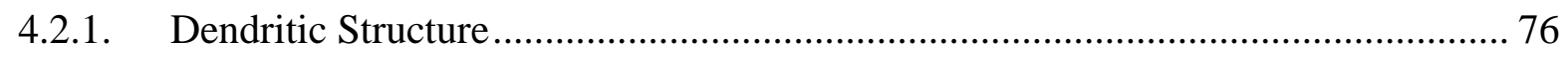

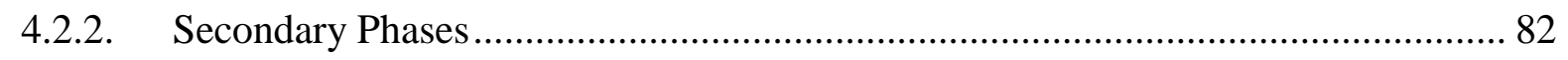

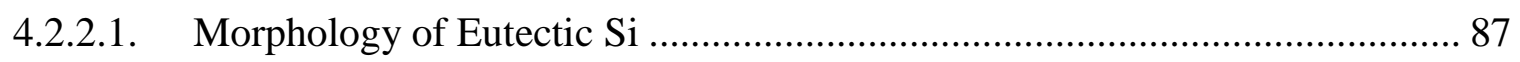

4.2.2.2. Morphology of Intermetallic Compounds ……………................................... 95

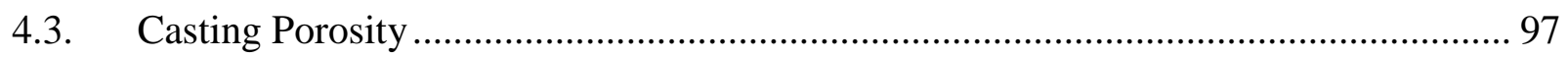

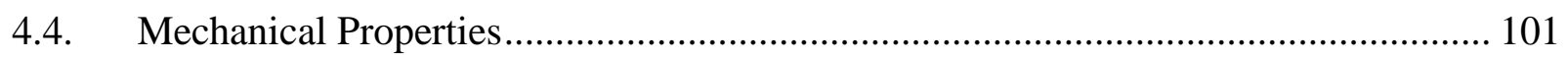

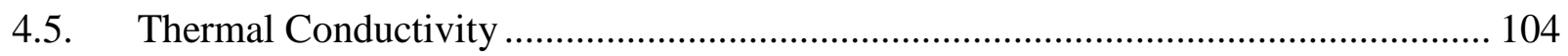

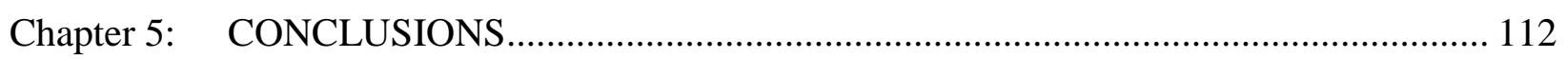

Chapter 6: RECOMMENDATIONS FOR FUTURE WORK ……………………............... 115

APPENDIX A: AL-SI-CU TERNARY PHASE DIAGRAM ……………………….................... 116

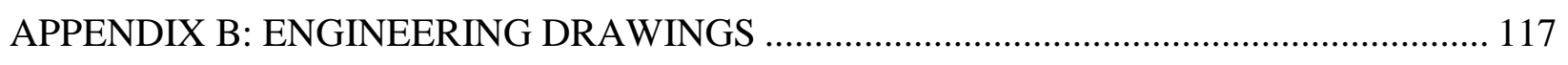

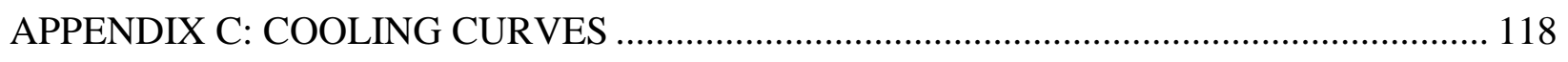

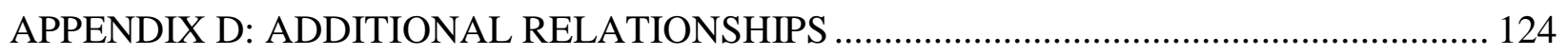

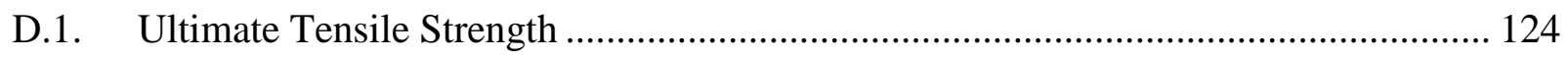

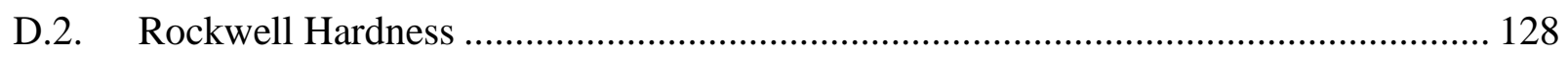

D.3. Thermal Conductivity ..................................................................................... 132

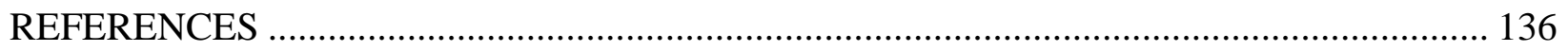




\section{LIST OF TABLES}

Table 2-1: Nominal chemical composition of A319 alloy [1] .............................................. 5

Table 2-2: Typical properties of permanent mould as-cast 319 -type alloys [1] ......................... 5

Table 2-3: Description of phase formation reactions during solidification of A319 [21] ........... 23

Table 2-4: Effect of elements in and out of solid solution on the resistivity of aluminum [25] ... 27

Table 3-1: Built-in SOLIDCast property data for Al 319.0 ................................................... 42

Table 3-2: Average experimental chemical composition of A319 alloy ................................. 48

Table 3-3: Initial mould temperatures for experimental castings .............................................. 50

Table 3-4: Metallographic polishing procedure ................................................................. 53

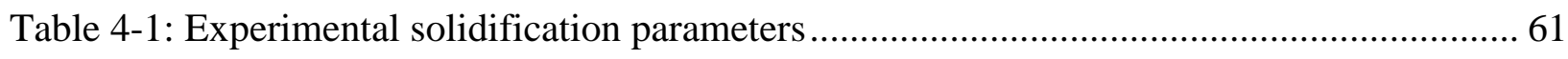

Table 4-2: Median values for the eutectic Si particle morphology in each casting condition ...... 95 


\section{LIST OF FIGURES}

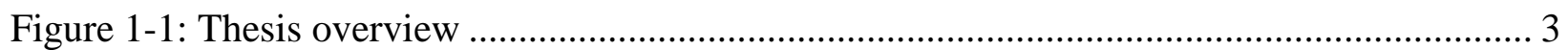

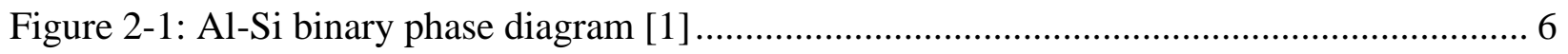

Figure 2-2: Optical micrograph of A319 in as-cast condition [3] .......................................... 7

Figure 2-3: Optical micrographs of Al-Si eutectic morphology: (a) fully unmodified microstructure, (b) lamellar microstructure, (c) partially modified microstructure, (d) modified microstructure, and (e) very fine microstructure [7] ....................................... 8

Figure 2-4: BSE images of $\mathrm{A} 319$ in the as-cast condition showing: (a) eutectic $\mathrm{Al}_{2} \mathrm{Cu}$ morphology, (b) blocky $\mathrm{Al}_{2} \mathrm{Cu}$ morphology [3] ........................................................ 9

Figure 2-5: BSE images for an Al-6.5Si-3.5Cu alloy with an Fe:Mn ratio of: (a) 25, (b) 1.67, (c)

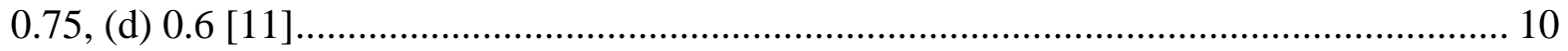

Figure 2-6: Tensile properties of a 319 alloy as a function of the Fe/Mn ratio showing: (a) ultimate tensile strength and yield strength in as-cast (left bars) and T6 heat treated conditions (right bars), (b) percent elongation in the T6 condition [11] 11

Figure 2-7: Schematic curve for volume free energy, total free energy, and surface free energy as a function of nucleating particle radius [12] 13

Figure 2-8: Typical cooling curve in homogeneous nucleation showing undercooling [13] ....... 14

Figure 2-9: Schematic of heterogeneous nucleation on a surface [12] ................................... 15

Figure 2-10: Schematic of dendrites and secondary dendrite arm spacing [15]...................... 16

Figure 2-11: Schematic plot of nucleation rate, growth rate, and overall transformation rate as a

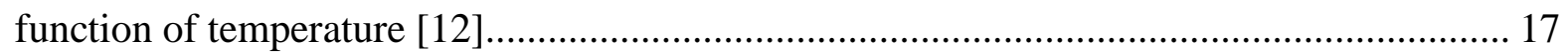

Figure 2-12: Schematic representation of coring during non-equilibrium cooling in an

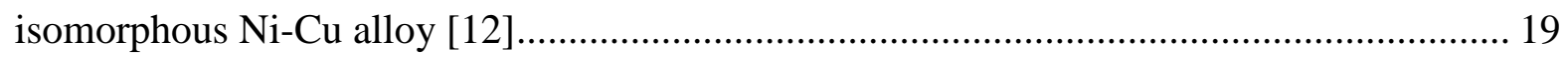

Figure 2-13: Mechanisms of dislocation interactions with secondary particles: (a) particle

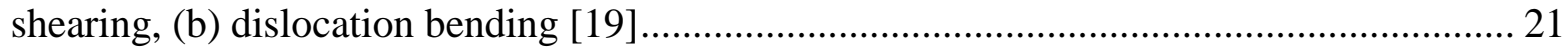

Figure 2-14: Typical cooling curve, first derivative curve, and zero line for 319 alloy [22] ....... 23 Figure 2-15: Room-temperature electrical conductivity of $\mathrm{Al}-\mathrm{Si}-\mathrm{Mg}$ alloys at low Si levels after

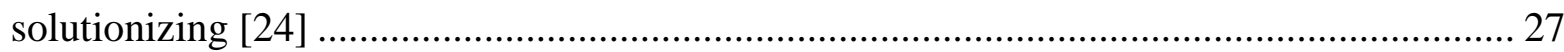


Figure 2-16: Room-temperature electrical conductivity of Al-Si-Mg alloys at hypoeutectic Si

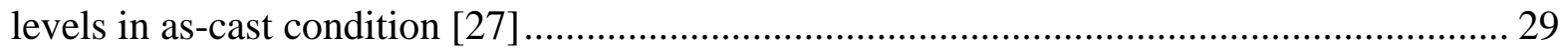

Figure 2-17: SEM micrographs and schematic representations of electron collisions with deepetched eutectic Si: (a) unmodified and (b) modified [27] ............................................... 30

Figure 2-18: Thermal conductivity in Al 380 as a function of porosity: directly measured (solid line) and estimated by the Maxwell model (broken line) [29] ......................................... 31

Figure 2-19: Variation of thermal conductivity of A319 as a function of SDAS ( $\lambda$ ) [33] .......... 32

Figure 2-20: Electrical conductivity as a function of SDAS for modified (0.038 wt.\% Sr) and

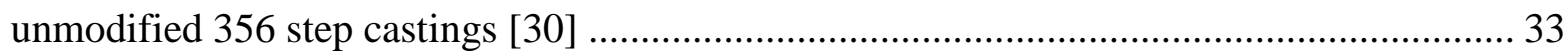

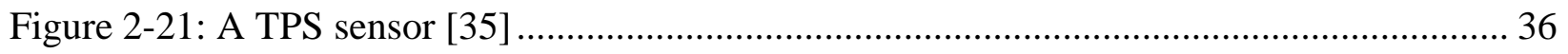

Figure 2-22: Temperature increase of the TPS sensor (top curve) and the sample surface (bottom

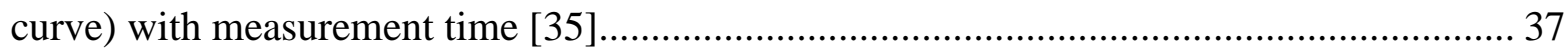

Figure 3-1: Model of an example casting design .......................................................... 41

Figure 3-2: Simulated cooling curve for Al 319.0 ....................................................... 43

Figure 3-3: Simulated primary solidification rate as a function of initial mould temperature and casting thickness 44

Figure 3-4: Simulated graphical representation of the variation in solidification rate for a $10 \mathrm{~mm}$ thick casting with $500{ }^{\circ} \mathrm{C}$ initial mould temperature................................................... 45

Figure 3-5: Final casting (left) and permanent mould (right) designs ................................... 47

Figure 3-6: Thermocouple placement and labeling in the permanent mould ............................ 49

Figure 3-7: Typical cooling curve attained for A319 alloy ............................................. 51

Figure 3-8: Analyzed sample locations (arrows indicate measurement side).......................... 52

Figure 3-9: Specific heat measurement setup ............................................................ 58

Figure 3-10: Thermal conductivity and diffusivity measurement setup ................................ 59

Figure 4-1: Experimental cooling curves for all initial mould temperatures........................... 61

Figure 4-2: Primary solidification rate as a function of initial mould temperature ................... 62

Figure 4-3: Primary solidification rate as a function of average mould temperature at the start of solidification 64

Figure 4-4: Total solidification rate and local solidification time as a function of initial mould

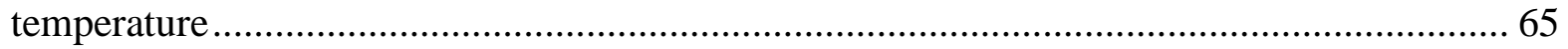

Figure 4-5: Primary solidification rate as a function of primary solidification time 67 
Figure 4-6: Total solidification rate as a function of local solidification time 67

Figure 4-7: Total solidification rate as a function of primary solidification rate. 69

Figure 4-8: Local solidification time as a function of primary solidification time. 69

Figure 4-9: Graphical exaggeration of cooling curves for fast solidification (A) and slow solidification (B), demonstrating a greater difference in rates at lower temperatures 70

Figure 4-10: Primary solidification rate as a function of local solidification time ..................... 71

Figure 4-11: Total solidification rate as a function of primary solidification time .................... 72

Figure 4-12: Top view of SOLIDCast simulated mould and casting geometry ....................... 75

Figure 4-13: Experimental and simulated primary solidification rate of A319 as a function of mould temperature, using the suggested $1135 \mathrm{~W} / \mathrm{m}^{2} \mathrm{~K}$ and a best-fitted $6000 \mathrm{~W} / \mathrm{m}^{2} \mathrm{~K}$ metalmould convective heat transfer coefficient 75

Figure 4-14: Optical micrographs at 50x magnification showing progressive refinement of dendritic structure (characterized by SDAS values shown) with decreasing initial mould temperature. 77

Figure 4-15: SDAS of all samples as a function of initial mould temperature (measurement error

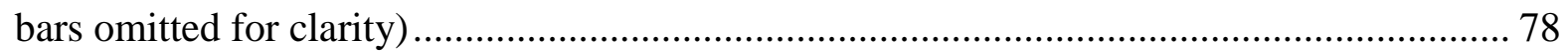

Figure 4-16: Average SDAS as a function of initial mould temperature ................................ 79

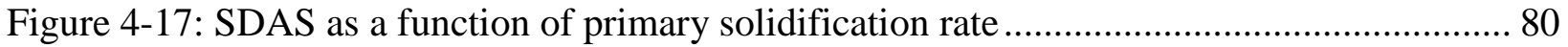

Figure 4-18: SDAS as a function of total solidification rate ............................................. 81

Figure 4-19: SDAS as a function of primary solidification time ........................................... 81

Figure 4-20: SDAS as a function of local solidification time ........................................... 82

Figure 4-21: Optical micrographs of the general microstructure for $690{ }^{\circ} \mathrm{C}$ (top, 100x magnification) and $200{ }^{\circ} \mathrm{C}$ (bottom, 500x magnification) mould temperatures .................. 84

Figure 4-22: Backscattered electron images of intermetallic compounds for $690{ }^{\circ} \mathrm{C}$ (top, 200x magnification) and $200{ }^{\circ} \mathrm{C}$ (bottom, 800x magnification) mould temperatures 85

Figure 4-23: EDX analysis of (a) $\mathrm{Al}_{2} \mathrm{Cu}$, (b) $\mathrm{Al}_{5} \mathrm{Mg}_{8} \mathrm{Cu}_{2} \mathrm{Si}_{6}$, (c) $\alpha-\mathrm{Al}_{15}(\mathrm{Fe}, \mathrm{Mn})_{3} \mathrm{Si}_{2}$, and (d) $\beta-\mathrm{Al}_{5} \mathrm{FeSi}$ 86

Figure 4-24: Area fraction of secondary phases as a function of mould temperature 87

Figure 4-25: Optical micrographs of the eutectic Si morphology for $690{ }^{\circ} \mathrm{C}$ (left, 200x magnification) and $200{ }^{\circ} \mathrm{C}$ (right, 1000x magnification) mould temperatures . 88

Figure 4-26: Median aspect ratio of eutectic Si particles as a function of mould temperature .... 89 
Figure 4-27: Median sphericity of eutectic Si particles as a function of mould temperature 89

Figure 4-28: Median circular diameter of eutectic Si particles as a function of mould temperature 90

Figure 4-29: Median circular diameter of eutectic Si particles as a function of SDAS. 91

Figure 4-30: Median circular diameter of eutectic Si particles as a function of primary solidification rate. 92

Figure 4-31: Median circular diameter of eutectic Si particles as a function of total solidification rate 93

Figure 4-32: Median circular diameter of eutectic $\mathrm{Si}$ particles as a function of primary solidification time. 93

Figure 4-33: Median circular diameter of eutectic Si particles as a function of local solidification time 94

Figure 4-34: Backscattered electron images of Fe-bearing phases for $497{ }^{\circ} \mathrm{C}$ (left, 200x magnification) and $449^{\circ} \mathrm{C}$ (right, 300x magnification) mould temperatures . 96

Figure 4-35: Percentage porosity of microscopy samples as a function of casting location and initial mould temperature 97

Figure 4-36: Optical micrograph at 50x magnification of interdendritic shrinkage porosity for $690{ }^{\circ} \mathrm{C}$ mould temperature 98

Figure 4-37: Optical micrograph at 1000x magnification of microporosity around the complex $\mathrm{Al}_{2} \mathrm{Cu}$ eutectic for $200{ }^{\circ} \mathrm{C}$ mould temperature 99

Figure 4-38: Percentage porosity of all thermal conductivity rods as a function of initial mould temperature. 100

Figure 4-39: Density of selected thermal conductivity rods as a function of initial mould temperature.

Figure 4-40: Percentage porosity of selected thermal conductivity rods as a function of initial mould temperature. 101

Figure 4-41: Ultimate tensile strength as a function of initial mould temperature 102

Figure 4-42: Rockwell hardness as a function of initial mould temperature. 103

Figure 4-43: Specific heat as a function of casting location and initial mould temperature ...... 104 Figure 4-44: Volumetric specific heat as a function of casting location and initial mould temperature 105 
Figure 4-45: Thermal diffusivity as a function of initial mould temperature .......................... 106

Figure 4-46: Thermal conductivity as a function of initial mould temperature ....................... 107

Figure 4-47: Schematic of heat transfer via electron flow through a dendritic structure with (a) coarse secondary phases and (b) fine secondary phases ............................................. 109

Figure 4-48: Schematic of heat transfer via electron flow through a dendritic structure with (a)

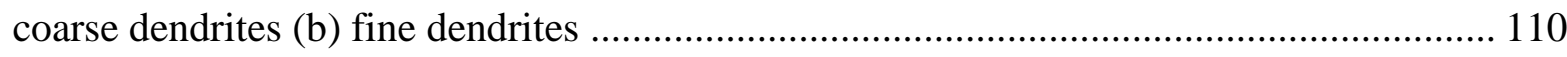




\begin{tabular}{|c|c|c|}
\hline English & & Unit \\
\hline$c_{p}$ & Specific heat capacity & $\mathrm{J} / \mathrm{kg}-\mathrm{K}$ \\
\hline$d$ & Average grain diameter & $\mathrm{m}$ \\
\hline$D_{c}$ & Eutectic Si median circular diameter & $\mu \mathrm{m}$ \\
\hline$G$ & Gibbs free energy & $\mathrm{J}$ \\
\hline$k$ & Thermal conductivity & $\mathrm{W} / \mathrm{m}-\mathrm{K}$ \\
\hline$L$ & Lorenz Number & $\Omega-\mathrm{W} / \mathrm{K}^{2}$ \\
\hline$L_{p}$ & Length of the primary dendrite arm & $\mu \mathrm{m}$ \\
\hline$m$ & Sample mass & $\mathrm{g}$ \\
\hline$m_{b}$ & Mass of a beaker with water & $\mathrm{g}$ \\
\hline$m_{b s}$ & Mass of a beaker with water and with a suspended sample & $\mathrm{g}$ \\
\hline$N_{s}$ & Total number of secondary dendrite arms & - \\
\hline$P$ & Power & $\mathrm{W}$ \\
\hline$q$ & Steady state heat flux per unit cross-sectional area & $\mathrm{W} / \mathrm{m}^{2}$ \\
\hline$r$ & Radius & $\mathrm{m}$ \\
\hline$R$ & Electrical resistance & $\Omega$ \\
\hline$R^{2}$ & Coefficient of determination & - \\
\hline$T$ & Temperature & $\mathrm{K},{ }^{\circ} \mathrm{C}$ \\
\hline$\Delta T_{L \rightarrow E}$ & Primary freezing range (liquidus to Al-Si eutectic) & ${ }^{\circ} \mathrm{C}$ \\
\hline$\Delta t_{L \rightarrow E}$ & Primary solidification time (liquidus to Al-Si eutectic) & $\mathrm{s}$ \\
\hline$\Delta T_{L \rightarrow S}$ & Total freezing range (liquidus to solidus) & ${ }^{\circ} \mathrm{C}$ \\
\hline$\Delta t_{L \rightarrow S}$ & Local solidification time (liquidus to solidus) & s \\
\hline$S p$ & Sphericity & - \\
\hline$S R_{P}$ & Primary solidification rate & ${ }^{\circ} \mathrm{C} / \mathrm{s}$ \\
\hline$S R_{T}$ & Total solidification rate & ${ }^{\circ} \mathrm{C} / \mathrm{s}$ \\
\hline$x$ & Position & $\mathrm{m}$ \\
\hline
\end{tabular}




\section{Greek}

$\begin{array}{llc}\alpha & \text { Thermal diffusivity } & \mathrm{mm}^{2} / \mathrm{s} \\ \gamma & \text { Surface free energy } & \mathrm{J} / \mathrm{m}^{2} \\ \delta & \text { Thickness } & \mathrm{m} \\ \varepsilon & \text { Elongation } & \mathrm{m} / \mathrm{m} \\ \theta & \text { Solid-surface contact angle } & \circ \\ \mu & \text { Material-specific constant } & - \\ \rho & \text { Sample density } & \mathrm{g} / \mathrm{cm}^{3} \\ \rho_{t h} & \text { Theoretical pore-free density } & \mathrm{g} / \mathrm{cm}^{3} \\ \rho_{w} & \text { Density of water } & \mathrm{g} / \mathrm{cm}^{3} \\ \sigma_{e} & \text { Electrical Conductivity } & \mathrm{S} / \mathrm{m}^{3} \\ \varphi & \text { Characteristic time } & \mathrm{s}\end{array}$

\section{Elements and Intermetallics}

\begin{tabular}{|c|c|}
\hline $\mathrm{Al}$ & Aluminum \\
\hline $\mathrm{Al}_{2} \mathrm{Cu}$ & Intermetallic in $\mathrm{Cu}$-containing $\mathrm{Al}$ alloys \\
\hline $\mathrm{Al}_{5} \mathrm{Mg}_{8} \mathrm{Cu}_{2} \mathrm{Si}_{6}$ & Intermetallic in $319 \mathrm{Al}$ alloys \\
\hline $\mathrm{Al}_{15}(\mathrm{Fe}, \mathrm{Mn})_{3} \mathrm{Si}_{2}$ & Intermetallic in $319 \mathrm{Al}$ alloys \\
\hline $\mathrm{Al}_{5} \mathrm{FeSi}$ & Intermetallic in $319 \mathrm{Al}$ alloys \\
\hline $\mathrm{Cr}$ & Chromium \\
\hline $\mathrm{Cu}$ & Copper \\
\hline $\mathrm{Fe}$ & Iron \\
\hline $\mathrm{Mg}$ & Magnesium \\
\hline $\mathrm{Mg}_{2} \mathrm{Si}$ & Intermetallic in $319 \mathrm{Al}$ alloys \\
\hline $\mathrm{Mn}$ & Manganese \\
\hline $\mathrm{Ni}$ & Nickel \\
\hline $\mathrm{Si}$ & Silicon \\
\hline $\mathrm{Sn}$ & Tin \\
\hline $\mathrm{Sr}$ & Strontium \\
\hline Ti & Titanium \\
\hline
\end{tabular}




$\begin{array}{ll}\text { Abbreviations } & \\ \text { DSC } & \text { Differential Scanning Calorimetry } \\ \text { EDX } & \text { Energy Dispersive X-ray Spectroscopy } \\ \text { HRE } & \text { Rockwell Hardness Number - E scale } \\ \text { IACS } & \text { International Annealed Copper Standard for electrical conductivity } \\ \text { OM } & \text { Optical Microscopy } \\ \text { SDAS } & \text { Secondary Dendrite Arm Spacing } \\ \text { SEM } & \text { Scanning Electron Microscopy } \\ \text { TCR } & \text { Temperature Coefficient of Resistance } \\ \text { TPS } & \text { Transient Plane Source } \\ \text { UTS } & \text { Ultimate Tensile Strength } \\ \text { XRD } & \text { X-Ray Diffraction } \\ \text { YS } & \text { Yield Strength }\end{array}$




\section{Chapter 1: INTRODUCTION}

Increased fuel costs and government legislation on carbon emissions are providing the impetus for lighter and more fuel efficient vehicles. Aluminum alloys have been found to be a suitable replacement to ferrous alloys for automotive components, due to aluminum's lower density and higher strength-to-weight ratio than steel and cast iron. In particular, A319 aluminum alloy is commonly used in powertrain components, due to its good castability and strength at ambient and elevated temperatures. Increased use of light aluminum alloys for automotive parts results in significant reductions in fuel consumption and hence harmful gas emissions. Furthermore, the automotive industry aims to improve engine efficiency by reducing the amount of rejected heat from the combustion reactions. Yet, powertrain components must have sufficient material properties to support the corresponding higher operating temperatures.

One of the major challenges associated with increasing the operating temperatures of aluminum powertrain components is the accumulation of thermal stresses. At high combustion temperatures, non-uniform heating causes differential expansion rates within the part. As a result, detrimental stresses are induced, which can cause premature failure. Consequently, operating temperatures are limited by the components' strength and thermal conductivity. While high strength allows the material to better resist thermal stresses, high thermal conductivity improves the heat transfer within the part. This promotes a lower and more uniform temperature distribution in the part and hence reduces the stresses.

There has been much research devoted towards improving the mechanical properties of A319 and other aluminum alloys, perhaps most commonly via increasing the casting solidification rate. At faster solidification rates, strengthening is attained by the refinement of the alloy dendritic structure and secondary phases. In contrast, there has been little investigation into the effect of solidification rate on thermal conductivity, and most suggested relationships have been derived from inadequate data.

The objective of this research was to comprehensively study the influence of solidification rate on thermal conductivity of A319 alloy. Castings of identical composition and size were produced 
with a large range of solidification rates by manipulating the permanent mould preheating temperature. Thermal analysis was conducted to isolate and compare several solidification parameters at varying mould preheating temperatures. Microstructural changes were quantified using optical and scanning electron microscopy, mechanical properties of the castings were characterized by hardness and tensile testing, and thermal conductivity measurements were performed using the transient plane source method. Therefore, direct correlations between the A319 alloy solidification conditions, microstructure and properties were developed, enabling an improved understanding of the influence of solidification on thermal conductivity. These results can be used to produce lightweight powertrain components with enhanced properties that promote better fuel efficiency and conservation of the environment.

This thesis has been structured as follows:

In Chapter 2, a concise review of the literature available on A319 aluminum alloy, solidification mechanisms, and thermal conductivity is presented. This includes the published results regarding metallurgical influences on conductivity, and concludes with an overview of various techniques for measuring thermal conductivity.

In Chapter 3, the experimental methodology of this research is described. This includes the permanent mould design, melting and casting experiments, thermal analysis, sample preparation, microscopic evaluation, and mechanical and thermal property measurements.

In Chapter 4, the thermal analysis, microstructural analysis, porosity, mechanical properties, and thermal conductivity of the castings are presented. Also included in this chapter is the development of relationships between solidification parameters, the comparison of results to simulated cooling curves, and a discussion of the correlations between solidification, microstructure, and properties.

In Chapter 5, conclusions obtained from this research are summarized.

In Chapter 6, a list of recommendations for future work is offered.

The flowchart in Figure 1-1 depicts an overview of the research presented in this thesis. 


\section{Influence of Solidification Parameters on Thermal Conductivity}

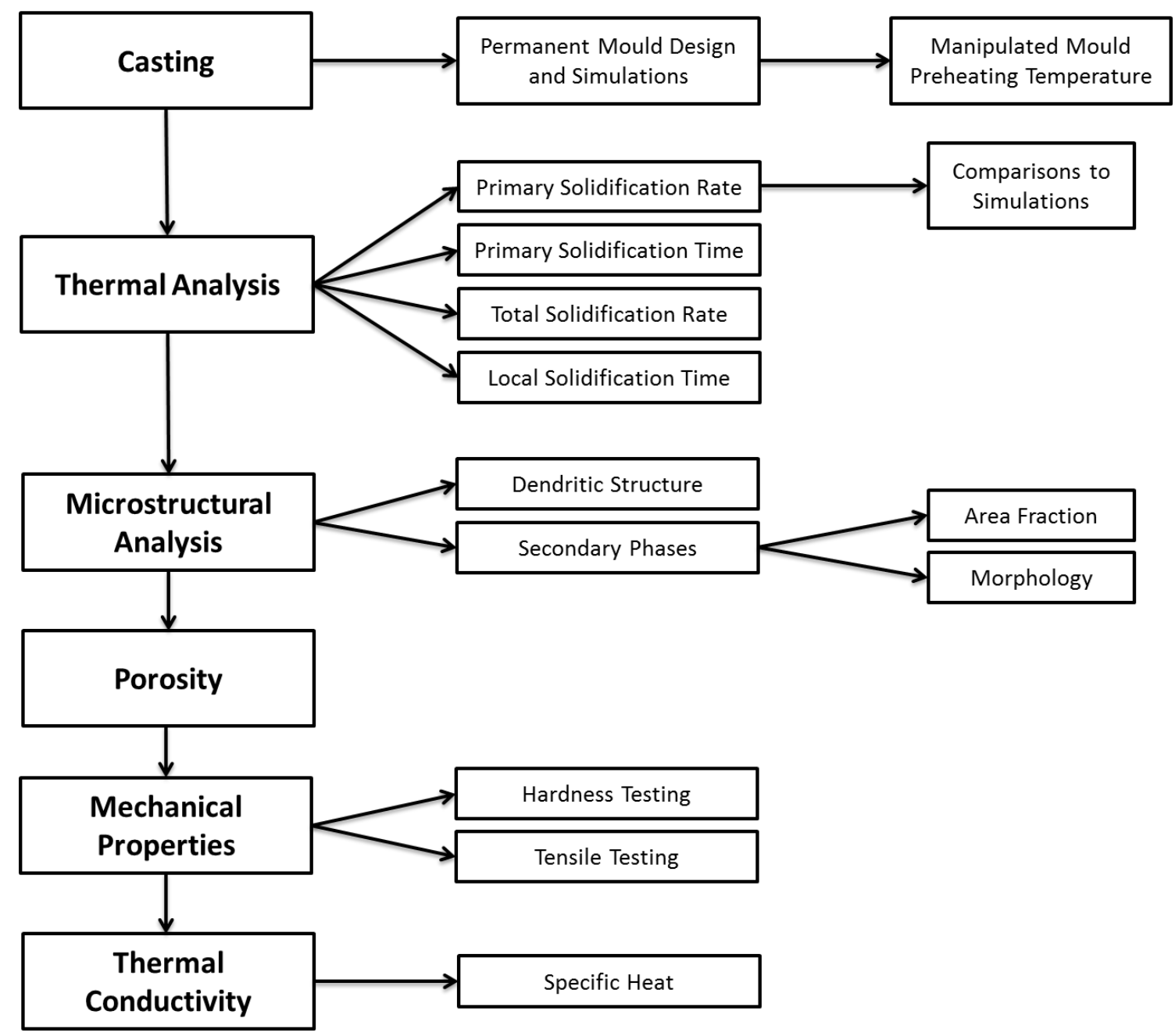

Figure 1-1: Thesis overview 


\section{Chapter 2: LITERATURE REVIEW}

This chapter begins with an introduction of A319 aluminum alloy, with an emphasis on its microstructural characteristics. Then, the kinetics of alloy solidification during casting are described, including a discussion of nucleation theory, dendritic growth, the control and influence of phase size, and the development of A319 microstructure. This is followed with a review of thermal conductivity and its manipulation via metallurgical factors. Finally, the chapter concludes with a description of the common techniques for characterizing thermal conductivity.

\subsection{A319 Aluminum Alloy}

Aluminum and its alloys are very popular for many applications because of its appearance, light weight, fluidity, castability, fabricability, weldability, physical and mechanical properties, hot tear resistance, and corrosion resistance. As a lightweight metal with a density of only $2.7 \mathrm{~g} / \mathrm{cm}^{3}$, approximately a third of the density of steel, aluminum is commonly used in automotive and aerospace applications that strive to reduce vehicular weight for better fuel efficiency [1]. Also, exposed aluminum surfaces oxidize to form an inert and passivating aluminum oxide layer which prevents further corrosion. The layer is only a few ten-millionths of an inch thick, is colourless and transparent, and it does not flake off to expose fresh surface. Yet, the major limitation in using aluminum is its relatively low strength and hardness, as pure aluminum has a yield strength of only about $10 \mathrm{MPa}$ in the annealed condition [1]. Therefore, for applications requiring high strength, such as for powertrain components, various alloying elements can be added to aluminum to enhance its mechanical properties.

One particular alloy used in the production of powertrain components is the A319 aluminum alloy. This is an Al-Si-Cu alloy with minor amounts of $\mathrm{Mg}$, Ti, Fe, Mn, Zn, and Ni. The nominal chemical composition of A319 is given in Table 2-1. The alloy is hypo-eutectic in the Al-Si system, having 5.5-6.5 wt.\% Si, whereas the Al-Si eutectic composition is $12.6 \mathrm{wt} \% \mathrm{Si}$ (Figure 2-1). Silicon is added far in excess of solubility or its need for strengthening, because it improves 
casting soundness, freedom from cracking, and wear resistance [2]. As well, it contains 3.0-4.0 wt.\% $\mathrm{Cu}$ to enable precipitation heat treatment for additional alloy strengthening [1]. The Al-Si-Cu ternary phase diagram can be seen in Appendix A.

Typical as-cast properties of A319 alloy are presented in Table 2-2. Overall, the combination of light weight, good castability, and moderate mechanical and thermal properties has contributed to A319 alloy's prominence in the automotive industry.

Table 2-1: Nominal chemical composition of A319 alloy [1]

\begin{tabular}{|c|c|c|c|c|c|c|c|c|c|c|}
\hline Component & $\mathbf{S i}$ & $\mathbf{C u}$ & $\mathbf{M g}$ & $\mathbf{T i}$ & $\mathbf{F e}$ & $\mathbf{M n}$ & $\mathbf{Z n}$ & $\mathbf{N i}$ & Other & Al \\
\hline Wt.\% & $5.5-6.5$ & $3.0-4.0$ & 0.10 & 0.20 & 0.6 & 0.10 & 0.1 & 0.1 & 0.20 & balance \\
\hline
\end{tabular}

Table 2-2: Typical properties of permanent mould as-cast 319-type alloys [1]

\begin{tabular}{|c|c|c|c|c|c|}
\hline $\begin{array}{c}\text { Ultimate } \\
\text { Tensile } \\
\text { Strength } \\
\text { (MPa) }\end{array}$ & $\begin{array}{c}\text { Yield } \\
\text { Strength } \\
\text { (MPa) }\end{array}$ & $\begin{array}{c}\text { Elongation } \\
(\mathbf{\%})\end{array}$ & $\begin{array}{c}\text { Hardness } \\
\text { (HB) }\end{array}$ & $\begin{array}{c}\text { Shear } \\
\text { Strength } \\
\text { (MPa) }\end{array}$ & $\begin{array}{c}\text { Thermal } \\
\text { Conductivity } \\
\text { (W/m-K) }\end{array}$ \\
\hline 235 & 130 & 2.5 & 85 & 165 & 109 \\
\hline
\end{tabular}




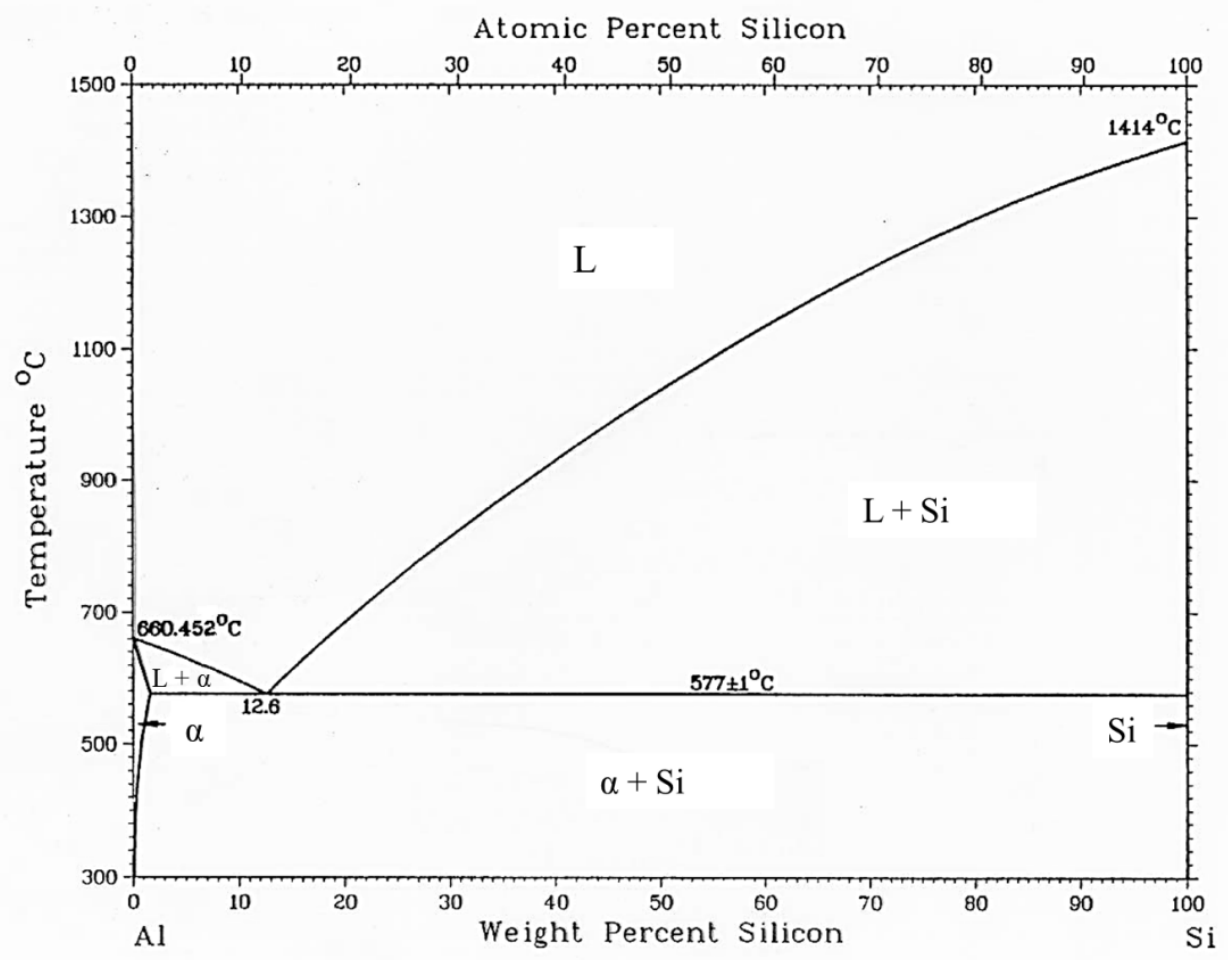

Figure 2-1: Al-Si binary phase diagram [1]

\subsubsection{Microstructure}

No element has complete miscibility in aluminum in solid state, but $\mathrm{Cu}, \mathrm{Mg}, \mathrm{Mn}, \mathrm{Si}$, and $\mathrm{Zn}$ all have significant solid solubility in aluminum [1]. For concentrations below the solubility limit, the alloying element is essentially in a single phase solid solution with the aluminum. On the other hand, for concentrations exceeding the solubility limit, the alloying element forms a second-phase microstructural constituent. This constituent either consists of the pure alloying element or an intermetallic compound phase.

The A319 alloy typically consists of an $\alpha$-Al matrix, $\mathrm{Al}-\mathrm{Si}$ eutectic, and $\mathrm{Al}_{2} \mathrm{Cu}$ intermetallic phases (Figure 2-2). As well, $\beta-\mathrm{Al}_{5} \mathrm{FeSi}$ and $\alpha-\mathrm{Al}_{15}(\mathrm{Fe}, \mathrm{Mn})_{3} \mathrm{Si}_{2}$ phases are common in the alloy from $\mathrm{Fe}$ impurities, and $\mathrm{Al}_{5} \mathrm{Mg}_{8} \mathrm{Cu}_{2} \mathrm{Si}_{6}$ phases result from $\mathrm{Mg}$ additions. These phases are discussed in this section. 


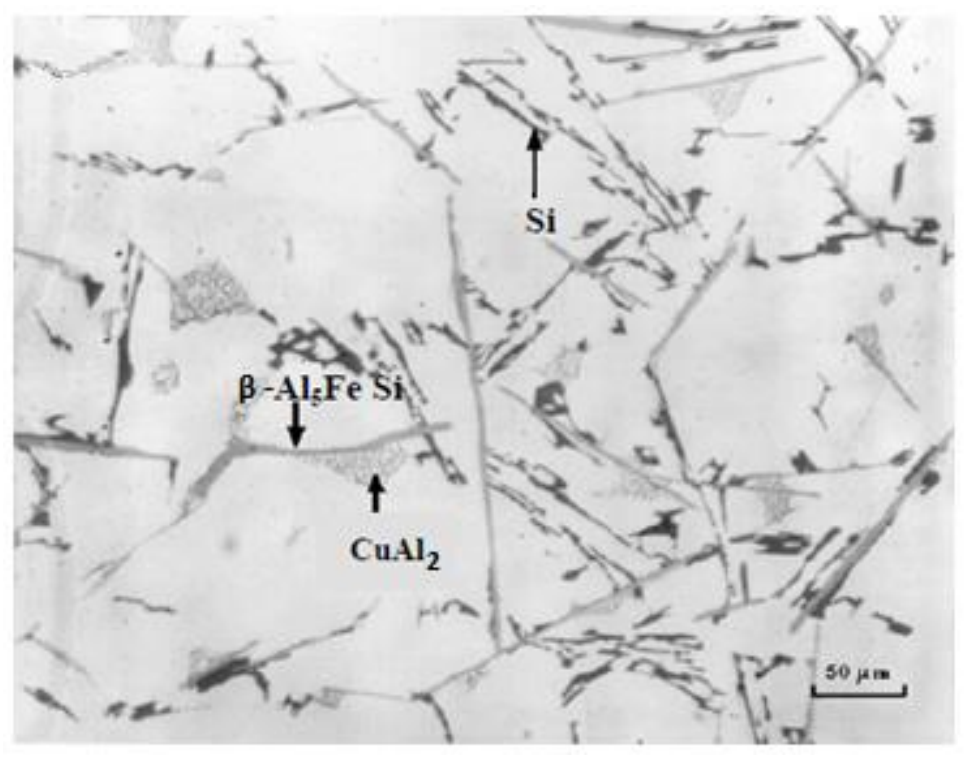

Figure 2-2: Optical micrograph of A319 in as-cast condition [3]

\subsubsection{Eutectic Si}

As indicated by the hypoeutectic region of the $\mathrm{Al}-\mathrm{Si}$ phase diagram (Figure 2-1, above), $\mathrm{Si}$ nucleates together with $\mathrm{Al}$ as part of a eutectic reaction. This leads to a phase of nearly pure silicon surrounded by aluminum. Eutectic silicon is naturally present in the microstructure as coarse, acicular flakes. This phase is detrimental to the alloy's mechanical properties, since the phase is brittle and the tips of the silicon needles promote stress concentrations [4]. However, it is possible to progressively modify the eutectic Si from fully unmodified flakes to fine lamellae to fibrous particles (Figure 2-3). This modification improves elongation and strength, promotes a more ductile fracture surface, and reduces solution heat treatment time [5]. A fine fibrous structure is most effectively achieved via trace additions of chemical modifiers, commonly $\mathrm{Sr}$ [6]. However, in the absence of chemical modification, rapid solidification has been found to produce some refinement in the Si flakes and/or a lamellar structure [5]. The mechanism of this refinement is discussed in Section 2.2.3. 


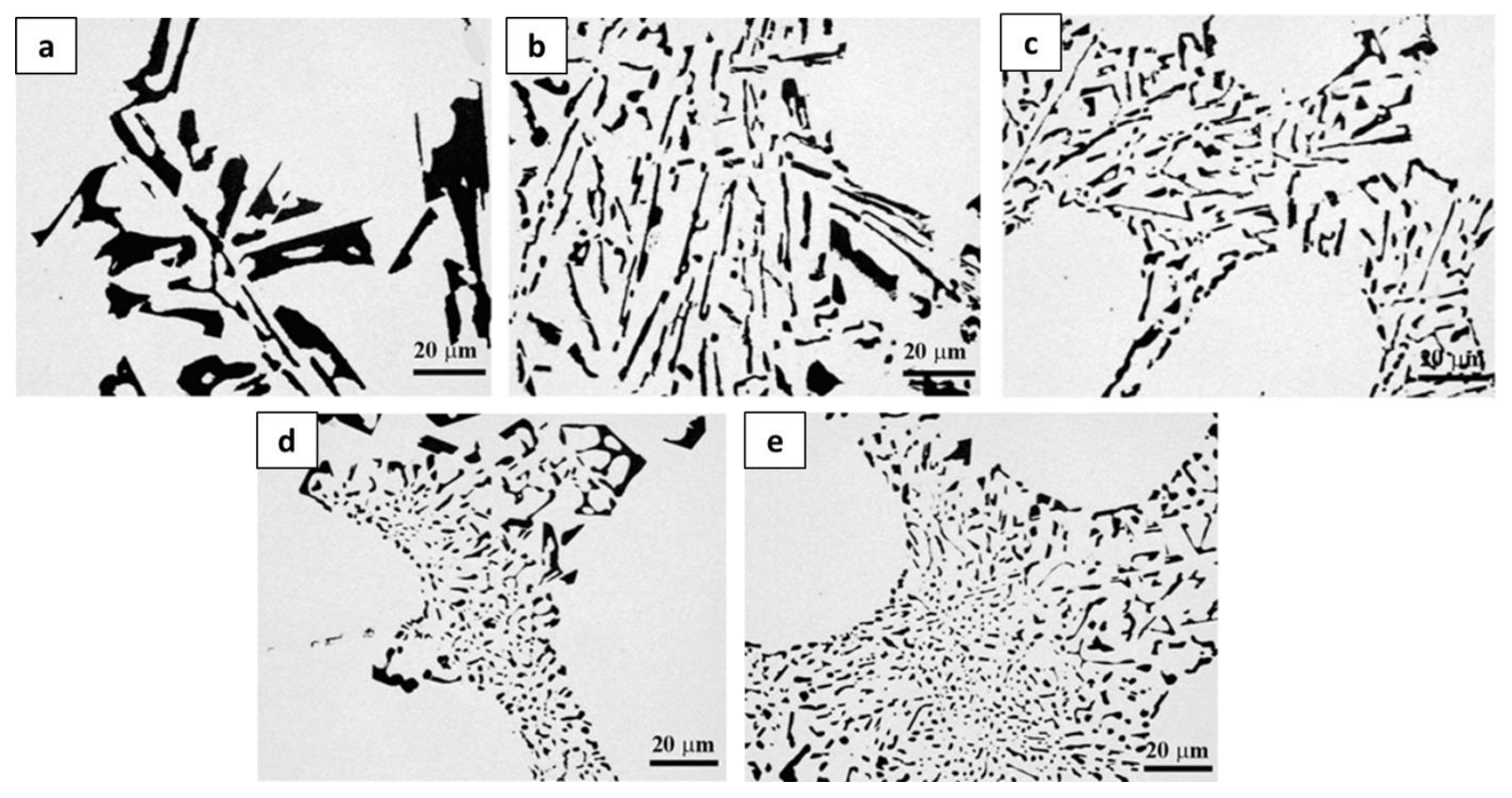

Figure 2-3: Optical micrographs of Al-Si eutectic morphology: (a) fully unmodified microstructure, (b) lamellar microstructure, (c) partially modified microstructure, (d) modified microstructure, and (e) very fine microstructure [7]

\subsubsection{2. $\quad A l$-Cu Intermetallics}

Aluminum and $\mathrm{Cu}$ form a phase with stoichiometry $\mathrm{Al}_{2} \mathrm{Cu}$ that enhances the strength and hardness of the alloy. Also, this phase is instrumental in the alloy's heat treatability, since $\mathrm{Al}_{2} \mathrm{Cu}$ can be dissolved into the $\alpha$-Al matrix at elevated temperatures for subsequent controlled precipitation of finer, more uniformly-distributed particles. The intermetallic compound forms during solidification in the interdendritic regions with both eutectic and blocky morphologies. The eutectic morphology has a lamellar structure of alternating $\mathrm{Al}_{2} \mathrm{Cu}$ and $\alpha$-Al layers, whereas the blocky morphology appears as clusters of larger $\mathrm{Al}_{2} \mathrm{Cu}$ particles embedded in the aluminum matrix (Figure 2-4). The eutectic morphology requires less time to dissolve during a heat treatment, and is therefore preferred in the as-cast microstructure for applications requiring precipitation hardening. Yet, $\mathrm{Sr}$ additions for eutectic Si modification have been observed to promote a greater formation of the blocky morphology [3]. 

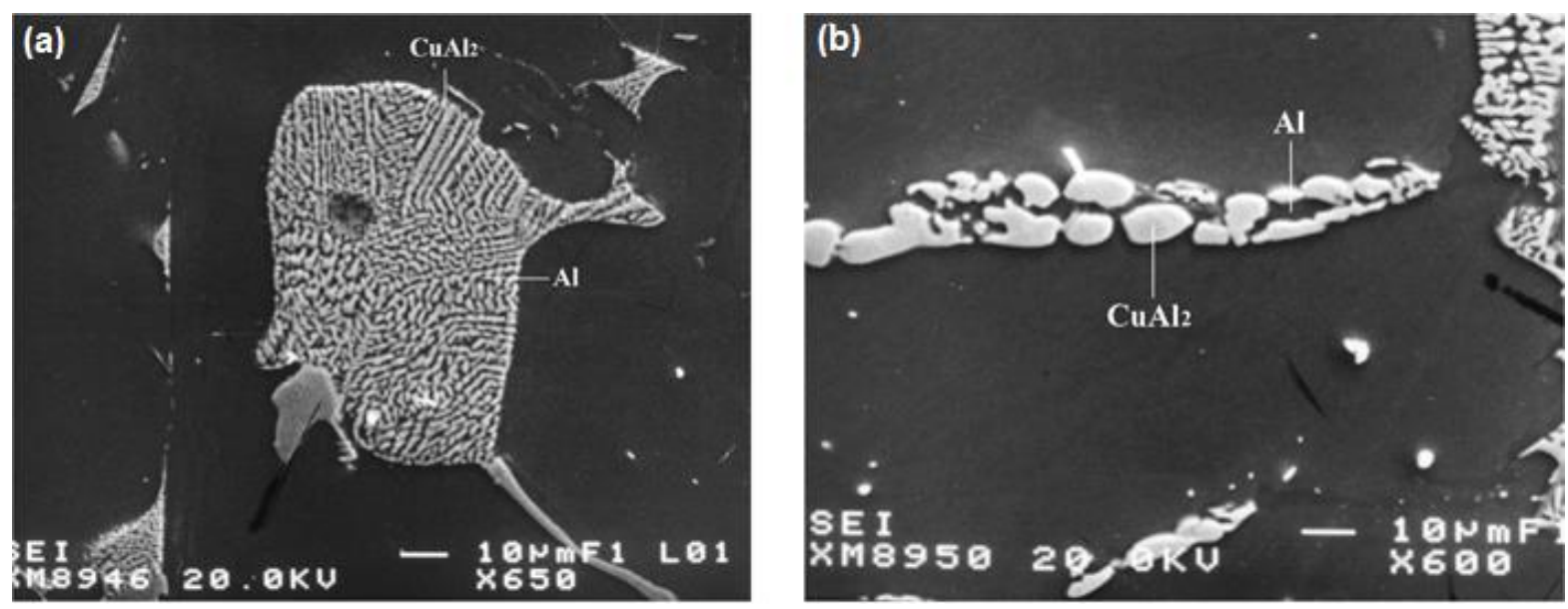

Figure 2-4: BSE images of A319 in the as-cast condition showing: (a) eutectic $\mathrm{Al}_{2} \mathrm{Cu}$ morphology, (b) blocky $\mathrm{Al}_{2} \mathrm{Cu}$ morphology [3]

\subsubsection{Mg-Bearing Intermetallics}

Magnesium additions to $\mathrm{Al}-\mathrm{Si}-\mathrm{Cu}$ alloys promote the formation of $\mathrm{Mg}$-bearing intermetallics that improve the alloy strength and accelerate the dissolution and precipitation kinetics during precipitation heat treatment [8]. While $\mathrm{Mg}_{2} \mathrm{Si}$ may form in 319-type alloys, the compound $\mathrm{Al}_{5} \mathrm{Mg}_{8} \mathrm{Cu}_{2} \mathrm{Si}_{6}$ is much more common due to the copper concentration. Since both $\mathrm{Al}_{5} \mathrm{Mg}_{8} \mathrm{Cu}_{2} \mathrm{Si}_{6}$ and $\mathrm{Al}_{2} \mathrm{Cu}$ precipitate near the alloy's solidus point, the two phases tend to precipitate in clusters as part of a complex eutectic reaction.

\subsubsection{Fe-Bearing Intermetallics}

The presence of the impurity Fe in Al-Si alloys like A319 typically leads to the formation of the acicular $\beta-\mathrm{Al}{ }_{5} \mathrm{FeSi}$ intermetallic. This phase is detrimental to the alloy's mechanical properties due to its hardness, brittleness, and its poor bond strength with the aluminum matrix [9]. However, additions of manganese can suppress the formation of $\beta-\mathrm{Al}_{5} \mathrm{FeSi}$ in favour of $\alpha$ $\mathrm{Al}_{15}(\mathrm{Fe}, \mathrm{Mn})_{3} \mathrm{Si}_{2}$, which is less harmful due its more compact Chinese-script morphology (Figure 2-5) [10]. Yet, excess Mn can promote the formation of polyhedral primary $\alpha$ phase, which is also undesired for its brittleness. The critical Fe/Mn ratio for the complete suppression of the $\beta$ phase is dependent on cooling rate: At very low cooling rates, there is sufficient time for primary 
$\alpha$ crystals to form. At higher cooling rates, initial formation of the Al dendrites causes the development of the Chinese-script $\alpha$ morphology in the interdendritic regions. Finally, very high cooling rates lead to the formation of both Chinese-script $\alpha$ and needle-like $\beta$ phases. For example, Narayanan et al. [9] found that the Chinese-script morphology was dominant for a $\mathrm{Fe} / \mathrm{Mn}$ ratio of 1.5 at cooling rates around $10^{\circ} \mathrm{C} / \mathrm{s}$. But while the Chinese-script morphology is preferred, Hwang et al. [11] found that its influence on mechanical properties is only apparent in a heat treated condition. As shown in Figure 2-6, the 319-type alloy studied experienced a peak in tensile strength and ductility at the ratio for which the $\beta$ phase was completely suppressed (0.75). Nonetheless, in the as-cast condition, virtually no changes in mechanical properties were observed regardless of the presence $\beta$ or even primary $\alpha$ phases.
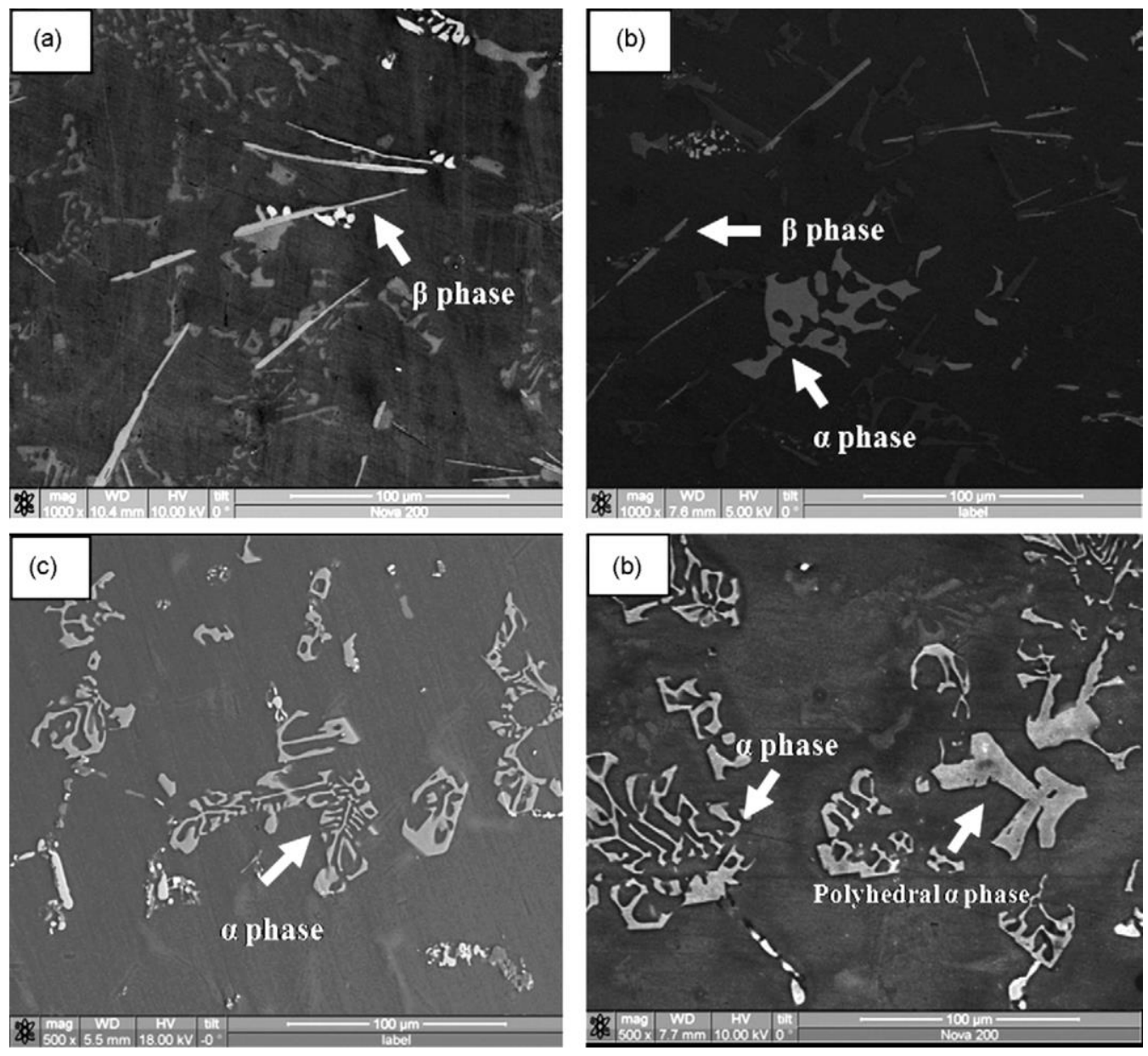

Figure 2-5: BSE images for an Al-6.5Si-3.5Cu alloy with an Fe:Mn ratio of: (a) 25, (b) 1.67, (c) 0.75 , (d) $0.6[11]$ 

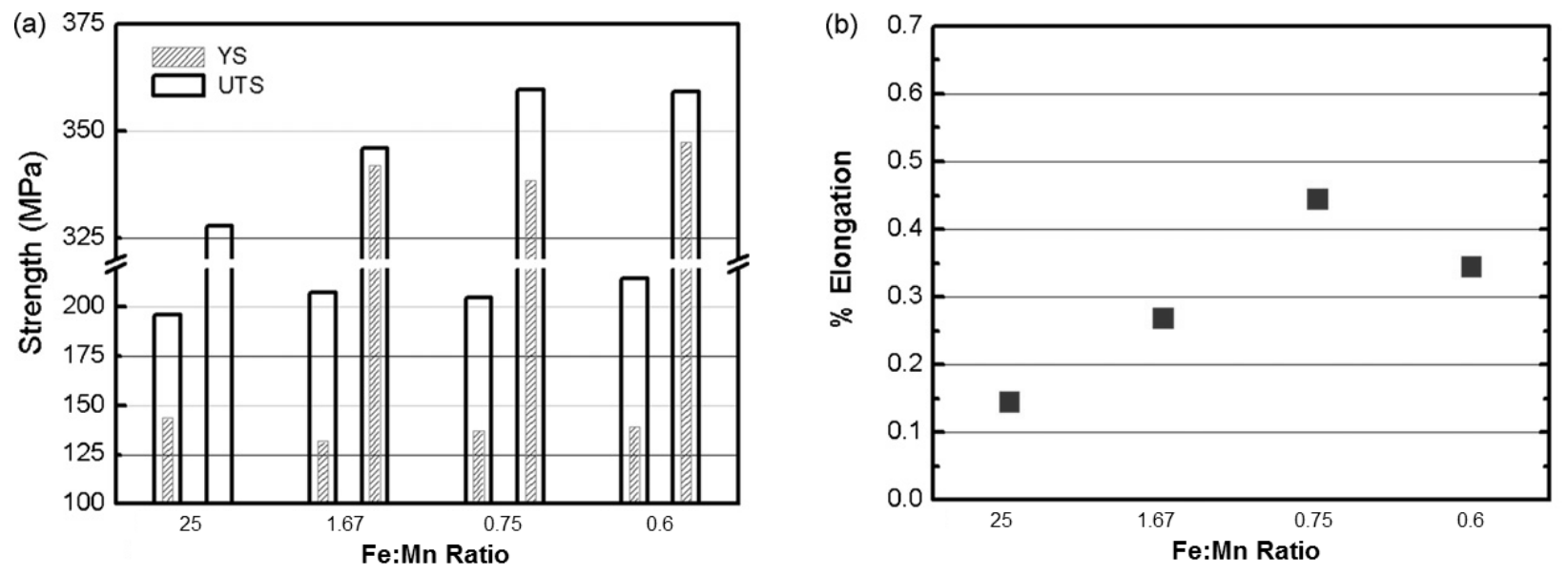

Figure 2-6: Tensile properties of a 319 alloy as a function of the Fe/Mn ratio showing: (a) ultimate tensile strength and yield strength in as-cast (left bars) and T6 heat treated conditions (right bars), (b) percent elongation in the T6 condition [11]

\subsection{Solidification}

Many of the material's properties are determined by its solidification conditions. This section describes the kinetics of phase nucleation and growth, and discusses the influence of their manipulation on phase size and resulting mechanical properties. As well, the specific series of reactions that take place during the solidification of A319 alloy are presented.

\subsubsection{Nucleation Theory}

Solidification involves a series of phase transformations from disordered liquid metal to a crystalline solid structure. This transformation begins with the nucleation of nano-sized crystallites of the primary phase, which grow in size until the phase reaches its equilibrium fraction [12]. Nucleation can occur either homogeneously or heterogeneously, as discussed in the following sections. 


\subsubsection{Homogeneous Nucleation}

In homogeneous nucleation, nuclei of the new phase forms uniformly throughout the bulk of the liquid melt. This can occur only if enough atoms in the liquid cluster together to form a sufficiently stable particle that will continue to grow spontaneously. In other words, growth of the nucleating particle must result in a reduction of its total free energy. The total free energy change of a nucleating particle $(\Delta G)$ corresponds to a balance of its volume free energy $\left(\Delta G_{v}\right)$, which describes the energy associated with cooling from liquid to solid, and the surface free energy, which describes the energy associated with the formation of a surface between the solid and the liquid. Assuming a spherical nucleating particle, the total free energy change can be expressed by the following equation [12]:

$$
\Delta G=\frac{4}{3} \pi r^{3} \Delta G_{v}+4 \pi r^{2} \gamma
$$

Equation 2-1

Where:

$\frac{4}{3} \pi r^{3}:$ Volume of nucleating particle

$4 \pi r^{2}:$ Surface area of nucleating particle

$\gamma:$ Surface free energy

With increasing cluster size, the volume free energy decreases whereas the surface free energy increases (Figure 2-7). As a result, there is a critical radius for a nucleating particle $\left(r^{*}\right)$ for which additional growth will reduce the total free energy. Above this size, the particle will be a stable nucleant and continue to grow spontaneously, but below this size, the cluster will be unstable and dissolve back into the liquid melt. 


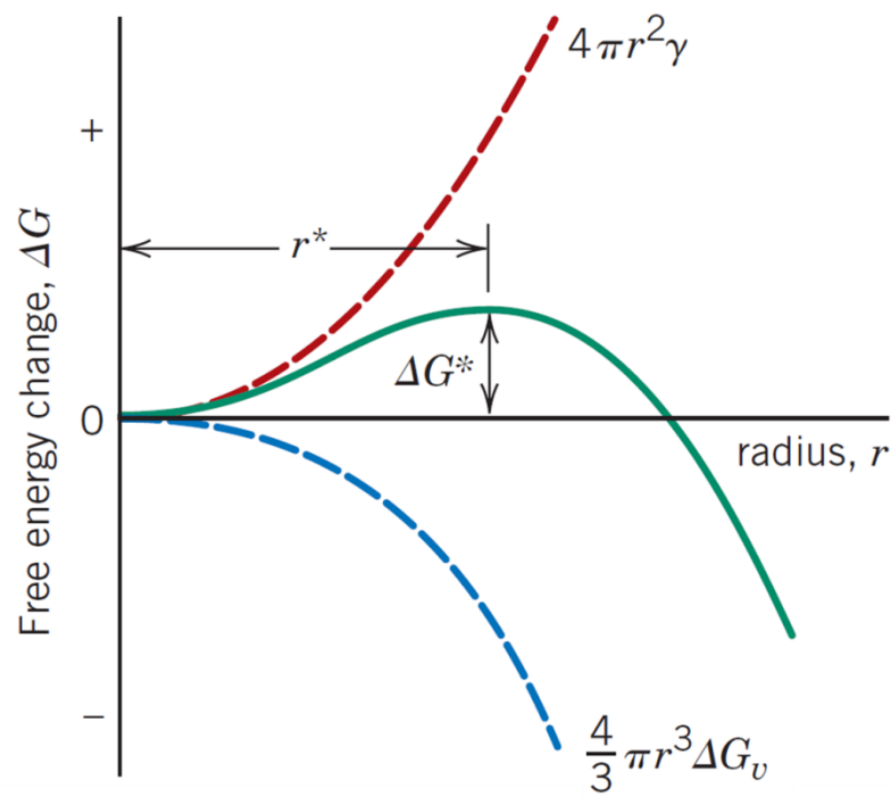

Figure 2-7: Schematic curve for volume free energy, total free energy, and surface free energy as a function of nucleating particle radius [12]

The critical nucleus radius is a function of temperature. At the equilibrium solidification temperature, the critical radius for homogeneous nucleation is too large to enable nucleation. However, as the undercooling from the equilibrium solidification temperature increases, the critical radius decreases, which improves the probability for nucleation. As shown in Figure 2-8, as the liquid metal cools, it decreases in temperature past the equilibrium solidification temperature $\left(T_{E}\right)$ to an undercooled nucleation temperature $\left(T_{N}\right)$. At that point, nucleation is initiated and latent heat is evolved with crystals growth, promoting a rise in melt temperature called recalescence. Continued growth occurs at the recalescence temperature $\left(T_{G}\right)$ until the phase reaches its equilibrium fraction. 


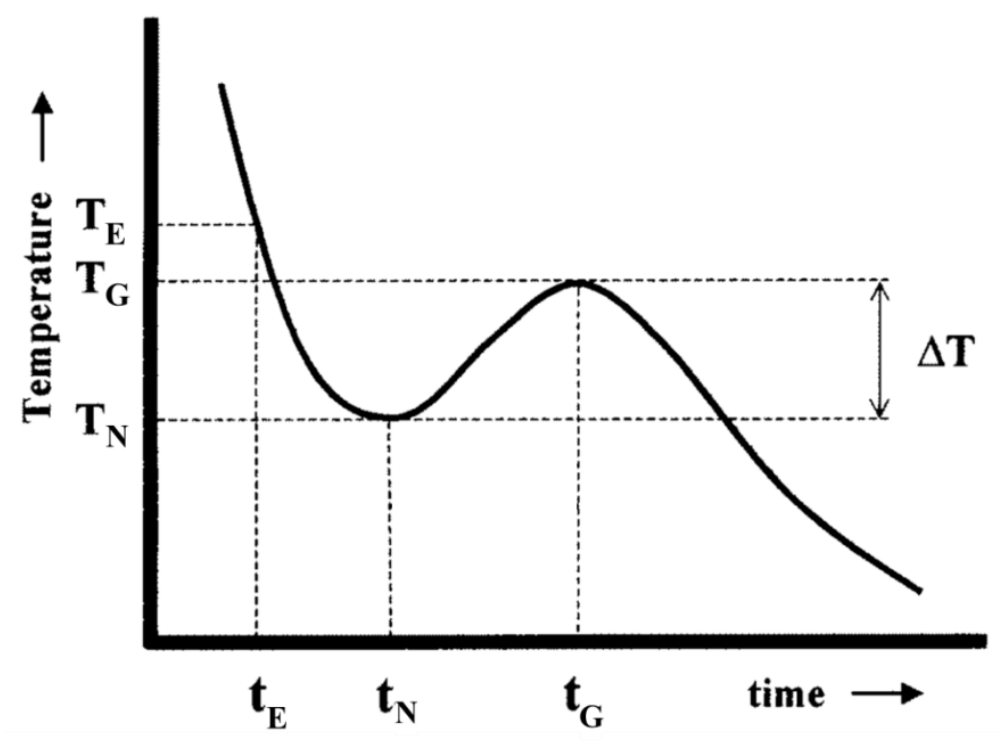

Figure 2-8: Typical cooling curve in homogeneous nucleation showing undercooling [13]

\subsubsection{Heterogeneous Nucleation}

In heterogeneous nucleation, nuclei form on a foreign substrate, such as impurities, inclusions, or mould walls. In this case, the pre-existing surface reduces the surface free energy, which lowers the critical nucleant radius. As a result, nucleation occurs much more readily and with minimal undercooling. The effectiveness of a substrate for heterogeneous nucleation is quantified by the contact angle between the surface and the solid nucleus $(\theta)$. As shown in Figure 2-9, the contact angle is defined from the balance of surface tensions at the interfaces between the surface, solid, and liquid [12]:

$$
\gamma_{I L}=\gamma_{S I}+\gamma_{S L} \cos \theta
$$

Equation 2-2

Where:

$\gamma_{I L}$ : Liquid-surface interfacial tension energy

$\gamma_{S I}$ : Solid-surface interfacial tension energy

$\gamma_{S L}$ : Solid-liquid interfacial tension energy 


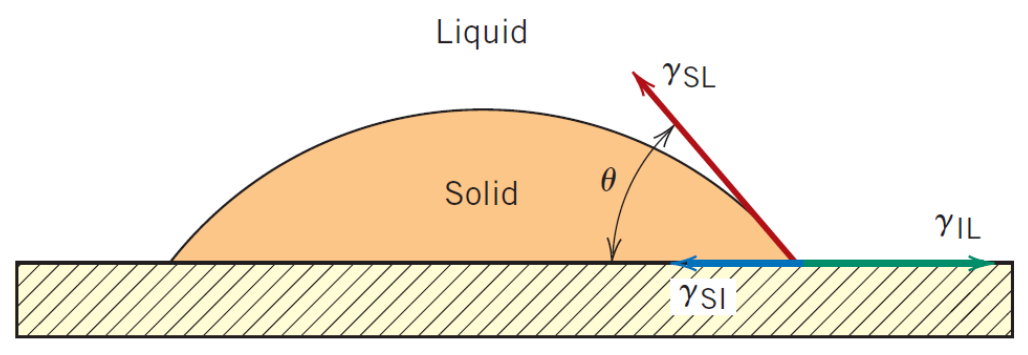

Surface or interface

Figure 2-9: Schematic of heterogeneous nucleation on a surface [12]

A lower contact angle indicates better wettability between the solid nucleant and the surface, and is therefore preferred for heterogeneous nucleation. This occurs when the substrate crystal structures and lattice parameters are very similar to those of the nucleating solid, minimizing the interfacial tension energy between them. Specific inoculants that meet that condition are usually added to liquid melts to promote heterogeneous nucleation, causing grain refinement (discussed in Section 2.2.3). In the presence of these inoculants, there is minimal undercooling, so the growth temperature is usually lower than the nucleation temperature.

\subsubsection{Dendritic Growth}

Once a stable nucleus is formed, it continues to grow spontaneously via atomic diffusion through the cooling liquid. For the matrix phase, each nucleus grows as a single grain in the microstructure until it meets with the others at coherency. In most Al-Si castings, grains solidify as dendrites, which are long and thin spikes with secondary and sometimes tertiary arms that grow along favourable crystallographic directions, as illustrated in Figure 2-10 [2]. Dendritic solidification occurs as a result of constitutional undercooling, in which compositional factors influence the equilibrium solidification of the alloy [14]. In this case, a solidifying primary phase rejects solute in front of the solid-liquid interface. This leads to a compositional gradient in the liquid, in which the liquid directly ahead of the interface is richer in solute than the liquid farther from the interface. Referring to the hypoeutectic region of a binary phase diagram (e.g. in Figure 2-1, above), liquid with a lower concentration of solute has a higher equilibrium solidification 
temperature. As a result, the tip of a random protuberance at the solid-liquid interface will be in solute-lean liquid with a greater amount of undercooling, despite a similar absolute temperature to the liquid directly at the interface. This promotes the lateral growth of the protuberance tip to displace solute perpendicular to the solidifying primary dendrite arm, in order to reduce the concentration gradient. In the same way, secondary dendrite arms can then form perpendicular from the primary arm, resulting in a dendritic structure.

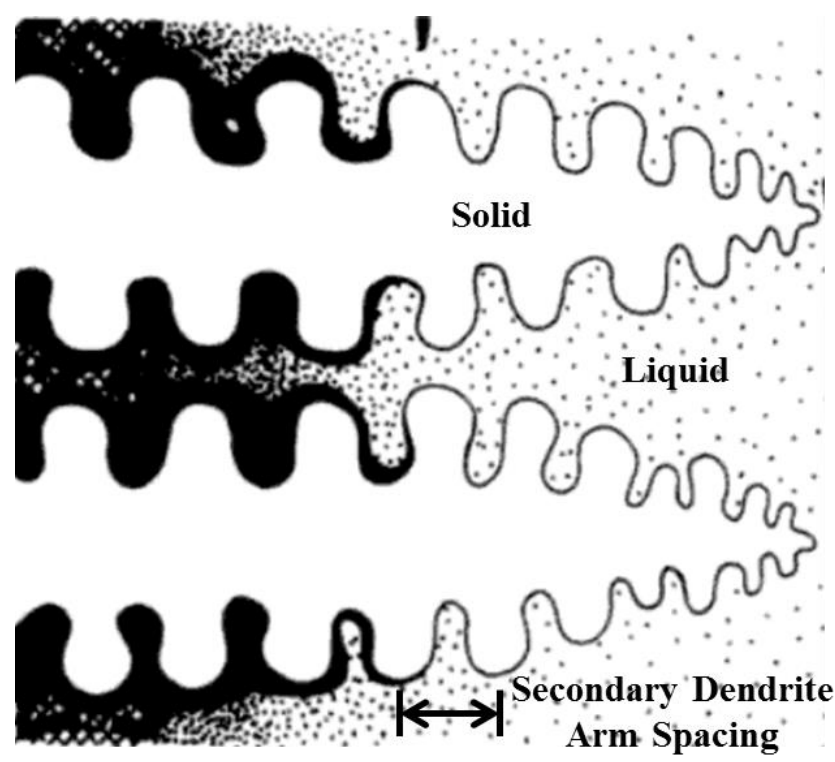

Figure 2-10: Schematic of dendrites and secondary dendrite arm spacing [15]

\subsubsection{Controlling Phase Size}

Both nucleation and growth are a function of temperature, as illustrated in Figure 2-11. Growth rates are a function of atomic diffusion rates, which decrease with temperature. On the other hand, nucleation rates increase as temperature decreases below the equilibrium solidification temperature, due to the decrease in critical nucleant radius. Consequently, the final size of the new phase in the microstructure is a function of its transformation temperature: At slow solidification rates, the transformation occurs near the equilibrium solidification temperature where growth rates are high and nucleation rates are low. This leads to the formation of a few nuclei that grow rapidly, resulting in few, coarse phases in the microstructure. On the other hand, 
at fast solidification rates, the transformation occurs at low temperatures where growth rates are low and nucleation rates are high. This leads to the formation of many nuclei that grow slowly, resulting in many, fine phases in the microstructure. Nonetheless, nucleation also requires atomic diffusion to form clusters, so at very low temperatures nucleation rates also decrease. The alloy solidification rate is typically controlled by the casting mould preheating temperature. At lower mould temperatures, the temperature gradient between the liquid melt and the mould is greater. This promotes more rapid heat transfer from the alloy.

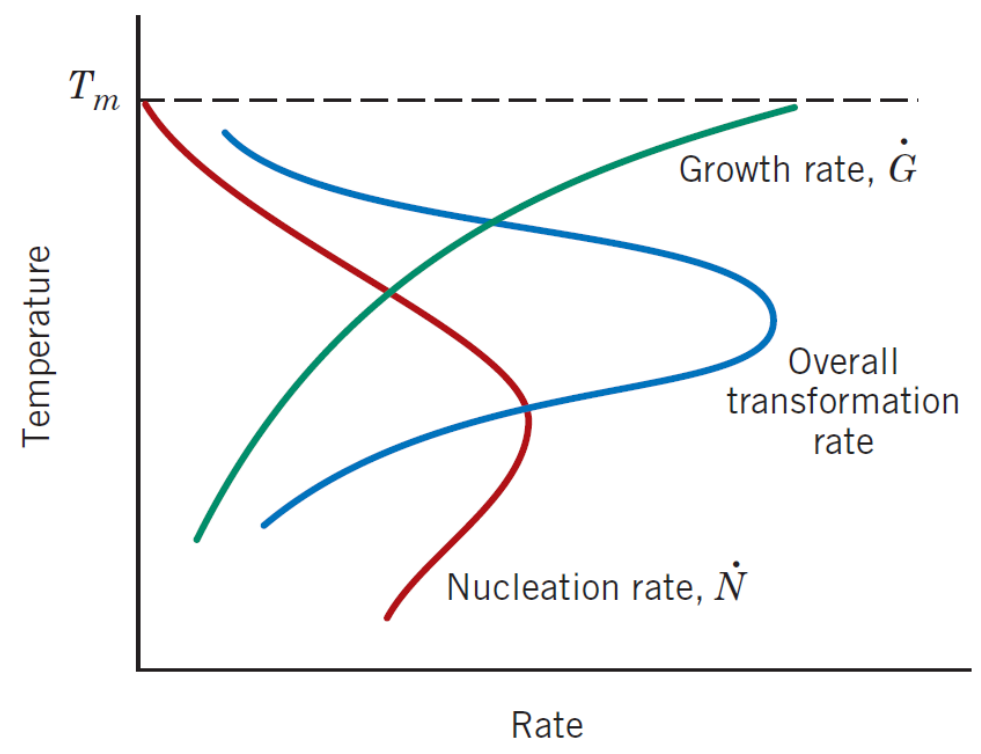

Figure 2-11: Schematic plot of nucleation rate, growth rate, and overall transformation rate as a function of temperature [12]

The size of primary phase dendrites is typically quantified by its secondary dendrite arm spacing (SDAS), as shown in Figure 2-10. The relationship between SDAS and cooling rate $(C R)$ is typically reported by the following equation [16]:

$$
S D A S=\mu_{1}(C R)^{-0.34 \pm 0.02}
$$

Where:

$\mu_{1}$ : Material-specific constant 
Similarly, it is generally accepted that SDAS is a function of the local solidification time $\left(\Delta t_{L \rightarrow S}\right)$ by the following equation [16]:

$$
S D A S=\mu_{2}\left(\Delta t_{L \rightarrow S}\right)^{1 / 3}
$$

Equation 2-4

Where:

$\mu_{2}$ : Material-specific constant

A consequence of faster solidification is non-equilibrium cooling. The information presented in a phase diagram are only realized for extremely slow cooling, in which there is sufficient time to continuously maintain phase equilibrium via atomic diffusion through and between the phases. Yet at faster cooling rates, non-equilibrium microstructures can develop during solidification. While sufficiently rapid diffusion rates are typically maintained in the liquid alloy, diffusion in the forming solid is hindered much more significantly by non-equilibrium cooling [12]. Accordingly, a rapidly cooling liquid of a given bulk composition will remain in phase equilibrium until solid particles begin to form at the equilibrium liquidus temperature. However, with continued cooling, the growing particles lack sufficient time to equilibrate, promoting cored phases with radial negative concentration gradients of solute (Figure 2-12). Even though each core layer solidifies with a progressively lower equilibrium composition, the overall cored solids have a greater average composition of solute than expected from equilibrium conditions. Therefore, the proportion of liquid present at each temperature below the liquidus is greater than expected from equilibrium conditions. As a result, non-equilibrium cooling promotes a shift of the solidus to lower temperatures, such that overall freezing range of the alloy increases. 


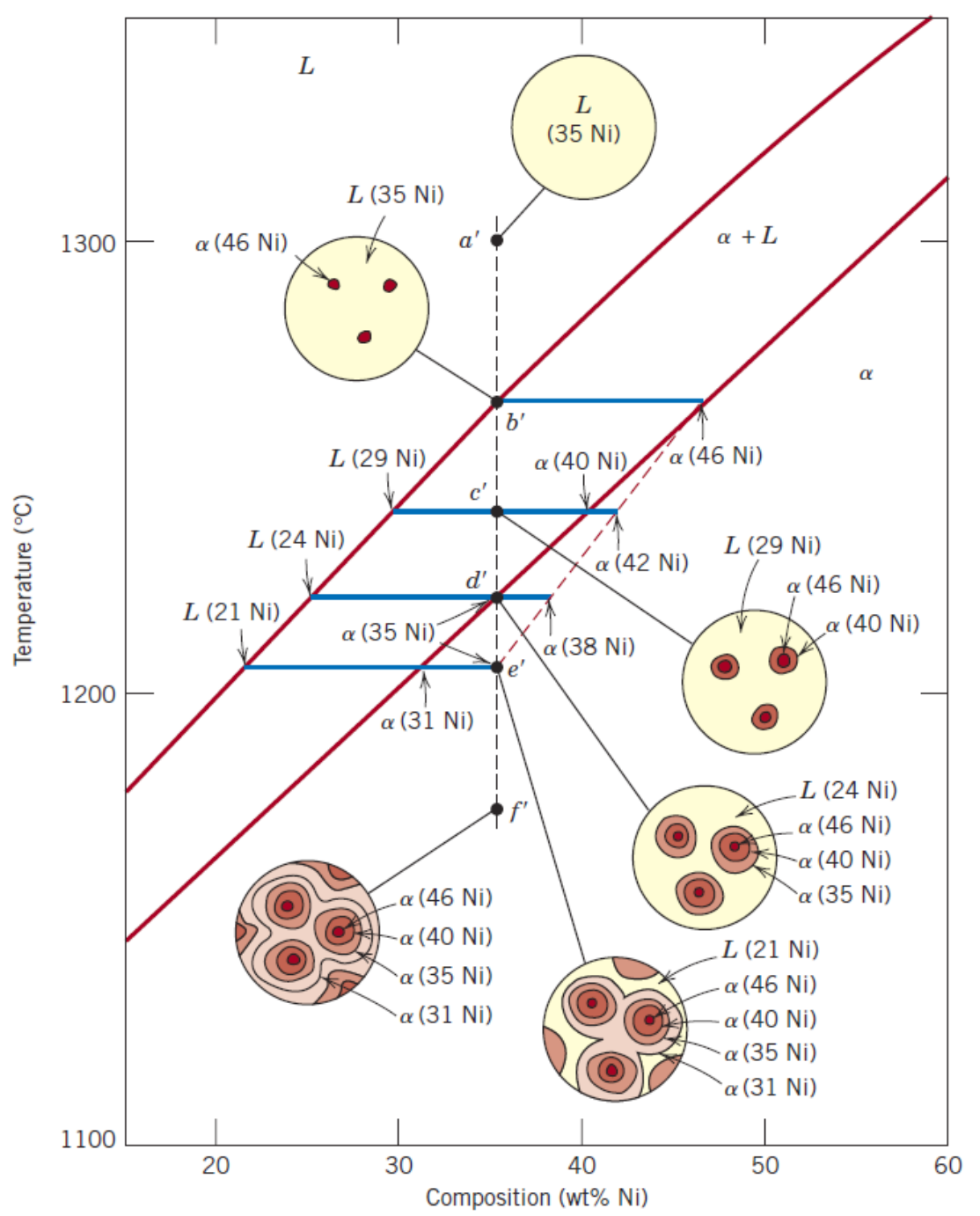

\section{Figure 2-12: Schematic representation of coring during non-equilibrium cooling in an isomorphous $\mathrm{Ni}-\mathrm{Cu}$ alloy [12]}

Aside from controlling solidification rate, the final size of the solid phases in the microstructure can be manipulated via the additions of grain refiners. These are chemical impurities added in trace amounts to promote the inoculation of primary phase (i.e. heterogeneous nucleation) during solidification. Since more particles are nucleated while growth rates are unchanged, the result is the formation of many, fine grains in the microstructure. The most common grain refiner in Al-Si alloys is $\mathrm{Ti}[1]$. 


\subsubsection{Influence on Mechanical Properties}

The mechanical properties of an alloy of a certain composition are correlated to the size of phases in its microstructure. In the case of the primary structure, grain size or SDAS reduction leads to greater material strength and hardness, surface finishing characteristics, and resistance to hot tearing [1]. Refinement of the primary structure increases the grain boundary area in the material. Grain boundaries are effective barriers to dislocation movement, since there is a discontinuity of slip planes and a crystallographic misorientation between adjacent grains [12]. Since dislocation movement is impeded across boundaries, plastic deformation is restricted. The strengthening associated with decreases in grain size is generally represented by the Hall-Petch equation [12]:

$$
Y S=\mu_{0}+\mu_{y} d^{-1 / 2}
$$

Equation 2-5

Where:

$Y S$ : Yield strength

$d$ : Average grain diameter

$\mu_{0}, \mu_{y}:$ Material-specific constants

Similar relationships exist between mechanical properties and SDAS. For example, SDAS has been related linearly to ultimate tensile strength (UTS) and logarithmically to elongation $(\varepsilon)$. One such set of relationships was found by Shi et al. [17] specifically for a particular Al-Si alloy A356:

$$
\begin{aligned}
& U T S=307.5-0.79(S D A S) \\
& \varepsilon=1.13+211.1(S D A S)^{-0.96}
\end{aligned}
$$

Equation 2-6

Equation 2-7

Furthermore, mechanical property benefits of a finer dendritic structure are related to the associated reduction in interdendritic shrinkage porosity [1]. As the SDAS decreases, the trapped pockets of liquid between the dendrite arms at coherency are progressively smaller. This results in a more even distribution of smaller shrinkage pores in the interdendritic regions.

Increasing cooling rate refines the secondary phases much in the same way as the primary phase. However, the resulting influence on mechanical properties is dependent on the particle hardness, 
size, shape, distribution, and coherency with the matrix [18]. Dislocations typically interact with particles in one of two ways (Figure 2-13): If a coherent or semi-coherent particle is not significantly harder than the matrix, the dislocation can shear the particle. Shearing occurs more readily in smaller particles (less than $10 \mathrm{~nm}$ ), and is only impeded by the coherency strain fields around the particle and the increase in particle-matrix interfacial energy associated with creating a new particle surface. Thus, these particles do not offer much resistance to dislocation motion, and so they do not significantly strengthen the alloy. On the other hand, if a particle is hard enough to withstand dislocation shearing, it effectively resists dislocation movement, and bypass can only occur by dislocation bending around the particle. Bending usually occurs for larger particles (on the order of $50 \mathrm{~nm}$ ), but the resulting strengthening is increased by decreases in particle size and spacing. As well, dislocation bending results in the multiplication of dislocations, since a dislocation loop is left behind on the particle. This increases the alloy's response to strain hardening [18].

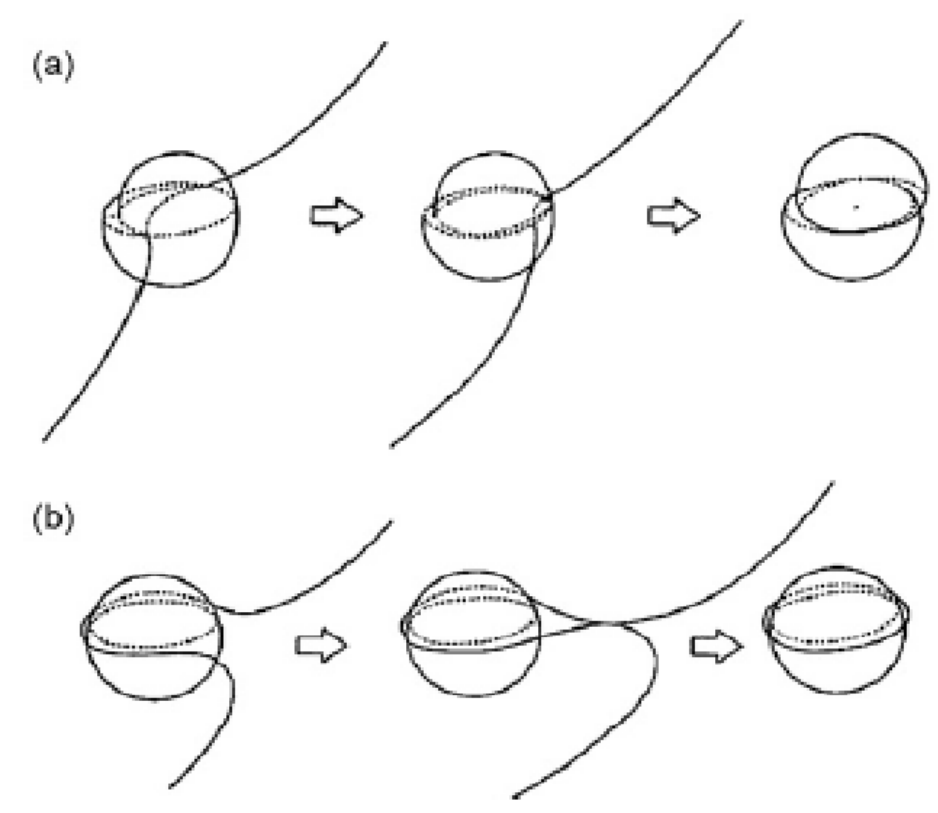

Figure 2-13: Mechanisms of dislocation interactions with secondary particles: (a) particle shearing, (b) dislocation bending [19] 
In contrast, some secondary phases are present in the microstructure with morphologies that are harmful to mechanical properties. For instance, acicular particles, like eutectic Si in A319, are stress risers, due to the concentration of stress at their tips. For these secondary phases, refinement of the particle size may improve mechanical properties, simply by offsetting their adverse morphology.

\subsubsection{Development of A319 Alloy Microstructure}

During the solidification of A319, several phases nucleate and grow in a specific sequence. However, the exact composition of the alloy and the cooling rate can vary the temperatures of certain reactions as well as the presence of some phases. Nonetheless, solidification begins with the nucleation of $\alpha$-Al dendrites. Since the dendrites grow at very high velocities $(\sim 50 \mu \mathrm{m} / \mathrm{s})$, dendritic coherency occurs at a very early stage of solidification, when the fraction of solid is only about $12 \%$ [2]. While the $\alpha$-Al dendrite arms coarsen, the Fe-bearing phases $\alpha$ $\mathrm{Al}_{15}(\mathrm{Fe}, \mathrm{Mn})_{3} \mathrm{Si}_{2}$ and/or $\beta-\mathrm{Al}_{5} \mathrm{FeSi}$ precipitate. As discussed in Section 2.1.1.4, above, $\mathrm{Mn}$ additions supress the precipitation of the needle-like $\beta$ phase in favour of the $\alpha$ Chinese-script phase. In the presence of $\mathrm{Mn}$, the $\alpha$ phase crystallizes first, followed by the formation of both $\alpha$ and $\beta$ together. As a result, at slower cooling rates, there can be sufficient time for most of the Fe to react before the $\beta$ phase can precipitate [9]. Next, the main eutectic reaction occurs, in which $\mathrm{Al}$ and $\mathrm{Si}$ precipitate together, while any remaining $\mathrm{Fe}$ continues to precipitate as $\beta-\mathrm{Al}_{5} \mathrm{FeSi}$. At

roughly this temperature, the alloy reaches rigidity, at a fraction of solid of about 51\% [2]. Following the main eutectic reaction, the blocky morphology of $\mathrm{Al}_{2} \mathrm{Cu}$ first forms, and then finely-dispersed particles of $\mathrm{Al}_{2} \mathrm{Cu}$ form as part of a complex eutectic reaction involving $\mathrm{Al}$, $\mathrm{Al}_{2} \mathrm{Cu}, \mathrm{Si}$, and $\mathrm{Al}_{5} \mathrm{Mg}_{8} \mathrm{Cu}_{2} \mathrm{Si}_{6}$ [20]. After this last reaction, all of the liquid has been transformed to solid, and solidification is complete. These solidification reactions are summarized in Table 2-3, and a typical cooling curve and its first derivate curve displaying reaction peaks are shown in Figure 2-14. 
Table 2-3: Description of phase formation reactions during solidification of A319 [21]

\begin{tabular}{|c|c|c|}
\hline Reaction No. & $\begin{array}{c}\text { Suggested } \\
\text { Temperature }\left({ }^{\circ} \mathbf{C}\right)\end{array}$ & Reaction \\
\hline 1 & 608 & $\mathrm{~L} \rightarrow \alpha-\mathrm{Al}$ dendritic network \\
\hline $2 \mathrm{a}$ & 590 & $\mathrm{~L} \rightarrow \mathrm{Al}+\mathrm{Al}_{15}(\mathrm{Fe}, \mathrm{Mn})_{3} \mathrm{Si}_{2}(\alpha-$-Chinese script phase $)$ \\
\hline $2 \mathrm{~b}$ & 590 & $\mathrm{~L} \rightarrow \mathrm{Al}+\mathrm{Al}_{15}(\mathrm{Fe}, \mathrm{Mn})_{3} \mathrm{Si}_{2}+\mathrm{Al}_{5} \mathrm{FeSi}(\beta$ needle-like phase $)$ \\
\hline 3 & 546 & $\mathrm{~L} \rightarrow \mathrm{Al}+\mathrm{Si}+\mathrm{Al}_{5} \mathrm{FeSi}$ \\
\hline 4 & 502 & $\mathrm{~L} \rightarrow \mathrm{Al}^{+} \mathrm{Al}_{2} \mathrm{Cu}+\mathrm{Si}+\mathrm{Al}_{5} \mathrm{FeSi}$ \\
\hline 5 & 492 & $\mathrm{~L} \rightarrow \mathrm{Al}+\mathrm{Al}_{2} \mathrm{Cu}+\mathrm{Si}+\mathrm{Al}_{5} \mathrm{Mg}_{8} \mathrm{Cu}_{2} \mathrm{Si}_{6}$ \\
\hline
\end{tabular}

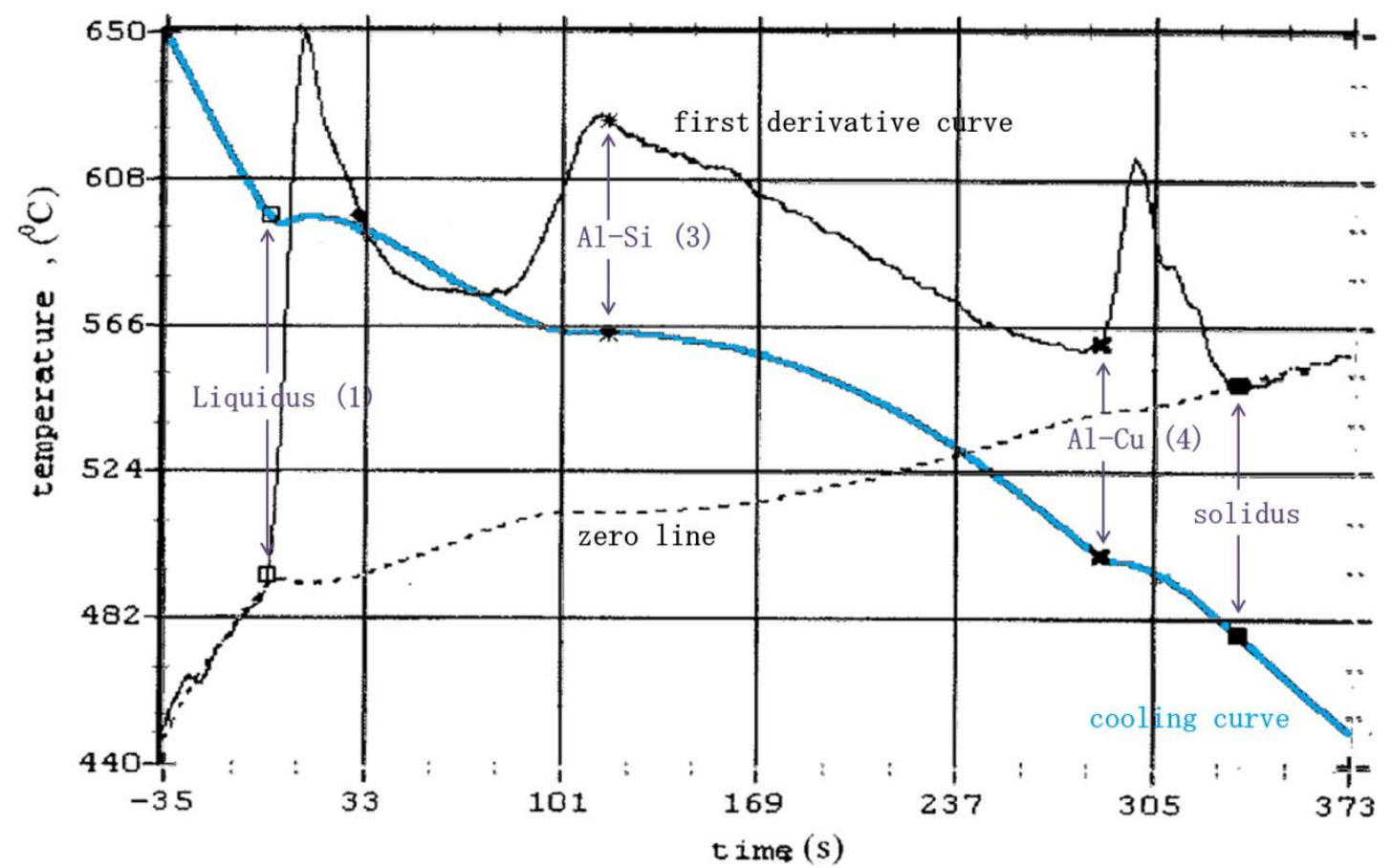

Figure 2-14: Typical cooling curve, first derivative curve, and zero line for 319 alloy [22]

\subsection{Thermal Conductivity}

Thermal conductivity $(k)$ describes the capability of a material to transfer heat internally (i.e. by conduction) to its lower temperature regions. According to Fourier's law [12], one-dimensional thermal conductivity is defined as the proportionality constant between the steady state heat flux 
per unit cross-sectional area $(q)$ and the change in temperature with respect to distance in the direction of heat flow $(d T / d x)$ :

$$
q=-k \frac{d T}{d x}
$$

Equation 2-8

Additionally, thermal conductivity is proportional to specific heat and density $(\rho)$ by thermal diffusivity $(\alpha)$, which describes the rate at which a material conducts heat relative to its ability to store the thermal energy:

$$
\boldsymbol{k}=\alpha \rho c_{p}
$$

Equation 2-9

The conduction of heat through a material occurs via two main thermal energy carriers: lattice vibration waves $\left(k_{l}\right)$ and free electrons $\left(k_{e}\right)$ :

$$
\boldsymbol{k}=\boldsymbol{k}_{\boldsymbol{l}}+\boldsymbol{k}_{\boldsymbol{e}}
$$

Equation 2-10

The former arises from the thermal energy associated with atomic vibrations, quantized by phonons. Phonons tend to propagate through a material with a temperature gradient from high to low temperature regions, such that their thermal energy is carried with them. On the other hand, thermal energy is converted to kinetic energy by free electrons. An increase in their kinetic energy promotes their flow through the material's temperature gradient. Consequently, the free electrons can transfer some of their kinetic energy to the atoms in colder regions in the form of thermal energy, via collisions with lattice waves or imperfections. In either case, the heat transfer through a material is hindered by scattering of the thermal energy carriers. As a result, heat transfer by free electrons is significantly more efficient in high-purity, ambient-temperature metals than by phonons. In metals, lattice imperfections are very efficient at scattering phonons, impeding their propagation to colder regions. However, free electrons have high velocities and are less prone to scattering. Thus, given their relatively large concentration of free electrons, metals are characterized as highly-conductive, compared to ceramics and polymers.

In addition to influencing thermal conductivity, free electrons are entirely responsible for electrical conductivity $\left(\sigma_{e}\right)$, which describes the ability for electrons to move through a material. Accordingly, the thermal and electrical conductivities are related by the Wiedemann-Franz law [12]: 


$$
\boldsymbol{k}=\boldsymbol{L T} \boldsymbol{\sigma}_{e}
$$

Equation 2-11

This relationship is dependent on both temperature $(T)$ and a constant called the Lorenz number $(L)$. In metals for which free electrons account for the entirety of heat conduction, the Lorenz number is both temperature- and alloy-independent, and it is theoretically equal to $L_{0}, 2.445 \times 10^{-8}$ $\Omega-\mathrm{W} / \mathrm{K}^{2}$. Otherwise, a correction factor must be applied to account for heat transfer via phonons [23].

When describing factors affecting the more significant electronic contribution to the thermal conductivity of metals, it is often more convenient to discuss electrical resistivity $\left(\rho_{e}\right)$, defined as the reciprocal of electrical conductivity. Predominantly, resistivity is increased - and therefore thermal and electrical conductivity is decreased - by the presence of "scattering centres." These centres obstruct electron mobility, causing both decreases in velocity and changes in direction. According to Matthiessen's rule [12], factors impeding electron motion are independent, such that the total electrical resistivity is equal to the sum of the individual contributions of the various types of scattering centres. For example, impurity atoms are significant sources of electron scattering, especially when the atoms are in solid solution. As well, lattice irregularities, such as thermal vibrations, dislocations, vacancies, grain boundaries, and porosity, all increase resistivity.

The following sections describe the published findings of the effect of alloying and solidification on thermal conductivity. As well, a review of common methods for measuring thermal conductivity is presented.

\subsubsection{Effect of Alloying}

Aluminum is the most thermally conductive in its purest form. However, any and all impurities or alloying elements contribute to scattering of thermal carriers, thus reducing conductivity. Many elements can be dissolved into the aluminum matrix, but they can also be present out of solution either by exceeding their solubility limits (under equilibrium conditions) or by precipitating as secondary phases. Therefore, the elemental concentrations in the solid solution, 
the volume fraction, size, morphology, and distribution of secondary phases all contribute to a reduction in thermal conductivity.

\subsubsection{Elements in Solid Solution}

According to Matthiessen's rule, elements in solid solution independently increase the overall alloy's resistivity almost linearly with their respective increases in concentration. This was observed by Mulazimoglu et al. [24], who demonstrated that the electrical conductivity of Al-Si$\mathrm{Mg}$ alloys decreased linearly with increasing $\mathrm{Si}$ or $\mathrm{Mg}$ concentrations at relatively constant and independent rates, at about $12 \%$ IACS per wt.\% Si and $10 \%$ IACS per wt.\% Mg (Figure 2-15). Since both elements were dissolved into the aluminum solid solution, their additive resistivity contributions were as expected. The points of slope change in the curves in Figure 2-15 are indicative of the Si solid solubility limits, which are slightly reduced from the binary alloy's values by the presence of $\mathrm{Mg}$.

The average increases to electrical resistivity with concentration of elements common in as-cast aluminum alloys are summarized in Table 2-4. As shown, the resistivity increase from a given element in solid solution appears to be related to the degree of lattice strain imposed by its dissolution. As well, the effects on conductivity with increasing elemental concentrations are much more adverse in solid solution than out of solid solution. 


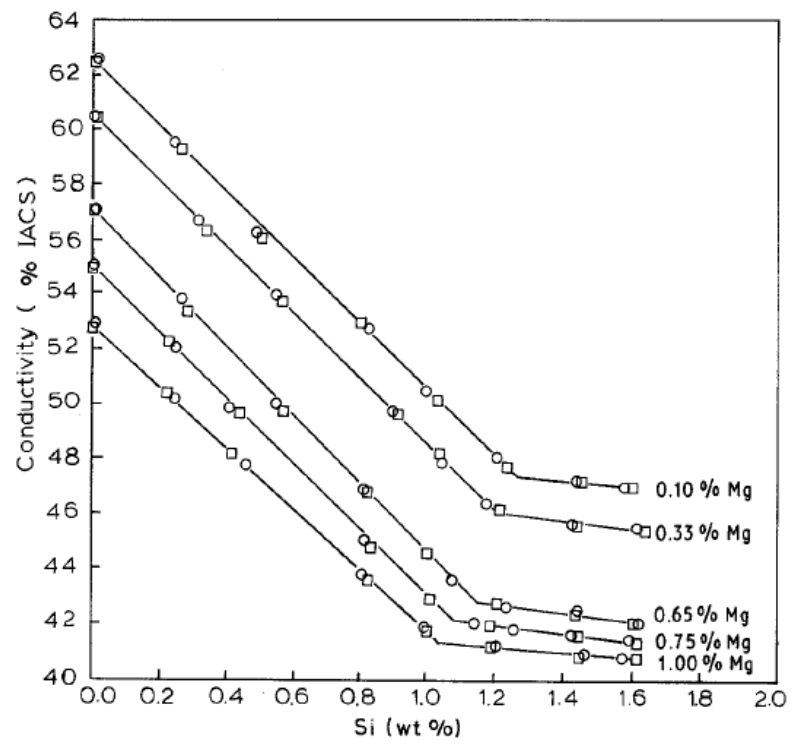

Figure 2-15: Room-temperature electrical conductivity of Al-Si-Mg alloys at low Si levels after solutionizing [24]

Table 2-4: Effect of elements in and out of solid solution on the resistivity of aluminum [25]

\begin{tabular}{cccccc}
\hline \multirow{2}{*}{ Element } & $\begin{array}{c}\text { Atomic } \\
\text { Radius } \\
(\mathrm{pm})\end{array}$ & $\begin{array}{c}\text { Crystal } \\
\text { Structure }\end{array}$ & $\begin{array}{c}\text { Maximum Solubility } \\
\text { in Al (wt.\%) }\end{array}$ & $\begin{array}{c}\text { Average Increase in Electrical } \\
\text { Resistivity per wt.\% }(\mu \Omega \text {-cm) }\end{array}$ \\
\cline { 5 - 6 } $\mathrm{Cr}$ & 125 & BCC & 0.77 & 4.00 & 0.18 \\
$\mathrm{In}$ Solution & $\begin{array}{c}\text { Out of Solution } \\
(\mathrm{a})\end{array}$ \\
$\mathrm{Fe}$ & 128 & FCC & 5.65 & 0.344 & 0.03 \\
$\mathrm{Li}$ & 124 & BCC & 0.05 & 2.56 & 0.058 \\
$\mathrm{Mg}$ & 152 & BCC & 4 & 3.31 & 0.68 \\
$\mathrm{Mn}$ & 160 & HCP & 14.9 & $0.54(\mathrm{~b})$ & $0.22(\mathrm{~b})$ \\
$\mathrm{Ni}$ & 112 & Cubic & 1.82 & 2.94 & 0.34 \\
$\mathrm{Si}$ & 125 & FCC & 0.05 & 0.81 & 0.061 \\
$\mathrm{Ti}$ & 118 & Dia. Cubic & 1.65 & 1.02 & 0.088 \\
$\mathrm{~V}$ & 145 & HCP & 1 & 2.88 & 0.12 \\
$\mathrm{Zn}$ & 132 & BCC & 0.6 & 3.58 & 0.28 \\
$\mathrm{Zr}$ & 133 & HCP & 82.8 & $0.094(\mathrm{c})$ & $0.023(\mathrm{c})$ \\
\hline $\mathrm{Adn}$ & 159 & HCP & 0.28 & 1.74 & 0.044 \\
\hline
\end{tabular}

Add above increase to the base resistivity for high purity aluminum, $2.71 \mu \Omega$-cm at $298 \mathrm{~K}\left(25^{\circ} \mathrm{C}\right)$.

(a) Limited to twice the concentration given for the maximum solid solubility, except as noted.

(b) limited to approximately $10 \%$, (c) limited to approximately $20 \%$. 


\subsubsection{Secondary Phases}

Secondary phases also reduce the alloy's thermal conductivity, although the influence is less than when the element or compound is in solid solution. Decreases in thermal conductivity are usually proportional to the volume fraction of intermetallic phases [26]. Also, since the secondary phases generally form in random crystal orientations, even alloys with high secondary phase volume fractions should demonstrate isotropic conductivity behaviour.

Mulazimoglu et al. [27] found up to a $37 \%$ decrease in room-temperature electrical conductivity with Si increases from 2 to 12.6 wt.\% (Figure 2-16). While Si solubility in Al is exceeded, there is an increase in volume fraction of the eutectic Si phase in the microstructure. The resistivity of $\mathrm{Si}$ is many orders of magnitude larger than that of the Al solid solution: $2.0 \times 10^{11} \mu \Omega-\mathrm{cm}$ compared to approximately $\sim 3.4 \mu \Omega$-cm at room temperature [27]. However, in Figure 2-16, the conductivity appears to approach a constant value for higher Si levels. This may indicate a point where conductivity becomes more influenced by the Al matrix than by increased volume fraction of eutectic Si. In any case, as discussed above, the conductivity is diminished less by increasing amounts of eutectic Si phase than by increasing amounts of Si in solid solution. As well, regardless of whether $\mathrm{Si}$ is present in the solution or in the eutectic phase, $\mathrm{Mg}$ reduces conductivity due to its dissolution into the solid solution.

The bulk conductivities of dissolved elements and secondary phases are often much less than the Al matrix, such as for Si. Yet, the bulk resistivity values may not necessarily apply when present as microscopic phases [26]. In fact, even the addition of more conductive elements, like $\mathrm{Cu}$, increases the electrical resistivity of aluminum alloys for all concentrations [28]. For instance, Stadler et al. [26] found that increasing volume fraction in $\mathrm{Al}_{2} \mathrm{Cu}$, a common intermetallic in A319, in Mg-containing Al-Si alloys reduced thermal conductivity. When in solid solution, any atoms will create lattice irregularities that decrease conductivity, regardless of their bulk conductivities. But usually elements will precipitate out as compounds that are less conductive than the Al matrix. The lower conductive phases resist electron flow more than the surrounding aluminum matrix, and more conductive phases may still increase the alloy's overall resistivity due to thermal contact resistance between the phase and the matrix. 


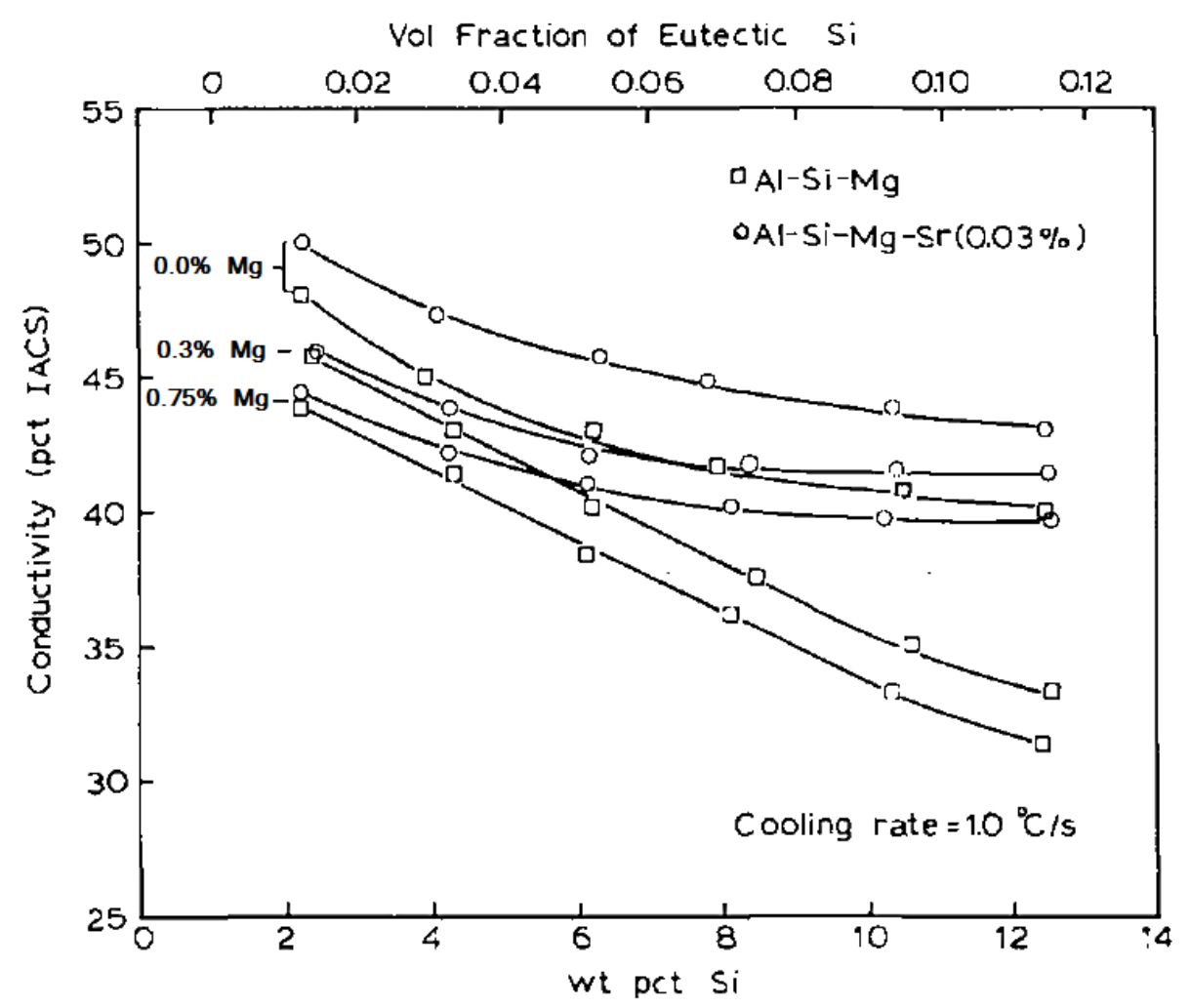

Figure 2-16: Room-temperature electrical conductivity of Al-Si-Mg alloys at hypoeutectic Si levels in as-cast condition [27]

In addition to volume fraction, the extent of the influence of secondary phases on thermal conductivity is dependent on their morphology and distribution. In general, the preferred mode of heat conduction is through the Al matrix. As a result, conductivity is reduced by increasing the concentration of lattice irregularities, primarily by dissolution of other elements into the matrix. In regions of secondary phases, electron collisions with the phases can occur, hence decreasing their mean free path. However, secondary phases distributed throughout the microstructure are not as harmful as a more concentrated solid solution, because the electrons still have paths to flow between the phases through the more conductive $\mathrm{Al}$ matrix. Consequently, fine, round, and well-distributed phases are preferred to coarse, acicular, and segregated phases, since the latter promotes more electron collisions that impede their flow through the material (Figure 2-17). 


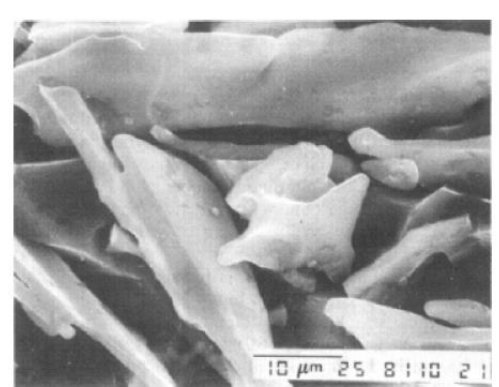

(a)

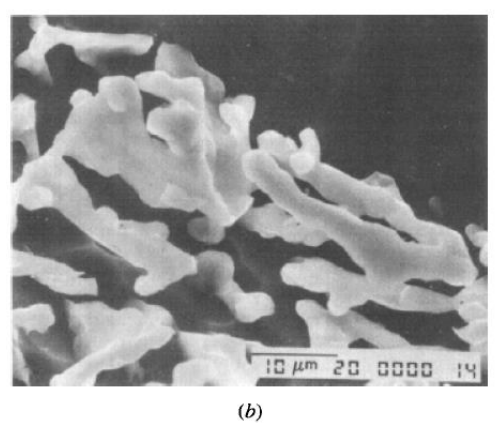

(b)

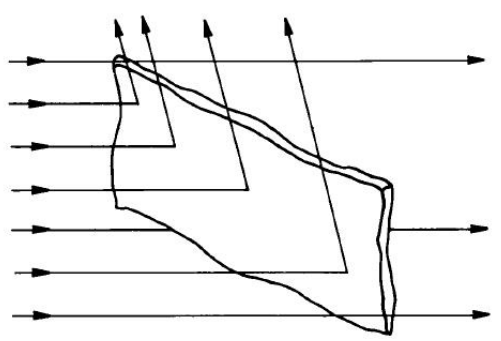

(a)

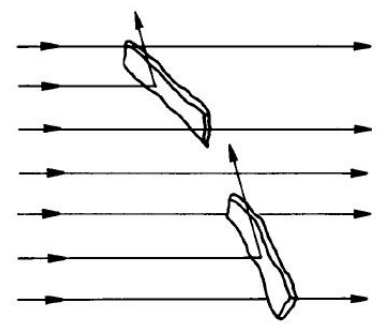

(b)

Figure 2-17: SEM micrographs and schematic representations of electron collisions with deep-etched eutectic Si: (a) unmodified and (b) modified [27]

\subsubsection{Effect of Porosity}

It is well-known that casting porosity has a significant adverse effect on a material's mechanical properties, whether from shrinkage or gas. Additionally, porosity has been observed to decrease thermal conductivity, since it effectively impedes heat transfer. Much like the other microstructural phases, pores can be considered as secondary phases containing still air, which has a much lower thermal conductivity than aluminum, roughly $0.02 \mathrm{~W} / \mathrm{m}-\mathrm{K}$ [12]. The effect of porosity can be estimated using the Maxwell model [29], which assumes a two-phase material consisting of a continuous, porosity-free matrix (Al) with a volume fraction $(\phi)$ of uniformlydispersed, spherical second-phases (air):

$$
\boldsymbol{k}=\frac{\boldsymbol{k}_{A l}\left[\boldsymbol{k}_{\text {air }}+2 k_{A l}+2 \phi\left(k_{\text {air }}-k_{A l}\right)\right]}{\left[\boldsymbol{k}_{\text {air }}+2 k_{A l}-\phi\left(k_{\text {air }}-k_{A l}\right)\right]}
$$

Equation 2-12

Empirical relationships between porosity and thermal conductivity have been found in the literature. For instance, Manzano Ramirez et al. [29] introduced 0.43-10.35 vol.\% of gaseous pores, at least $100 \mu \mathrm{m}$ in diameter, into a $380 \mathrm{Al}$ alloy (Al-8.4Si-3.6Cu-1.4Zn) by increasing the liquid melt temperature to promote hydrogen dissolution. Whereas thermal diffusivity was 
relatively insensitive to porosity, average specific heat, and hence thermal conductivity, decreased linearly with increasing pore volume fraction. Their results corresponded relatively well to those estimated by the Maxwell model (Figure 2-18). A large linear increase in electrical conductivity with increasing density was also seen for several hypoeutectic Al-Si-Cu alloys in the $20-26 \mathrm{~g} / \mathrm{cm}^{3}$ range by Argo et al. [30].

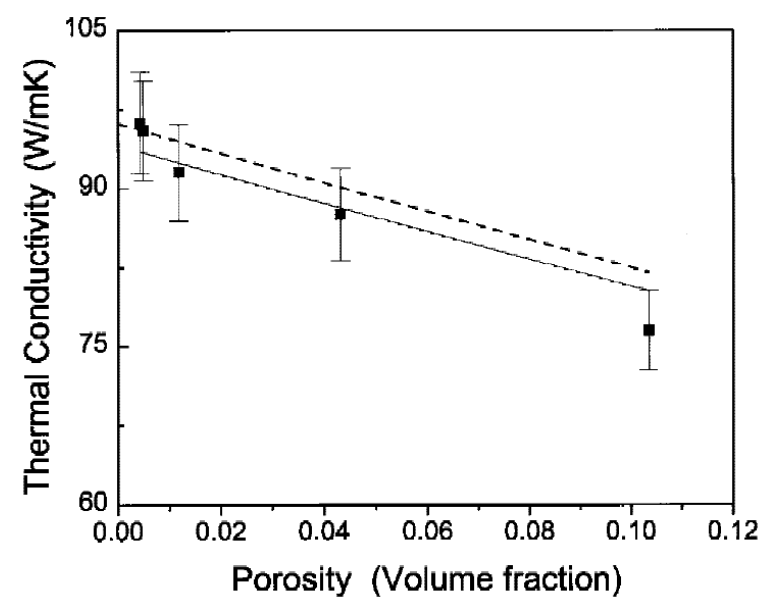

Figure 2-18: Thermal conductivity in Al 380 as a function of porosity: directly measured (solid line) and estimated by the Maxwell model (broken line) [29]

\subsubsection{Effect of Solidification}

As indicated above, the concentration of the solid solution and the volume fraction, morphology, and distribution of secondary phases in the microstructure are quite influential on an alloy's thermal conductivity. Yet, these features are not only determined by the alloy's composition, but also by the casting and solidification parameters. As described in Section 2.2.3, cooling rate during casting affects the formation and thus the morphology of the primary dendrites and the secondary phases. As well, solidification parameters can control the levels of porosity present in a cast part. Therefore, there exists a relationship between solidification parameters and thermal conductivity, but it relates to a variety of factors.

First, increasing cooling rate leads to a finer dendritic structure. The increase in grain boundary density with decreasing SDAS may cause an increase in the resistivity of the alloy, as the 
boundaries impede electron flow. However, in most reported Al-Si alloys, the grain size has a secondary effect compared to the other influences associated with cooling rate [31]. Second, faster cooling promotes the refinement of secondary phases. In particular, a rapid cooling rate can cause the formation of fine lamellae of eutectic Si instead of coarse plates, in the absence of chemical modification [32].

Published results in the literature indicate that faster solidification results in higher conductivity. For example, Vázquez-López et al. [33] found that thermal conductivity, diffusivity, and specific heat increased in an A319 alloy with constant Sr content (0.01 wt.\%) with decreasing SDAS in the 104.2-23.4 $\mu \mathrm{m}$ range (Figure 2-19). The change in SDAS was attained by extracting samples from various depths through a directionally-solidified casting. The decrease in SDAS was associated with an increase in integral dendrite perimeter. Since the same Si content and degree of modification were claimed for all samples, the increase was attributed to the form of the $\mathrm{Al}$ channels.

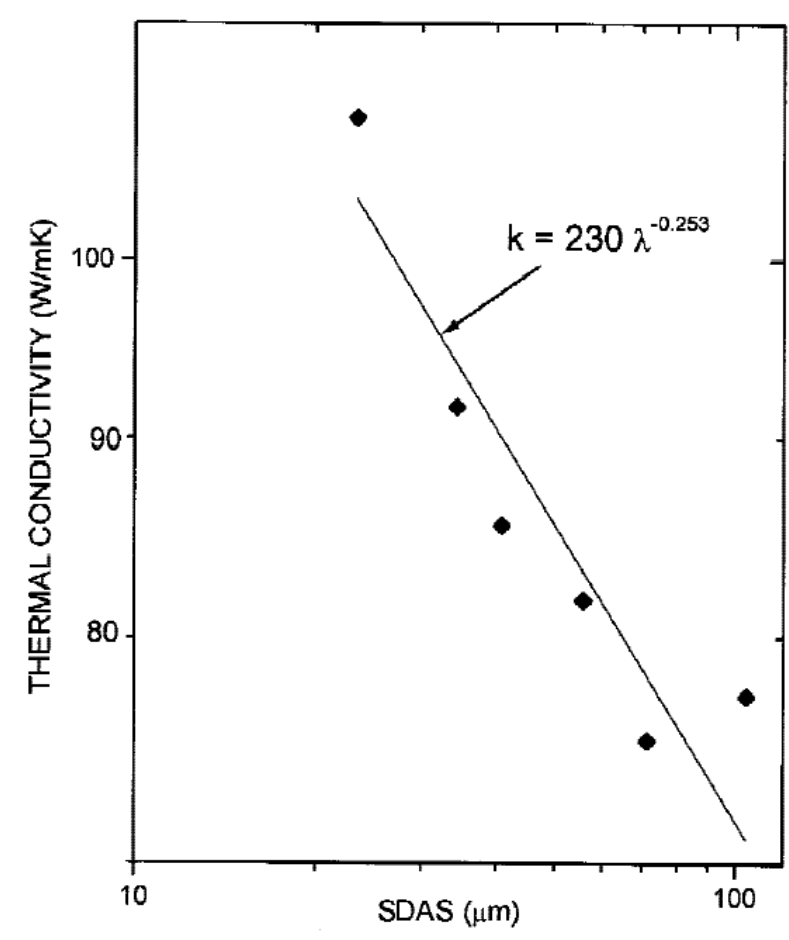

Figure 2-19: Variation of thermal conductivity of A319 as a function of SDAS ( $\lambda$ ) [33] 
As well, Argo et al. [30] found that the electrical conductivity of both unmodified and Srmodified $356 \mathrm{Al}$ alloy step castings decreased with increasing SDAS in the $20-150 \mu \mathrm{m}$ range in (Figure 2-20). Similarly, Oger et al. [34] found an increase in electrical resistivity of A356 alloy with decreasing cooling rate in the $0.50-0.05{ }^{\circ} \mathrm{C} / \mathrm{s}$ range. However, they noted a counter-balance between the beneficial effects of eutectic Si modification and the adverse effects of SDAS and porosity.

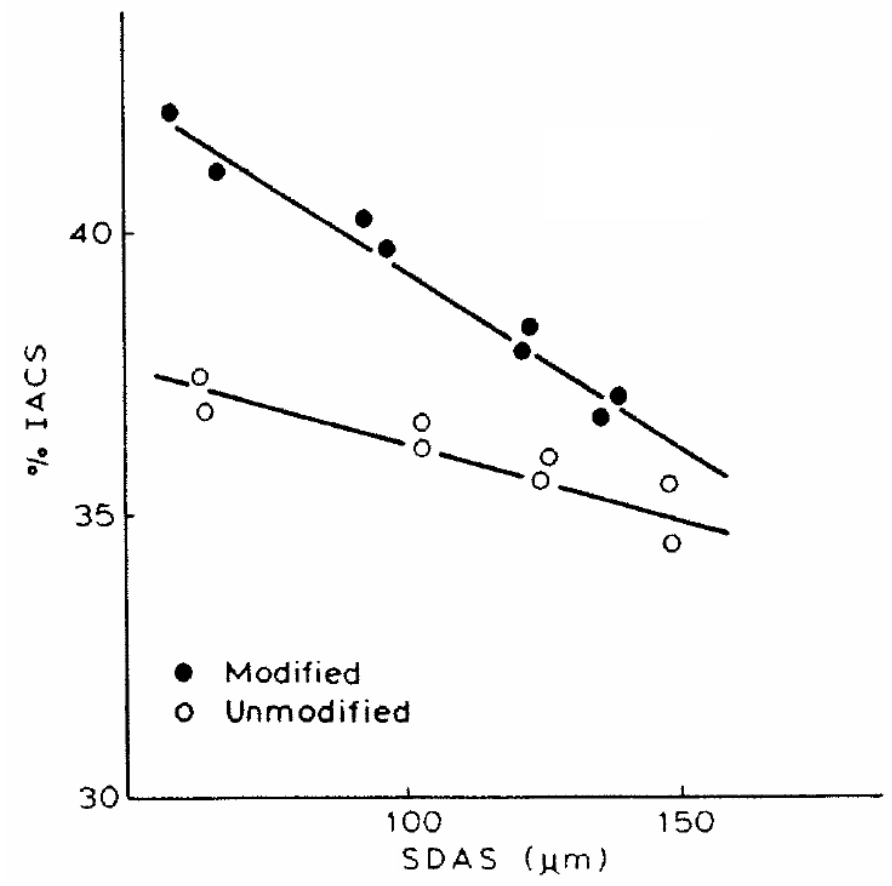

Figure 2-20: Electrical conductivity as a function of SDAS for modified (0.038 wt.\% Sr) and unmodified 356 step castings [30]

Despite the common trend in these results, all of the work studying the effect of solidification on thermal conductivity failed to present a complete microstructural assessment to evidence the suggested mechanisms. Solidification influences many aspects of the material, and relating conductivity to isolated parameters like SDAS and Si modification without characterizing changes in all other microstructural aspects is inadequate. Consequently, there is a need for a comprehensive study of the influence of solidification on thermal conductivity to gain a better understanding of the mechanism of heat transfer and the relative significance of all factors. 


\subsubsection{Measurement Techniques}

There are two main categories of measuring thermal conductivity: indirect and direct measurements. Whereas the latter utilizes apparatus to determine the material's thermal properties, the former involves determining the material's electrical counterparts, such as electrical conductivity or resistivity, from which thermal conductivity can be calculated using the Wiedemann-Franz law (Equation 2-11, above). Although indirect measurements are more common due to their simple and inexpensive techniques, direct measurements are preferred for their level of accuracy.

The two most common indirect measurement techniques are the four-probe technique for electrical resistivity and the eddy-current technique for electrical conductivity. In the four-probe method, a constant electric current $(I)$ is applied to a bar (with length $l$ and diameter $D$ ) and the resulting voltage drop $(V)$ across it is measured. Resistivity is then calculated simply using Ohm's law:

$$
\rho=\frac{\pi V D^{2}}{4 I l}
$$

Equation 2-13

This method requires intimate contact between the material and electric leads, and so liquid metal measurements become problematic due to ensuing reactions between them. On the other hand, the eddy-current technique induces a changing magnetic field in a material via a circular coil carrying alternating current. The magnetic field generates eddy current within the material which can be monitored and related back to the material's electrical conductivity. While such indirect techniques are suitable for measuring electrical properties, their reliance as tools for determining thermal properties is hindered by the accuracy of the mathematical relationship used, i.e. in uncertainties of the Lorenz number.

On the other hand, direct measurements often find density, specific heat, and thermal diffusivity separately, and then calculate thermal conductivity using Equation 2-9. Density is usually measured based on its geometry using the hydrostatic displacement technique (Archimedes' principle). Specific heat is typically measured using differential scanning calorimetry (DSC), but it can be estimated as a weighted sum of the specific heats of the alloying elements. Alternatively, volumetric heat capacity (the product of density and specific heat) can be 
determined using the thermal relaxation method, where the temperature rise is measured under continuous light illumination. Then, there are several different techniques for measuring thermal diffusivity. The laser flash method strikes the front face of a thin disc with a short energy pulse while monitoring the temperature rise on the sample's rear face. Similarly, the periodic (Angstrom) method involves periodically heating one end of a rod and measuring the temperature oscillations at the opposite end. In this method, thermal diffusivity is determined by the phase lag between the thermal oscillations. Also, the photoacoustic (PA) technique or a photopyroelectric (PPE) technique focuses a light source onto the front face of a sample, which gives rise to periodic temperature variations through the material via optical absorption. Consequent pressure fluctuations (for PA) or thermal waves (for PPE) on the rear face can be registered by the detector and the phase shift can be correlated to the thermal diffusivity.

Thermal conductivity can also be measured directly by several techniques without the need for intermediate thermal diffusivity measurements. For example, steady-state measurements can be taken based on Fourier's law (Equation 2-8), in which a material is subjected to a heat load at one end and the change in temperature with distance from the heated end is recorded. The steady-state method has been extended to comparative methods, in which both the material and a standard reference material (e.g. pure copper) are subjected to a heat load that conducts past their interface, and the resulting temperature change in the material studied is recorded. Yet, there is often error in these measurements given that heat loss to the surroundings, for example via convection, is difficult to eliminate.

In contrast, the transient plane source (TPS) technique enables the simultaneous determination of thermal conductivity, thermal diffusivity, and specific heat. This method is discussed in the following section.

\subsubsection{Transient Plane Source Technique}

The TPS technique (recognized in ISO 22007-2) is a fast and accurate method for determining the thermal properties of numerous types of isotropic and anisotropic materials, such as solids, liquids, pastes, and thin films, with a wide range of thermal conductivities. This method utilizes a sensor consisting of a double spiral of $10 \mu \mathrm{m}$ thick nickel encapsulated between two layers of 
$25 \mu \mathrm{m}$ thick Kapton (polyimide film) for mechanical strength and electrical insulation (Figure 2-21). The sensor is usually placed between two sample halves, and it acts as both a heat source for raising the sample temperature and as a measurement device to record the time-dependent temperature increase. This effectively determines the amount of heat dissipated through the material, which can be mathematically related to its thermal properties.

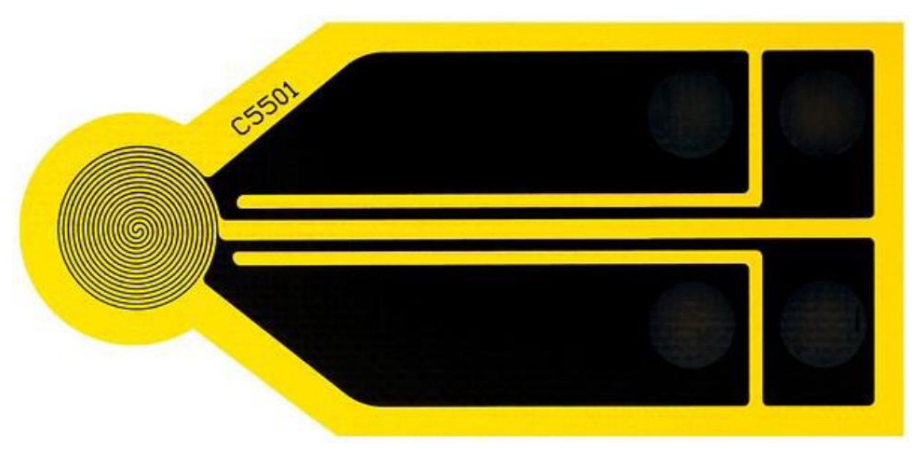

Figure 2-21: A TPS sensor [35]

During measurements, a constant current is applied to the sensor for a short time duration in order to increase the sensor temperature by $0.4^{\circ} \mathrm{K}$ to $4^{\circ} \mathrm{K}$. The change in the sensor's temperature is associated with a change in its electrical resistance, and so the variation in temperature over the measurement time can be determined by recording resistance (usually for 200 data points). Assuming that the sensor consists of concentric ring heat sources located in an infinitely large sample, its time-dependent temperature increase during transient heating can be expressed as the following [35]:

$$
\Delta T_{\text {ave }}(\tau)+\Delta T_{i}=\frac{1}{T C R}\left(\frac{R(t)}{R_{0}}-1\right)
$$

Where:

$\Delta T_{\text {ave }}(\tau)$ : Temperature increase of the sample surface on the other side of the insulating layer and facing the sensor 
$\Delta T_{i}$ : Constant temperature difference that develops almost momentarily over the thin insulating layers covering the two sides of the nickel element

TCR: Temperature coefficient of the resistivity for nickel

$R(t)$ : Time-dependent sensor disk resistance

$R_{0}$ : Resistance of the sensor disk before it is heated or at time $t=0$

In this equation, $\Delta T_{i}$ provides a measure of thermal contact between the sample surface and the sensor, as shown in Figure 2-22. The thermal contact becomes constant after a very short time $\left(\Delta t_{i}\right)$, estimated as the following [35]:

$$
\Delta t_{i}=\frac{\delta^{2}}{\alpha_{i}}
$$

Where:

$\delta^{2}$ : Thickness of the insulating layer

$\alpha_{i}$ : Thermal diffusivity of the layer material

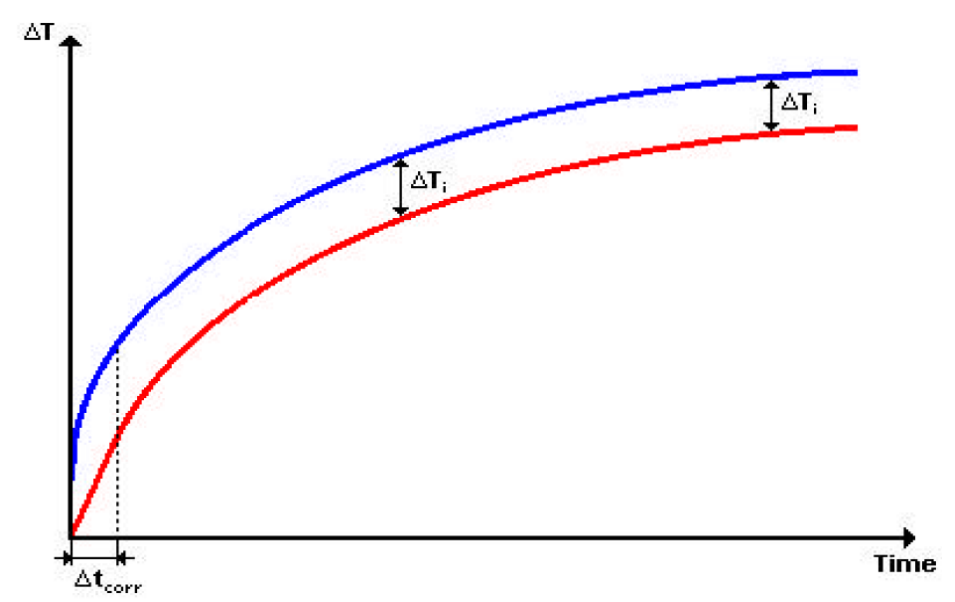

Figure 2-22: Temperature increase of the TPS sensor (top curve) and the sample surface (bottom curve) with measurement time [35] 
On the other hand, theoretically, the time-dependent temperature increase and related parameters can also be expressed as the following [35]:

$$
\begin{gathered}
\Delta T_{a v e, t h}(\tau)=\frac{P_{0}}{\pi^{3 / 2} r_{d} k} F(\tau) \\
\tau=\sqrt{t / \varphi} \\
\varphi=\frac{r_{d}^{2}}{\alpha}
\end{gathered}
$$

Equation 2-18

Where:

$P_{0}$ : Total output power from the sensor

$r_{d}$ : Overall radius of the sensor disk

$k$ : Thermal conductivity of the sample

$F(\tau)$ : Dimensionless time-dependent function of $\tau$

$t$ : Time measured from the start of the transient recording

$\varphi$ : Characteristic time

$\alpha$ : Thermal diffusivity of the sample

Therefore, according to the combination of the above equations, the plot of the recorded temperature increase as a function of $F(\tau)$ is linear, where the slope is $\frac{P_{0}}{\pi^{3 / 2} r_{d} k}$ and the intercept is $\Delta T_{i}$, for experimental times much longer than $\Delta t_{i}$. Since both $k$ and $\alpha$ are unknown before the experiment, the straight line is obtained via an iterative process. This enables the determination of both thermal conductivity and diffusivity from a single transient measurement.

There are many variants of the TPS technique, but they all rely on the same basic theory. For example, single-sided measurements can be taken, where instead of placing the sensor between two sample halves, it is placed between a single sample and an insulating backing material with known thermal properties. In this method, the thermal contribution of the backing material is accounted for during the processing of the measurement data, allowing for the determination of 
the sample's thermal properties in the final results. Furthermore, the one-dimensional module allows for measurements of cylindrical rods with diameters slightly larger than the sensor diameter. In this method, heat propagates mainly in the direction of the rod length (perpendicular to the sensor radius), enabling measurements on samples with limited cross-sectional areas. Yet, this prevents that capability to directly acquire the sample's thermal diffusivity, and so volumetric specific heat is a required input for meaningful results. One-dimensional measurements are suitable for determining thermal conductivities from $1 \mathrm{~W} / \mathrm{m}-\mathrm{K}$ to above 500 $\mathrm{W} / \mathrm{m}-\mathrm{K}$, with accuracy within $\pm 5 \%$ and reproducibility with $\pm 2 \%$ within the whole range [36]. In any case, the size of the sensor, the heating power, and the measurement time are all parameters to optimize the experiment, such that sufficient heat penetrates through the material without reaching the sample boundaries.

Additionally, the specific heat capacity module can be used to determine the specific heat capacity of isotropic or anisotropic solid materials, typically with thermal conductivities greater than $0.02 \mathrm{~W} / \mathrm{m}-\mathrm{K}$, with better accuracy than $\pm 2 \%$ [37]. In this method, the sensor is placed in contact with the sample, and the entire assembly is surrounded by a thermally insulating backing material. Measurements are made over a long period of time, relative to the time required to establish non-varying temperature gradients in the sample, during which temperature is continuously recorded by following the resistance increase of the sensor. 


\section{Chapter 3: EXPERIMENTAL PROCEDURE}

As outlined in Figure 1-1, above, determining the influence of solidification parameters on thermal conductivity in A319 alloy involved the production and characterization of controlled castings. This chapter describes the experimental procedure conducted to complete each stage of this study, including the design, simulation, and machining of a permanent mould, melting and casting details, thermal analysis, microstructural analysis, porosity measurements, mechanical testing, and thermal conductivity measurements.

\subsection{Permanent Mould Design}

A successful study required the production of castings in which solidification rate could be carefully controlled with ease and over a wide range without affecting other casting features (e.g. composition, defects, etc.). Yet, several other casting characteristics were desirable for improving the quality of the study, including repeatability and comparability of casting conditions, microstructural homogeneity within a casting, and minimal porosity and other defects. As well, a sufficient casting size was needed to allow for the preparation of samples for microstructural, mechanical and thermal property testing, whereas the maximum size was limited to that of the furnace chamber.

Accordingly, several permanent mould concepts were designed, considering both casting geometry and mould preheating temperature as means to vary solidification rate. Casting simulations were conducted using SOLIDCast with add-on flow modeling module FLOWCast to evaluate attainable solidification rates, ease of mould cavity filling, and likely regions of shrinkage and porosity. The software uses FDM (Finite Difference Method) and CFD (Computational Fluid Dynamics) to simulate liquid metal flow and solidification. Initial concepts were book-moulds, including intricate riser and gating systems to enable high-quality castings. However, during experimental trials on an ASTM standard tensile mould (B108-06), it was found that when pouring at mould temperatures above $500{ }^{\circ} \mathrm{C}$, the high-fluidity molten aluminum alloy seeped through the parting line and out of the mould cavity, despite excessive 
mould clamping. Therefore, a single-sided mould design was necessary to ensure proper mould filling.

Step block moulds are commonly used for similar studies on solidification rate, as they enable the production of several progressively larger (and slower cooling) steps in a single casting. However, the use of such a mould would lead to excessive waste metal. For example, the whole casting would need to be filled even in situations when only one casting of a certain condition is required. Also, the difference in solidification rate between each successive step is not constant, and so aiming for unattained solidification rates may result in some steps with redundant conditions. Furthermore, the modeling software indicated a high susceptibility to shrinkage in the centre of the step block casting.

In contrast, a mould for a single "bar" casting was preferred, as it allowed for geometricallyidentical castings with a high level of microstructural control via the variation of mould temperature alone. As well, a simple, symmetrical design promoted uniform solidification within the casting and minimal waste in sample preparation. The selected casting minimum dimensions were $150 \mathrm{~mm}$ in length, $30 \mathrm{~mm}$ in height, and $10 \mathrm{~mm}$ in thickness to enable the production of both bars for tensile testing and rods for thermal conductivity testing. They were designed with a $5^{\circ}$ draft to facilitate casting removal from the mould, and an additional wider "riser" was placed at the top to raise shrinkage regions away from the main casting section. An example casting model can be seen in Figure 3-1.

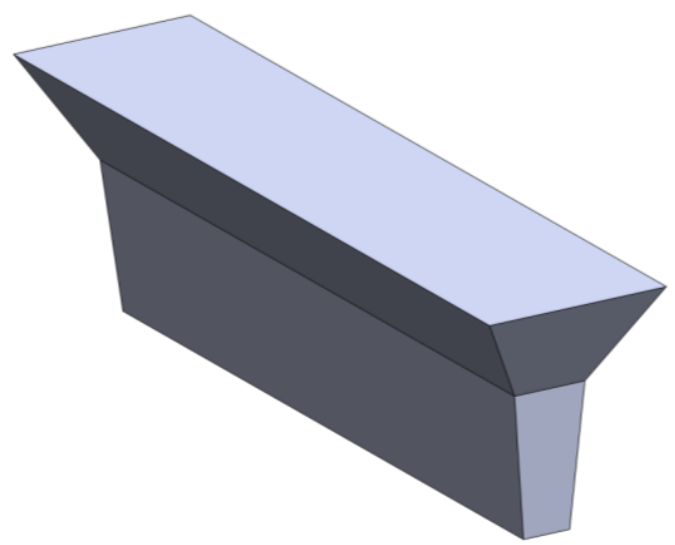

Figure 3-1: Model of an example casting design 
Realistic mould preheating temperatures in the casting facility were from ambient temperature to about $700{ }^{\circ} \mathrm{C}$, so SOLIDCast was used to simulate the effect of casting size on solidification rate within this temperature range. In the simulations, minimum casting thickness was variable while other geometrical parameters were held constant. A $10 \mathrm{~mm}$ high riser with a $50^{\circ}$ draft was found to be effective, and so it was used for most of the simulations. The built-in casting material Al 319.0 was selected, whose properties are listed in Table 3-1. A rectangular open mould $22 \mathrm{~mm}$ thick was modeled around the casting in accordance with the expected mould fabrication from a standard 2.5 inch $(63.5 \mathrm{~mm})$ thick steel block. The mould material was selected as $\mathrm{H} 13$ tool steel with thermal conductivity, specific heat, and density values of $24.5 \mathrm{~W} / \mathrm{m}-\mathrm{K}, 460 \mathrm{~J} / \mathrm{kg}-\mathrm{K}$, and $7800 \mathrm{~kg} / \mathrm{m}^{3}$, respectively. On the other hand, the initial mould temperature was variable. Tool steel was chosen to afford dimensional stability in the casting cavity for mould heating temperatures up to and above around $800{ }^{\circ} \mathrm{C}$. The suggested heat transfer coefficients for the $\mathrm{Al}$ alloy and ambient air, for the H13 mould and ambient air, and for the Al alloy and the H13 mould were $8.5 \mathrm{~W} / \mathrm{m}^{2} \mathrm{~K}, 48.8 \mathrm{~W} / \mathrm{m}^{2} \mathrm{~K}$, and $1135 \mathrm{~W} / \mathrm{m}^{2} \mathrm{~K}$, respectively. The ambient temperature was selected as $20^{\circ} \mathrm{C}$, the casting initial pouring temperature was set at $715^{\circ} \mathrm{C}$, and the pouring time was estimated as $4 \mathrm{~s}$. The castings were simulated using a $3 \mathrm{~mm}$ node size mesh for each casting thickness and initial mould temperature.

Table 3-1: Built-in SOLIDCast property data for Al 319.0

\begin{tabular}{|c|c|c|c|c|c|c|}
\hline $\begin{array}{c}\text { Thermal } \\
\text { conductivity } \\
(\mathrm{W} / \mathrm{m}-\mathrm{K})\end{array}$ & $\begin{array}{c}\text { Specific } \\
\text { Heat } \\
(\mathrm{J} / \mathrm{kg}-\mathrm{K})\end{array}$ & $\begin{array}{c}\text { Density } \\
\left(\mathrm{kg} / \mathrm{m}^{3}\right)\end{array}$ & $\begin{array}{c}\text { Latent Heat } \\
\text { of Fusion } \\
(\mathrm{J} / \mathrm{kg})\end{array}$ & $\begin{array}{c}\text { Liquidus } \\
\text { Temperature } \\
\left({ }^{\circ} \mathrm{C}\right)\end{array}$ & $\begin{array}{c}\text { Al-Si Eutectic } \\
\text { Temperature } \\
\left({ }^{\circ} \mathrm{C}\right)\end{array}$ & $\begin{array}{c}\text { Solidus } \\
\text { Temperature } \\
\left({ }^{\circ} \mathrm{C}\right)\end{array}$ \\
\hline 108.79 & 962.3 & 2767.91 & 388175.1 & 609 & 547 & 482 \\
\hline
\end{tabular}

For each simulation, the temperature profile of the molten alloy was recorded during solidification as function of time at the absolute centre of the main section of the casting (i.e. at centre length, centre thickness, and $15 \mathrm{~mm}$ from the bottom). SOLIDCast's built-in Al 319.0 cooling curve is shown in Figure 3-2, yet the time scale on the abscissa was correlated to the 
initial mould temperature and casting thickness. From these curves, the primary solidification rate was calculated for each condition as follows:

$$
S R_{P}=\frac{\Delta T_{L \rightarrow E}}{\Delta t_{L \rightarrow E}}
$$

Where:

$S R_{P}$ : Primary solidification rate

$\Delta T_{L \rightarrow E}$ : Primary freezing range (temperature difference between liquidus and Al-Si eutectic reactions)

$\Delta t_{L \rightarrow E}$ : Primary solidification time (time difference between liquidus and Al-Si eutectic reactions)

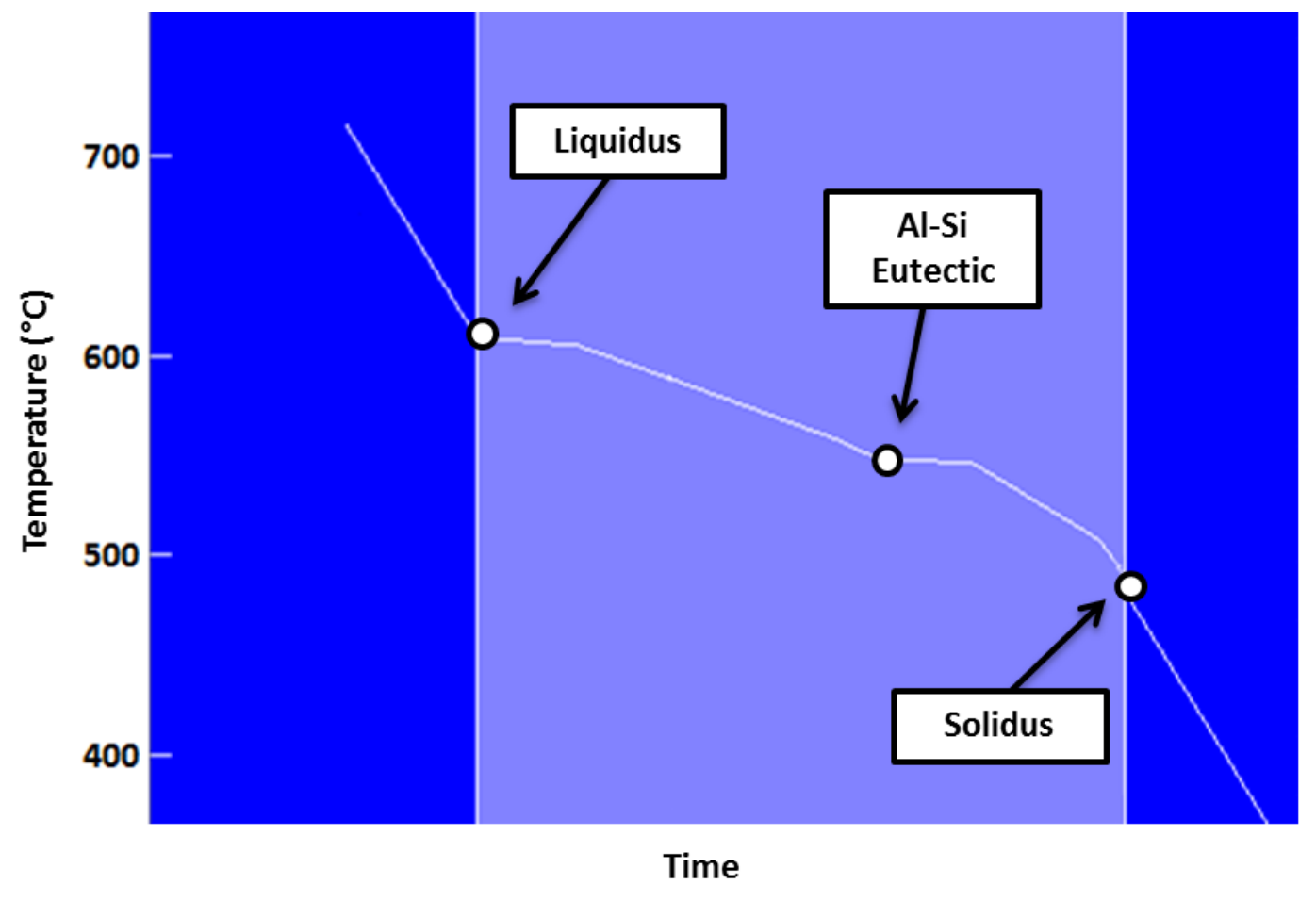

Figure 3-2: Simulated cooling curve for Al 319.0 
The results from these simulations are summarized in Figure 3-3. For each casting thickness, the solidification rate increased as the initial mould temperature decreased, in a relationship characterized by a fifth order polynomial. At progressively lower mould temperatures, the difference in temperature between the molten aluminum and the mould is greater, promoting enhanced heat transfer rates. At initial mould temperatures around the Al-Si eutectic temperature $(547$

${ }^{\circ} \mathrm{C}$ ) and above, there was little change in the solidification rate. However, below this temperature, further decreases in initial mould temperatures resulted in significant increases in solidification rate. Moreover, for a given mould temperature, progressively smaller casting thicknesses resulted in higher solidification rates. Although the rates were very similar for each thickness around the Al-Si eutectic temperature and above, the slope of the solidification rate versus initial mould temperature curve at lower temperatures was increasingly steeper with decreasing casting thickness.

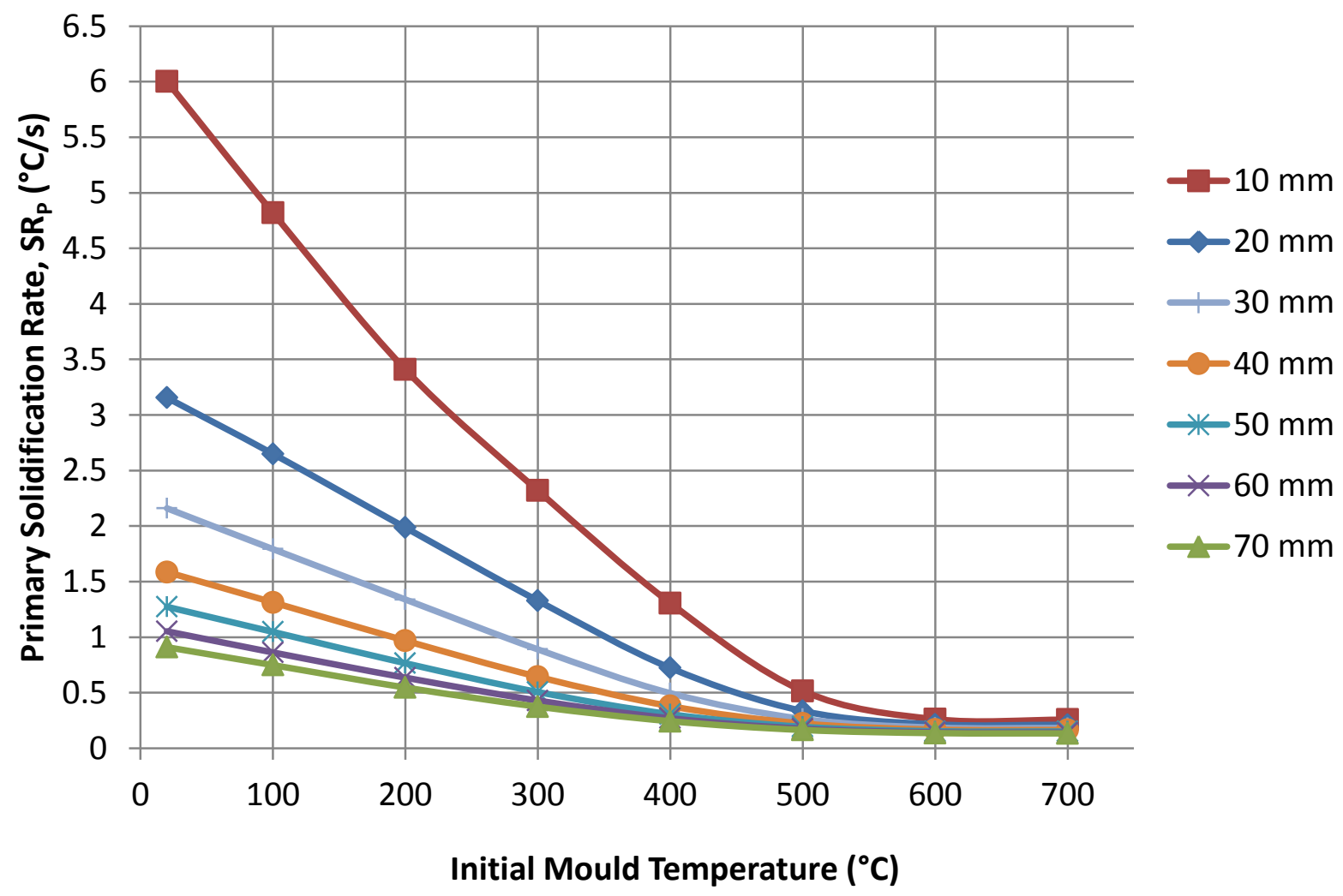

Figure 3-3: Simulated primary solidification rate as a function of initial mould temperature and casting thickness 
These results were not very sensitive to changes in some of the other simulation parameters. For example, simulations were run using finer meshes (up to $1.5 \mathrm{~mm}$ node size) and lower melt pouring temperatures (down to $700{ }^{\circ} \mathrm{C}$ ) with insignificant changes to solidification rate trends. As well, other riser designs, including with $30^{\circ}$ drafts and $10 \mathrm{~mm}$ or $20 \mathrm{~mm}$ heights, were also effective while minimally altering the solidification rate trends. Also, the solidification rates were fairly uniform throughout the casting, especially at higher mould temperatures (Figure 3-4).

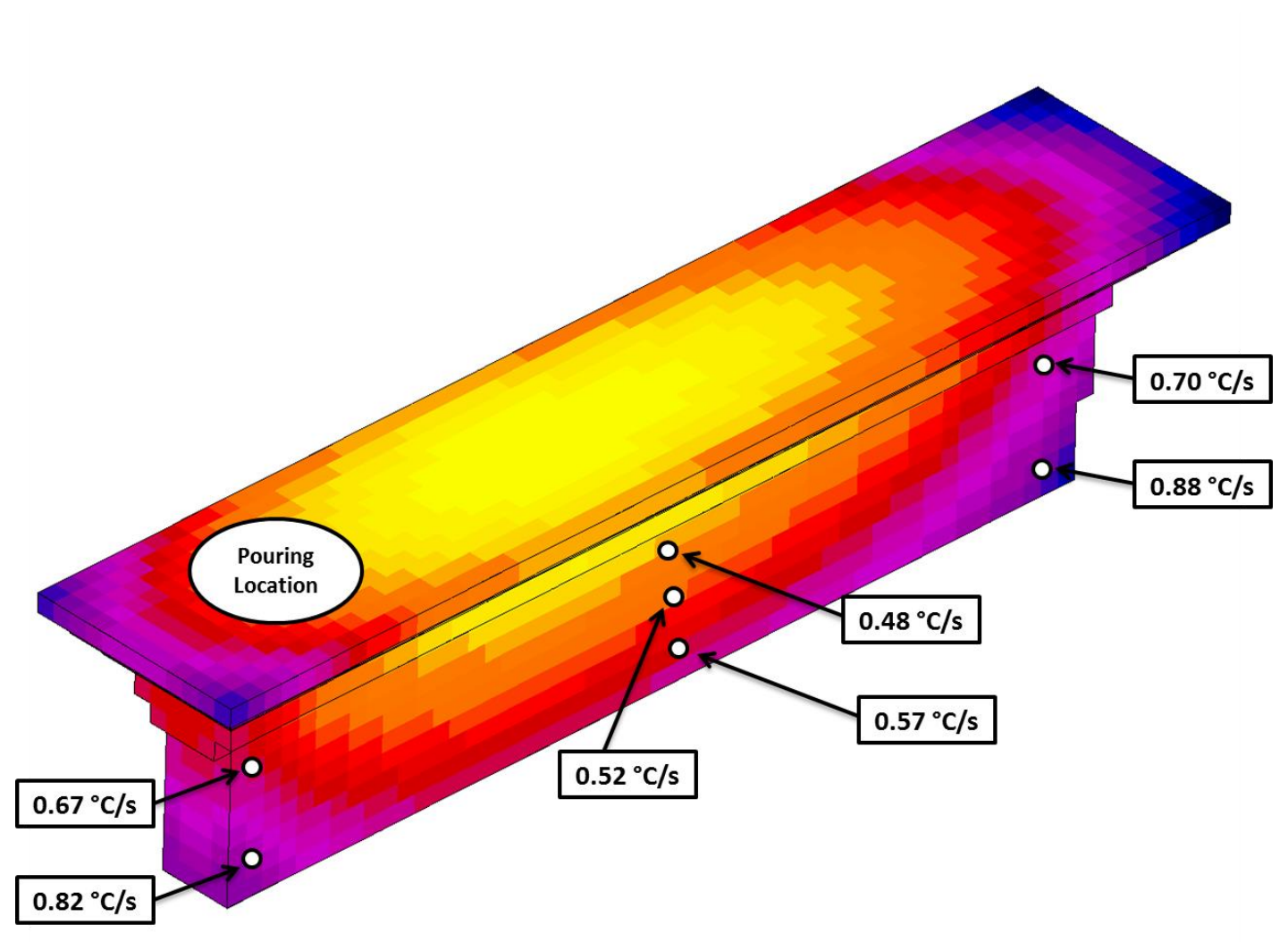

Figure 3-4: Simulated graphical representation of the variation in solidification rate for a $10 \mathrm{~mm}$ thick casting with $500{ }^{\circ} \mathrm{C}$ initial mould temperature

From Figure 3-3, it was clear that the $10 \mathrm{~mm}$ thick casting was the most suitable, since it enabled the largest range of solidification rates while remaining within the geometrical constraints for 
sample preparation. In addition, the SOLIDCast simulations indicated that this thickness promoted less shrinkage and porosity than the larger sizes. Therefore, the final casting was designed to be $150 \mathrm{~mm}$ long and $10 \mathrm{~mm}$ thick at the bottom, $30 \mathrm{~mm}$ high with a $5^{\circ}$ draft angle, followed by a $35^{\circ}$ riser $15 \mathrm{~mm}$ high (Figure 3-5). This riser angle was chosen to increase the number of casting cavities within a single mould. Casting ends were modified from rectangular to circular and all internal edges were filleted with a $1.6 \mathrm{~mm}(0.0625 \mathrm{inch})$ radius to facilitate casting removal from the mould and prevent casting defects like hot tearing.

Two permanent moulds were fabricated from $160 \mathrm{~mm}$ x $225 \mathrm{~mm}$ x $64 \mathrm{~mm}$ (6.25 in x 8.875 in x 2.5 in) blocks of H13 tool steel. These dimensions allowed them to both fit within the furnace chamber with room for easy insertion and removal. The moulds were designed to each contain three casting cavities, such that a total of six geometrically-identical castings could be produced at once with the same alloy batch. Mastercam CAD/CAM software was used as an aid in developing an efficient CNC mill program to machine the casting cavities into the moulds. The H13 was effectively milled with an adequate surface finish using solid carbide tools (a 0.5 in ball-nose end-mill for the risers and roughing; a 0.25 in bull-nose end-mill for finishing the main casting section) with forced air cooling. Afterwards, each mould was manually machined to add four $3.2 \mathrm{~mm}$ (0.125 in) thermocouple holes and one ANSI 1/2"-13 hole for insertion of an eye bolt for mould carrying.

Detailed engineering drawings for the castings and the moulds can be seen in Appendix B. 

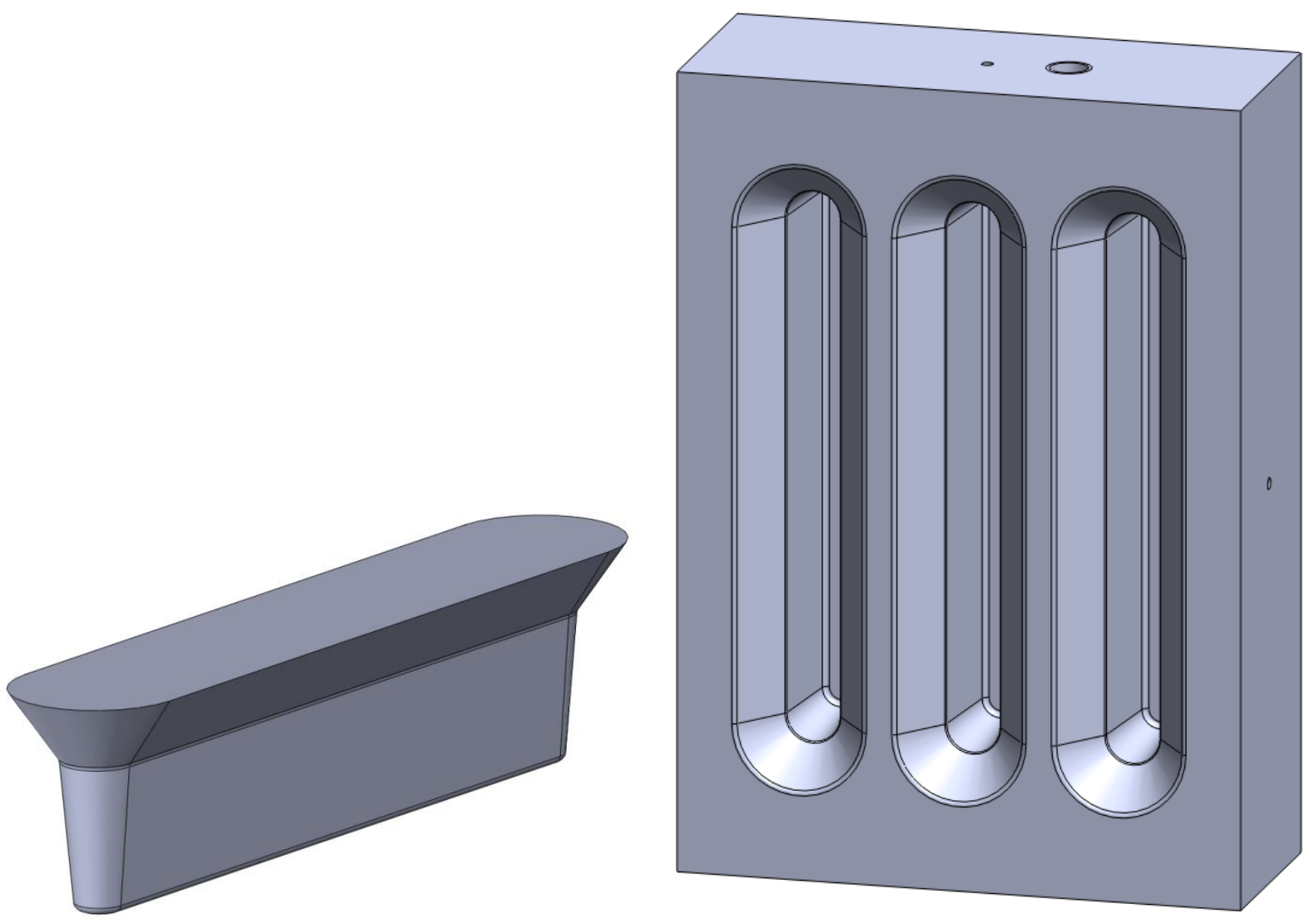

Figure 3-5: Final casting (left) and permanent mould (right) designs

\subsection{Alloy Melting and Casting}

A319 alloy was cast at varying mould temperatures to determine the effect of solidification time or rate on microstructure, mechanical, and thermal properties. The alloy was obtained as ingots from Wabash Alloys LLC.

For each production run (two moulds, six castings), approximately $2.2 \mathrm{~kg}$ of metal was melted in a silicon-carbide crucible. The crucible was heated in an electric resistance furnace at $750{ }^{\circ} \mathrm{C}$ for at least $1.5 \mathrm{~h}$ until molten. Next, commercial purity $\mathrm{Mg}(99.8 \mathrm{wt} . \%)$ was added to raise its concentration to about $0.40 \mathrm{wt} \%$, to enhance the alloy response to precipitation heat treatment. Thin slices of $\mathrm{Mg}$ were added by manually plunging and stirring for approximately $30 \mathrm{~s}$ under a $\mathrm{CO}_{2}$ cover gas, and the melt was allowed to settle for $20 \mathrm{~min}$ to ensure effective dissolution. The melt was then skimmed and treated with 0.25 wt.\% sodium fluorosilicate degasser and flux 
(powder) to reduce inclusions and entrained hydrogen. The degasser and flux was manually stirred under a fume hood and allowed to settle for 5-10 min. Each time the mould reached a desired preheating temperature (as discussed in the following section), the melt was skimmed, removed from the furnace, and poured into a single mould cavity, and the remaining metal was returned to the furnace. For each casting, the pouring temperature was approximately $715^{\circ} \mathrm{C}$.

The composition of the castings as determined from an optical emission spectrometer is presented in Table 3-2.

Table 3-2: Average experimental chemical composition of A319 alloy

\begin{tabular}{|c|c|c|c|c|c|c|c|c|c|c|}
\hline Component & Si & Cu & Mg & Ti & Fe & Mn & Zn & Ni & Other & Al \\
\hline Wt.\% & 6.37 & 3.35 & 0.40 & 0.13 & 0.66 & 0.34 & 0.79 & 0.05 & 0.22 & bal. \\
\hline
\end{tabular}

\subsubsection{Mould Temperature Control}

The moulds were heated in an electric furnace at least $150{ }^{\circ} \mathrm{C}$ above the maximum desired mould preheating temperature for the casting production run for a minimum of $1 \mathrm{~h}$ to ensure complete soaking. The moulds were removed from the furnace and allowed to cool on a firebrick in still air and homogenize in temperature before pouring. During this time, four K-type thermocouples with $3.175 \mathrm{~mm}$ diameter ceramic sleeves were inserted into holes in the four sides of the mould, each at the centre length of the side and $30 \mathrm{~mm}$ from the top. The holes extended into the mould such that there was about $15 \mathrm{~mm}$ of mould material between the thermocouple and the nearest casting cavity. Furthermore, three more thermocouples were suspended at centre length and width of each cavity, $30 \mathrm{~mm}$ from the top of the mould, to capture the cooling curves of each casting. These thermocouples were suspended by placing a steel cover plate over half the top of the mould with three holes in it, in which they were secured using steel stoppers. The thermocouples were attached to a Daytronic System 10 data acquisition unit for temperature monitoring and recording. The thermocouple placement and labeling can be seen in Figure 3-6. 


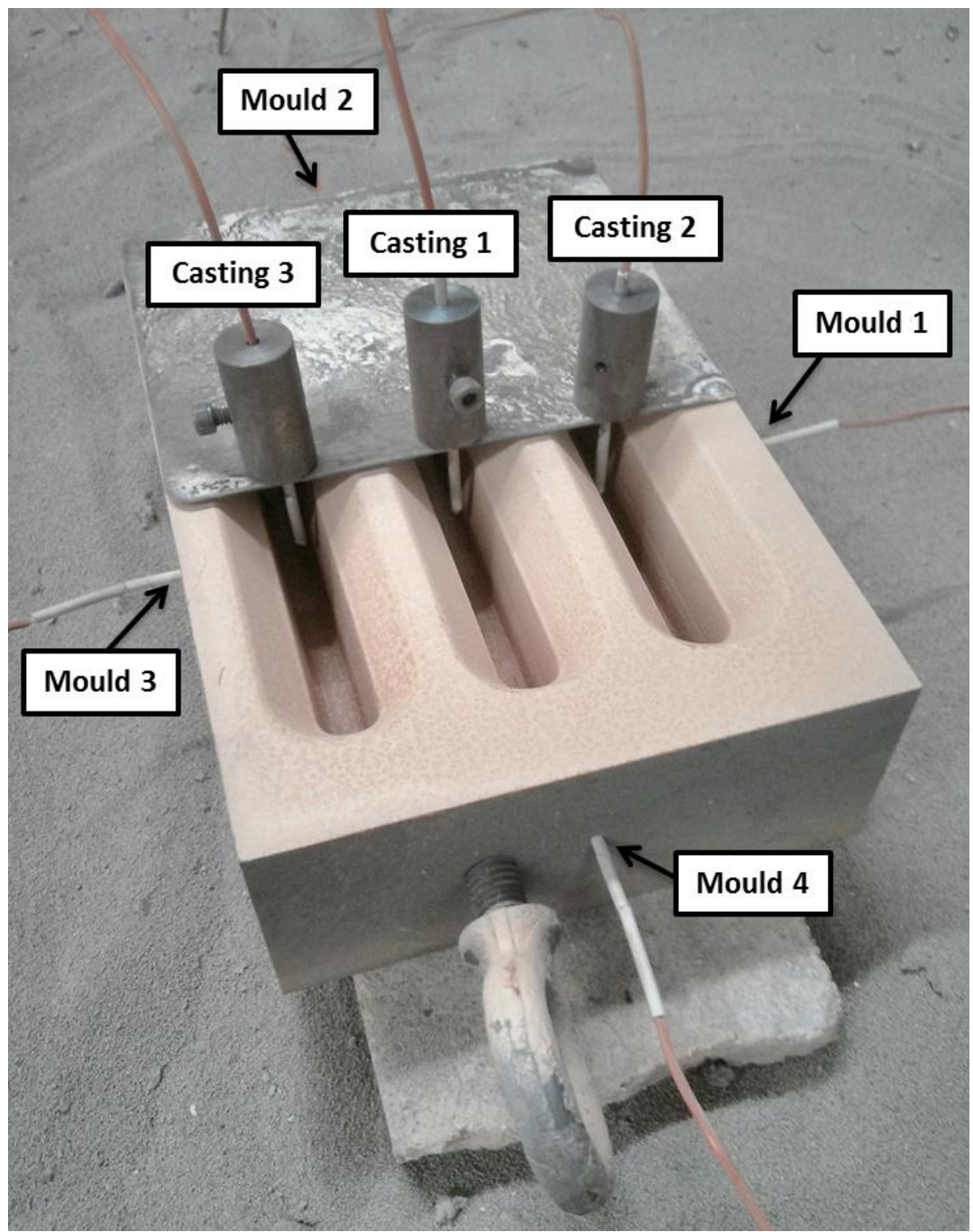

Figure 3-6: Thermocouple placement and labeling in the permanent mould

For these experiments, each mould cavity was considered isolated for the purpose of producing a casting with particular solidification characteristics. This was achieved by assigning the closest thermocouple(s) to each casting cavity as an indicator of its effective mould temperature. After all, heat transfer to the mould is most significant in the area directly surrounding the casting. Referring to Figure 3-6, the effective mould temperature for Casting 2 and Casting 3 were determined from thermocouples Mould 1 and Mould 3, respectively. For Casting 1, at the centre of the mould, the lower of the temperature readings between thermocouples Mould 2 and 
Mould 4 was taken as the effective mould temperature. Therefore, during casting, all four mould thermocouples for each of the two moulds (denoted "A" and "B") were monitored, and molten metal was poured into a given cavity once its assigned thermocouple indicated a desired initial mould temperature. Based on the simulations in Figure 3-3, above, and the capabilities of producing six castings in one production run, the intended initial mould temperatures for the experiments were at least from $700{ }^{\circ} \mathrm{C}$ to $200{ }^{\circ} \mathrm{C}$ in $50{ }^{\circ} \mathrm{C}$ intervals. The achieved mould temperatures for the castings are presented in Table 3-3.

Table 3-3: Initial mould temperatures for experimental castings

\begin{tabular}{|c|c|c|c|c|}
\hline \multirow{2}{*}{$\begin{array}{c}\text { Production } \\
\text { Run }\end{array}$} & \multicolumn{4}{|c|}{ Initial Mould Temperature at Pour $\left({ }^{\circ} \mathbf{C}\right)$} \\
\cline { 2 - 5 } & & Casting 1 & Casting 2 & Casting 3 \\
\hline \multirow{3}{*}{1} & Mould A & 690 & 647 & 497 \\
\cline { 2 - 5 } & Mould B & 588 & 545 & - \\
\hline \multirow{2}{*}{2} & Mould A & 449 & 349 & 250 \\
\cline { 2 - 5 } & Mould B & 397 & 300 & 200 \\
\hline
\end{tabular}

\subsection{Thermal Analysis}

Thermal analysis was carried out using the data recorded by the thermocouples suspended in the casting cavities (Figure 3-6, above). The data acquisition software was programmed to record temperature measurements every $0.2 \mathrm{~s}$ during the entire production run and for an additional 90 min. A typical cooling curve generated from the temperature-time data for A319 alloy is displayed in Figure 3-7. These curves were analyzed in conjunction with their first derivate curves to obtain the temperatures and times of the liquidus, Al-Si eutectic, and solidus points (with reference to Figure 2-14, above). This data was used to calculate the primary solidification rate $\left(S R_{P}\right)$ and the total solidification rate $\left(S R_{T}\right)$. As defined previously (Equation 3-1), the 
primary solidification rate considers the change in temperature with respect to time between the liquidus and the Al-Si eutectic. This range is useful for characterizing the growth of the primary dendritic structure before the evolution of other phases in the alloy. In contrast, the total solidification rate considers the change in temperature with respect to time between the liquidus and the solidus. This range characterizes the entire development of the alloy microstructure as it transforms from liquid to solid. The total solidification rate is defined by the following equation:

$$
S R_{T}=\frac{\Delta T_{L \rightarrow S}}{\Delta t_{L \rightarrow S}}
$$

Equation 3-2

Where:

$\Delta T_{L \rightarrow S}$ : Total freezing range (temperature difference between liquidus and solidus)

$\Delta t_{L \rightarrow S}$ : Local solidification time (time difference between liquidus and solidus)

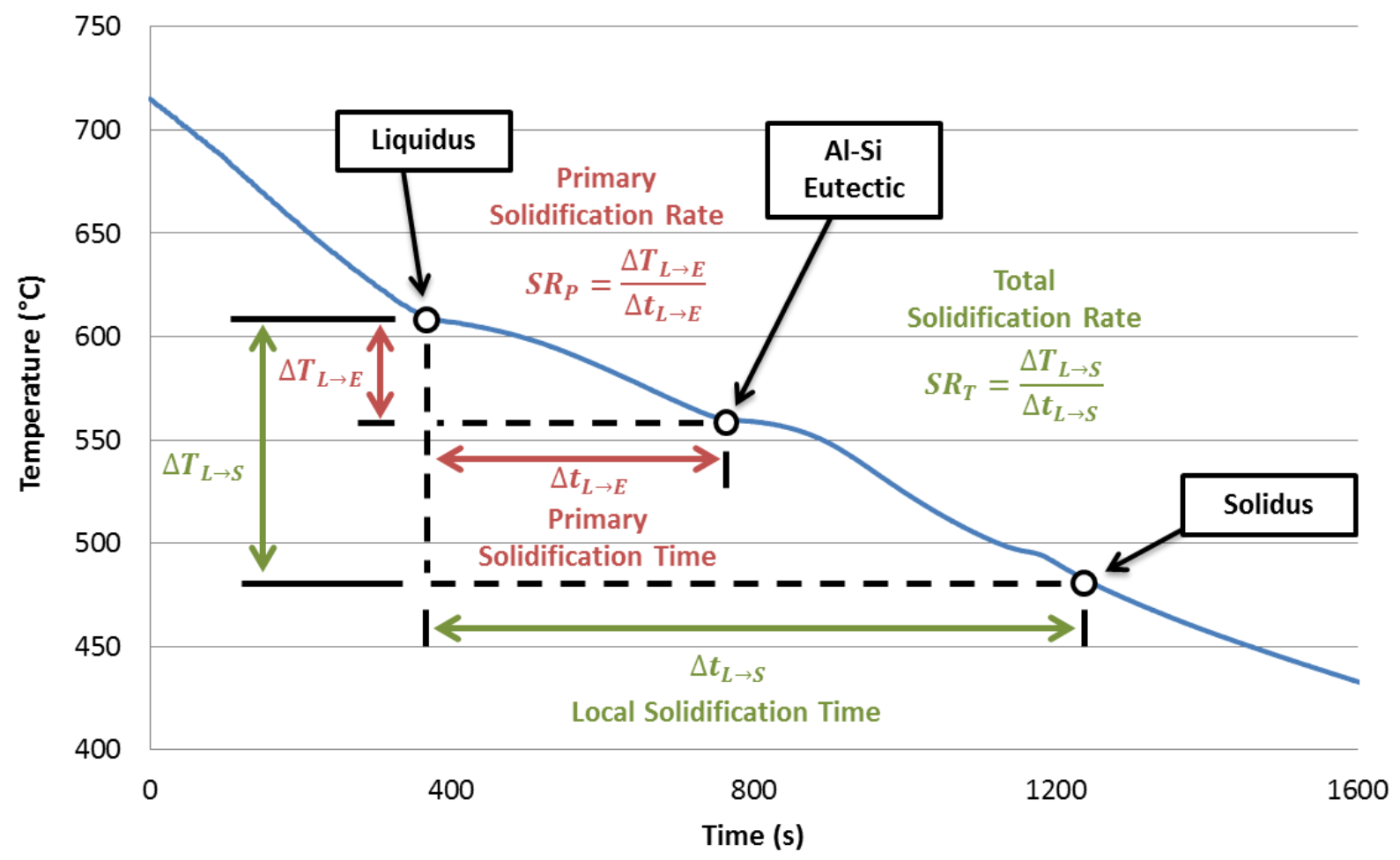

Figure 3-7: Typical cooling curve attained for A319 alloy 


\subsection{Sample Sectioning and Preparation}

The castings were sectioned into four samples for microstructural analysis, two bars for tensile testing, and two rods for thermal conductivity measurements, as indicated in Figure 3-8. The analyzed sample sides are designated by the arrows in the figure. The details of their preparation are outlined in this section.

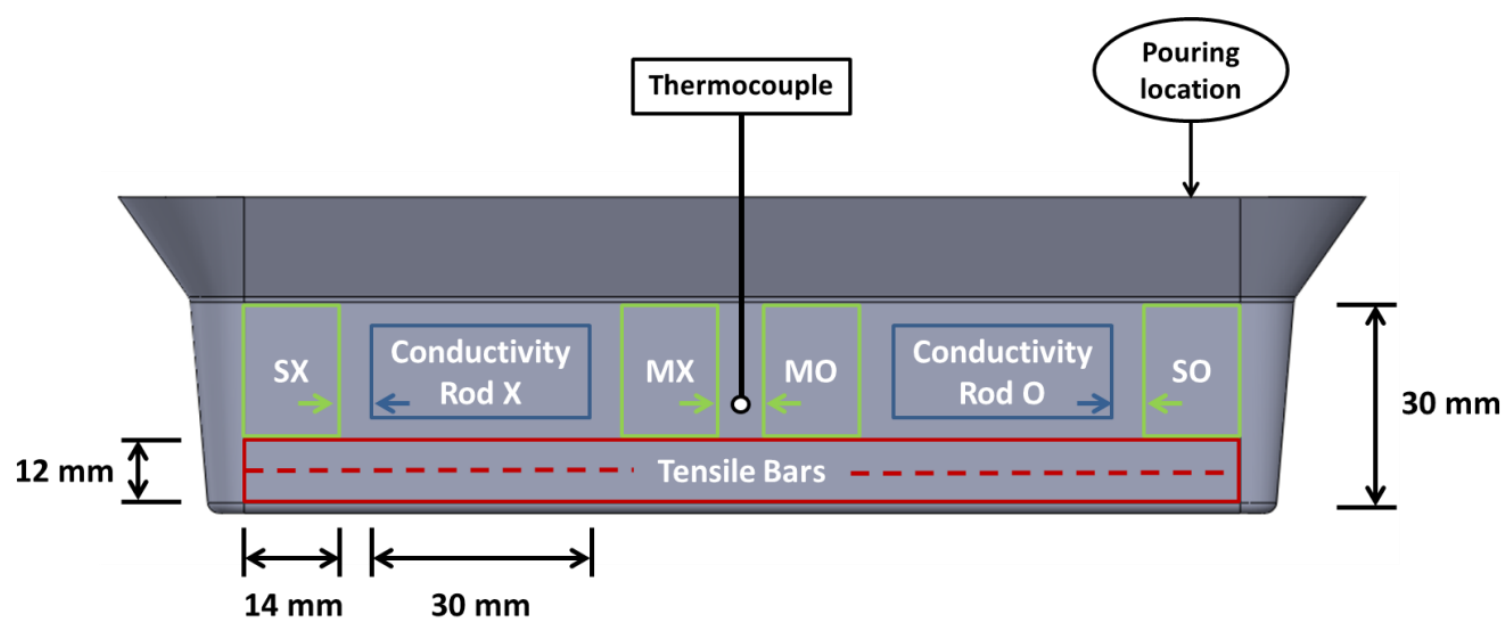

Figure 3-8: Analyzed sample locations (arrows indicate measurement side)

\subsubsection{Microscopy Samples}

For microstructural analysis, a total of four samples $14 \mathrm{~mm}$ in height, $18 \mathrm{~mm}$ in length, and the width of the casting were extracted for each condition. The samples were taken from the middle (denoted with an "M" prefix) and sides (denoted with an "S" prefix) of the casting, both on the side that was open for pouring (denoted with an "O" suffix) and the side that was closed by the cover plate for holding the thermocouple (denoted with an "X" suffix). This allowed a complete characterization of the casting and an evaluation of the microstructural homogeneity. For each sample, the side facing the casting centre was analyzed. This ensured that the middle samples corresponded well with the thermocouple readings, and it limited the influence of a chill effect on measurements for the side samples. 
After cutting the samples from the casting using a vertical band-saw, they were prepared by successive grinding and polishing steps with SiC papers, alumina, diamond suspension, and colloidal silica on a manual polishing wheel. Polishing to certain steps enabled microstructural analysis using optical microscopy (OM), scanning electron microscopy (SEM), and energy dispersive X-ray spectroscopy (EDX). These samples were also used for Rockwell hardness, porosity, and specific heat measurements. The metallographic polishing procedure is detailed in Table 3-4.

Abrasive SiC grinding steps were followed by rinsing the samples with water and drying them with compressed air, whereas the polishing steps were followed with the use of an ultrasonic cleaner with water. This was done to remove excess abrasive particles from the sample surface. Furthermore, in order to prevent the formation of a surface film during the polishing step with colloidal silica, the Chemomet cloth was flushed with water for $10 \mathrm{~s}$ prior to step completion before the samples were dried with compressed air.

Table 3-4: Metallographic polishing procedure

\begin{tabular}{|c|c|c|}
\hline Step & Abrasive Grit / Polishing Cloth & Analysis Enabled \\
\hline 1 & $120 \mathrm{SiC}$ & - \\
\hline 2 & $400 \mathrm{SiC}$ & - \\
\hline 3 & $600 \mathrm{SiC}$ & Rockwell hardness \\
\hline 4 & $1200 \mathrm{SiC}$ & $\begin{array}{c}\text { Grain size or OM for SDAS } \\
\text { Porosity measurements } \\
\text { Specific heat measurements }\end{array}$ \\
\hline 5 & Lecloth $+5 \mu \mathrm{m}$ alumina & \begin{tabular}{c}
- \\
\hline 6
\end{tabular} \\
\hline 7 & Lecloth $+3 \mu \mathrm{m}$ diamond suspension & $\begin{array}{c}\text { OM for eutectic Si morphology } \\
\text { SEM and EDX }\end{array}$ \\
\hline
\end{tabular}




\subsubsection{Tensile Samples}

The bottom $12 \mathrm{~mm}$ of each casting was sectioned off to create two samples for tensile testing, one on top of the other (Figure 3-8, above). Tensile bars were machined to a width of $6.35 \mathrm{~mm}$ (0.25 in) and a gauge length of $25.4 \mathrm{~mm}$ ( 1 in) in accordance with the ASTM B557 sub-sized standard [38].

\subsubsection{Thermal Conductivity Samples}

The remaining material under the riser was used to create two rods around $30 \mathrm{~mm}$ in length for thermal conductivity measurements. The rods were turned down to a diameter of $13 \mathrm{~mm}$, and one side of each was machined flat on a lathe for good contact with the thermal conductivity apparatus. As indicated by the arrows in Figure 3-8, above, the flat side of the rod faced the sides of the casting, to prevent excessive porosity from influencing the measurements. Sample surfaces were also subjected to an additional polishing step with 1200 grit SiC paper prior to testing.

\subsection{Microstructural Analysis}

Optical and scanning electron microscopy was performed on each of the four microscopy samples (SX, MX, MO, and SO) for each solidification condition. Microstructural characterization included measurement of secondary dendrite arm spacing (SDAS) as well as quantitative image analysis and microanalysis of secondary phases. The procedures for these characterizations are outlined in this section.

\subsubsection{Measurement of Secondary Dendrite Arm Spacing (SDAS)}

Manual SDAS measurements were performed using optical micrographs taken with a Nikon Eclipse MA200 inverted metallurgical microscope instrumented with a uEye CCD camera. The measurements were facilitated by Buehler OmniMet image analysis software, which enabled direct length readings standardized to a microscope calibration slide. The equations for 
determining SDAS commonly found in the literature assume that each dendrite is symmetrical about the primary arm. The following modified equation was therefore used to account for dendrites that have a different number of secondary arms on either side of the primary arm, thereby improving measurement accuracy and statistics:

$$
S D A S=\frac{2 L_{p}}{N_{S}-2}
$$

Equation 3-3

Where:

$L_{p}:$ Length of the primary dendrite arm

$N_{s}$ : Total number of secondary dendrite arms counted on both sides of the primary arm

The average SDAS for each sample was determined using measurements of a minimum of 20 dendrites over at least seven optical micrographs at 50x or 100x magnifications.

\subsubsection{Quantitative Image Analysis}

Buehler OmniMet image analysis software was used to measure the area fraction of $\mathrm{Al}_{2} \mathrm{Cu}$ and Fe-bearing intermetallics in the microstructures, using at least 20 backscattered electron images taken of the SX sample from each casting condition. The backscattered electron images were taken using a JOEL JSM-6380LV scanning electron microscope at magnifications ranging from 200x to 500x. Additionally, OmniMet was used in conjunction with optical micrographs at magnifications between $200 x$ and $1000 x$ to quantify the area fraction and morphological characteristics of the eutectic Si phase. At least 20 images were used for each of the SO and SX samples from every casting condition. The software was used to measure several morphological characteristics: First, the aspect ratio is the ratio of maximum length to minimum length of a particle, which describes the elongation of the particle. Second, the equivalent circular diameter is the diameter of a circle with an equivalent area to a particle, which describes the relative size of a particle. Third, sphericity describes the roundness of a particle by a number in the range of 0 to 1 , for which 1 is a perfect circle. Sphericity $(S p)$ is defined by the following equation: 


$$
S p=\frac{4 \pi A}{P^{2}}
$$

Equation 3-4

Where:

$A$ : Particle area

$P$ : Particle perimeter

Particle length, width, area and perimeter were also measured separately by the software.

\subsubsection{Phase Microanalysis}

Energy dispersive X-ray spectroscopy (EDX) was performed using a JOEL JSM-6380LV scanning electron microscope to determine the elements present in the primary dendrites and the secondary phases in the microstructure. The compositions of the phases were estimated using readings from a minimum of five particles each.

\subsection{Density and Porosity Measurements}

Density was measured using the hydrostatic displacement technique. This method utilizes Archimedes' Principle, and compares the mass of the sample to the measured mass of the sample suspended in a beaker of water. After doing so, density $(\rho)$ can be evaluated by the following equation:

$$
\rho=\frac{m \rho_{w}}{m_{b s}-m_{b}}
$$

Where:

$m$ : Mass of the sample in air

$\rho_{w}:$ Density of water

$m_{b s}$ : Mass of the beaker with water and with the suspended sample

$m_{b}$ : Mass of the beaker with water 
For these calculations, the density of water was taken as $0.9978 \mathrm{~g} / \mathrm{cm}^{3}$ for $22{ }^{\circ} \mathrm{C}$ [39]. Porosity was then calculated as the percent difference of the measured density relative to the theoretical pore-free density of the material $\left(\rho_{t h}\right)$ :

$$
\text { Porosity }=\frac{\rho_{t h}-\rho}{\rho_{t h}} \times 100 \%
$$

Equation 3-6

The theoretical density of A319 alloy was taken as $2.79 \mathrm{~g} / \mathrm{cm}^{3}[1]$.

\subsection{Mechanical Testing}

For each casting, the ultimate tensile strength (UTS) of the two extracted tensile bars was determined by using a United STM-50kN uniaxial tensile testing machine equipped with a United EZ-25 mm extensometer. The bars were pulled at a rate of $5 \mathrm{~mm} / \mathrm{min}$ until fracture.

Additionally, hardness measurements were taken on the microscopy samples using a Leco LR-300 Rockwell-type hardness tester. Measurements were taken on the HRE scale, using a 1/8" ball indenter with a loading of $100 \mathrm{~kg}$. The average hardness of a casting was found using at least nine readings on the SX samples.

\subsection{Thermal Conductivity Measurements}

A Thermtest Hot Disk TPS 2500S Thermal Constants Analyzer was used to measure the ambient temperature $\left(24-25{ }^{\circ} \mathrm{C}\right)$ specific heat, thermal diffusivity, and thermal conductivity of the castings via the transient plane source method. Direct specific heat measurements were conducted using the no holder specific heat module, in which a single microscopy sample was embedded into a block of thermally-insulating extruded polystyrene, with its polished surface in contact with a Kapton 5465 (3.189 mm radius) sensor (Figure 3-9). An additional piece of insulation was placed on top of the sample and sensor, and vertical pressure was applied with a thumbscrew to ensure good thermal contact between the sample and the sensor. A cylindrical polished stainless steel cover was placed over the assembly to protect against temperature disturbances to the sample during the measurement from air draft. Specific heat test parameters 
included an $80 \mathrm{~s}$ test time and $600 \mathrm{~mW}$ of power supplied to the sample. Each measurement was separated by at least $75 \mathrm{~min}$ and was preceded by a $40 \mathrm{~s}$ drift measurement to ensure thermal stability. Test data points 100-200 were analyzed to calculate specific heat, and the resulting value was multiplied by the sample density (measured separately) to determine the volumetric specific heat.

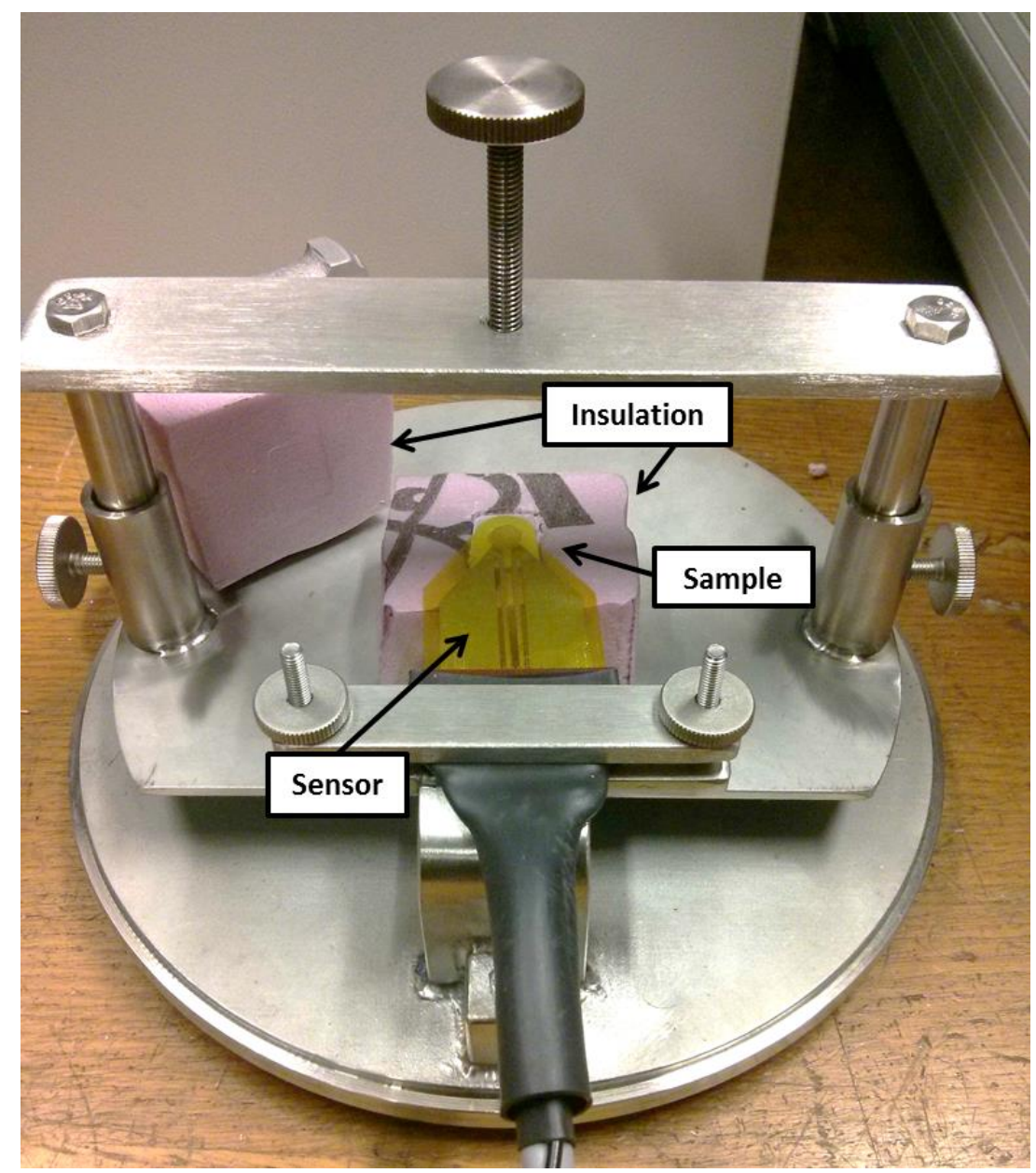

Figure 3-9: Specific heat measurement setup

Thermal diffusivity and conductivity were determined simultaneously using the single-sided, one-dimensional isotropic module, in which a Kapton 5501 (6.403 mm radius) sensor was fitted between a block of thermally-insulating extruded polystyrene and the polished end of a 
conductivity rod (Figure 3-10). Vertical pressure was applied with a thumbscrew to ensure good thermal contact between the rod and the sensor, and the cylindrical cover was placed over the assembly. Three measurements were conducted per sample, each using a $5 \mathrm{~s}$ test time and $1 \mathrm{~W}$ of heating power. Each measurement was separated by $15 \mathrm{~min}$ and preceded by a $40 \mathrm{~s}$ drift measurement to ensure thermal stability. Sample volumetric specific heat was input to improve the accuracy in determining thermal diffusivity and conductivity. The analyzed test data points were chosen to satisfy requirements for the sample probing depth, temperature increase, and total to characteristic time, with a mean deviation on the order of $10^{-5} \mathrm{~K}$.

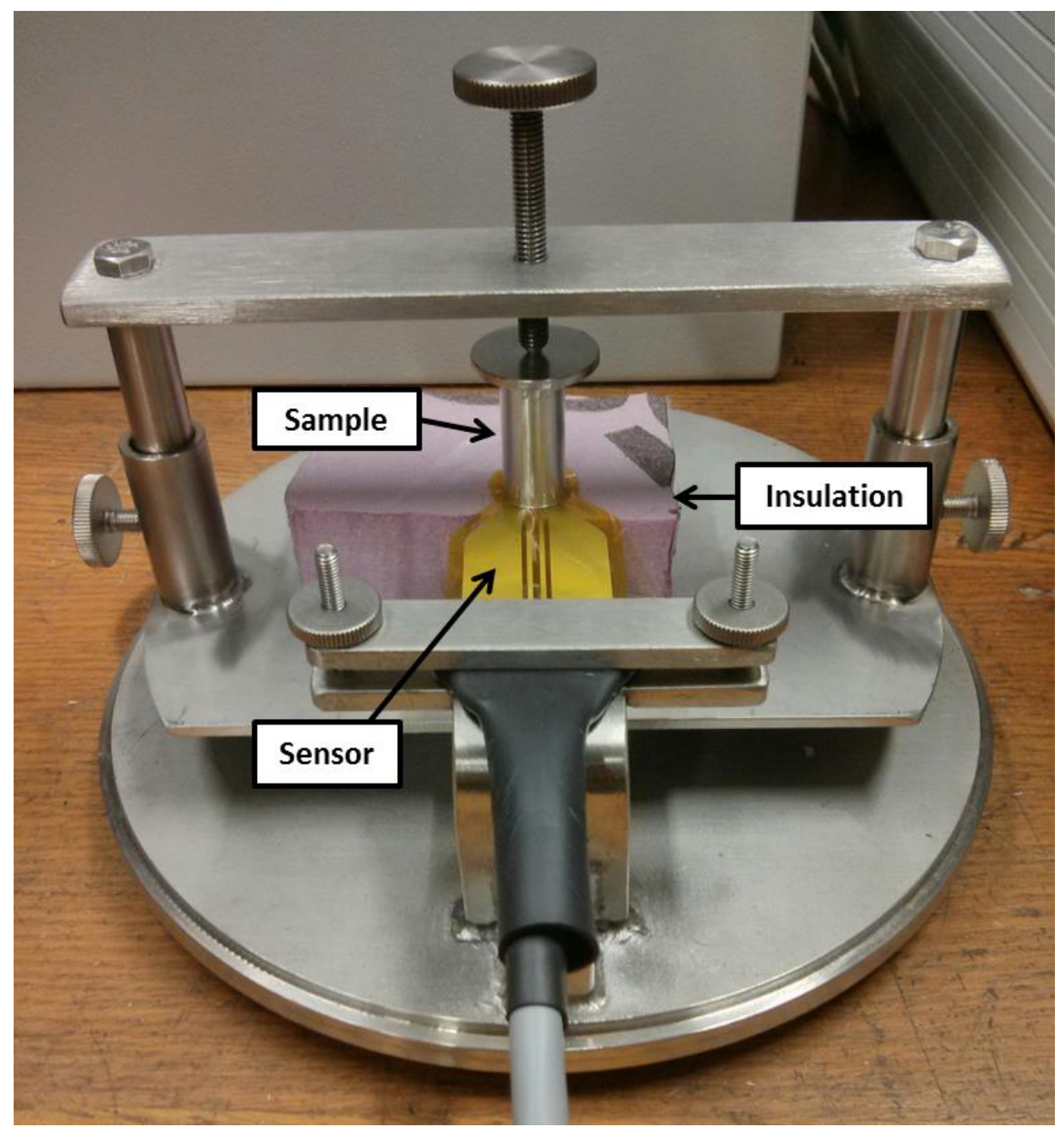

Figure 3-10: Thermal conductivity and diffusivity measurement setup 


\section{Chapter 4: RESULTS AND DISCUSSION}

In this chapter, the results from the casting experiments are presented and interpreted. This begins with the extraction of solidification parameters from the cooling curves, the development of relationships between them, and the comparison of the experimental data with simulated cooling curves. Then, the alloy microstructure is described as a function of solidification conditions, including the quantification of the dendritic structure size and the area fraction and morphology of the secondary phases. Next, the characterizations of the casting porosity and mechanical properties are presented. Finally, thermal conductivity measurements are revealed and related to the abovementioned findings.

\subsection{Thermal Analysis}

The experimental cooling curves are plotted in Figure 4-1 as a function of the initial mould temperature, whereas the individual curves are presented in Appendix C. For each casting, the shape of the cooling curve remained relatively constant, and the liquidus, Al-Si eutectic, and solidus temperatures were found to be approximately $608{ }^{\circ} \mathrm{C}, 560{ }^{\circ} \mathrm{C}$, and $485{ }^{\circ} \mathrm{C}$, respectively. The alloy liquidus temperature corresponds well to the predicted $610{ }^{\circ} \mathrm{C}$ from the equilibrium Al-Si-Cu ternary phase diagram (Appendix A). Even though non-equilibrium cooling promotes a shift in transformation temperatures (Section 2.2.3), this trend was not evidenced by the cooling curves, perhaps due to insufficient resolution of the K-type thermocouples, especially at faster cooling rates. Similarly, undercooling at the liquidus was not detected. However, the slopes of the cooling curves were progressively steeper with decreasing mould temperature. A lower mould temperature corresponds to a greater temperature gradient between the molten metal and the mould. According to Fourier's law of heat conduction (Equation 2-8) and analogous laws for convection and radiation, this promotes a greater heat transfer rate, which in turn causes faster metal cooling. 


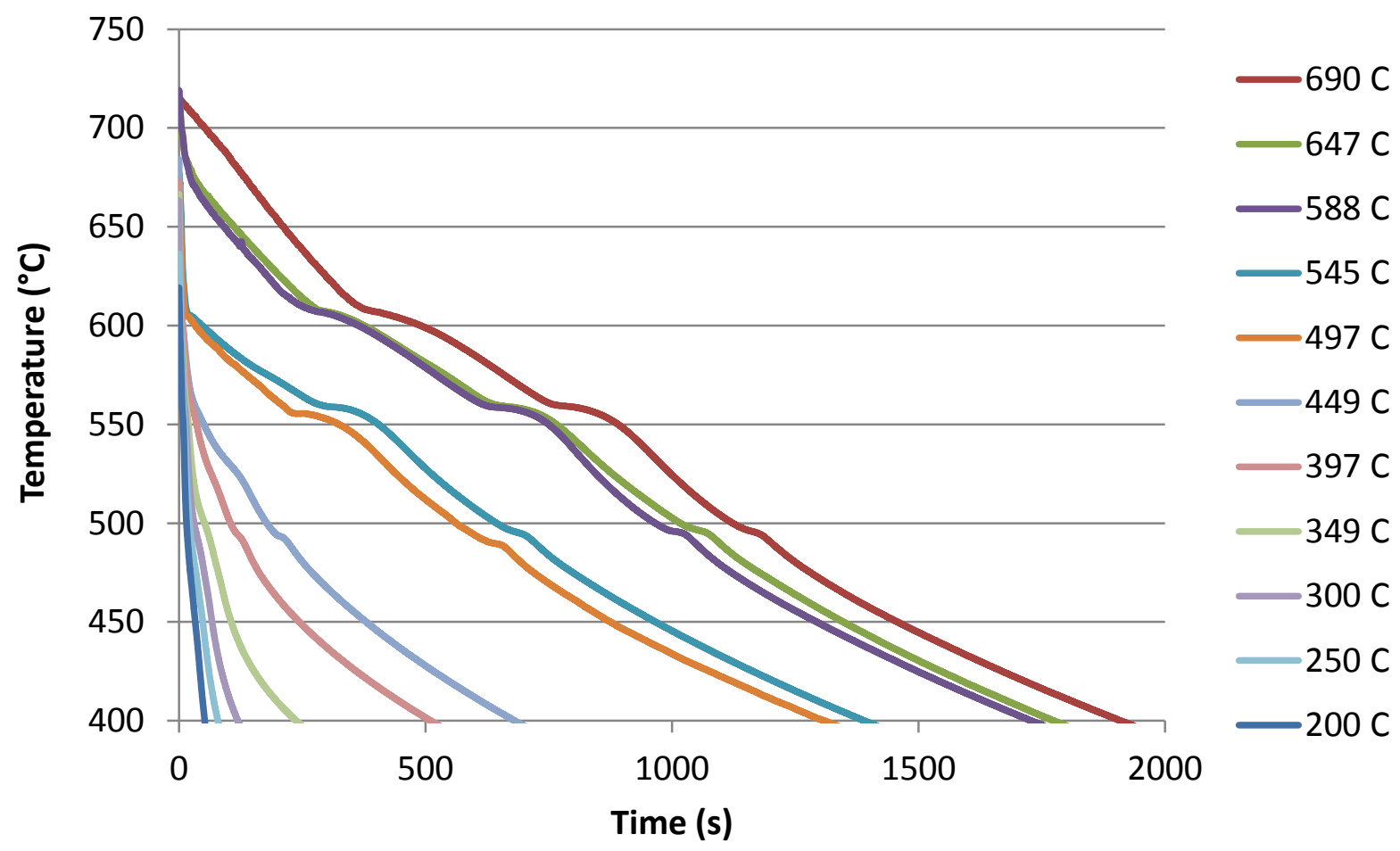

Figure 4-1: Experimental cooling curves for all initial mould temperatures

Table 4-1: Experimental solidification parameters

\begin{tabular}{|c|c|c|c|c|}
\hline $\begin{array}{c}\text { Initial Mould } \\
\text { Temperature } \\
\left({ }^{\circ} \mathrm{C}\right)\end{array}$ & $\begin{array}{c}\text { Primary } \\
\text { Solidification } \\
\text { Time }(\mathrm{s})\end{array}$ & $\begin{array}{c}\text { Primary } \\
\text { Solidification } \\
\text { Rate }\left({ }^{\circ} \mathrm{C} / \mathrm{s}\right)\end{array}$ & $\begin{array}{c}\text { Local } \\
\text { Solidification } \\
\text { Time }(\mathrm{s})\end{array}$ & $\begin{array}{c}\text { Total } \\
\text { Solidification } \\
\text { Rate }\left({ }^{\circ} \mathrm{C} / \mathrm{s}\right)\end{array}$ \\
\hline 200 & 6 & 8.52 & 19 & 6.61 \\
\hline 250 & 8 & 6.71 & 28 & 4.42 \\
\hline 300 & 9 & 5.41 & 47 & 2.78 \\
\hline 349 & 10 & 4.22 & 69 & 1.78 \\
\hline 397 & 16 & 2.55 & 138 & 0.89 \\
\hline 449 & 22 & 1.98 & 230 & 0.53 \\
\hline 497 & 215 & 0.23 & 670 & 0.18 \\
\hline 545 & 277 & 0.17 & 713 & 0.17 \\
\hline 588 & 363 & 0.13 & 784 & 0.15 \\
\hline 647 & 364 & 0.13 & 821 & 0.15 \\
\hline 690 & 386 & 0.13 & 836 & 0.14 \\
\hline
\end{tabular}


The cooling curves were utilized to extract the temperatures and times of the liquidus, $\mathrm{Al}-\mathrm{Si}$ eutectic, and solidus. These values were used to determine primary solidification time $\left(\Delta t_{L \rightarrow E}\right)$ and local solidification time $\left(\Delta t_{L \rightarrow S}\right)$, which enabled the calculations of primary solidification rate $\left(S R_{P}\right)$ and total solidification rate $\left(S R_{T}\right)$ according to Equations 3-1 and 3-2, respectively. As summarized in Table 4-1, a decrease in initial mould temperature corresponds to a decrease in solidification time and an increase in solidification rate, both in the region from liquidus to the Al-Si eutectic and for the entire solidification range.

The primary solidification rate best corresponds to the solidification of the primary dendrites, before the evolution of secondary phases in the microstructure. As shown in Figure 4-2, the rate decreases almost linearly with increasing mould temperature from $200{ }^{\circ} \mathrm{C}$ to $497{ }^{\circ} \mathrm{C}$. Yet for higher initial mould temperatures, the rate remained relatively constant at about $0.13{ }^{\circ} \mathrm{C} / \mathrm{s}$. The best fit of the linear region of the graph can be expressed by the following equation (with coefficient of determination of $R^{2}=0.9906$ ):

$$
S R_{P}=-0.03 T_{m}^{\prime}+13.59, \quad 200{ }^{\circ} C<T_{m}^{\prime}<500{ }^{\circ} C
$$

Equation 4-1

Where:

$T_{m}^{\prime}$ : Initial mould temperature

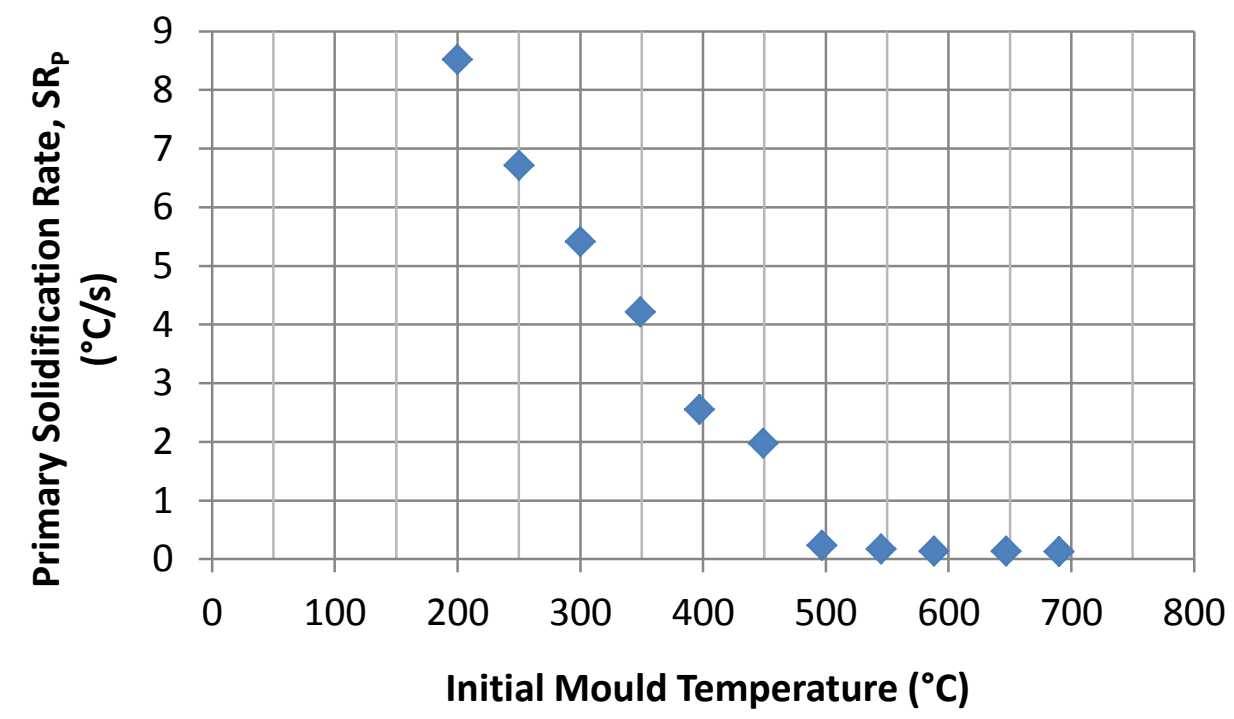

Figure 4-2: Primary solidification rate as a function of initial mould temperature 
This behaviour is likely related to the solidification temperature range of the alloy as well as mould cooling. During casting, the metal cools by heat transfer to the mould and to the ambient surroundings (still air) but the mould also cools by heat transfer to the surroundings. For mould temperatures less than the solidus $\left(\sim 485^{\circ} \mathrm{C}\right)$, the heat transfer to the mould driven by the large initial temperature difference promotes complete solidification that occurs fast enough that mould cooling is negligible. Hence, the initial mould temperature is a dominant influence on the solidification rate of the metal. However, for mould temperatures higher than the solidus, the melt is only semi-solid after approaching thermal equilibrium during that initial heat transfer. Therefore, complete solidification can only occur after the mould cools by heat transfer to the surroundings to below the solidus temperature. The heat transfer rate from the mould to the surroundings is significantly less than the heat transfer rate from the metal to the mould, so increases in initial mould temperature past the solidus does little to decrease the solidification rate. This is supported by Figure 4-3, which presents the primary solidification rate as a function of the average mould temperature determined from all four mould thermocouples (as opposed to the effective mould temperature as used above) at the instant the metal began to solidify. This plot is much more linear for the entire mould temperature range studied. For mould temperatures less than the alloy solidus temperature, the average mould temperature at the start of solidification closely matched the initial mould temperature (at the time of pouring), due to rapid heat transfer. In contrast, for all initial mould temperatures above the alloy solidus temperature, the average mould temperature at the start of solidification was almost constant, at a mould temperature about the alloy eutectic temperature $\left(\sim 560^{\circ} \mathrm{C}\right)$. 


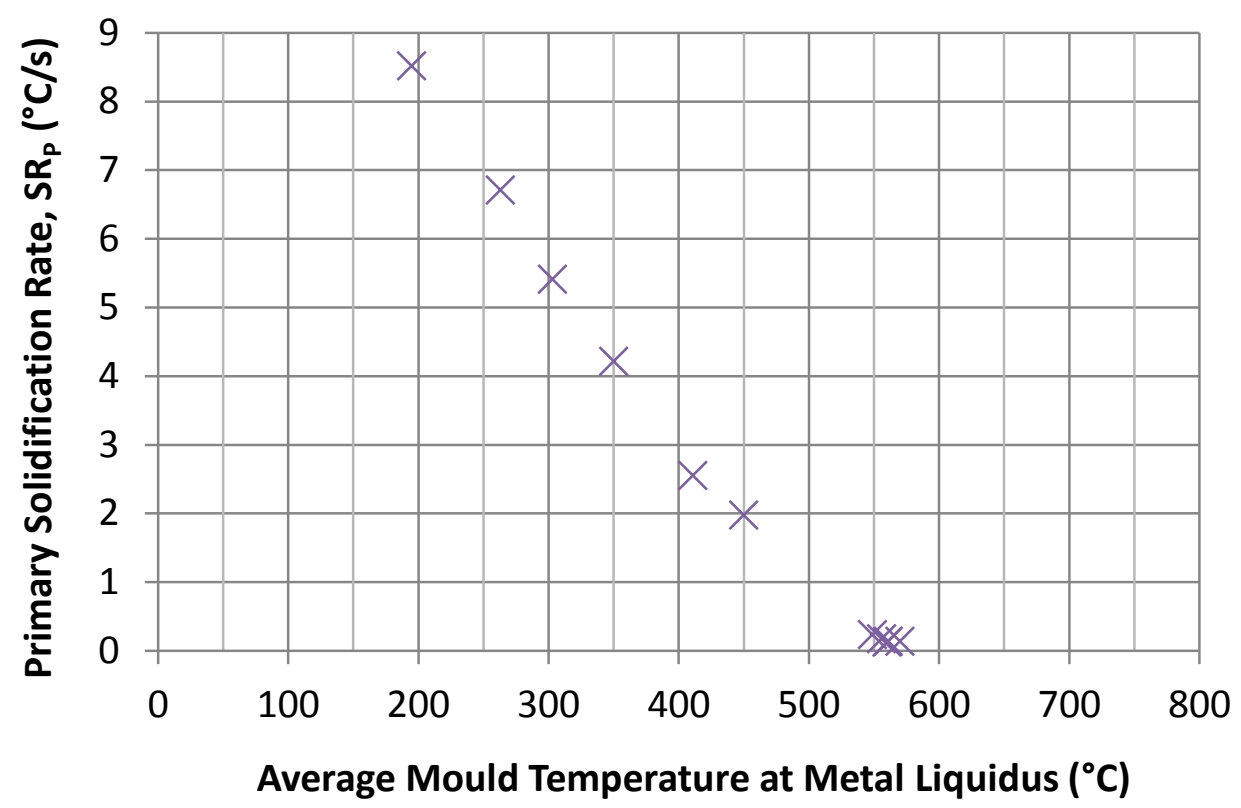

Figure 4-3: Primary solidification rate as a function of average mould temperature at the start of solidification

For each casting, the average mould temperature differed slightly from the effective mould temperature, especially at higher temperatures. This can be attributed to greater thermal homogenization time for lower mould temperatures, since the time since removal from the furnace is greater and the mould cooling rate is slower. Heat transfer at the metal-mould interface is complex, and it is difficult to provide evidence whether the average or effective mould temperature provides a more accurate characterization. Yet, the initial effective mould temperature was used for the majority of this research, due to its practicality for control during casting experiments.

In addition to primary solidification rate, total solidification rate and local solidification time are common parameters used to characterize the solidification of alloys. These parameters are plotted as a function of initial mould temperature in Figure 4-4. As expected, raising the mould temperature promotes longer solidification times and slower solidification rates. The total solidification rate plot demonstrates a similar trend to the primary solidification rate, yet the curve is much smoother and more exponential for the entire mould temperature range studied. The relationship can be estimated by the following best fit expression $\left(R^{2}=0.9301\right)$ : 


$$
S R_{T}=33.33 \exp \left(-0.01 T_{m}^{\prime}\right)
$$

Equation 4-2

On the other hand, the relationship between the local solidification time and the initial mould temperature is illustrated by an S-shaped curve. With increasing mould temperature, the solidification time increases exponentially up until about $500{ }^{\circ} \mathrm{C}$, after which the increases level off.

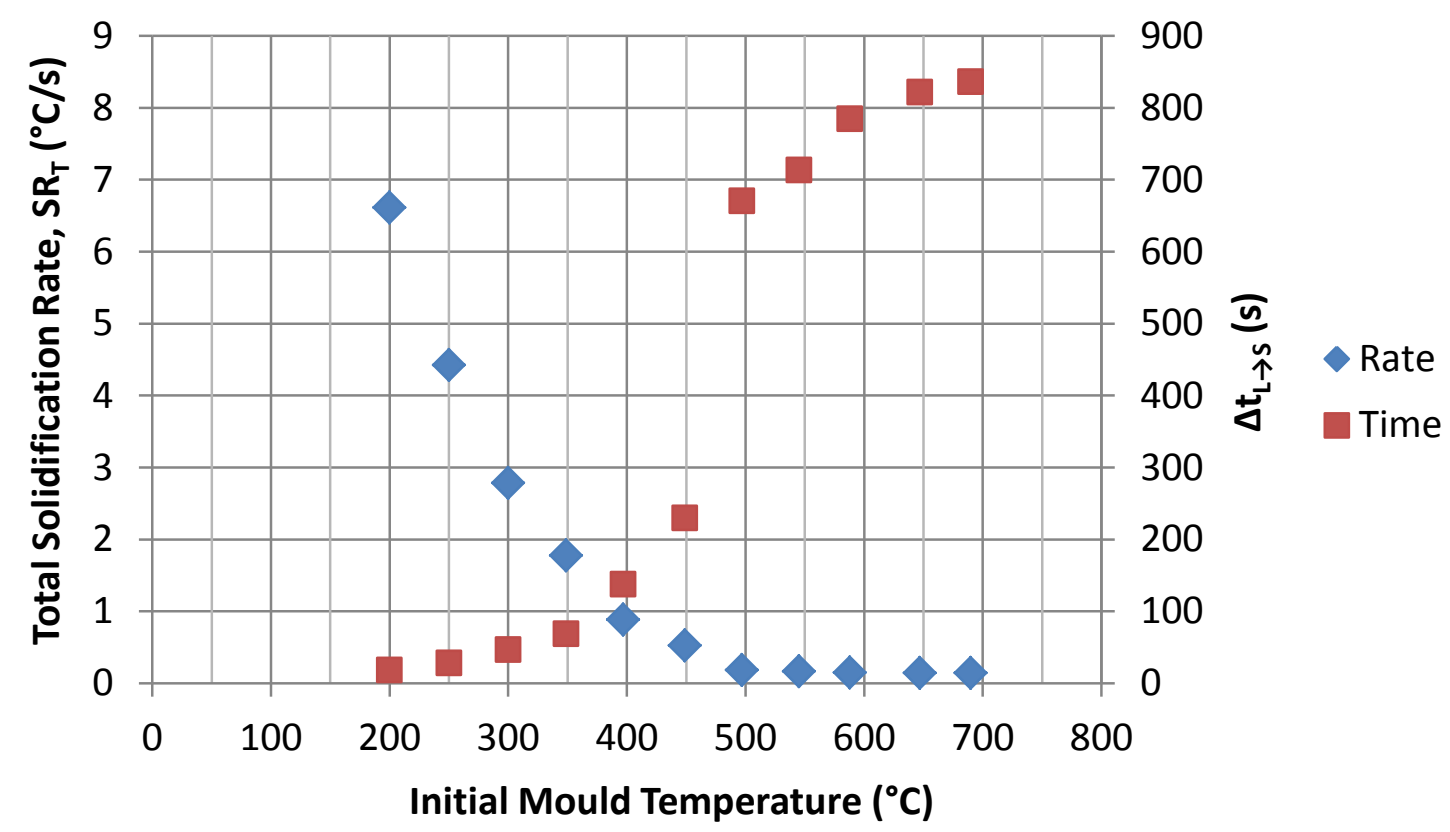

Figure 4-4: Total solidification rate and local solidification time as a function of initial mould temperature

\subsubsection{Relationships between Solidification Parameters}

Primary solidification rate, total solidification rate, primary solidification time, and local solidification time are all related parameters in the solidification of A319 and other alloys. However, these parameters are not directly proportional for changing solidification conditions. The literature is inconsistent in the use of a particular solidification parameter for presenting materials characterization, causing some difficulty in comparing works. Therefore, it is beneficial to determine the alloy-specific expressions relating each of the solidification parameters. 
For instance, primary solidification rate is inversely proportional to primary solidification time (Figure 4-5), whereas total solidification rate is inversely proportional to local solidification time (Figure 4-6). In either case, increases in solidification time are associated with decreases in its respective solidification rate. For very small solidification times, changes in solidification time significantly influence solidification rate. Yet for relatively large solidification times, further increases in time minimally affect the solidification rate. These relationships simply correspond to the definitions of the two solidification rates, as summarized above in Figure 3-7: Solidification rate is the quotient of the freezing range and the solidification time. As shown in Figure 4-1, above, the liquidus, Al-Si eutectic, and solidus temperatures were relatively constant, with average values of $608{ }^{\circ} \mathrm{C}, 560{ }^{\circ} \mathrm{C}$, and $485{ }^{\circ} \mathrm{C}$, respectively. Hence, the average primary freezing range and the average total freezing range were $48{ }^{\circ} \mathrm{C}$ and $123{ }^{\circ} \mathrm{C}$, respectively. Therefore, the relationship between primary solidification rate and primary solidification time can be expressed by the following equation $\left(R^{2}=0.9899\right)$ :

$$
S R_{P}=48.0\left(\Delta t_{L \rightarrow E}\right)^{-1}
$$

Equation 4-3

Similarly, the relationship between total solidification rate and local solidification time can be expressed by the following equation $\left(R^{2}=0.9992\right)$ :

$$
S R_{T}=123.0\left(\Delta t_{L \rightarrow S}\right)^{-1}
$$

Equation 4-4 


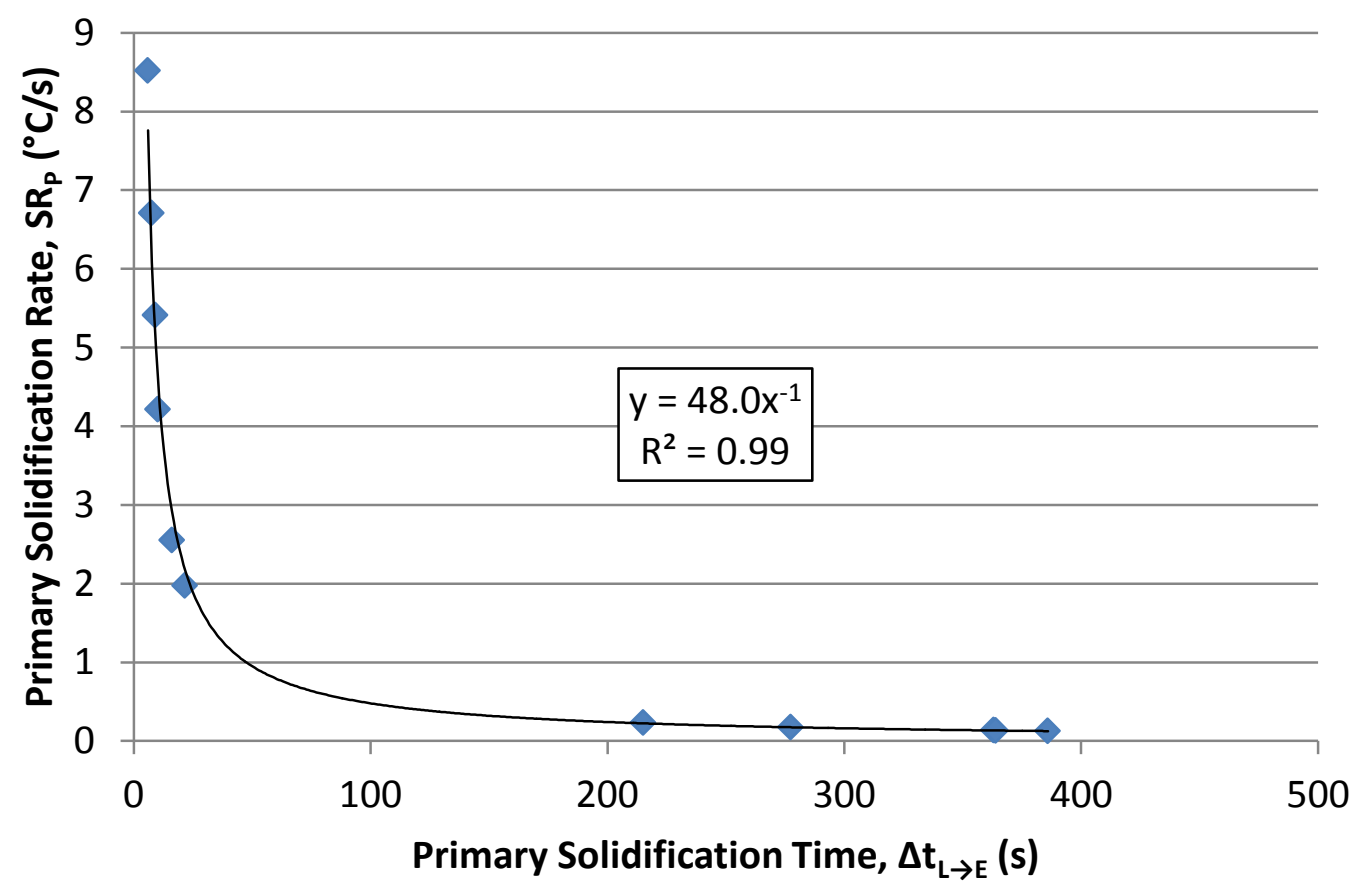

Figure 4-5: Primary solidification rate as a function of primary solidification time

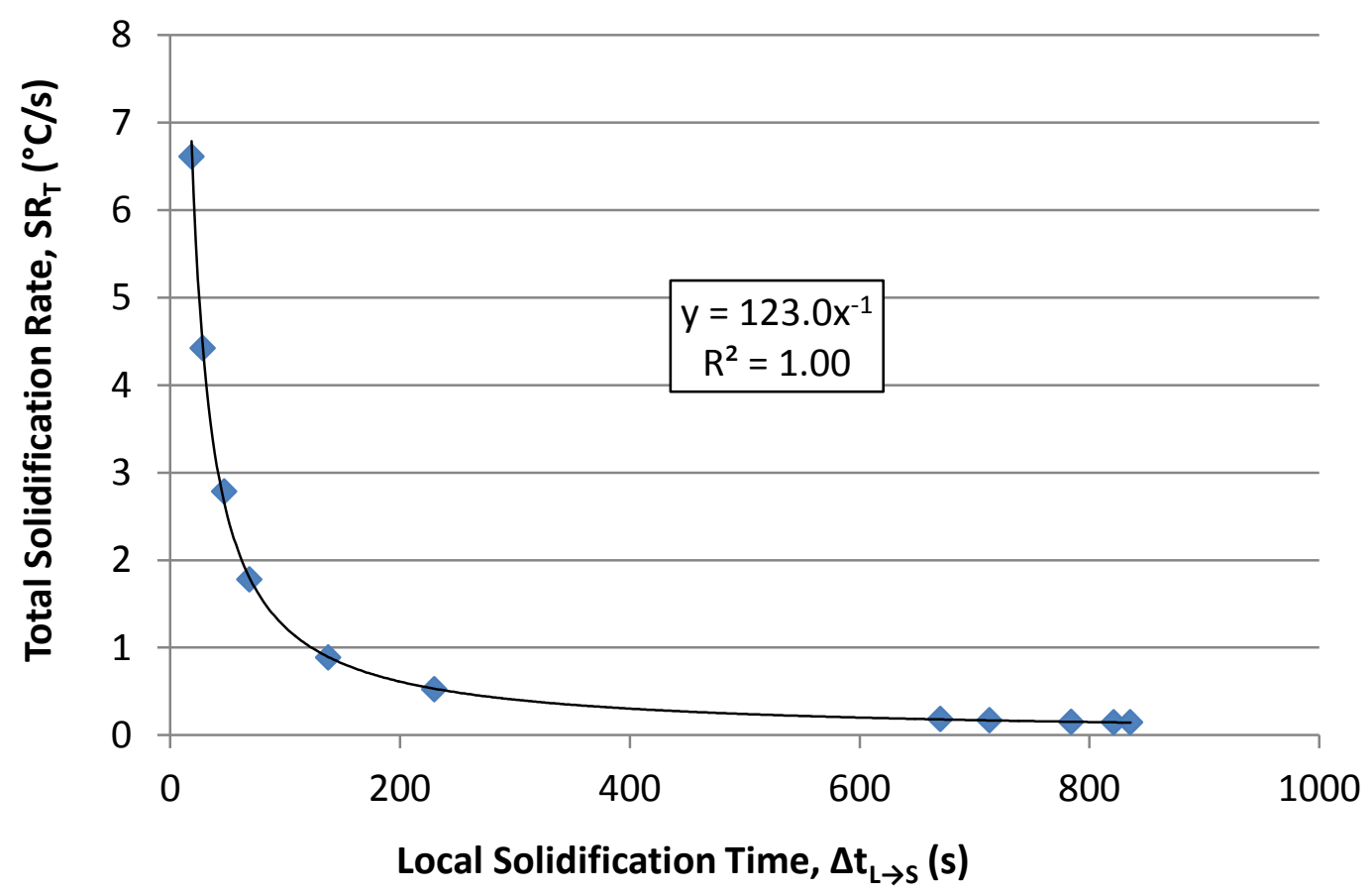

Figure 4-6: Total solidification rate as a function of local solidification time 
Additional relationships between the four solidification parameters can be approximated by the trendlines of their respective data plots. For example, the relationship between total solidification rate and primary solidification rate can be approximated by a logarithmic function (Figure 4-7), whereas the relationship between local solidification time and primary solidification time can be approximated by a quadratic polynomial (Figure 4-8). These trends can be explained by the changes in the shapes of the cooling curves. While the phase transformation temperatures were relatively constant for all castings, the cooling curves were progressively compressed with decreasing mould temperature. As well, since cooling rates decay with time, early stages of solidification (e.g. from liquidus to Al-Si eutectic) are compressed less than the later stages (e.g. from Al-Si eutectic to solidus). Therefore, as the mould temperature decreases, increases in primary solidification rate are associated with even greater increases in total solidification rate, and decreases in primary solidification time are associated with even greater decreases in local solidification time. This phenomenon is exaggerated graphically in Figure 4-9.

The line of best fit for the relationship between the two solidification rates can be expressed as follows $\left(R^{2}=0.9990\right)$ :

$$
S R_{T}=0.08\left(S R_{P}\right)^{2}+0.05\left(S R_{P}\right)+0.15
$$

Equation 4-5

The line of best fit for the relationship between the two solidification times can be expressed as follows $\left(R^{2}=0.9952\right)$ :

$$
\Delta t_{L \rightarrow S}=199.57 \ln \left(\Delta t_{L \rightarrow E}\right)-383.50
$$

Equation 4-6 


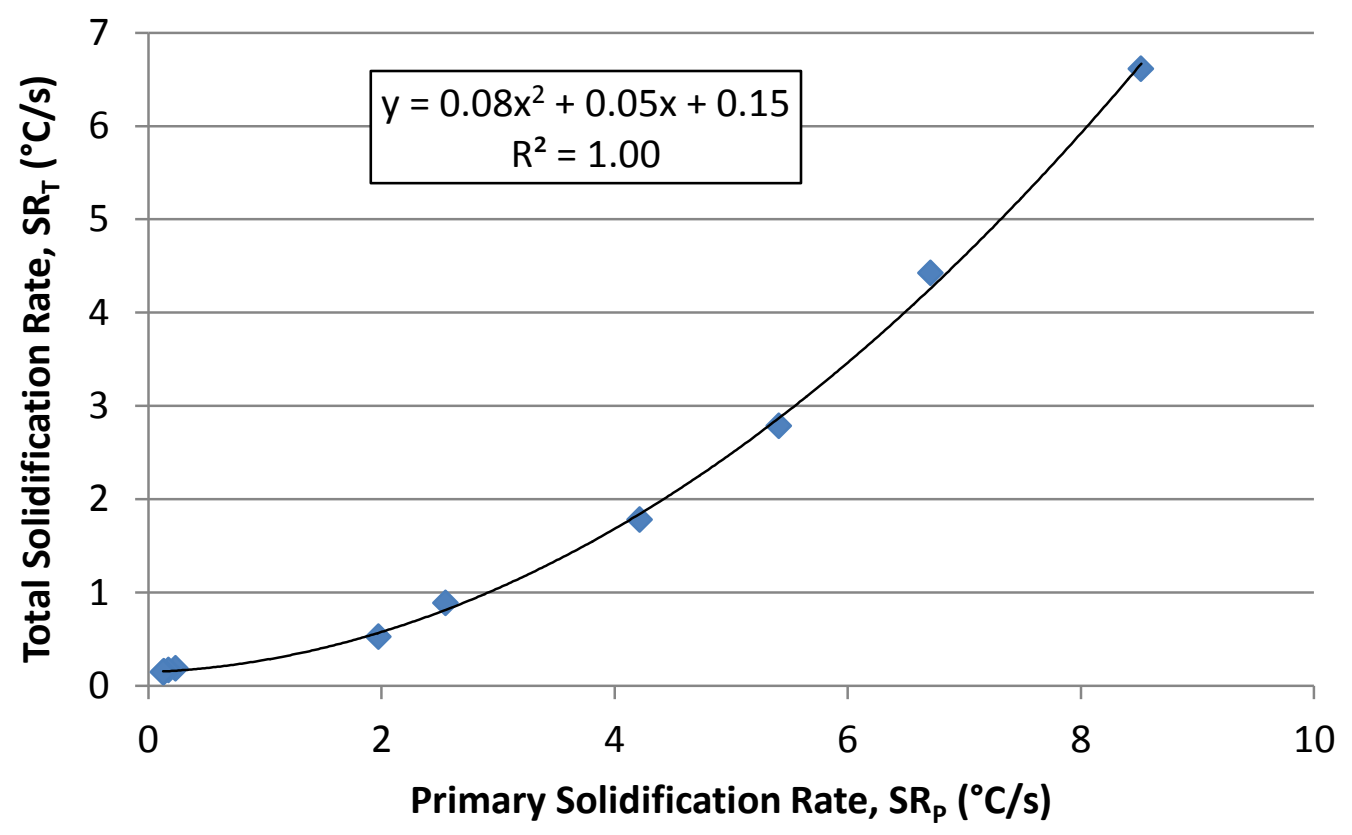

Figure 4-7: Total solidification rate as a function of primary solidification rate

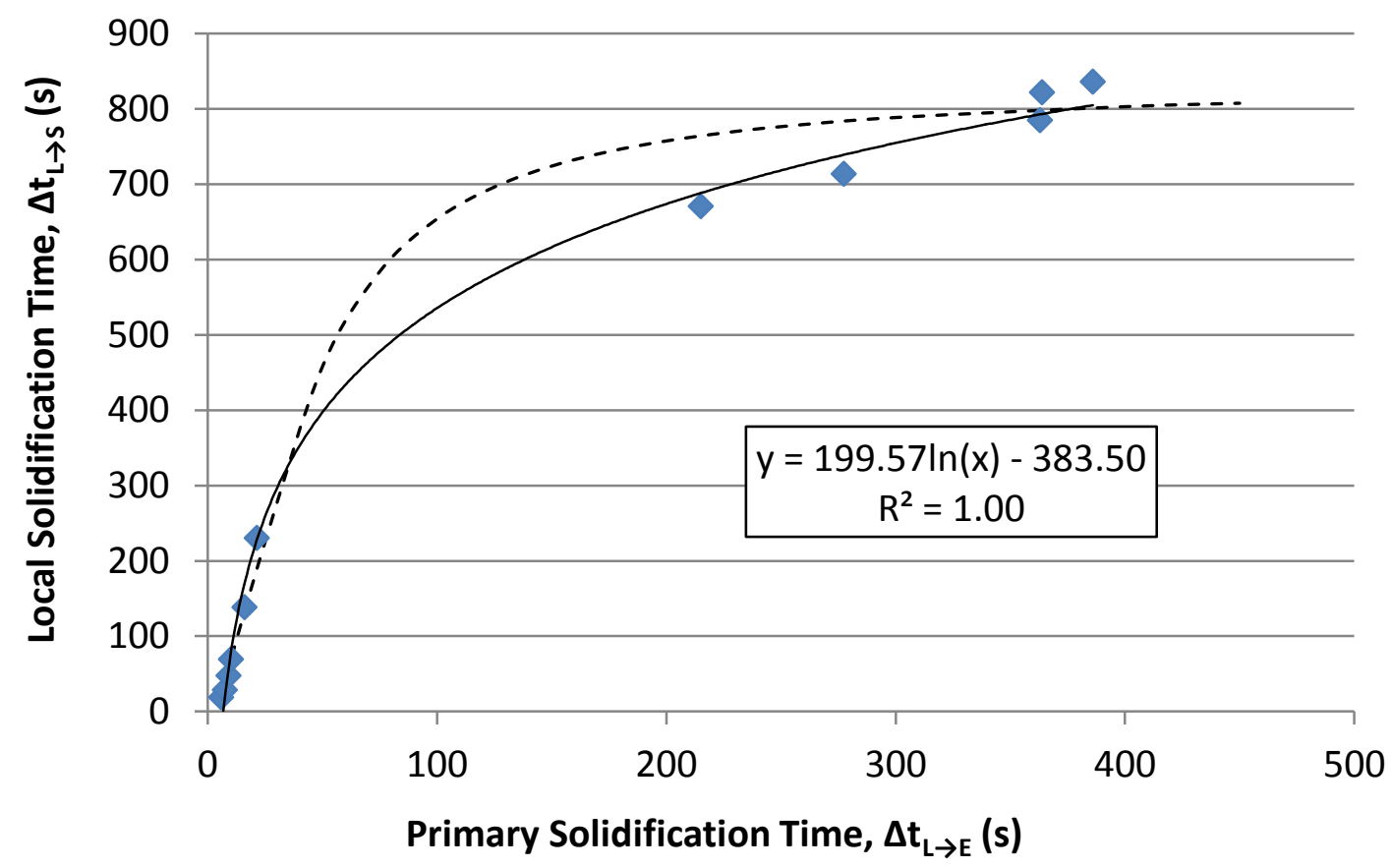

Figure 4-8: Local solidification time as a function of primary solidification time 


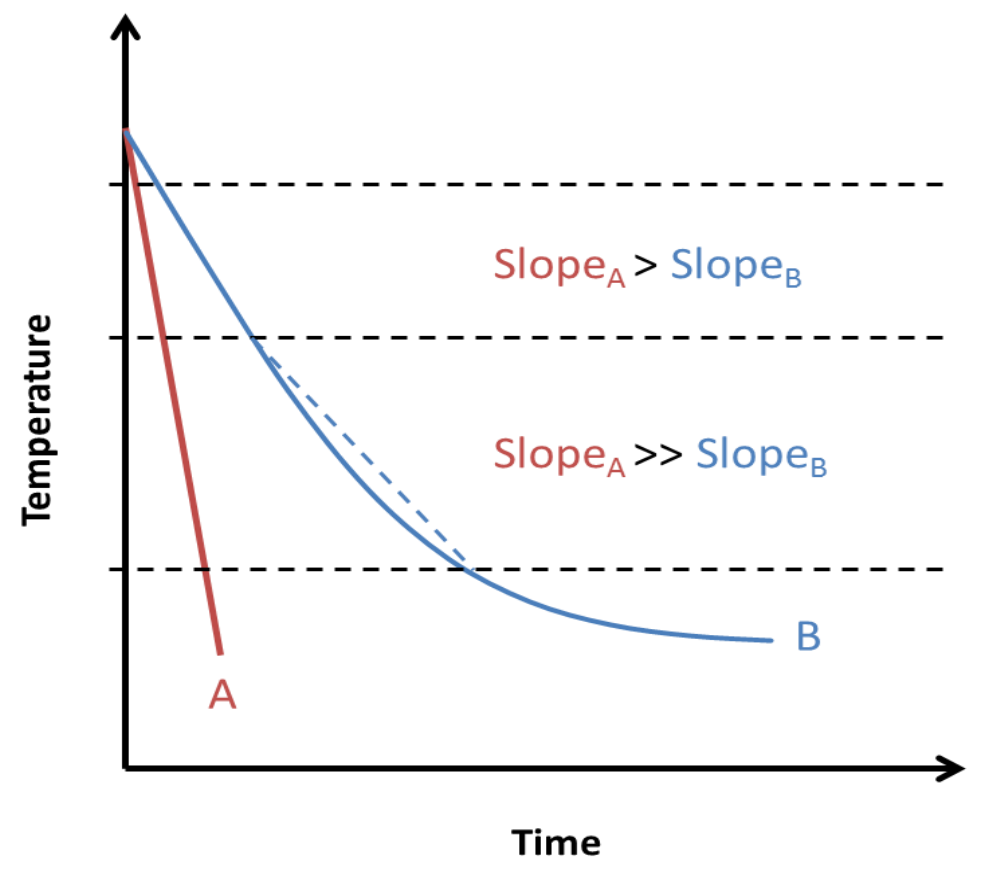

Figure 4-9: Graphical exaggeration of cooling curves for fast solidification (A) and slow
solidification (B), demonstrating a greater difference in rates at lower temperatures

Furthermore, the solidification rate for one range can be related to the solidification time of the other. As presented previously, the solidification rate decreases with increasing solidification time. However, whereas the relationship between primary solidification rate and local solidification time is represented by a logarithmic function, the relationship between total solidification rate and primary solidification time can be better approximated by a power law. For primary solidification rate and local solidification time (Figure 4-10), the expression of the line of best fit for all the data is as follows $\left(R^{2}=0.9706\right)$ :

$$
S R_{P}=-2.03 \ln \left(\Delta t_{L \rightarrow S}\right)+13.41
$$

Equation 4-7

For total solidification rate and primary solidification time (Figure 4-11), the expression of the line of best fit for all the data is as follows $\left(R^{2}=0.9194\right)$ :

$$
S R_{T}=14.18\left(\Delta t_{L \rightarrow E}\right)^{-0.80}
$$

Equation 4-8 
Since these relationships combine the two solidification regions, the differential suppression of the cooling curve discussed above may be a factor in the shapes of their curves. As well, the curves are likely influenced by the way the solidification rates were measured. Average rates were used, which included the slope changes in the cooling curves ("thermal arrests") that accompany phase transformations. Increasing the mould temperature increases the thermal arrest time. In contrast, for mould temperatures below the solidus, the thermal arrests are comparatively negligible (Figure 4-1, above).

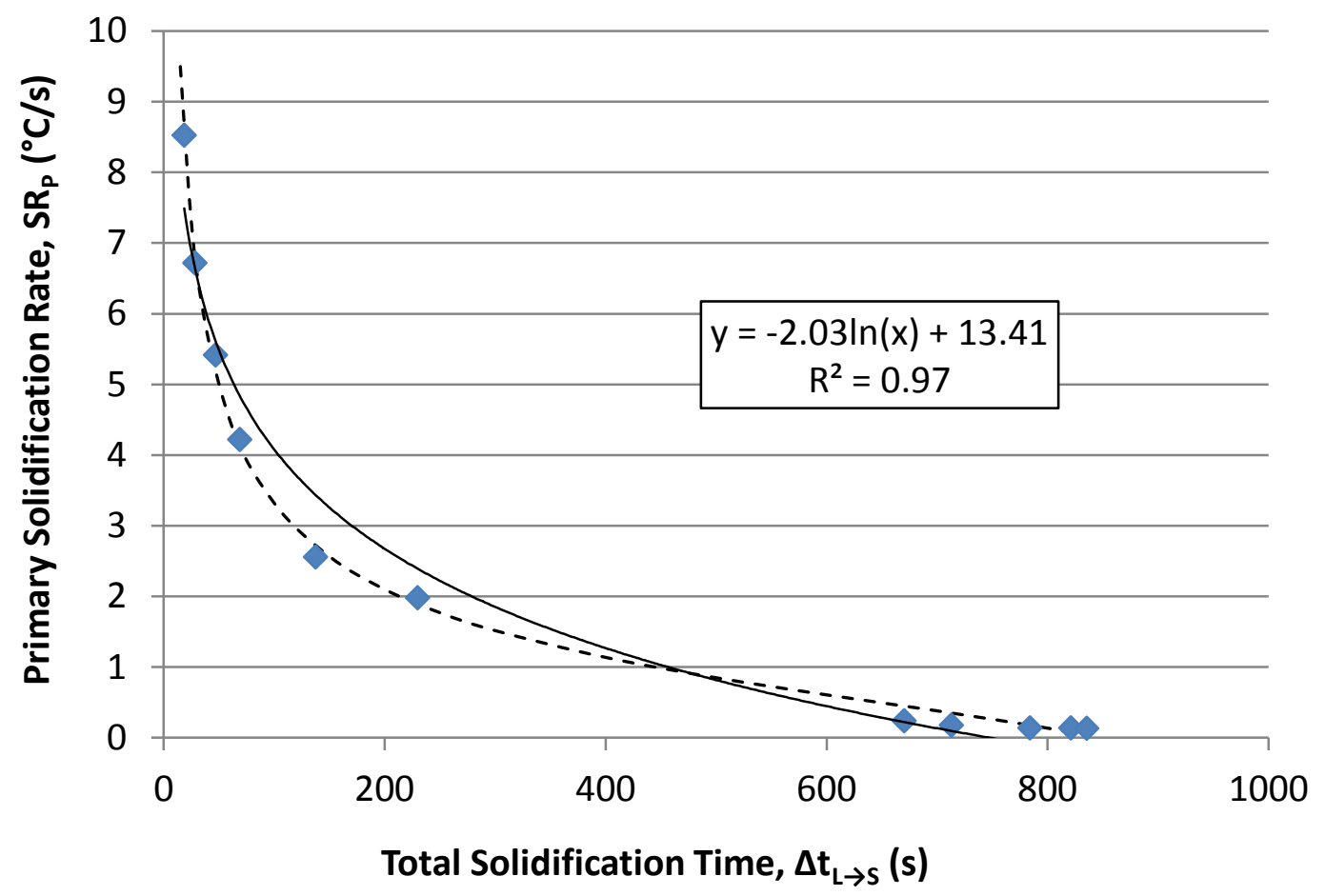

Figure 4-10: Primary solidification rate as a function of local solidification time 


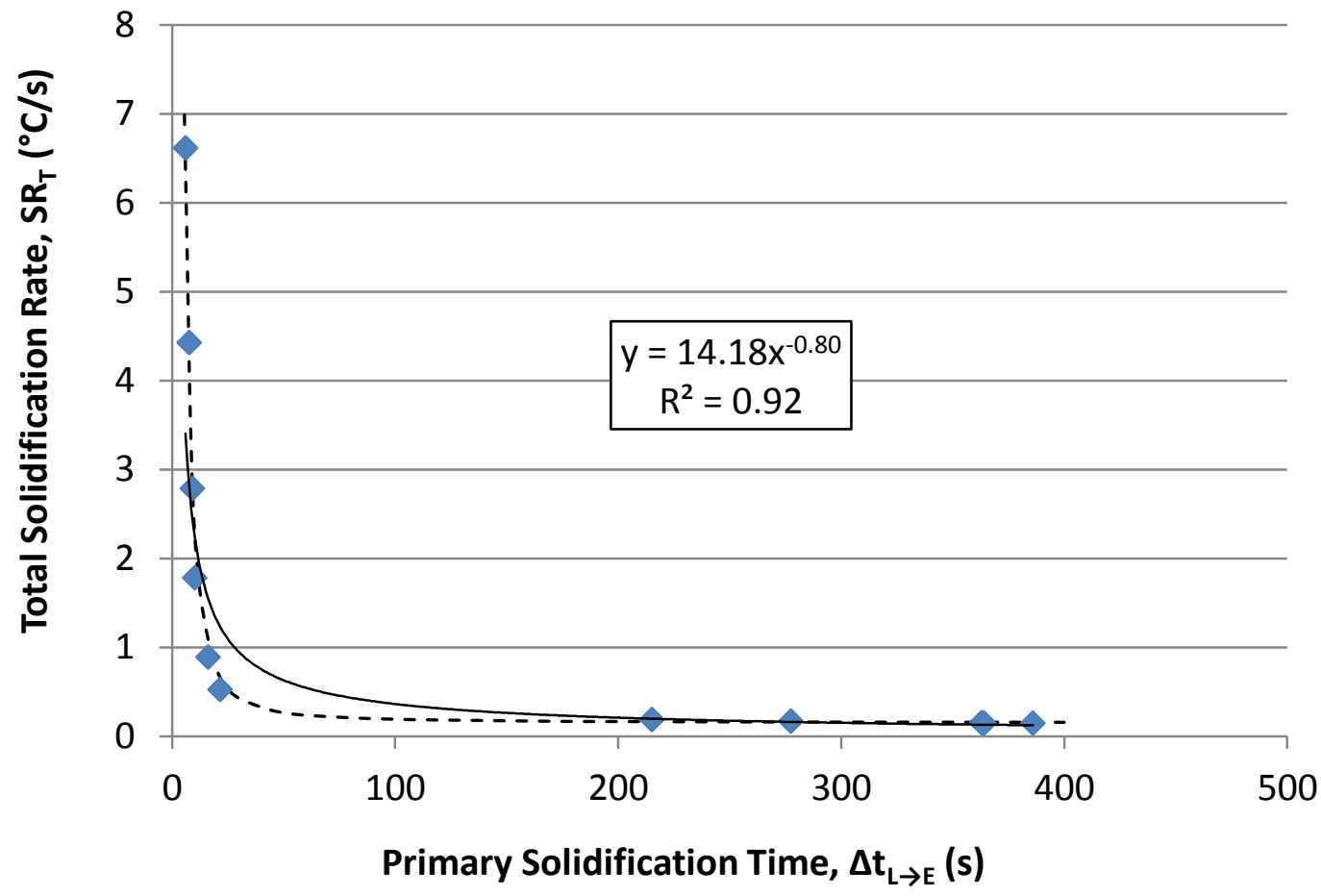

Figure 4-11: Total solidification rate as a function of primary solidification time

The equations given in this section are simple and useful for presenting the general relationships between any two of the four solidification parameters. Nonetheless, each expression is isolated in the sense that it cannot be mathematically combined with another to accurately determine a third relationship. However, it is possible to combine any three equations to create a unified set of six expressions, provided the three chosen are sufficiently accurate in portraying the data. For example, Equations 4-3 and 4-4 are reliable definitions of the solidification rates in terms of their respective solidification times. Equation 4-5, relating total solidification rate to primary solidification rate, is a suitable third equation, given its simple quadratic form and its high coefficient of determination $\left(R^{2}=0.9990\right)$. Then, the remaining three equations can be determined through a process of algebraic substitution and simplification:

Local solidification time as a function of primary solidification time $\left(R^{2}=0.9860\right)$ :

$$
\Delta t_{L \rightarrow S}=\frac{6.15 \times 10^{7}\left(\Delta t_{L \rightarrow E}\right)^{2}}{7.32 \times 10^{4}\left(\Delta t_{L \rightarrow E}\right)^{2}+1.11 \times 10^{6}\left(\Delta t_{L \rightarrow E}\right)+9.73 \times 10^{7}}
$$

Equation 4-9 
Primary solidification rate as a function of local solidification time $\left(R^{2}=0.9977\right)$ :

$$
S R_{P}=\frac{\sqrt{1.04 \times 10^{13}\left(\Delta t_{L \rightarrow S}\right)-1.18 \times 10^{10}\left(\Delta t_{L \rightarrow S}\right)^{2}}-2.31 \times 10^{4}\left(\Delta t_{L \rightarrow S}\right)}{8.45 \times 10^{4}\left(\Delta t_{L \rightarrow S}\right)}
$$

\section{Equation 4-10}

Total solidification rate as a function of primary solidification time $\left(R^{2}=0.9762\right)$ :

$$
S R_{T}=\frac{0.15\left(\Delta t_{L \rightarrow E}\right)^{2}+2.22\left(\Delta t_{L \rightarrow E}\right)+194.60}{\left(\Delta t_{L \rightarrow E}\right)^{2}}
$$

Equation 4-11

These expressions are presented graphically as the dotted lines in Figure 4-8, Figure 4-10, and Figure 4-11, above. With the exception of the relationship between the two solidification times (Figure 4-8), these derived equations fit the data more effectively than the simplified curve fits. However, the previous three functions are much more complex, impeding their transferability to other research, especially studies with other alloys. Since the continued derivations of such unified sets of expressions would unnecessarily complicate the findings presented in the following sections of Chapter 4, only approximations determined by the data plot trendlines are given for the relationships below.

\subsubsection{Simulations}

SOLIDCast software was used to simulate the A319 alloy primary solidification rate as a function of initial mould temperature using the final mould and casting geometries. As shown in Figure 4-12, simulations were run for only one casting in the centre cavity of the mould, using the same simulation parameters, Al 319.0 and H13 tool steel property data, and heat transfer coefficients as presented in Section 3.1 for the permanent mould design. The simulation results are plotted alongside the experimental casting results in Figure 4-13. There is a strong correspondence between the simulations and the experimental results at initial mould temperatures near $500{ }^{\circ} \mathrm{C}$ and higher. However, with decreasing mould temperature, the simulations predict that primary solidification rate increases with a much shallower slope than that found for the castings. Given the very small thermal mass ratio between the castings and the mould (on the order of 1:25), this is most likely due to the simulations underestimating the amount of heat transfer between the metal and the mould, characterized by the interfacial heat transfer coefficient. For these simulations, the metal-mould heat transfer coefficient used was 
$1135 \mathrm{~W} / \mathrm{m}^{2} \mathrm{~K}$, as suggested by the software. Yet, the heat transfer coefficient is influenced by numerous factors, such as the area of heat transfer, the mould and metal surface roughness, and the pressure of the casting system. Interfacial heat transfer coefficients have been reported to vary within a range of $500-16500 \mathrm{~W} / \mathrm{m}^{2} \mathrm{~K}$ in the literature [40]. Consequently, the simulations were repeated varying the heat transfer coefficient between the metal and the mould while keeping all other parameters constant. The best fit to the experimental data was found for a heat transfer coefficient of about $6000 \mathrm{~W} / \mathrm{m}^{2} \mathrm{~K}$ (Figure 4-13). This value closely resembles the $6578 \mathrm{~W} / \mathrm{m}^{2} \mathrm{~K}$ value estimated by Paul and Venugopal for $6063 \mathrm{Al}$ alloy cast in a permanent mould under similar conditions to the present study [41].

While experimental data was used to refine the simulations, there are a few general error sources inherent in the SOLIDCast software. For example, the simulations utilize constant thermal property and heat transfer coefficient values for calculating the heat transfer processes during casting. However, the metal and mould thermal conductivities, specific heat capacities, densities, and heat transfer coefficients are all dependent on temperature and casting time. Moreover, during casting, an air gap tends to form between the casting and the mould, reducing the rate of interfacial heat transfer. Even though the interfacial heat transfer rates were underestimated in this work, failure to consider the air gap may introduce error into such simulations. 


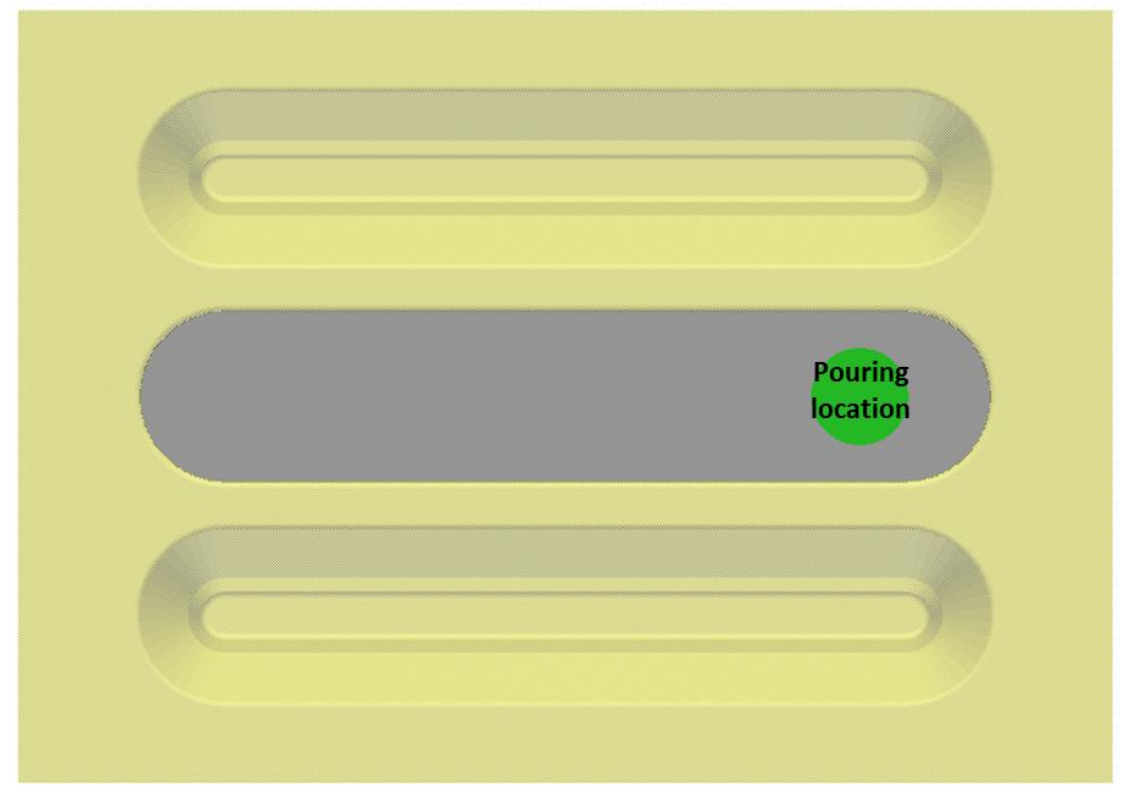

Figure 4-12: Top view of SOLIDCast simulated mould and casting geometry

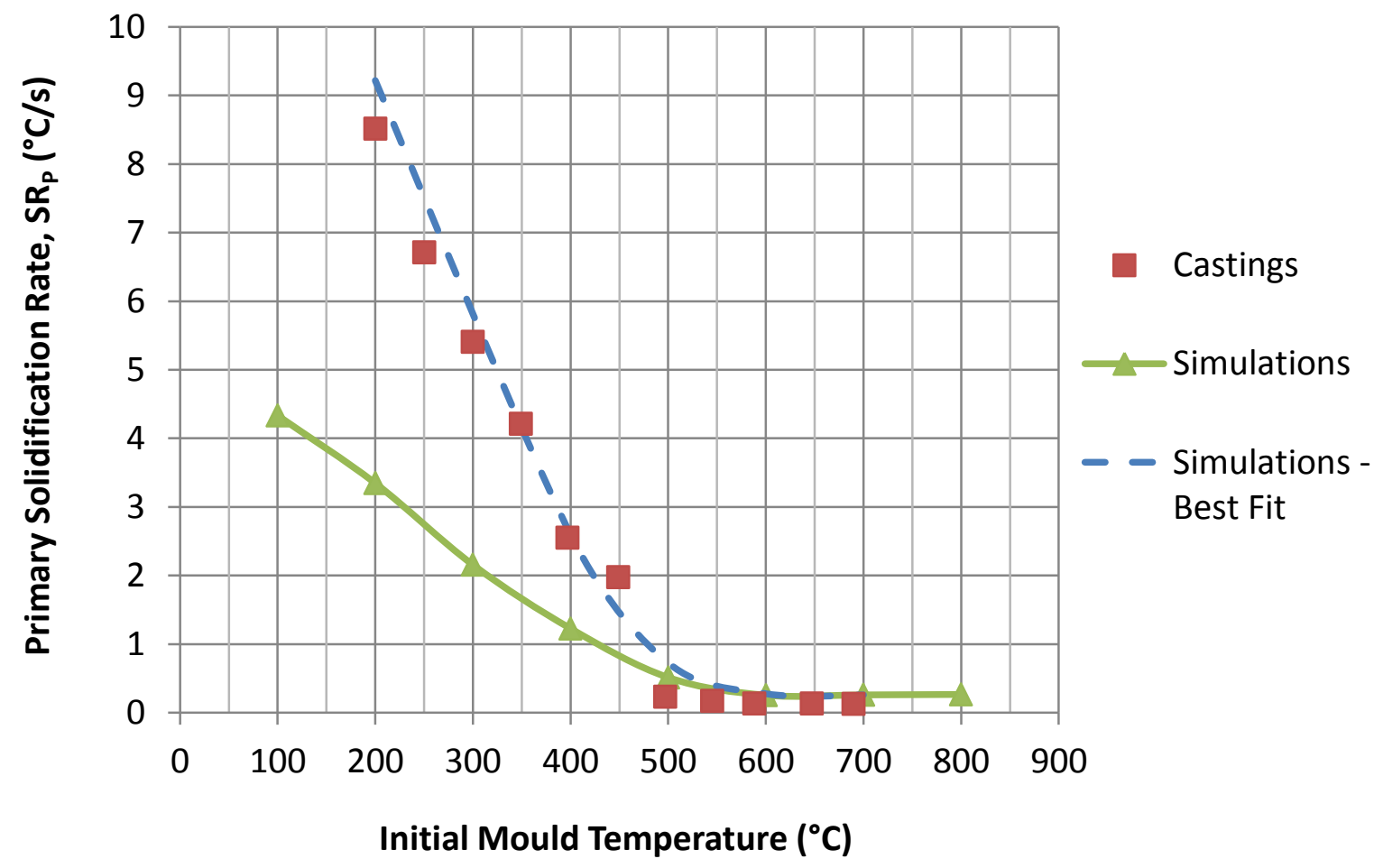

Figure 4-13: Experimental and simulated primary solidification rate of A319 as a function of mould temperature, using the suggested $1135 \mathrm{~W} / \mathrm{m}^{2} \mathrm{~K}$ and a best-fitted $6000 \mathrm{~W} / \mathrm{m}^{2} \mathrm{~K}$ metal-mould convective heat transfer coefficient 


\subsection{Microstructural Analysis}

As discussed in Section 2.2.3, changes in solidification parameters affect the nucleation and growth of all phases. The results can be separated into the effects on the dendritic structure and effects on the secondary phases in the microstructure. These results are presented in this section.

\subsubsection{Dendritic Structure}

The influence of the solidification parameters on microstructure is best captured by changes in the primary $\alpha$-Al dendritic structure. As shown in Figure 4-14, decreasing initial mould temperatures are accompanied by a refinement in the dendritic structure. As discussed in Section 2.2.3, the faster solidification rates at lower mould temperatures increase the dendritic nucleation rate and decrease the dendritic growth rate, such that the microstructure contains a greater number of smaller dendrites. The refinement in microstructure can be quantified by the average secondary dendrite arm spacing (SDAS), shown for all samples as a function of initial mould temperature in Figure 4-15. The average SDAS was found to range from about $28 \mu \mathrm{m}$ to about $102 \mu \mathrm{m}$ for initial mould temperatures of $200{ }^{\circ} \mathrm{C}$ and $690{ }^{\circ} \mathrm{C}$, respectively. The trend follows an S-curve, in which SDAS increases with a relatively shallow slope with increasing mould temperature at either high or low temperatures. However, between $400{ }^{\circ} \mathrm{C}$ and $500{ }^{\circ} \mathrm{C}$, the SDAS increases more significantly with increasing mould temperature. As well, the castings were found to have fairly uniform microstructures, with little variation in the SDAS readings for each of the SX, MX, MO, and SO samples for a given mould temperature. 

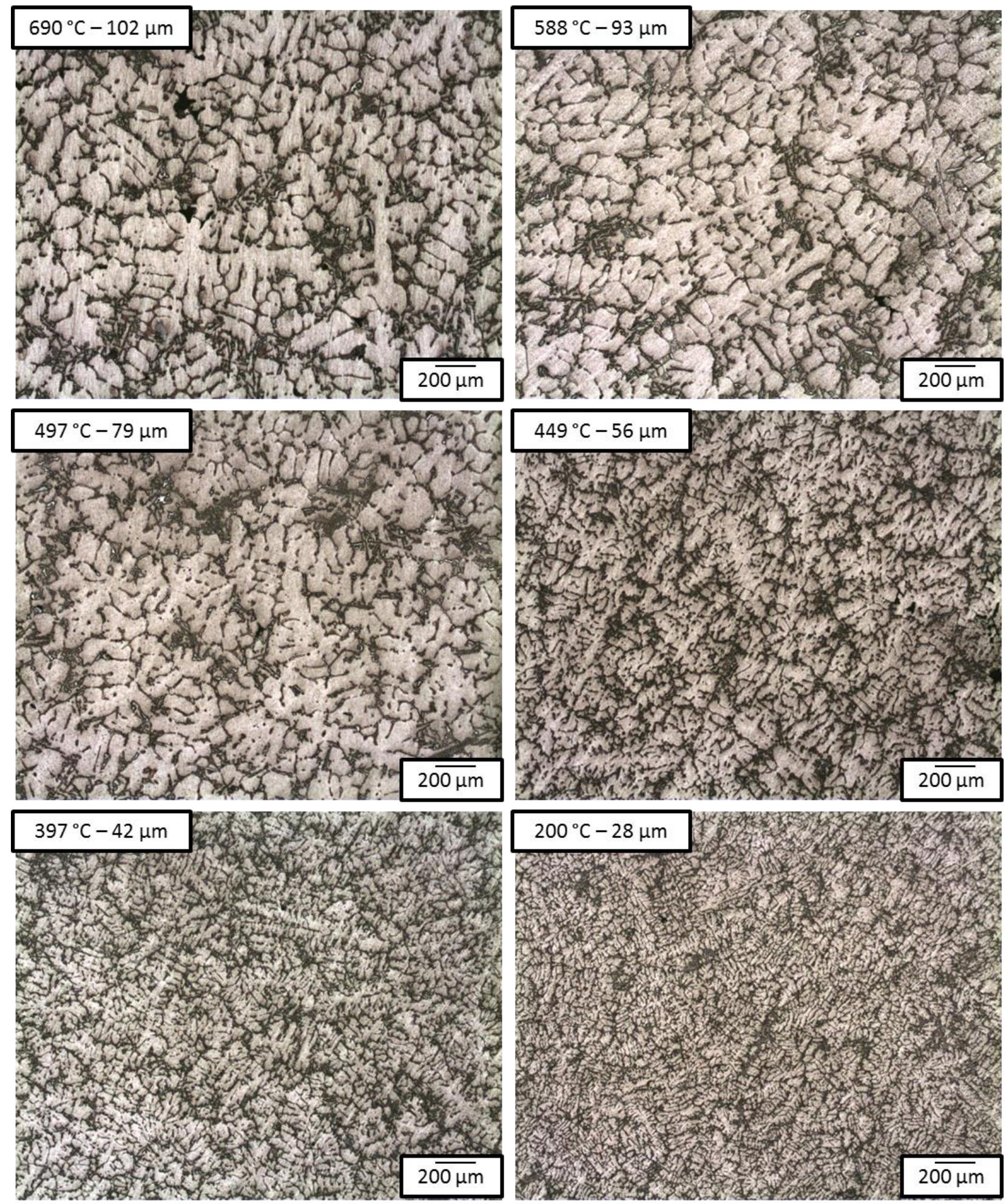

Figure 4-14: Optical micrographs at 50x magnification showing progressive refinement of dendritic structure (characterized by SDAS values shown) with decreasing initial mould temperature 


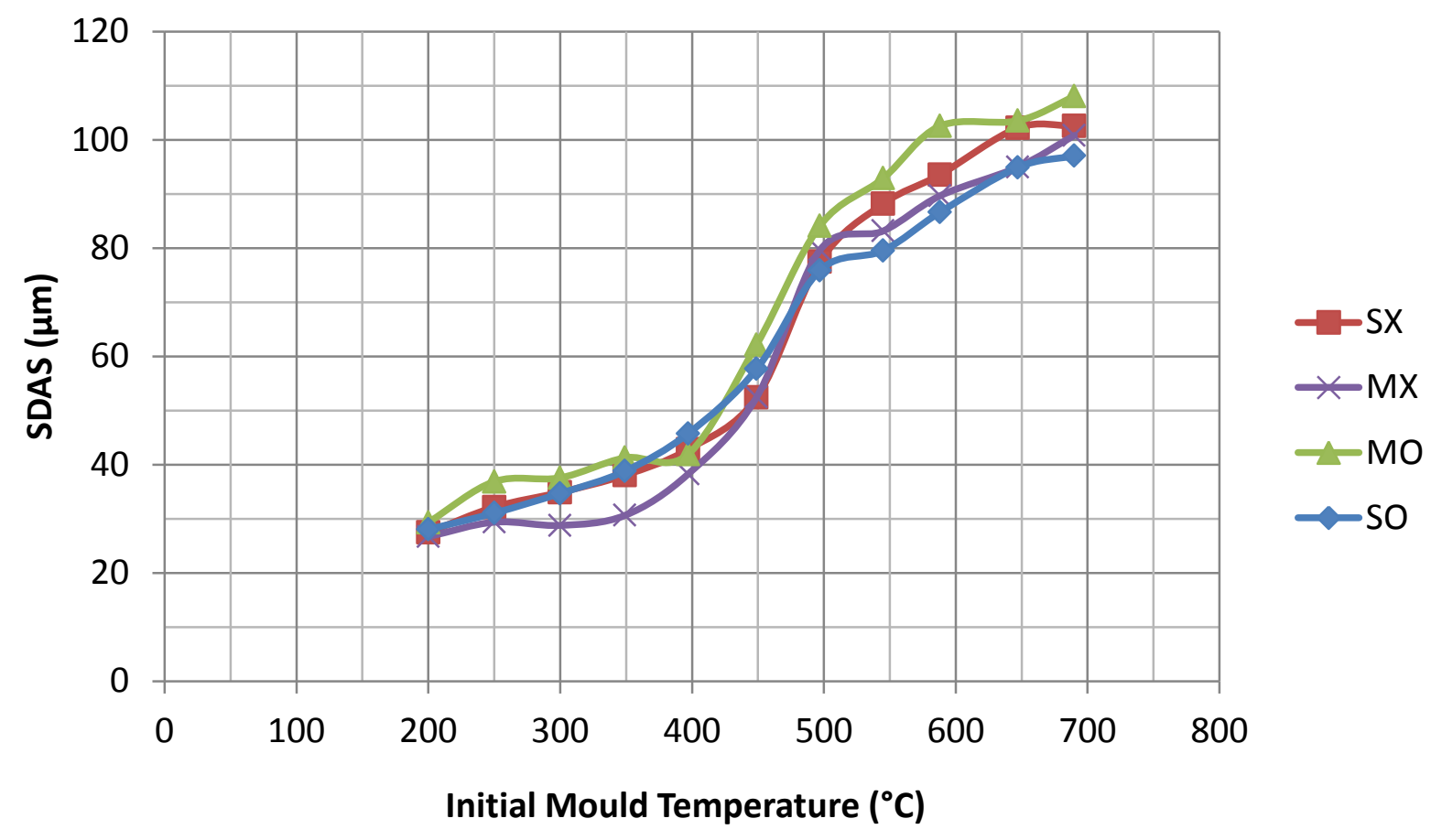

Figure 4-15: SDAS of all samples as a function of initial mould temperature (measurement error bars omitted for clarity)

The overall average SDAS values for each casting are presented as a function of initial mould temperature in Figure 4-16. In this and the following figures of this section, the error bars represent twice the standard deviation $( \pm \sigma)$ for all readings taken from a given casting (including all four samples). While the differences in successive castings are very gradual to the point of being statistically insignificant at either the high or low end of the S-curve, there are definite increases in SDAS from about $400{ }^{\circ} \mathrm{C}$ to $500{ }^{\circ} \mathrm{C}$. 


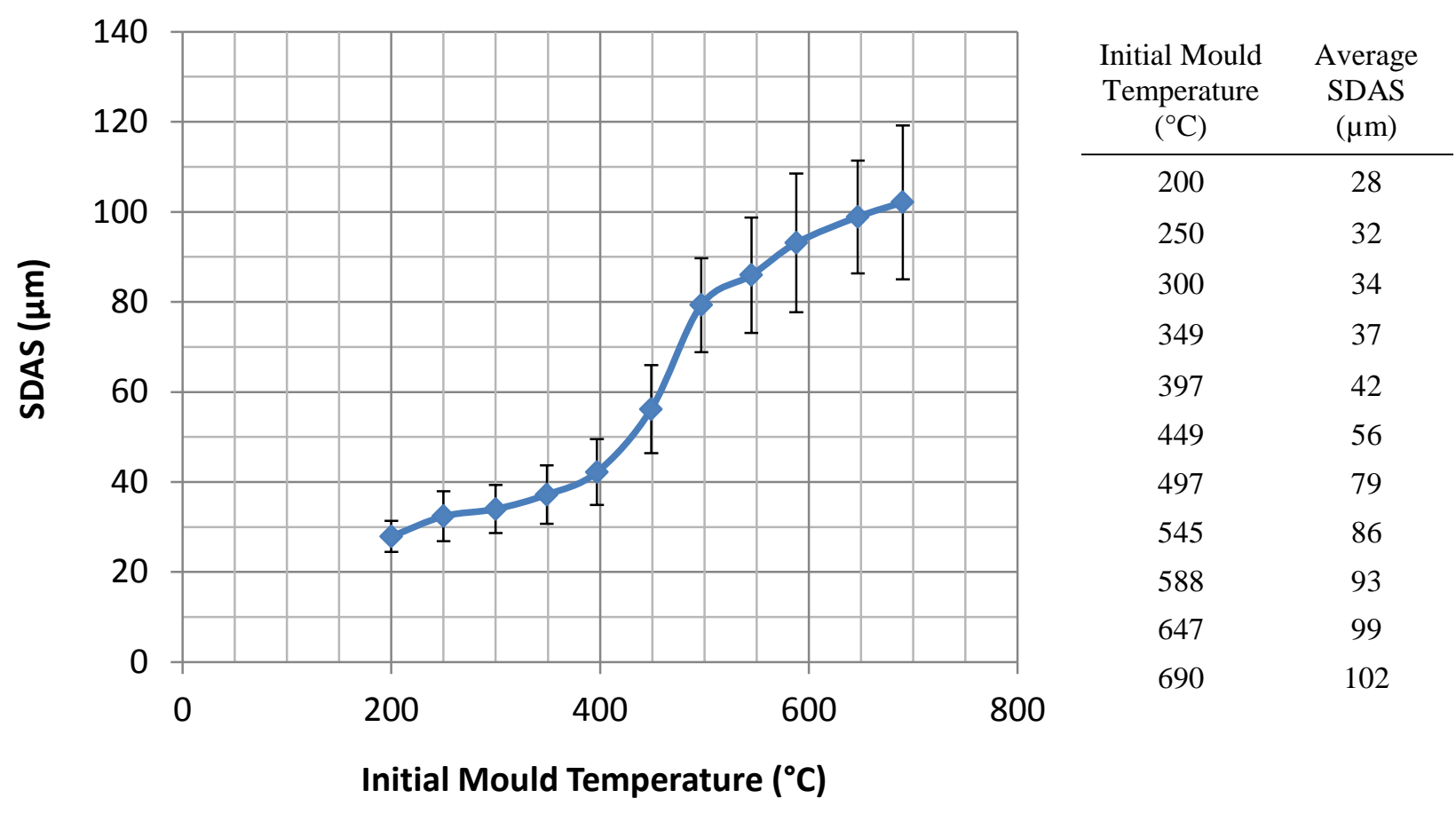

Figure 4-16: Average SDAS as a function of initial mould temperature

More meaningful and universal trends for the alloy can be made by relating the SDAS to the solidification rates and times. For instance, SDAS is plotted as a function of primary solidification rate in Figure 4-17. The relationship follows a power law, for which SDAS is strongly influenced by changes in primary solidification rate only at very small rates, but becomes weakly influenced at higher rates. The expression for the line of best fit is as follows $\left(R^{2}=0.9772\right)$ :

$$
S D A S=55.41\left(S R_{P}\right)^{-0.28}
$$

Equation 4-12 


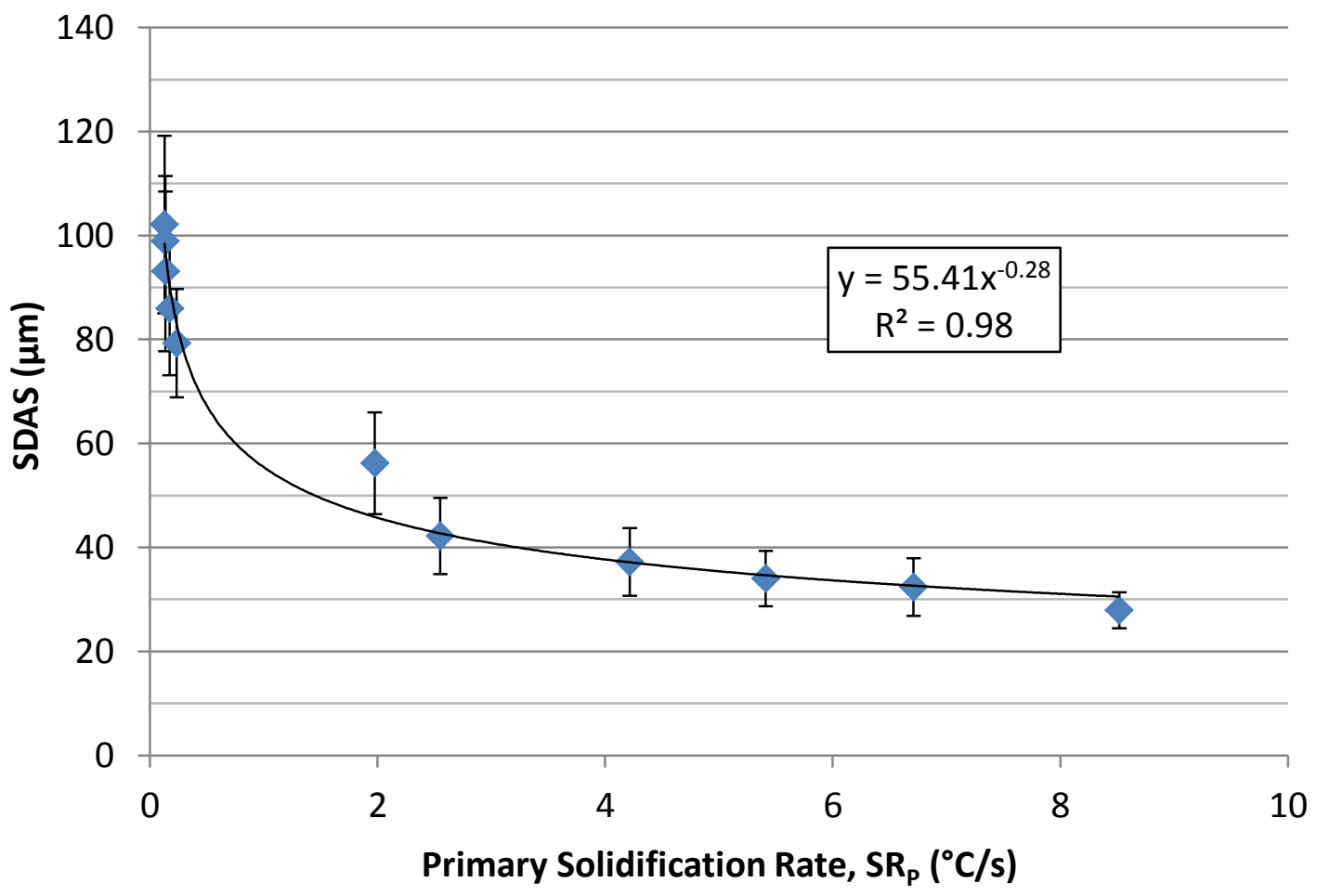

Figure 4-17: SDAS as a function of primary solidification rate

The relationship between SDAS and total solidification rate is presented in Figure 4-18. The trend closely resembles that of the primary solidification rate and can also be approximated by a power law. The line of best fit for this correlation can be expressed as the following $\left(R^{2}=\right.$ 0.9698):

$$
S D A S=48.23\left(S R_{T}\right)^{-0.33}
$$

Equation 4-13

On the other hand, the relationship between SDAS and primary solidification time can be best approximated by a logarithmic function, in which increases in SDAS are associated with increasing solidification time (Figure 4-19). The expression for the line of best fit for the data is as follows $\left(R^{2}=0.9785\right)$ :

$$
S D A S=16.15 \ln \left(\Delta t_{L \rightarrow E}\right)-0.43
$$

Equation 4-14 


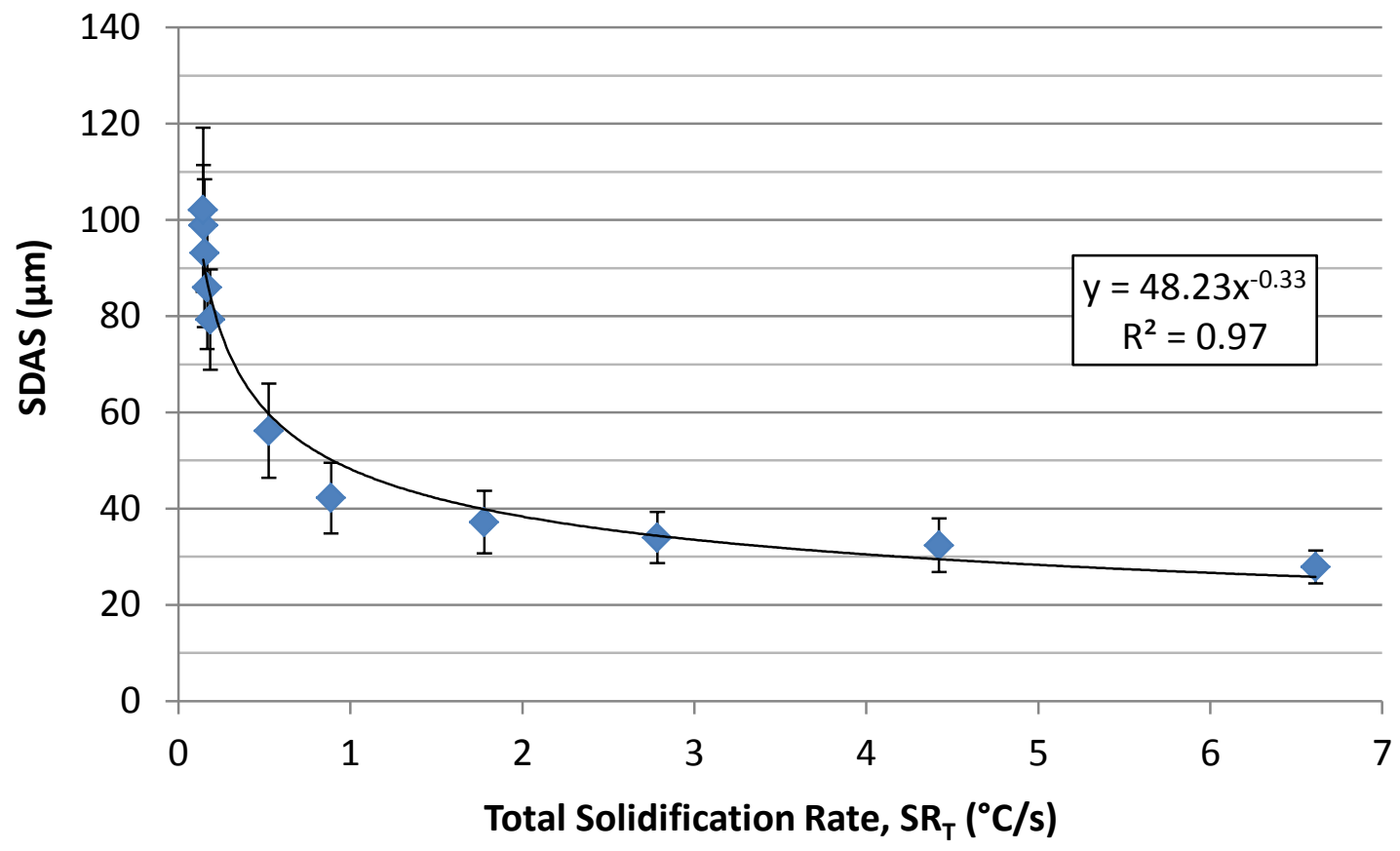

Figure 4-18: SDAS as a function of total solidification rate

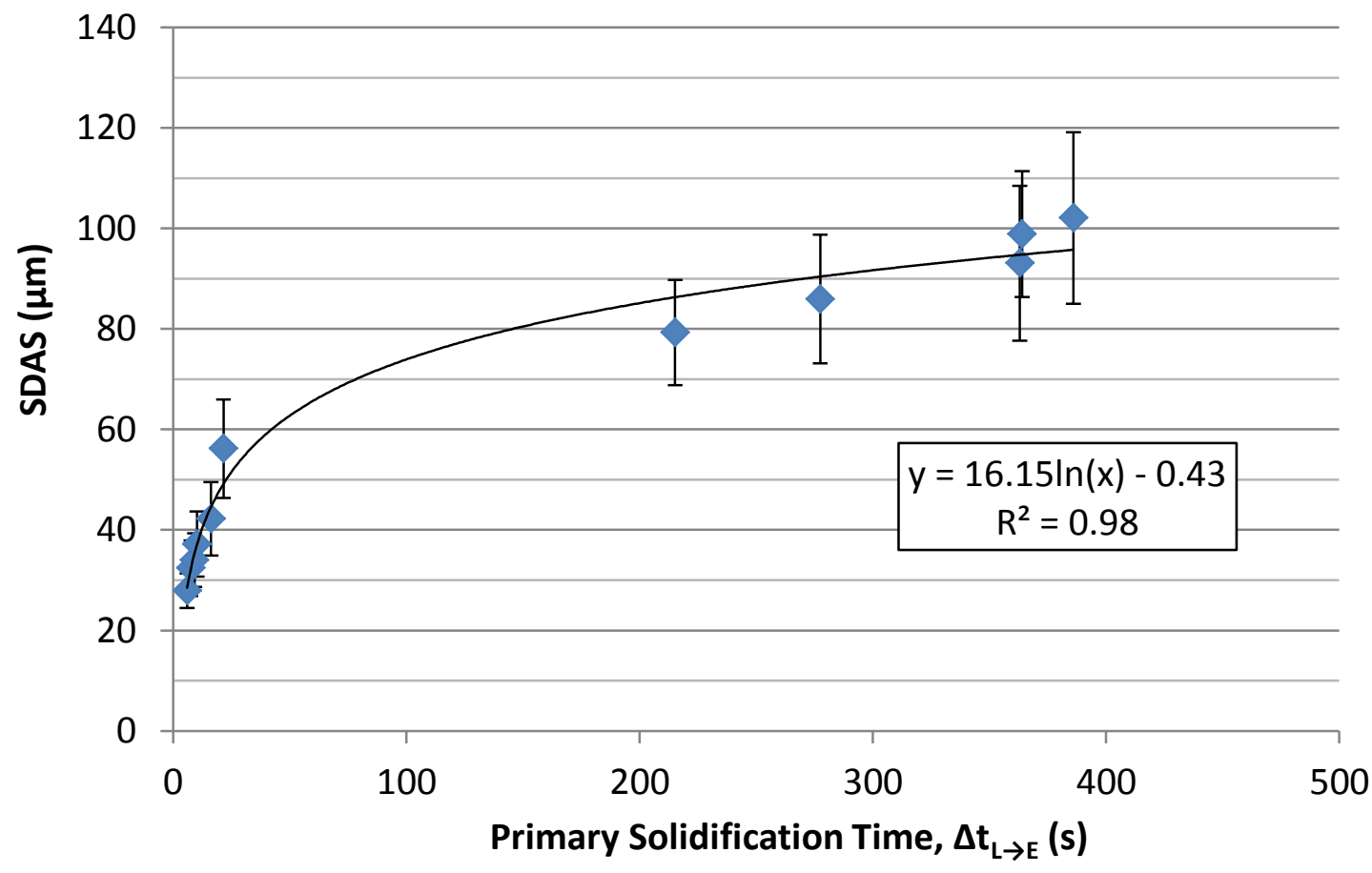

Figure 4-19: SDAS as a function of primary solidification time 
Finally, the best-fitting correlation was found for the relationship between SDAS and the local solidification time. As shown in Figure 4-20, SDAS increases linearly with increasing time. Although each of the solidification parameters have been shown to correlate well to the SDAS, the highest coefficient of determination for this data indicates that the local solidification time is most appropriate for controlling SDAS. The line of best fit for this relationship can be expressed as the following $\left(R^{2}=0.9857\right)$ :

$$
S D A S=0.08\left(\Delta t_{L \rightarrow S}\right)+30.56
$$

Equation 4-15

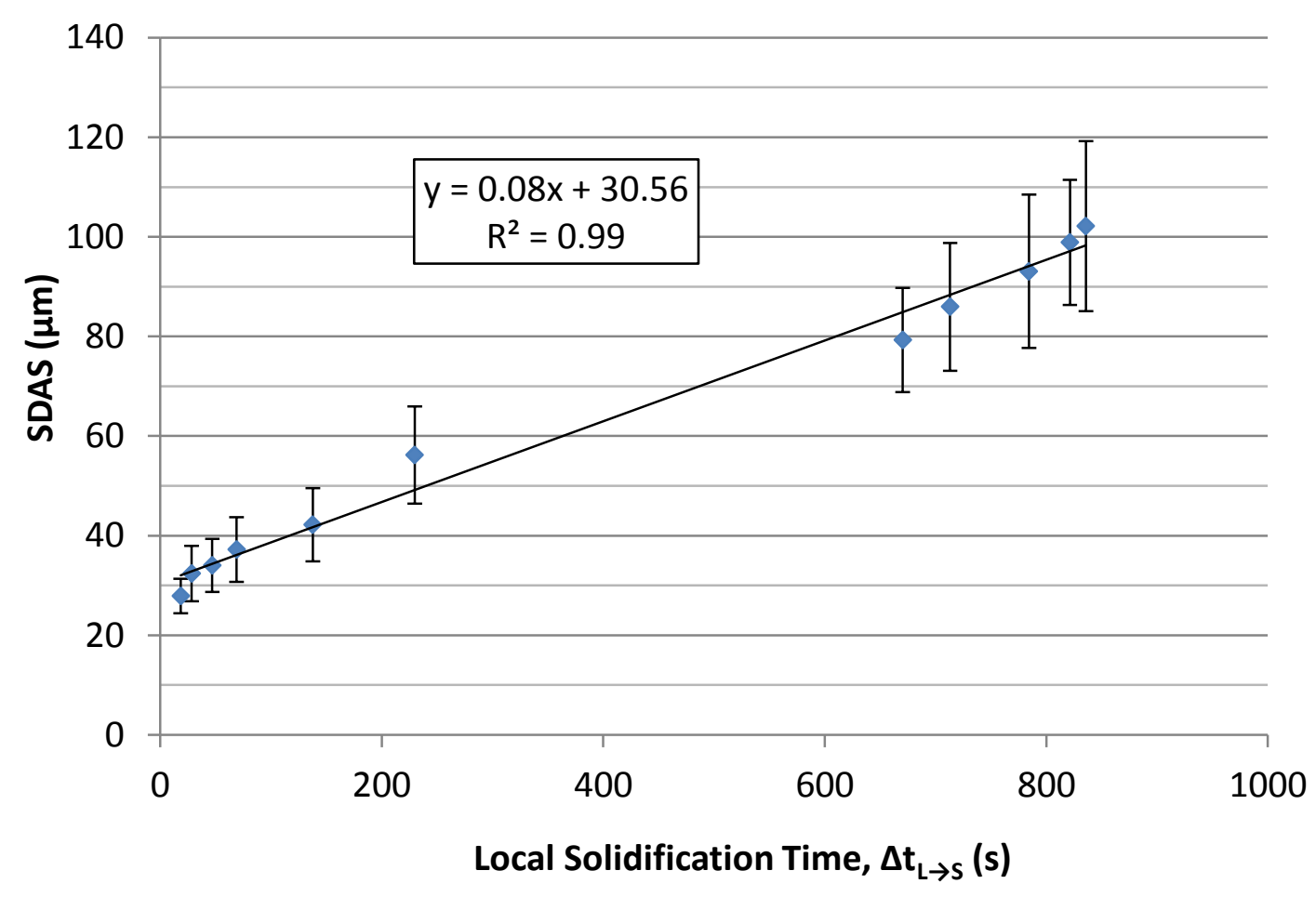

Figure 4-20: SDAS as a function of local solidification time

\subsubsection{Secondary Phases}

Optical and backscattered electron micrographs of the general microstructures of the A319 castings are depicted in Figure 4-21 and Figure 4-22, respectively. The compositions of the secondary phases were evaluated using EDX, as shown in Figure 4-23. While the accuracy of EDX only enables an estimation of the elements present in each phase, its results were used in 
conjunction with findings in the literature for 319-type alloys to determine the stoichiometries [42]. As shown below, the microstructures appear very similar regardless of the solidification conditions, consisting of an $\alpha$-Al dendritic matrix with acicular $\mathrm{Si}$ particles, blocky $\mathrm{Al}_{2} \mathrm{Cu}$ particles, and clusters of eutectic $\mathrm{Al}_{2} \mathrm{Cu}$ and $\mathrm{Al}_{5} \mathrm{Mg}_{8} \mathrm{Cu}_{2} \mathrm{Si}_{6}$ in the interdendritic regions. However, a key difference observed for castings with a faster solidification rate is an overall refinement of the entire microstructure. Much like for the dendritic structure, faster cooling limits the growth of all secondary phases and results in finer particles in smaller interdendritic regions. As well, another key difference between the microstructures is a transition in the composition and morphology of the Fe-bearing phase from the Chinese-script $\alpha-\mathrm{Al}_{15}(\mathrm{Fe}, \mathrm{Mn})_{3} \mathrm{Si}_{2}$ phase to the $\beta-\mathrm{Al}_{5} \mathrm{FeSi}$ phase with increasing solidification rate. Yet, for most of the secondary phases, no change in composition or morphology accompanies their refinement.

Furthermore, the area fractions of secondary phases were determined by image analysis for each casting condition. As presented in Figure 4-24, the area fraction of the secondary phases were independent of the initial mould temperature, and hence the solidification rate. In this figure, the error bars represent twice the standard deviation $( \pm \sigma)$ for all readings taken from a given casting (including at least one sample). On average, the microstructures were found to consist of $7.7 \%$ $( \pm 0.9 \%) \mathrm{Si}, 2.2 \%( \pm 0.6 \%) \mathrm{Al}_{2} \mathrm{Cu}$, and $2.7 \%( \pm 1.5 \%) \mathrm{Fe}-$ and Mg-bearing phases, by area. Note that the Fe- and Mg-bearing phases were measured together due to difficulty differentiating between their similar shades in the backscattered electron images. Yet, the predominant contribution to this measurement was from the Fe-bearing phases. These results indicate that the faster solidification rate did not hinder the precipitation of phases from the liquid metal, and so all castings consist of approximately the same concentration of elements dissolved in the aluminum solid solution. Also, since the area fraction of phases is the same but the interdendritic regions are smaller, the secondary phases are better distributed through the microstructure at faster solidification rates.

To summarize, the microstructures at higher initial mould temperatures closely resemble those at lower mould temperatures, but they appear more magnified and contain different Fe-bearing phases. The changes in morphologies of the secondary phases are discussed in detail in the following two sections. 

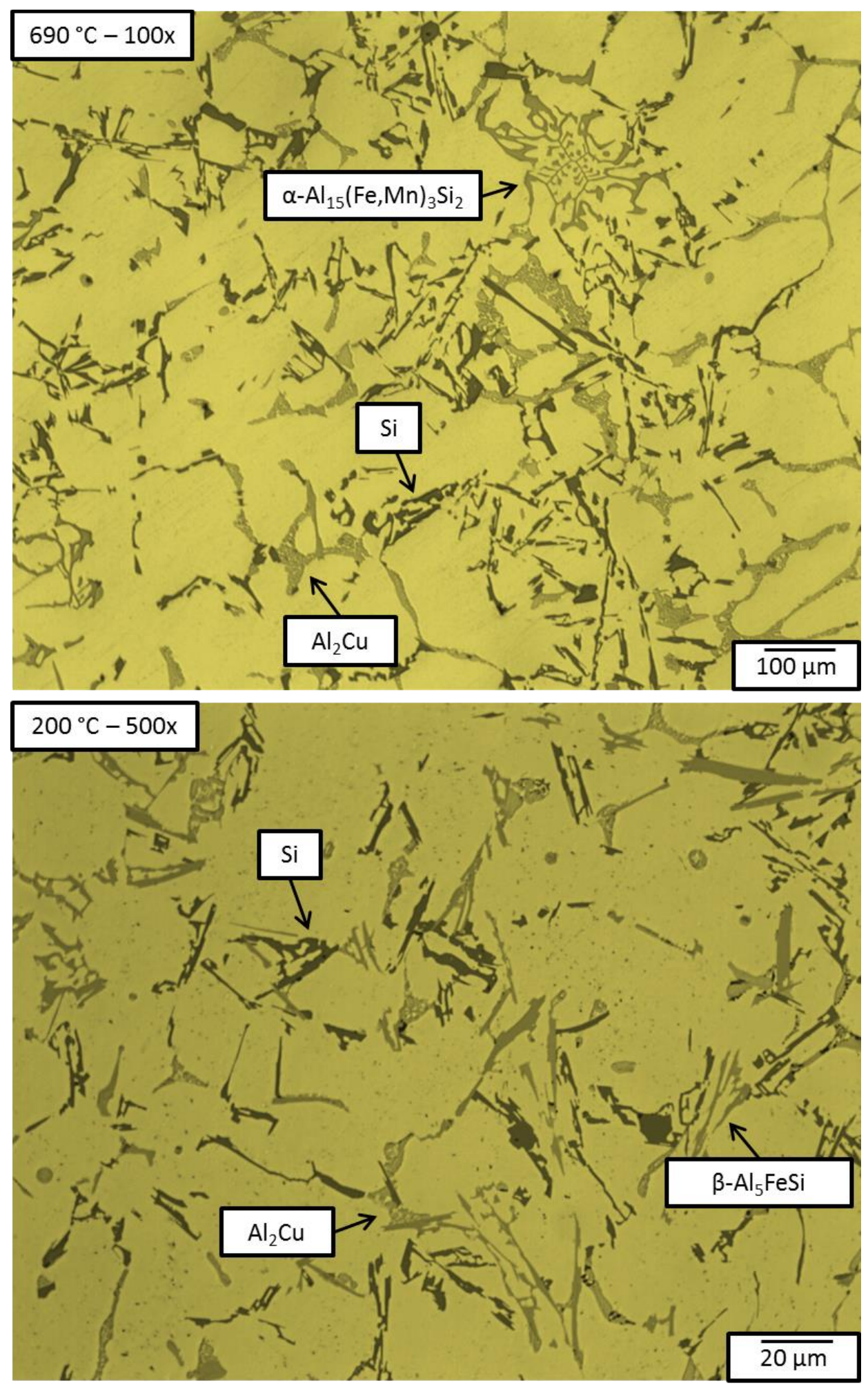

Figure 4-21: Optical micrographs of the general microstructure for $690{ }^{\circ} \mathrm{C}$ (top, $100 \mathrm{x}$ magnification) and $200{ }^{\circ} \mathrm{C}$ (bottom, 500x magnification) mould temperatures 

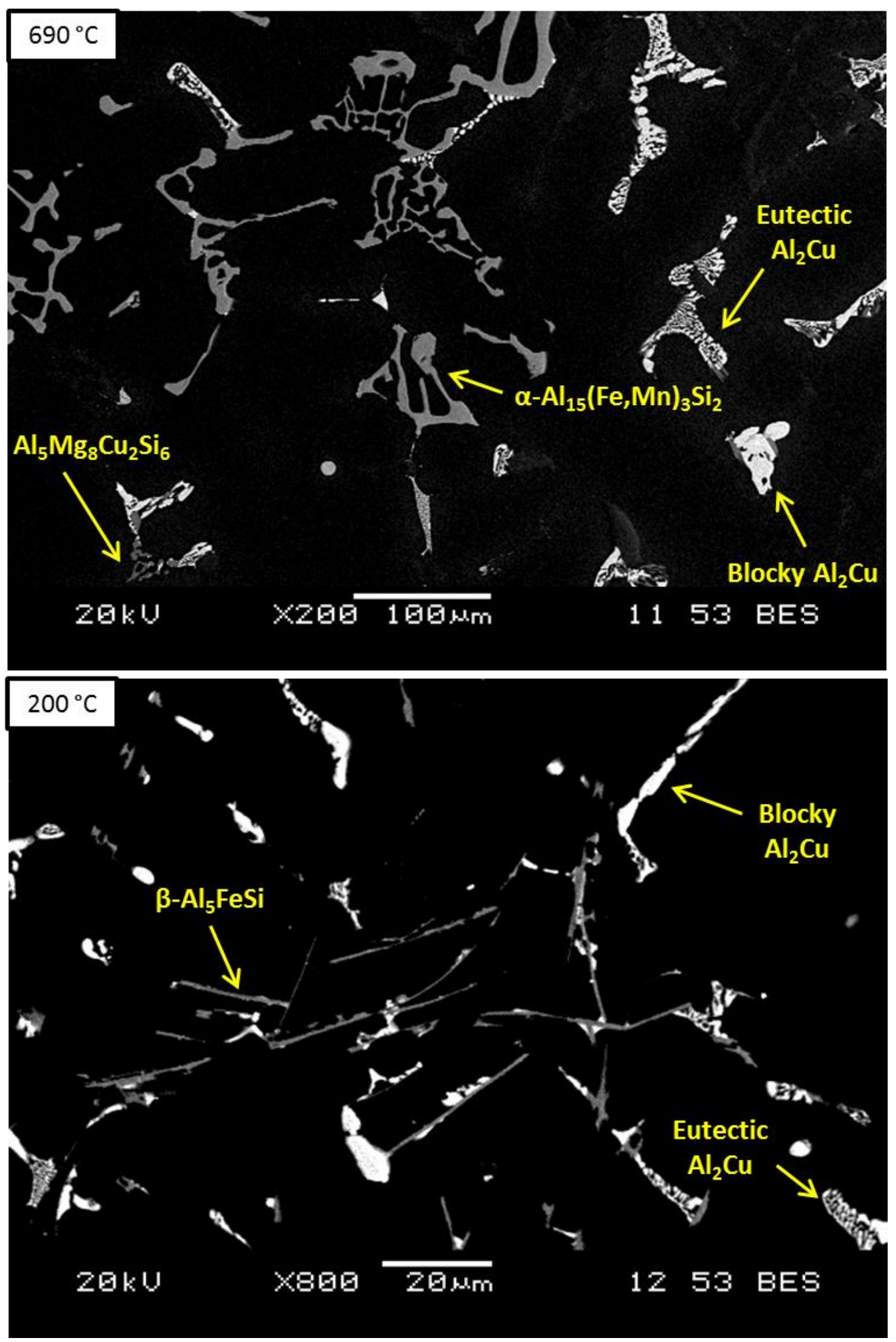

Figure 4-22: Backscattered electron images of intermetallic compounds for $690{ }^{\circ} \mathrm{C}$ (top, 200x magnification) and $200{ }^{\circ} \mathrm{C}$ (bottom, 800x magnification) mould temperatures 

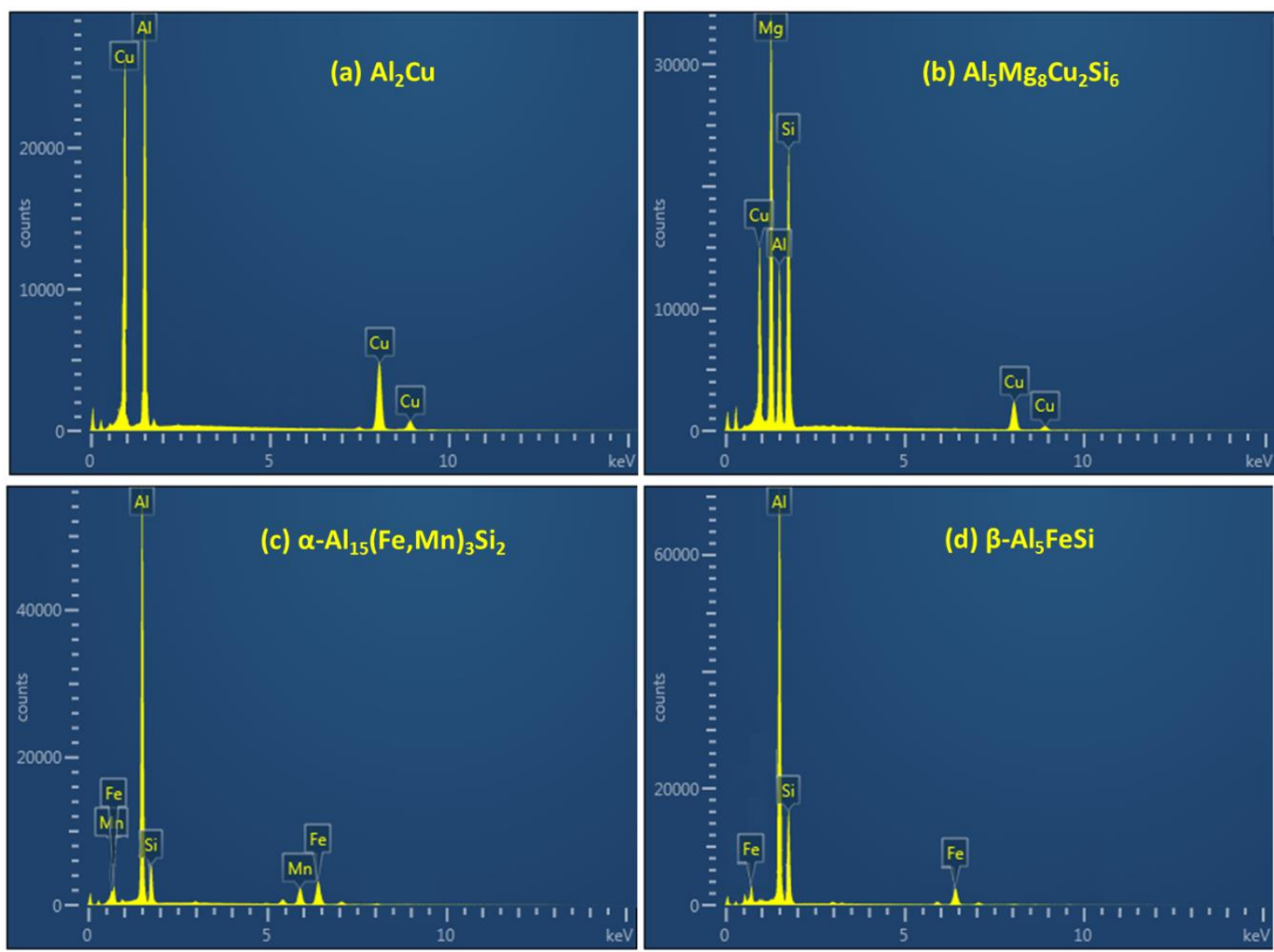

Figure 4-23: EDX analysis of (a) $\mathrm{Al}_{2} \mathrm{Cu}$, (b) $\mathrm{Al}_{5} \mathrm{Mg}_{8} \mathrm{Cu}_{2} \mathrm{Si}_{6}$, (c) $\alpha-\mathrm{Al}_{15}(\mathrm{Fe}, \mathrm{Mn})_{3} \mathrm{Si}_{2}$, and (d) $\beta-\mathrm{Al}_{5} \mathrm{FeSi}$ 


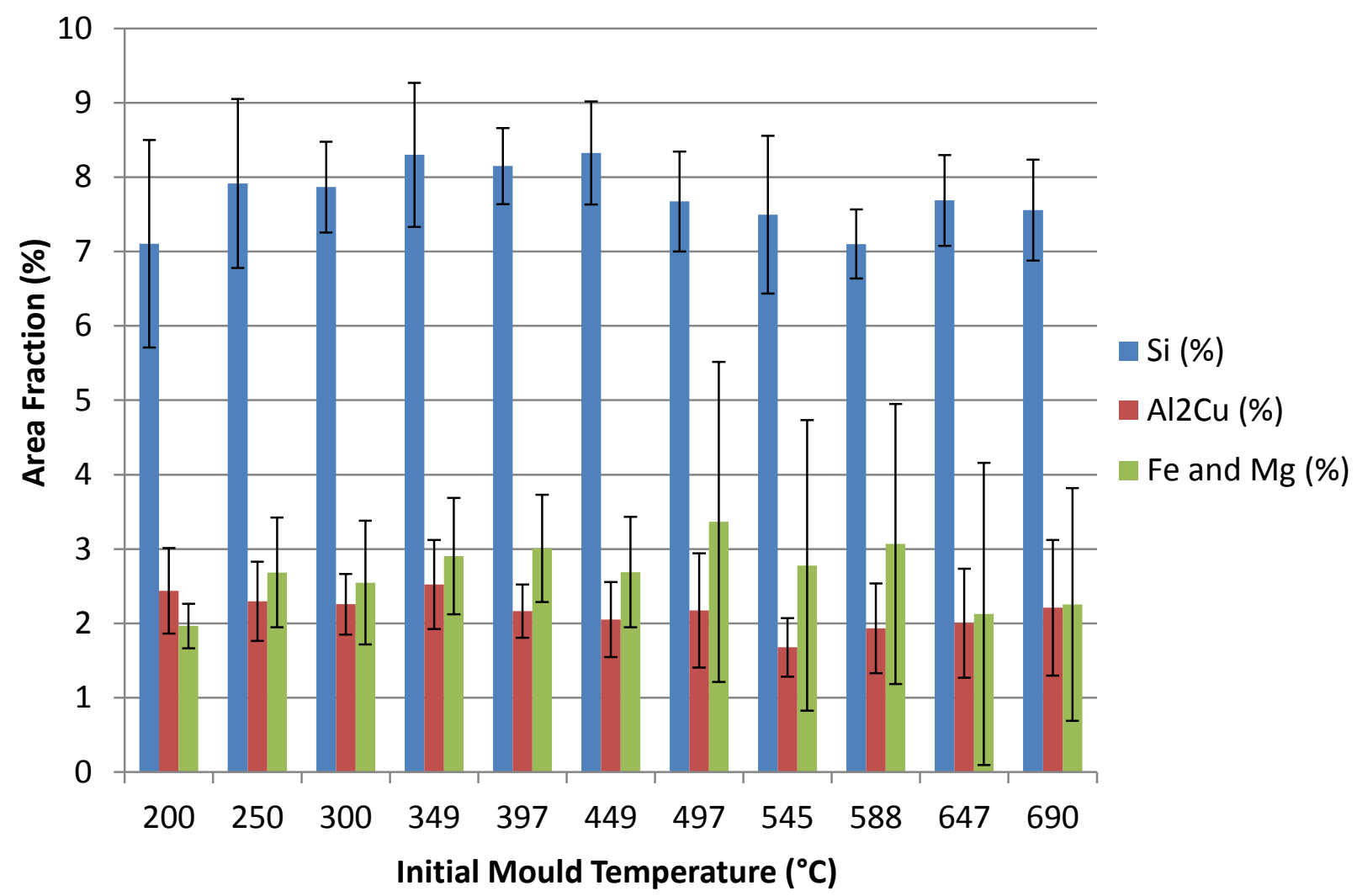

Figure 4-24: Area fraction of secondary phases as a function of mould temperature

\subsubsection{Morphology of Eutectic Si}

The eutectic Si phase is the most suitable secondary phase for characterizing the morphological effects of faster cooling. As shown in Figure 4-24, the area fraction of the Si phase in the microstructure is around three times that as for the intermetallic compounds, and hence it should have a significant influence on mechanical and thermal properties. Also, all of the $\mathrm{Si}$ in the microstructure is present as one eutectic Si phase, unlike the presence of both blocky and eutectic phases of $\mathrm{Al}_{2} \mathrm{Cu}$. As a result, it is easier to quantify the relatively uniform features of $\mathrm{Si}$ throughout the microstructure. As well, unlike the Fe-bearing phases, there are no compositional changes in eutectic $\mathrm{Si}$ associated with solidification rate.

Optical micrographs of the interdendritic Al-Si eutectic regions for the $690{ }^{\circ} \mathrm{C}$ and $200{ }^{\circ} \mathrm{C}$ mould temperature castings are shown in Figure 4-25, where Si is the dark phase. All Si was present as 
acicular plates, typical of alloys with no chemical eutectic modification (Section 2.1.1.1). The morphology of the Si phase is almost identical in shape for all casting conditions, yet the particles are significantly refined at lower mould temperatures. This was quantified by measuring the median particle aspect ratio, sphericity, and circular diameter for each condition using image analysis. The median values were found to be more suitable for comparison than averages, given the non-uniform distribution of particles in the microstructure. As shown in Figure 4-26 and Figure 4-27, the median aspect ratio and sphericity were found to be about 2.17 and 0.26 , respectively, independent of the mould temperature. Nonetheless, aspect ratio was found to decrease and sphericity was found to increase very slightly but almost linearly with decreasing mould temperature. Even though these trends were not very significant, they provide evidence of minor eutectic Si modification possible by increasing solidification rates, by decreasing particle elongation and increasing particle roundness. In contrast, the median circular diameter was found to decrease with decreasing mould temperature in accordance with an S-shaped curve (Figure 4-28). The circular diameter decreases with a relatively shallow slope with decreasing mould temperature at either high or low temperatures. However, between $497{ }^{\circ} \mathrm{C}$ and $449{ }^{\circ} \mathrm{C}$, the circular diameter decreases significantly with decreasing mould temperature. Overall, from highest to lowest mould temperature, the median circular diameter was reduced by about $75 \%$.
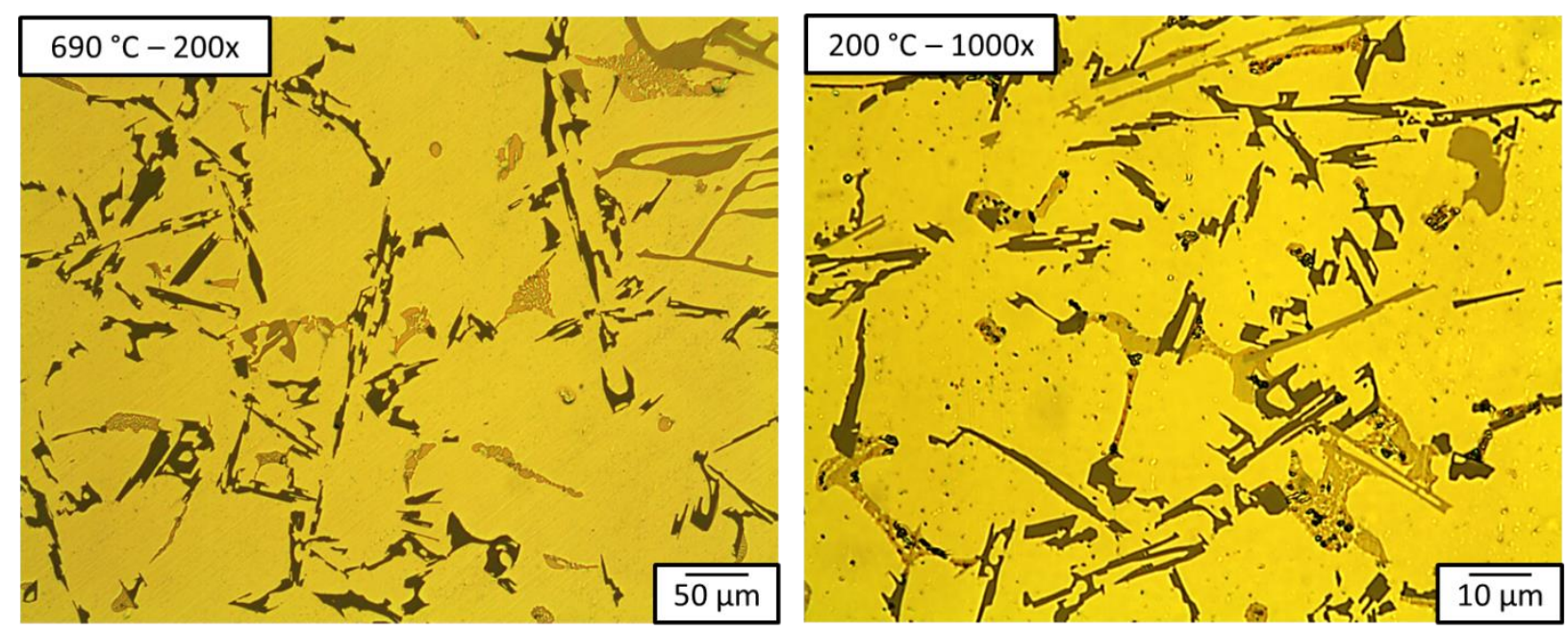

Figure 4-25: Optical micrographs of the eutectic Si morphology for $690{ }^{\circ} \mathrm{C}$ (left, 200x magnification) and $200{ }^{\circ} \mathrm{C}$ (right, 1000x magnification) mould temperatures 


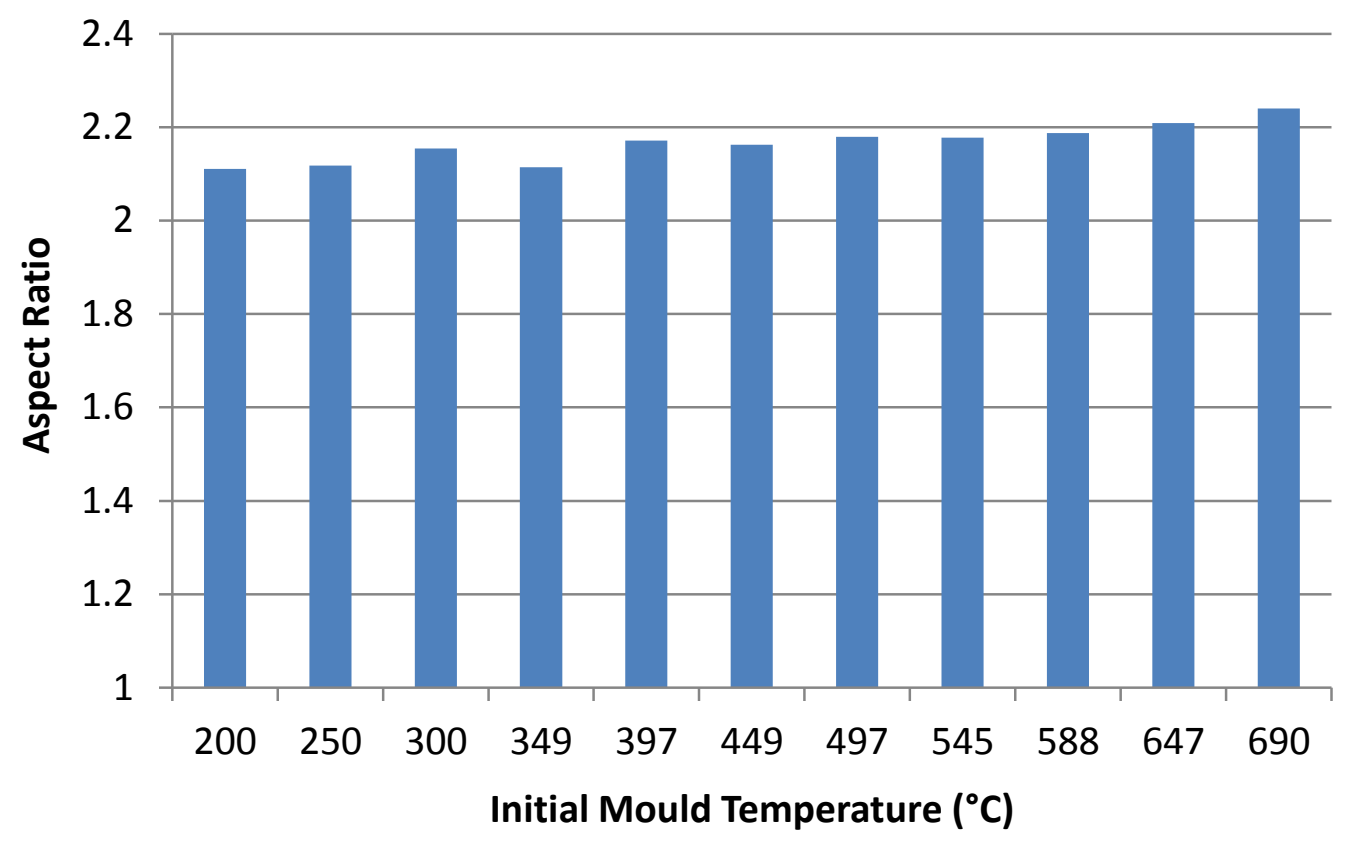

Figure 4-26: Median aspect ratio of eutectic Si particles as a function of mould temperature

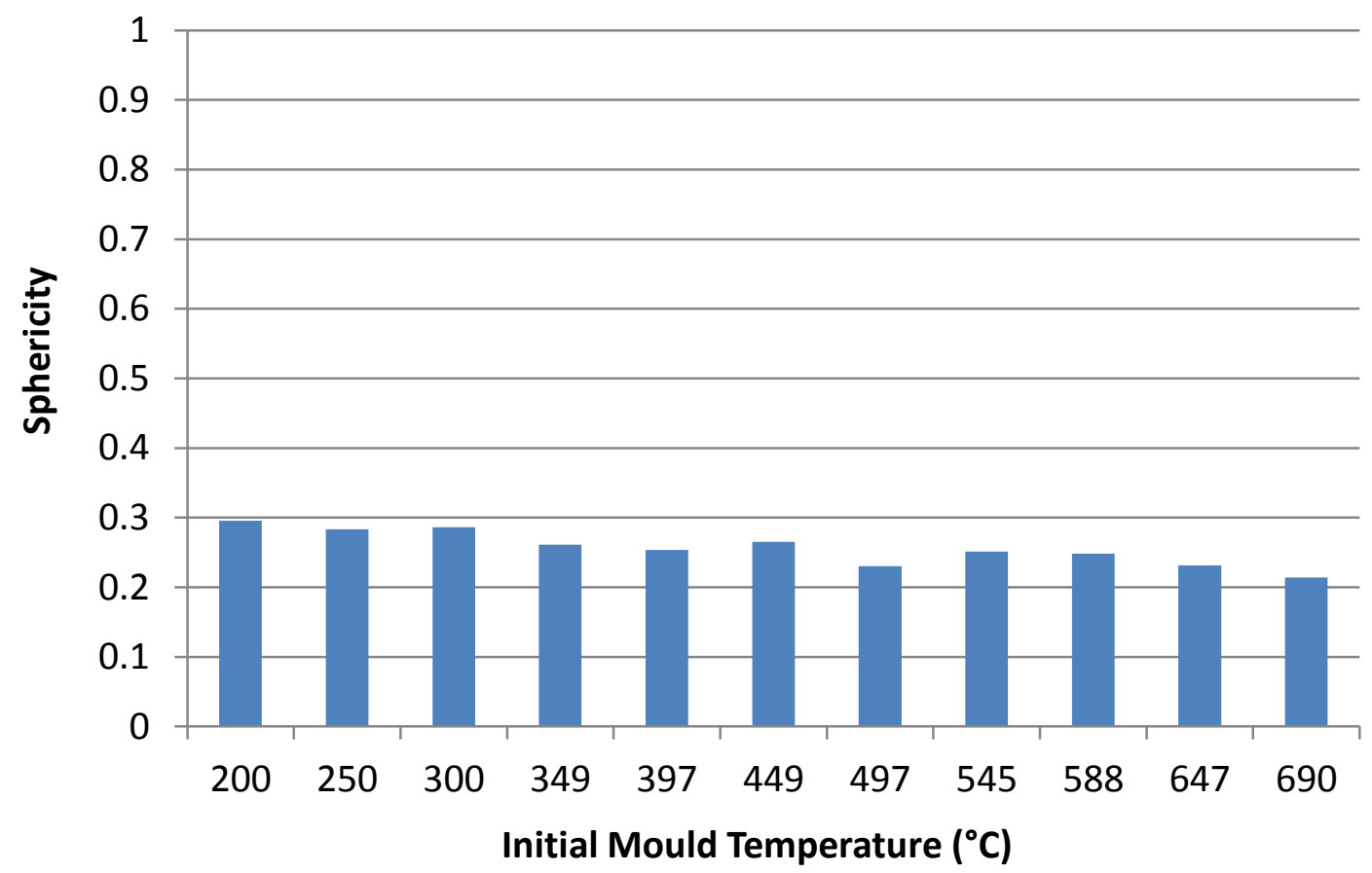

Figure 4-27: Median sphericity of eutectic Si particles as a function of mould temperature 


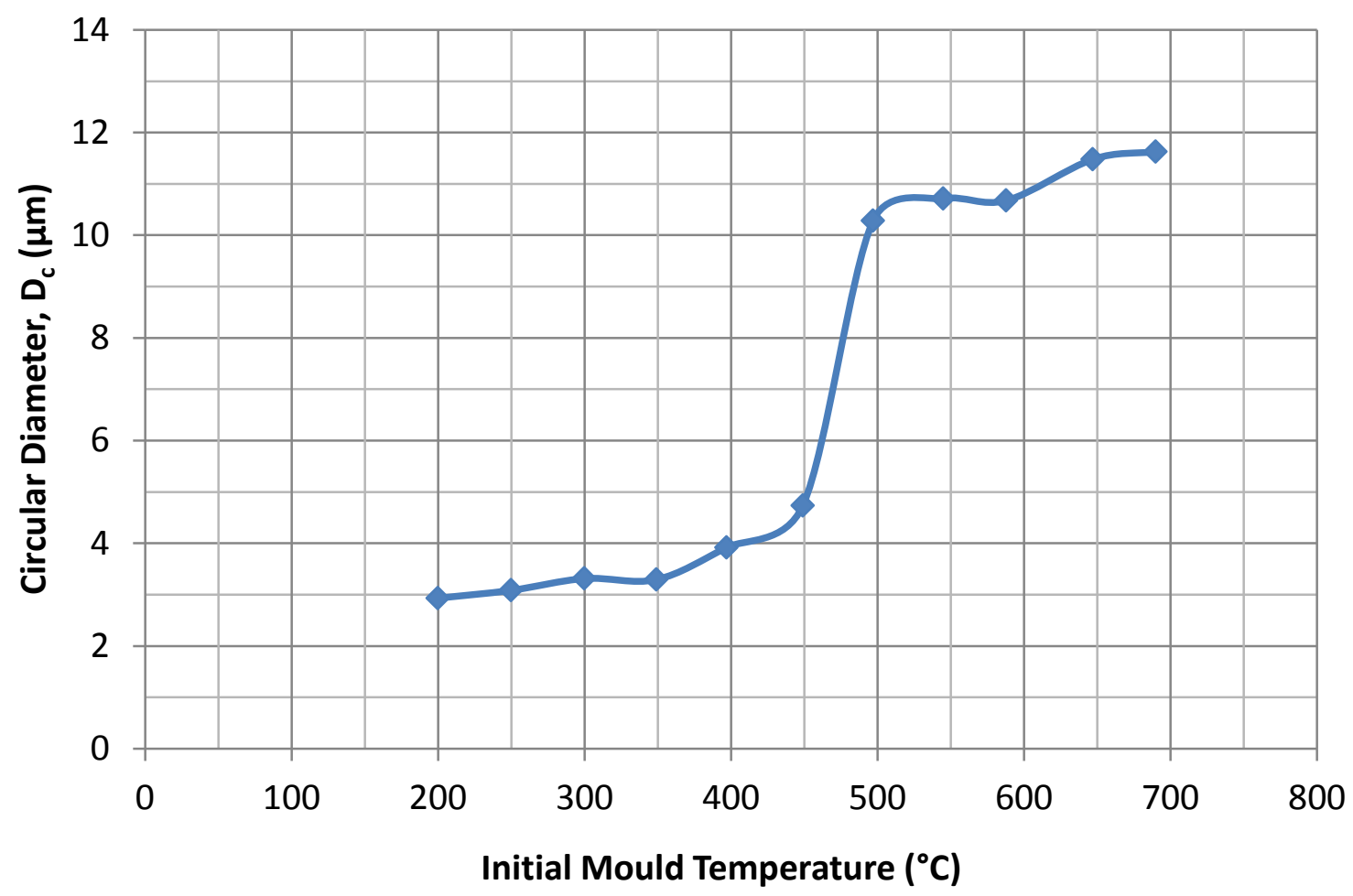

Figure 4-28: Median circular diameter of eutectic Si particles as a function of mould temperature

The circular diameter followed a similar trend to the dendritic structure when related to initial mould temperature. Consequently, the decrease in circular diameter can also be correlated to the decrease in SDAS. However, as shown in Figure 4-29, this relationship is not linear, but rather it also resembles an S-shape. The trend can be approximated best by the following logistic function $\left(R^{2}=0.9950\right)$ :

$$
D_{c}=\frac{8.6}{1+\exp [-0.11(S D A S-67)]}+3.05
$$

Equation 4-16

Where:

$D_{c}$ : Eutectic Si median circular diameter 


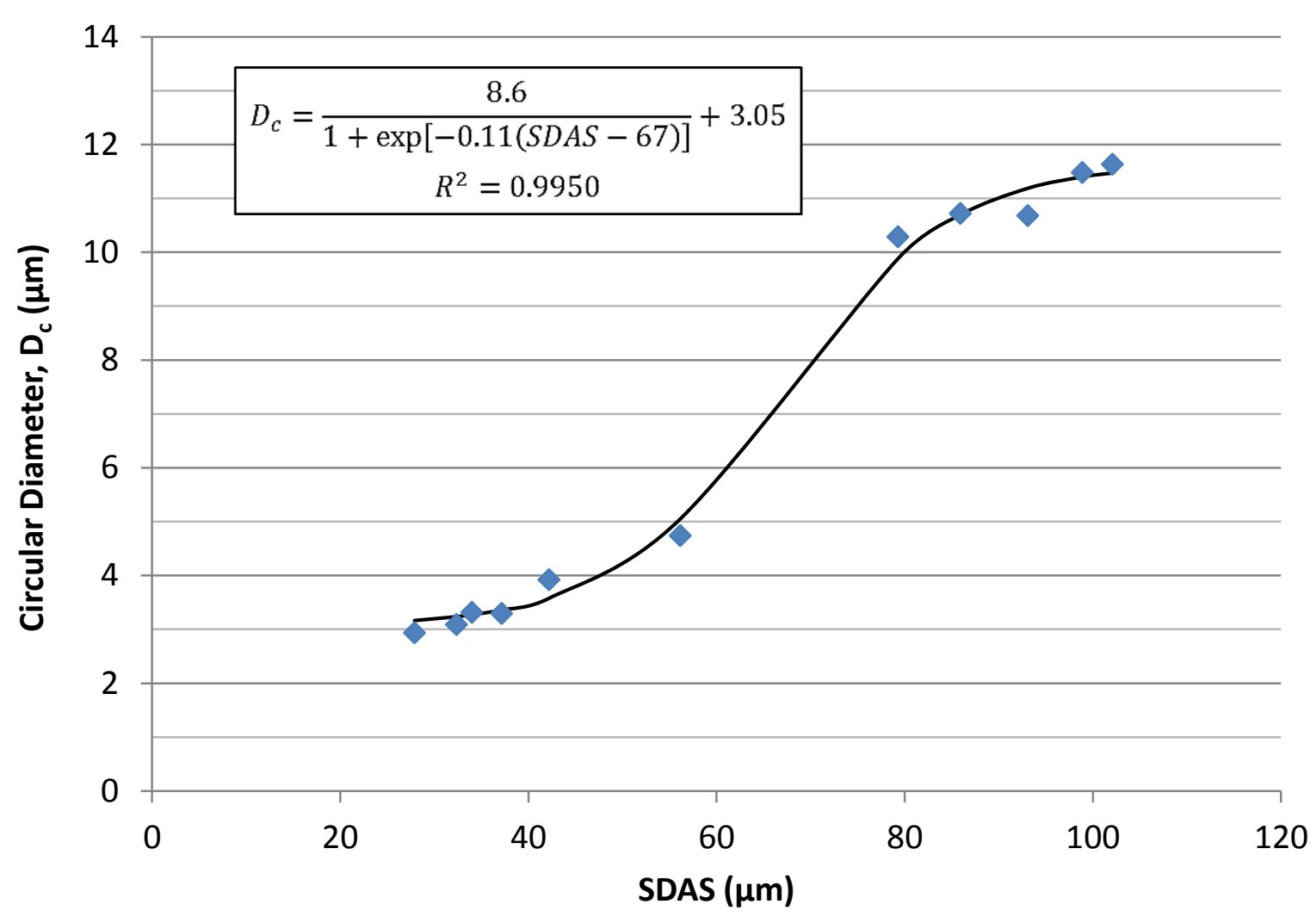

Figure 4-29: Median circular diameter of eutectic Si particles as a function of SDAS

Circular diameter can also be related directly to each of the solidification parameters. For example, power laws can be used to best describe the relationships between circular diameter and each of the primary and total solidification rates, as demonstrated in Figure 4-30 and Figure 4-31, respectively. A decrease in circular diameter is associated with an increase in solidification rate. For the primary solidification rate, the expression of the line of best fit is as follows $\left(R^{2}=0.9929\right)$ :

$$
D_{c}=5.79\left(S R_{P}\right)^{-0.34}
$$

Equation 4-17

For the total solidification rate, the expression of the line of best fit is as follows $\left(R^{2}=0.9236\right)$ :

$$
D_{c}=4.91\left(S R_{T}\right)^{-0.39}
$$

Equation 4-18

The approximation for total solidification rate is much weaker than that for primary solidification rate, as evidenced by its lower coefficient of determination. However, the correlations are also 
strong between circular diameter and the two solidification times. As shown in Figure 4-32 and Figure 4-33, a decrease in circular diameter is associated with a decrease in solidification time. For the primary solidification time, the line of best fit can also be expressed as a power law $\left(R^{2}=0.9953\right)$ :

$$
D_{c}=1.57\left(\Delta t_{L \rightarrow E}\right)^{0.34}
$$

Equation 4-19

In contrast, the relationship with the local solidification time follows a linear trend $\left(R^{2}=\right.$ 0.9951):

$$
D_{c}=0.01\left(\Delta t_{L \rightarrow S}\right)+2.63
$$

Equation 4-20

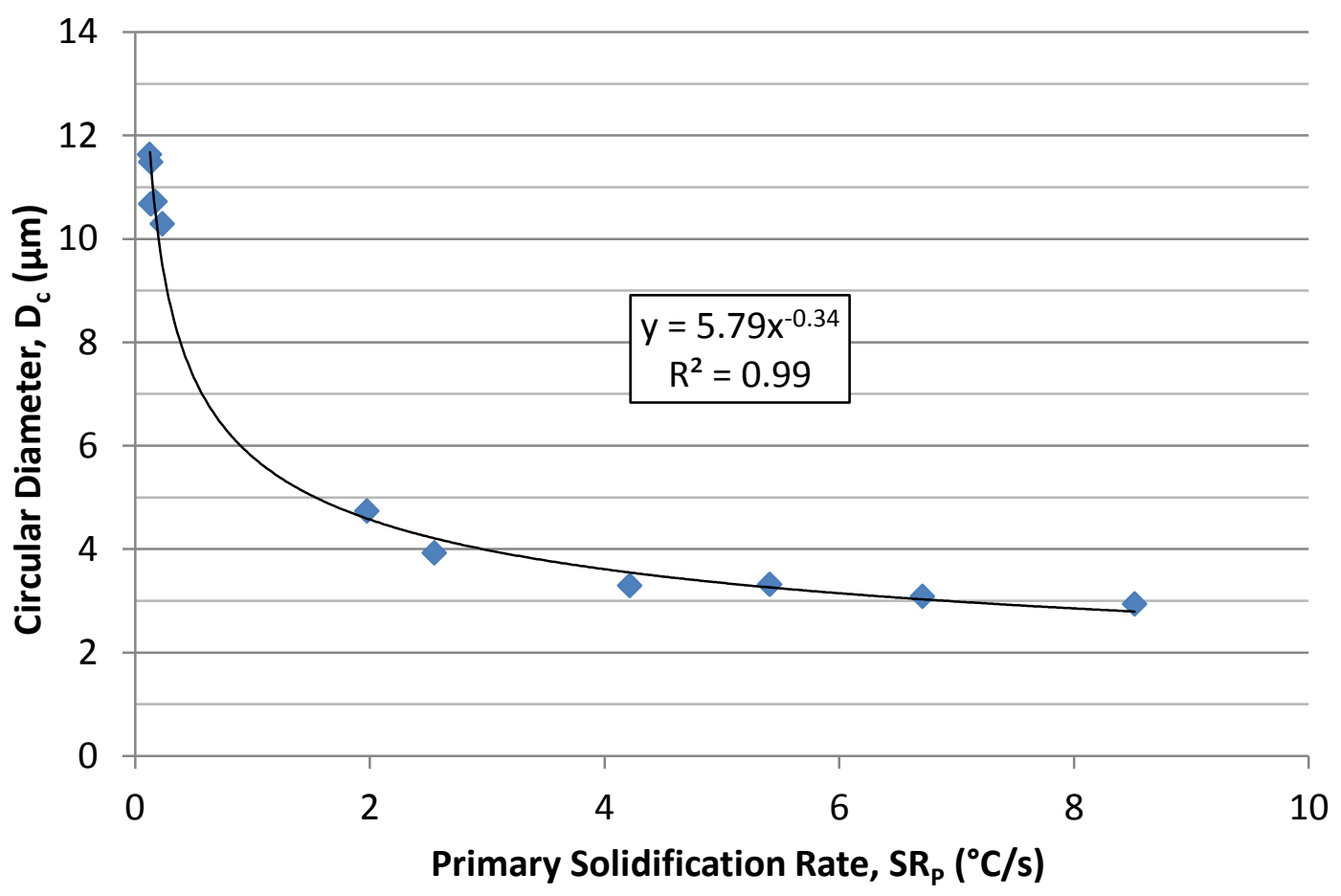

Figure 4-30: Median circular diameter of eutectic Si particles as a function of primary solidification rate 


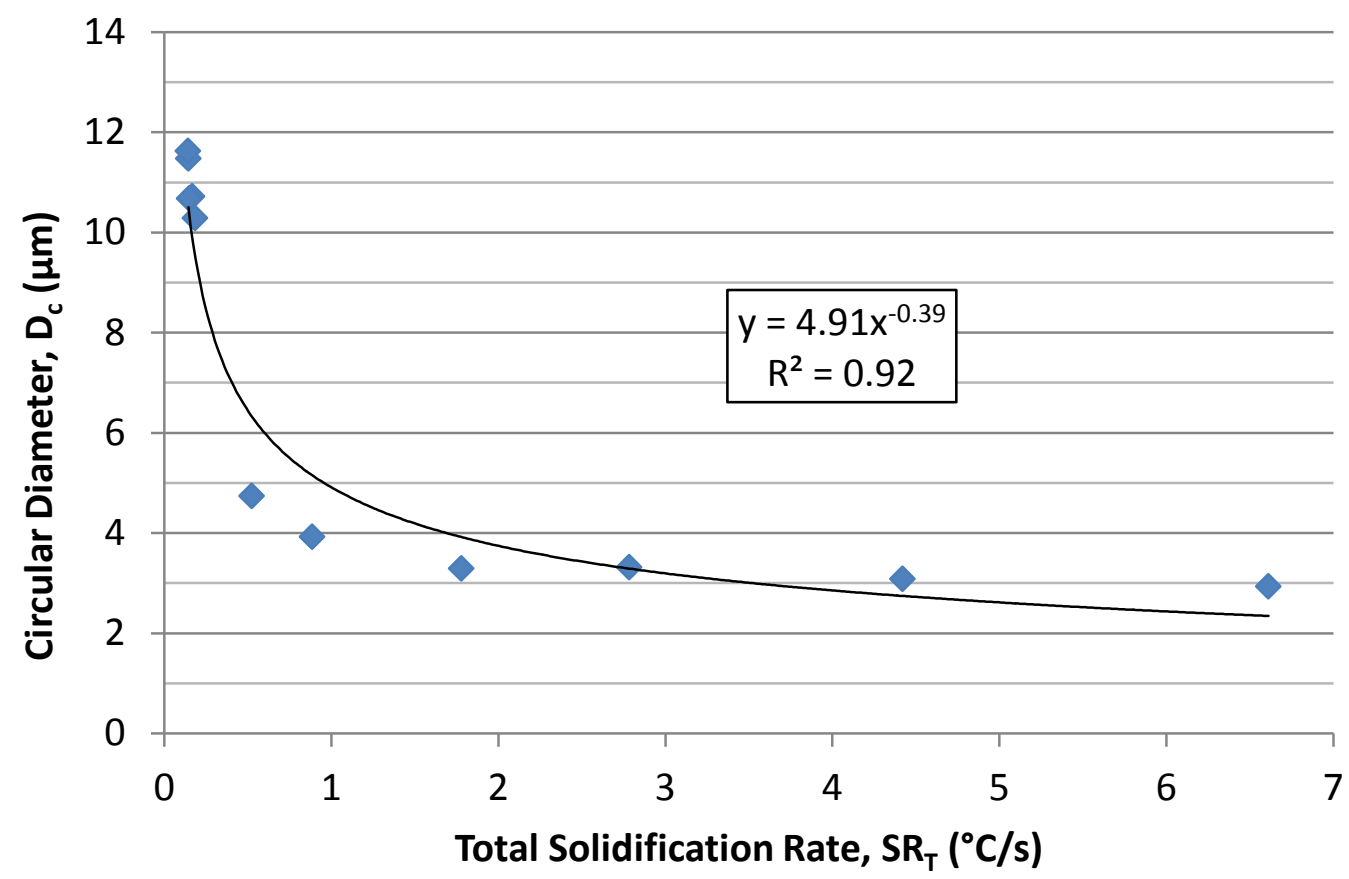

Figure 4-31: Median circular diameter of eutectic Si particles as a function of total solidification rate

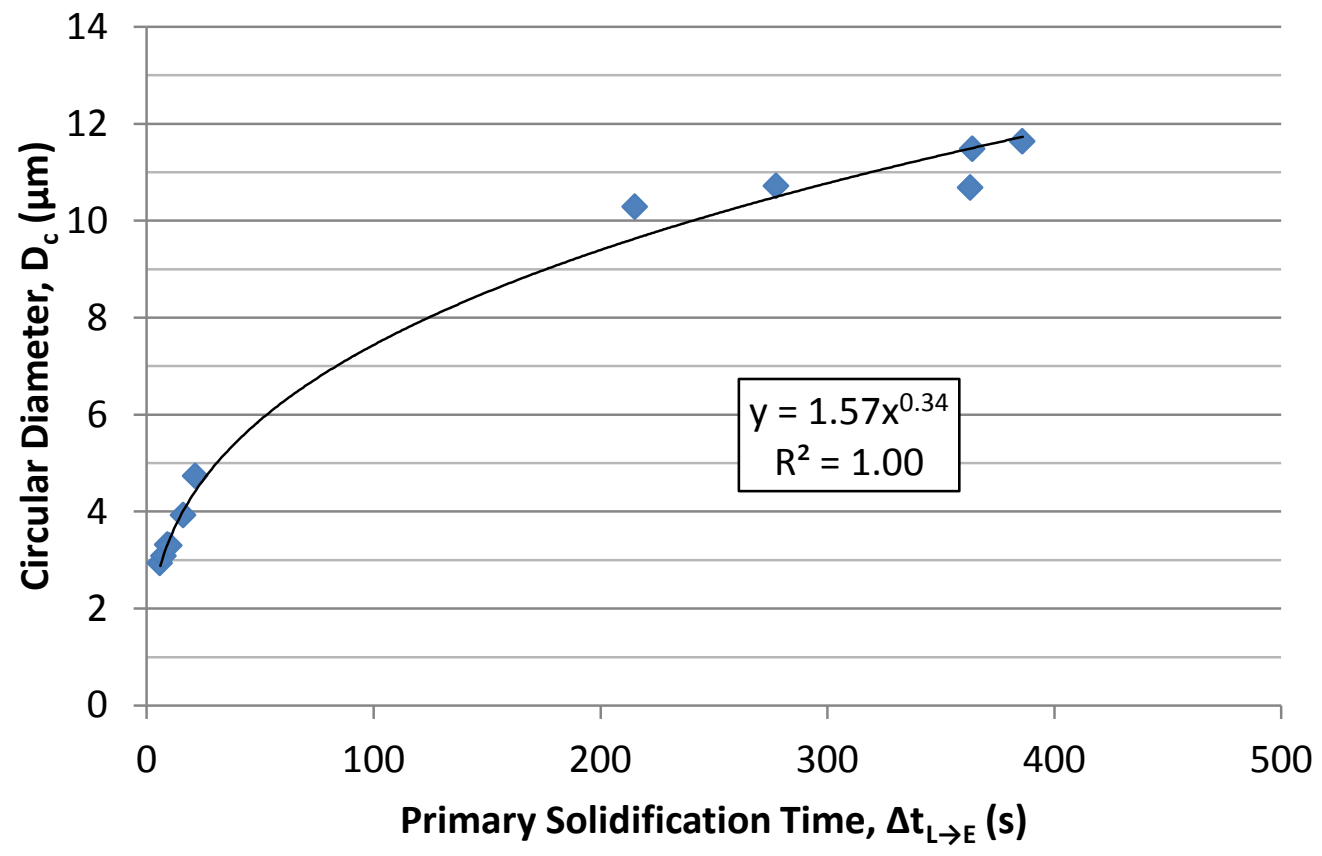

Figure 4-32: Median circular diameter of eutectic Si particles as a function of primary solidification time 


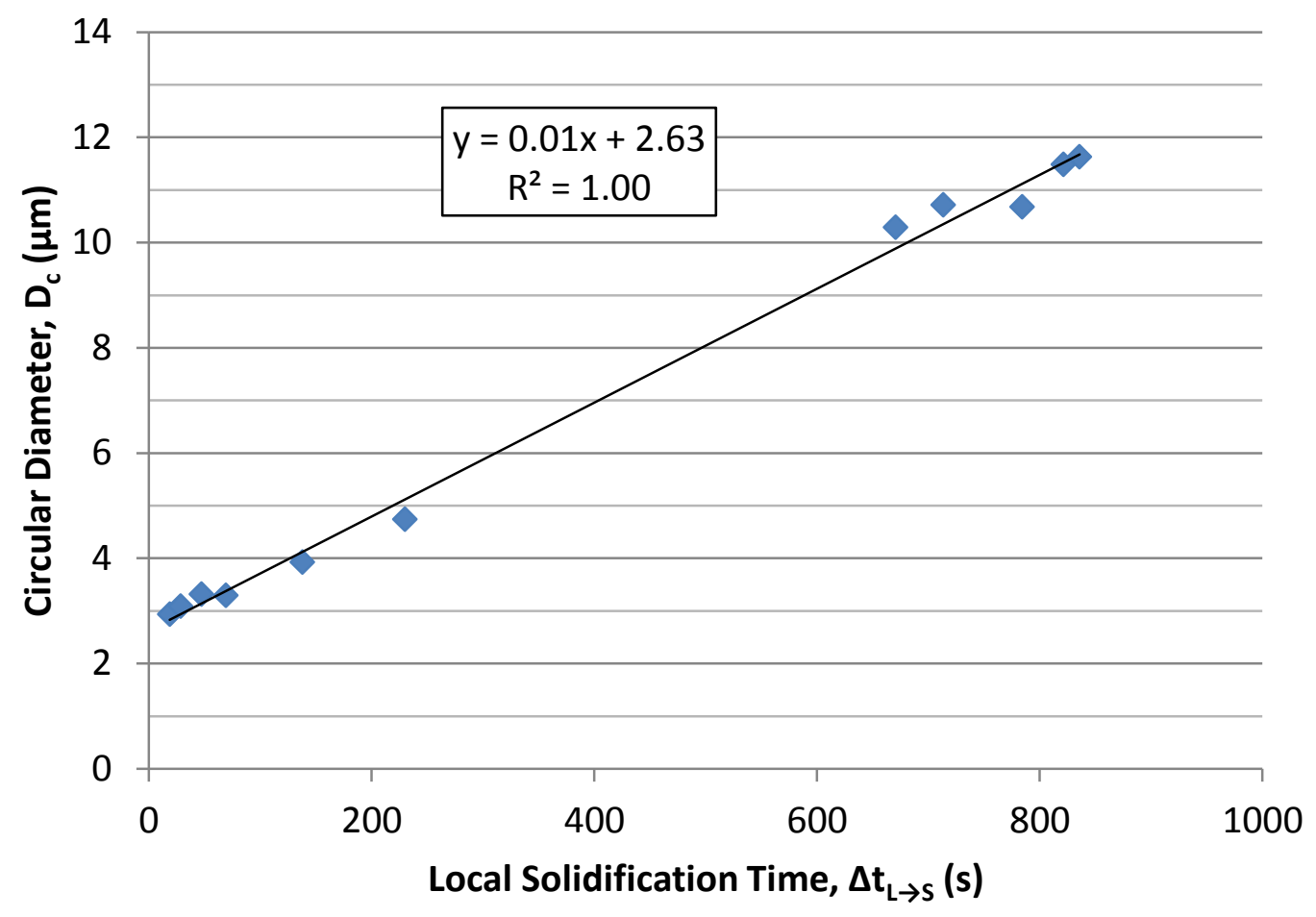

Figure 4-33: Median circular diameter of eutectic Si particles as a function of local solidification time

Similar trends as shown above for circular diameter were also seen for the median perimeter, area, width, and length of the eutectic Si particles. The values for each of the Si particle features for each solidification condition are summarized in Table 4-2. 
Table 4-2: Median values for the eutectic Si particle morphology in each casting condition

\begin{tabular}{|c|c|c|c|c|c|c|c|}
\hline $\begin{array}{c}\text { Initial Mould } \\
\text { Temperature } \\
\left({ }^{\circ} \mathbf{C}\right)\end{array}$ & $\begin{array}{c}\text { Aspect } \\
\text { Ratio }\end{array}$ & Sphericity & $\begin{array}{c}\text { Circular } \\
\text { Diameter } \\
(\boldsymbol{\mu m})\end{array}$ & $\begin{array}{c}\text { Area } \\
\left(\boldsymbol{\mu \mathbf { m } ^ { 2 } )}\right.\end{array}$ & $\begin{array}{c}\text { Length } \\
(\boldsymbol{\mu m})\end{array}$ & $\begin{array}{c}\text { Width } \\
(\boldsymbol{\mu m})\end{array}$ & $\begin{array}{c}\text { Perimeter } \\
(\boldsymbol{\mu m})\end{array}$ \\
\hline 200 & 2.11 & 0.30 & 2.9 & 6.7 & 5.5 & 2.3 & 16.9 \\
\hline 250 & 2.12 & 0.28 & 3.1 & 7.5 & 5.9 & 2.4 & 18.2 \\
\hline 300 & 2.15 & 0.29 & 3.3 & 8.6 & 6.3 & 2.6 & 19.5 \\
\hline 349 & 2.11 & 0.26 & 3.3 & 8.5 & 6.2 & 2.6 & 20.2 \\
\hline 397 & 2.17 & 0.25 & 3.9 & 12.1 & 7.4 & 3.0 & 24.5 \\
\hline 449 & 2.16 & 0.27 & 4.7 & 17.6 & 9.1 & 3.7 & 28.9 \\
\hline 497 & 2.18 & 0.23 & 10.3 & 83.1 & 20.2 & 8.2 & 66.0 \\
\hline 545 & 2.18 & 0.25 & 10.7 & 90.2 & 20.9 & 8.3 & 66.2 \\
\hline 588 & 2.19 & 0.25 & 10.7 & 89.5 & 20.9 & 8.5 & 65.2 \\
\hline 647 & 2.21 & 0.23 & 11.5 & 103.5 & 22.7 & 9.1 & 73.0 \\
\hline 690 & 2.24 & 0.21 & 11.6 & 106.2 & 23.6 & 9.3 & 77.9 \\
\hline
\end{tabular}

\subsubsection{Morphology of Intermetallic Compounds}

Approximately the same area fraction of intermetallic phases containing Fe was present in all casting microstructures, as demonstrated in Figure 4-24, above. As well, the Fe/Mn ratio in all castings was constant at about 1.94. Yet, unlike for Si, Fe-bearing phases were present with two distinctive morphologies and stoichiometries, depending on the solidification rate (Section 2.1.1.4). Figure 4-34 displays a stark transition in the phases for mould temperature range between $497{ }^{\circ} \mathrm{C}$ and $449{ }^{\circ} \mathrm{C}$. For high mould temperatures of $497{ }^{\circ} \mathrm{C}$ and above (primary solidification rates about $0.25{ }^{\circ} \mathrm{C} / \mathrm{s}$ and less), the compact, Chinese-script $\alpha-\mathrm{Al}_{15}(\mathrm{Fe}, \mathrm{Mn})_{3} \mathrm{Si}_{2}$ phase dominated the microstructure. However, for low mould temperatures of $449{ }^{\circ} \mathrm{C}$ and below (primary solidification rates about $2{ }^{\circ} \mathrm{C} / \mathrm{s}$ and greater), at least half of the Fe intermetallics formed as the needle-like $\beta-\mathrm{Al}_{5} \mathrm{FeSi}$ phase. In either case, higher solidification rates were associated with finer phases, similar to eutectic $\mathrm{Si}$. But above or below this critical range $\left(497{ }^{\circ} \mathrm{C}\right.$ to $449{ }^{\circ} \mathrm{C}$ mould temperatures), no gradual transition from $\alpha$ to $\beta$ phase was observed. 
The $\beta$ phase was significantly more evenly-distributed throughout the low mould temperature microstructures than the $\alpha$ phase in the high mould temperature microstructures. This is evidenced by the contrast in area fraction measurement standard deviations displayed in Figure 4-24, above. Furthermore, while the $\alpha$ phase was still present in the low mould temperature range, including for $200{ }^{\circ} \mathrm{C}$, it appeared more blocky and fragmented. This can be attributed to increased diffusion times at slower solidification rates. For high mould temperatures, there is sufficient time for Fe atoms to diffuse and agglomerate into relatively large, compact phases. On the other hand, at low mould temperatures, diffusion is restricted, resulting in the precipitation of smaller, better-dispersed Fe-bearing phases.
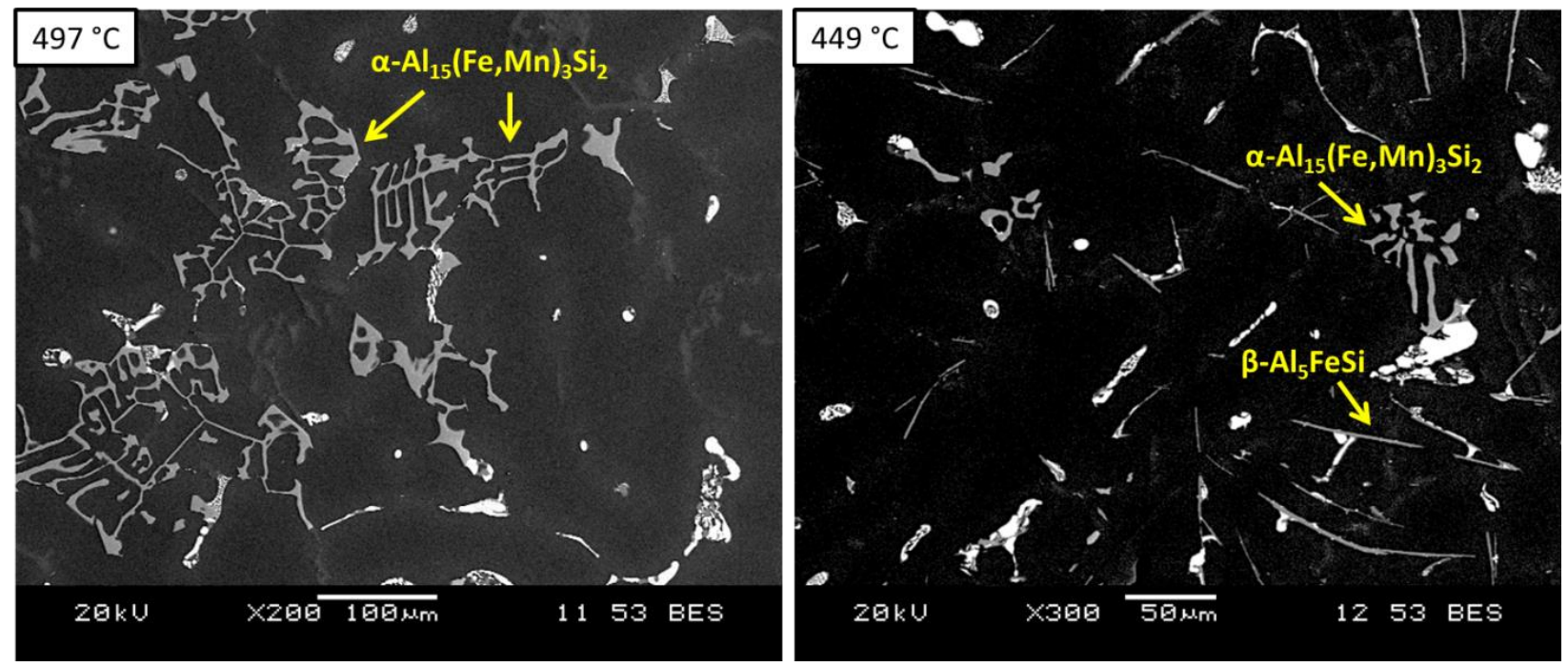

Figure 4-34: Backscattered electron images of Fe-bearing phases for $497{ }^{\circ} \mathrm{C}$ (left, 200x magnification) and $449{ }^{\circ} \mathrm{C}$ (right, 300x magnification) mould temperatures

The $\mathrm{Al}_{2} \mathrm{Cu}$ intermetallic was also present with two distinctive morphologies. As indicated in Figure 4-22, above, both blocky and eutectic $\mathrm{Al}_{2} \mathrm{Cu}$ morphologies were observed in all microstructures, independent of solidification rate. While faster cooling refined the $\mathrm{Al}_{2} \mathrm{Cu}$ particles, regardless of form, it did not noticeably affect the relative amounts of each phase. 


\subsection{Casting Porosity}

Density measurements were used to quantify the casting porosity of all four microscopy samples for each condition. As shown in Figure 4-35 (where error bars represent $\pm \sigma$ for two samples), the porosity levels in the castings with initial mould temperatures up to $449{ }^{\circ} \mathrm{C}$ were similar and relatively low, with values averaging about $1.3 \%( \pm 0.4 \%)$. As well, the porosity levels were relatively uniform in each casting between the middle and side samples. However, at higher mould temperatures, the porosity levels of the side samples increased to an average $2.2 \%$ $( \pm 0.6 \%)$, whereas the middle samples significantly increased to an average $6.9 \%$ with large deviations $( \pm 4.1 \%)$.

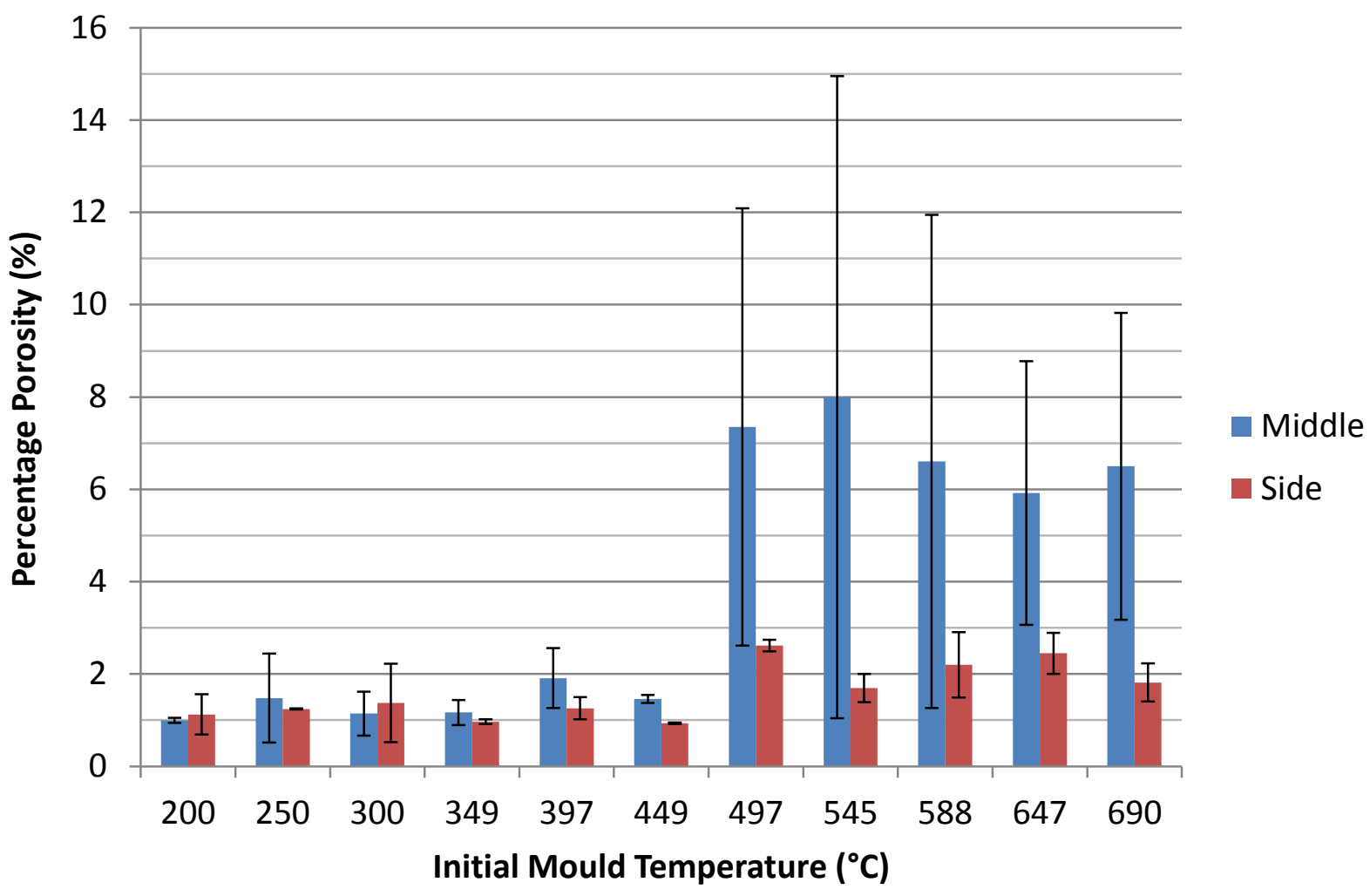

Figure 4-35: Percentage porosity of microscopy samples as a function of casting location and initial mould temperature 
As discussed in Section 2.2.3.1, the coarser dendritic structure of the slower cooling castings reaches dendrite coherency more rapidly, which prevents sufficient mass feeding into the interdendritic regions to compensate for shrinkage of the solidifying dendrites. This results in shrinkage porosity outlining the dendrites, as demonstrated in Figure 4-36. Accordingly, there was much more porosity in the middles of the castings relative to the sides of the castings, since the casting centres are the last locations to solidify. In contrast, optical micrographs revealed little evidence of spherical gas porosity in the samples.

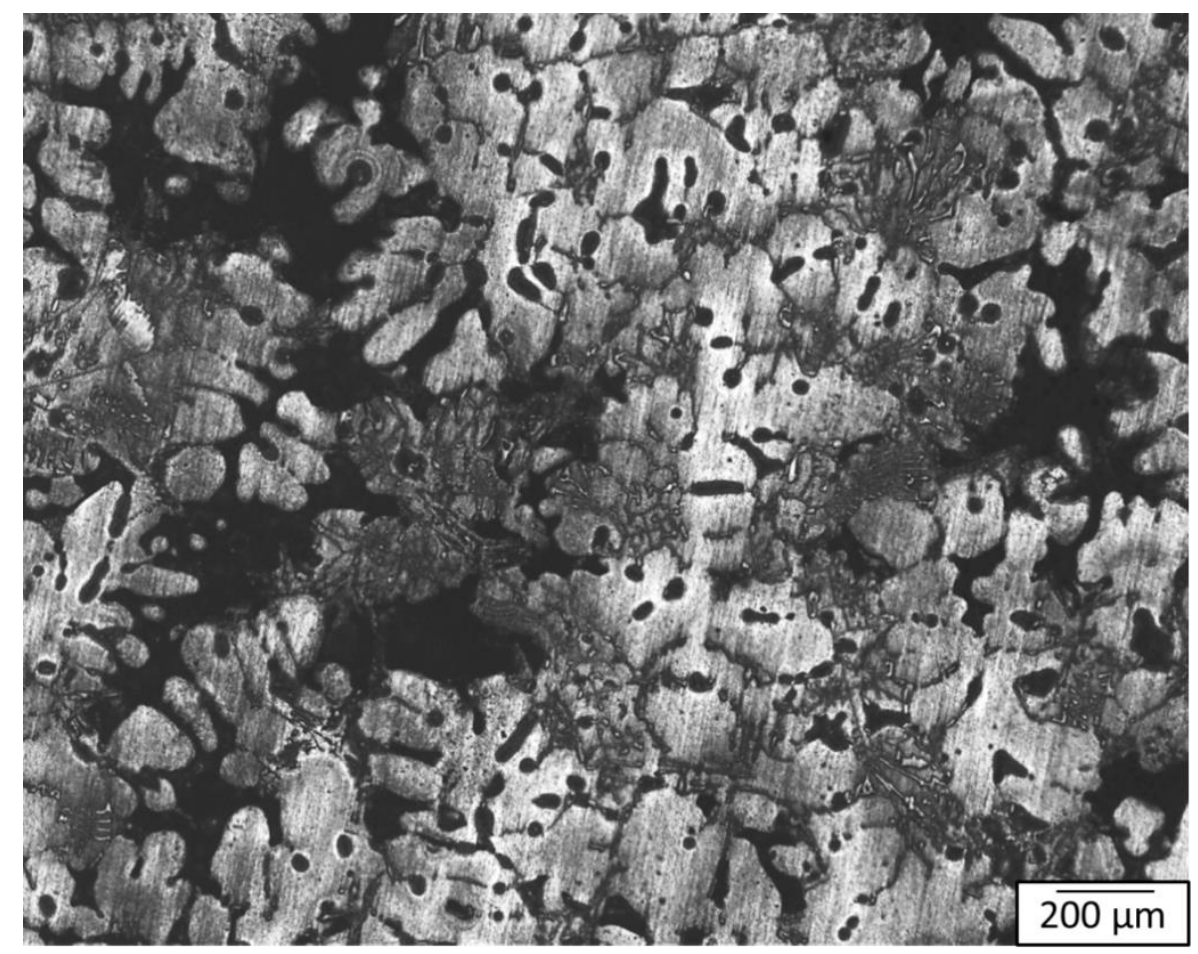

\section{Figure 4-36: Optical micrograph at 50x magnification of interdendritic shrinkage porosity for $690{ }^{\circ} \mathrm{C}$ mould temperature}

On the other hand, porosity in the lower mould temperature range could not readily be resolved by low magnification optical micrographs. However, at higher magnifications, it was found that the microstructures contained tiny microporosity segregated about and within the complex $\mathrm{Al}_{2} \mathrm{Cu}$ eutectic (Figure 4-37 and Figure 4-25, above). This segregation likely occurred given that the 
complex eutectic is the last reaction in the solidification of A319 (Section 2.2.4), and so the last remaining liquid is present about these phases.

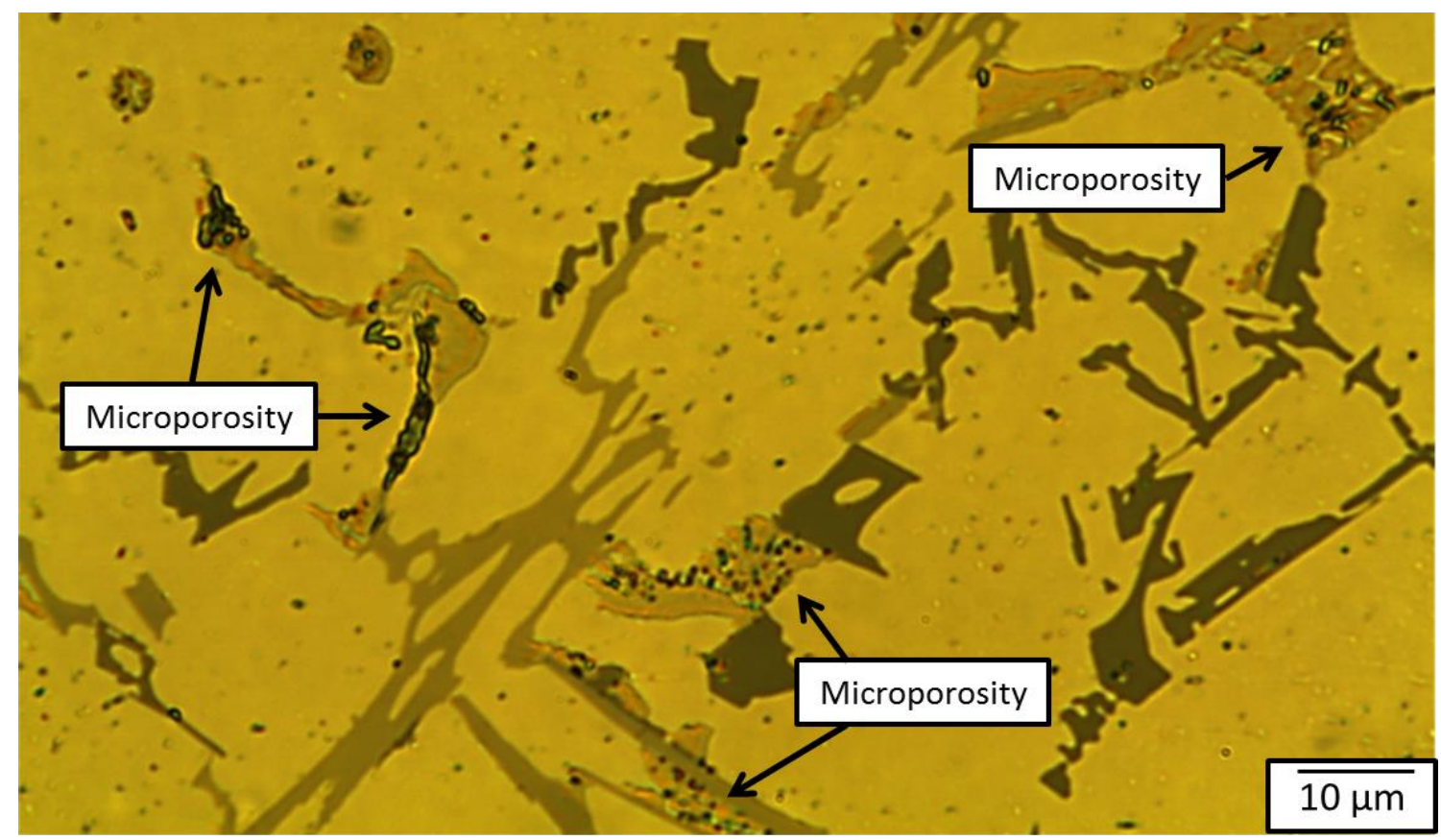

Figure 4-37: Optical micrograph at 1000x magnification of microporosity around the complex $\mathrm{Al}_{2} \mathrm{Cu}$ eutectic for $200{ }^{\circ} \mathrm{C}$ mould temperature

Density and percentage porosity were also evaluated for the two thermal conductivity rods from each casting. Some castings featured a large variance between the two rods, as shown in Figure 4-38. As a result, only one sample was chosen for each casting condition in an effort to keep porosity relatively constant and below $2 \%$ for thermal conductivity measurements. The rods utilized had an average density of $2.75 \mathrm{~g} / \mathrm{cm}^{3}\left( \pm 0.01 \mathrm{~g} / \mathrm{cm}^{3}\right)$ and an average percentage porosity of $1.3 \%( \pm 0.35 \%)$. However, with increasing mould temperature, the rod density decreased slightly but almost linearly from about $2.765 \mathrm{~g} / \mathrm{cm}^{3}$ to $2.740 \mathrm{~g} / \mathrm{cm}^{3}$ (Figure 4-39), and accordingly the rod percentage porosity increased slightly but almost linearly from about $0.8 \%$ to $1.8 \%$ (Figure 4-40). 


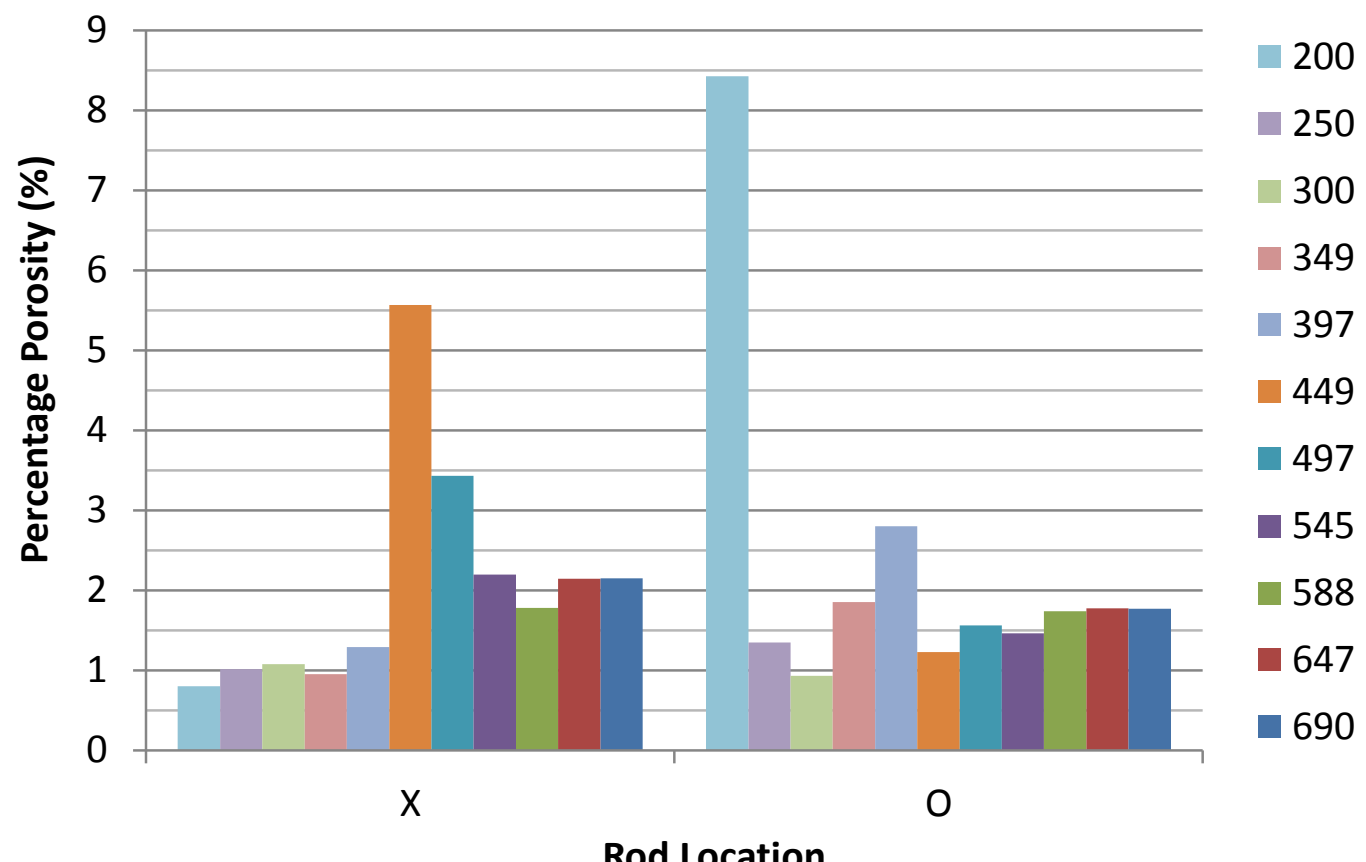

Figure 4-38: Percentage porosity of all thermal conductivity rods as a function of initial mould temperature

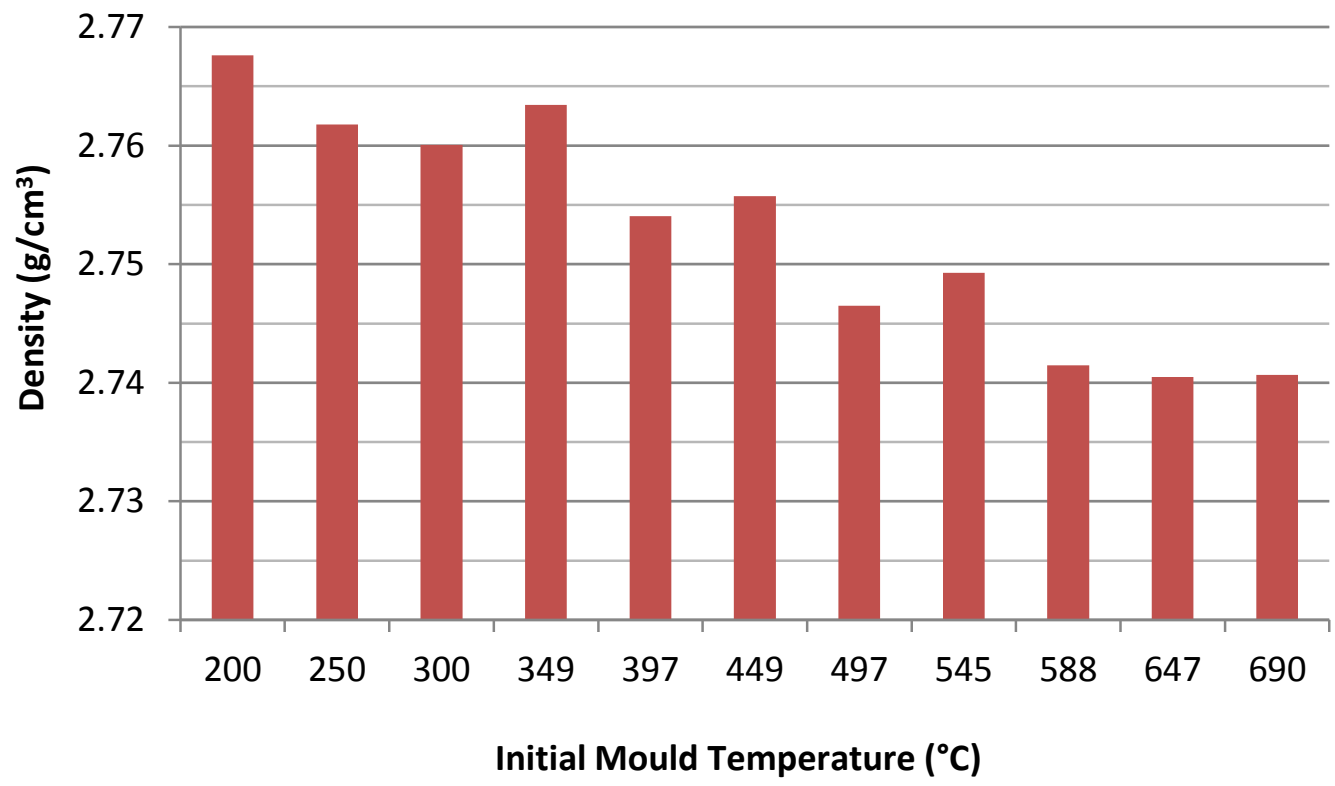

Figure 4-39: Density of selected thermal conductivity rods as a function of initial mould temperature 


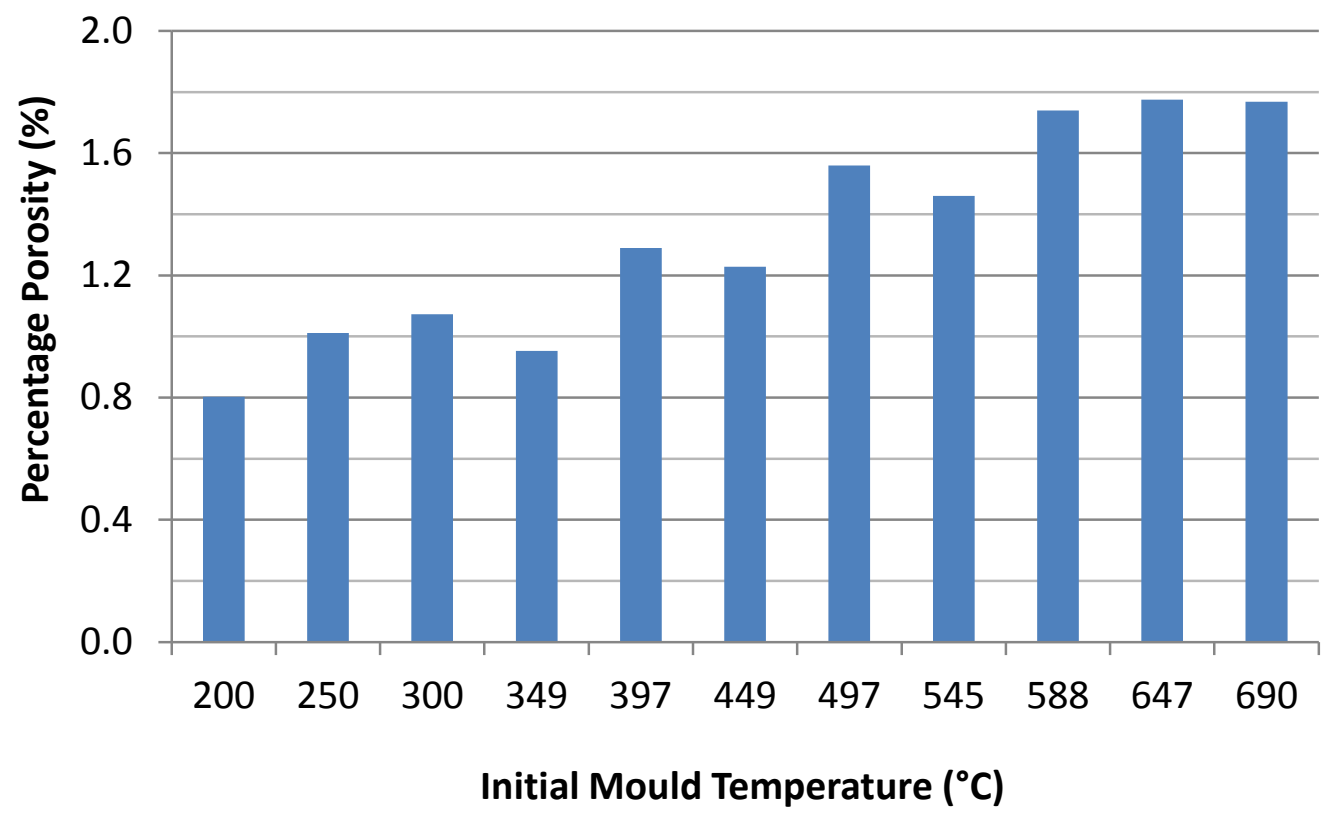

Figure 4-40: Percentage porosity of selected thermal conductivity rods as a function of initial mould temperature

\subsection{Mechanical Properties}

The ultimate tensile strengths of the castings are shown in Figure 4-41, where the error bars represent $\pm \sigma$ for the two tensile bars tested. Tensile strength increased consistently with decreasing initial mould temperature within the entire range of castings. This strengthening corresponds to the refinement of both the dendritic structure and the secondary phases observed at faster solidification rates. As discussed in Section 2.2.3.1, dislocation movement is effectively impeded by a finer dendritic structure, associated with larger grain boundary area, and finer, hard $\mathrm{Al}_{2} \mathrm{Cu}$ particles. As well, a reduction in the size of the acicular Si particles reduces the extent of their harm as stress concentrators, which also improves strength.

However, it is difficult to develop accurate mathematical relationships from the tensile data, due to the presence of high percentages of porosity in castings with high initial mould temperatures. As shown in Figure 4-35, above, there is a significant divide in porosity levels between the castings at low mould temperatures (less than $450{ }^{\circ} \mathrm{C}$ ) and those at high mould temperatures. Moreover, due to the geometrical specifications required for tensile testing, the gauges of the 
tensile bars necessarily correspond to the middles of the castings, where porosity is the most extreme. Porosity is detrimental to mechanical properties, so its influence prevents a true comparison between the high and low mould temperature castings within the context of solidification rate, solidification time, SDAS, or secondary phase morphology.

Additionally, while both Chinese-script $\alpha$ and needle-like $\beta$ Fe-bearing phases are present in the lower mould temperature range, only the former is present at higher mould temperatures. Since the $\beta$ phase is more harmful to mechanical properties (Section 2.1.1.4), this distinction further differentiates the two mould temperature ranges.

Consequently, it is more accurate to confine the development of tensile strength relationships to mould temperatures below $450{ }^{\circ} \mathrm{C}$, where porosity is relatively constant about $1.3 \%$. In this range, ultimate tensile strength increased by almost 30\% from about $210 \mathrm{MPa}$ to $270 \mathrm{MPa}$. This corresponds to about a 50\% reduction in SDAS, and almost a $40 \%$ reduction in median eutectic Si circular diameter. These relationships and those between ultimate tensile strength and the solidification parameters are shown in Appendix D.1.

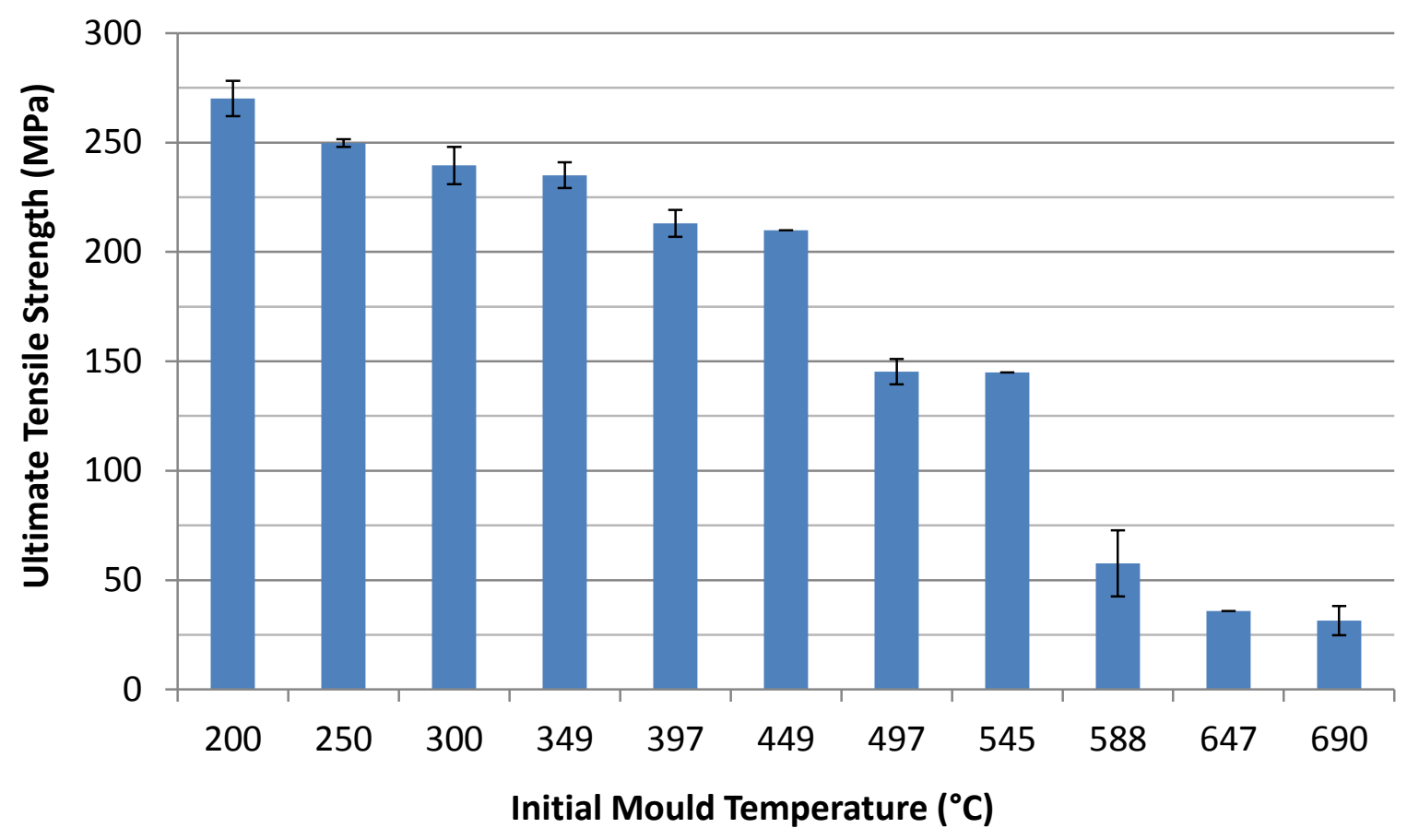

Figure 4-41: Ultimate tensile strength as a function of initial mould temperature 
On the other hand, Rockwell hardness testing was conducted on the side microscopy samples from each casting to alleviate the influence of porosity from the results. Yet, the high mould temperature range of castings still had about $1 \%$ higher porosity, and the low mould temperature range still had the presence of the $\beta$ Fe-bearing phases. As presented in Figure 4-42, hardness increased with a trend similar to a power law up to about $88 \mathrm{HRE}$ for the $200{ }^{\circ} \mathrm{C}$ initial mould temperature. At higher mould temperatures, the hardness appeared almost constant, given the large error bars (representing $\pm \sigma$ for nine measurements per sample). In particular, there was no evident disconnect from $497{ }^{\circ} \mathrm{C}$ to $449{ }^{\circ} \mathrm{C}$ mould temperatures, which separates the two mould temperature ranges. This indicates a balance between softening from the formation of $\beta$ phases with hardening from a finer dendritic structure, finer secondary phases, and slightly lower porosity.

The relationships between Rockwell hardness and the solidification parameters, SDAS, and median eutectic Si circular diameter are shown in Appendix D.2. Despite the value in their trends, the associated equations are presented with relatively low coefficients of determination.

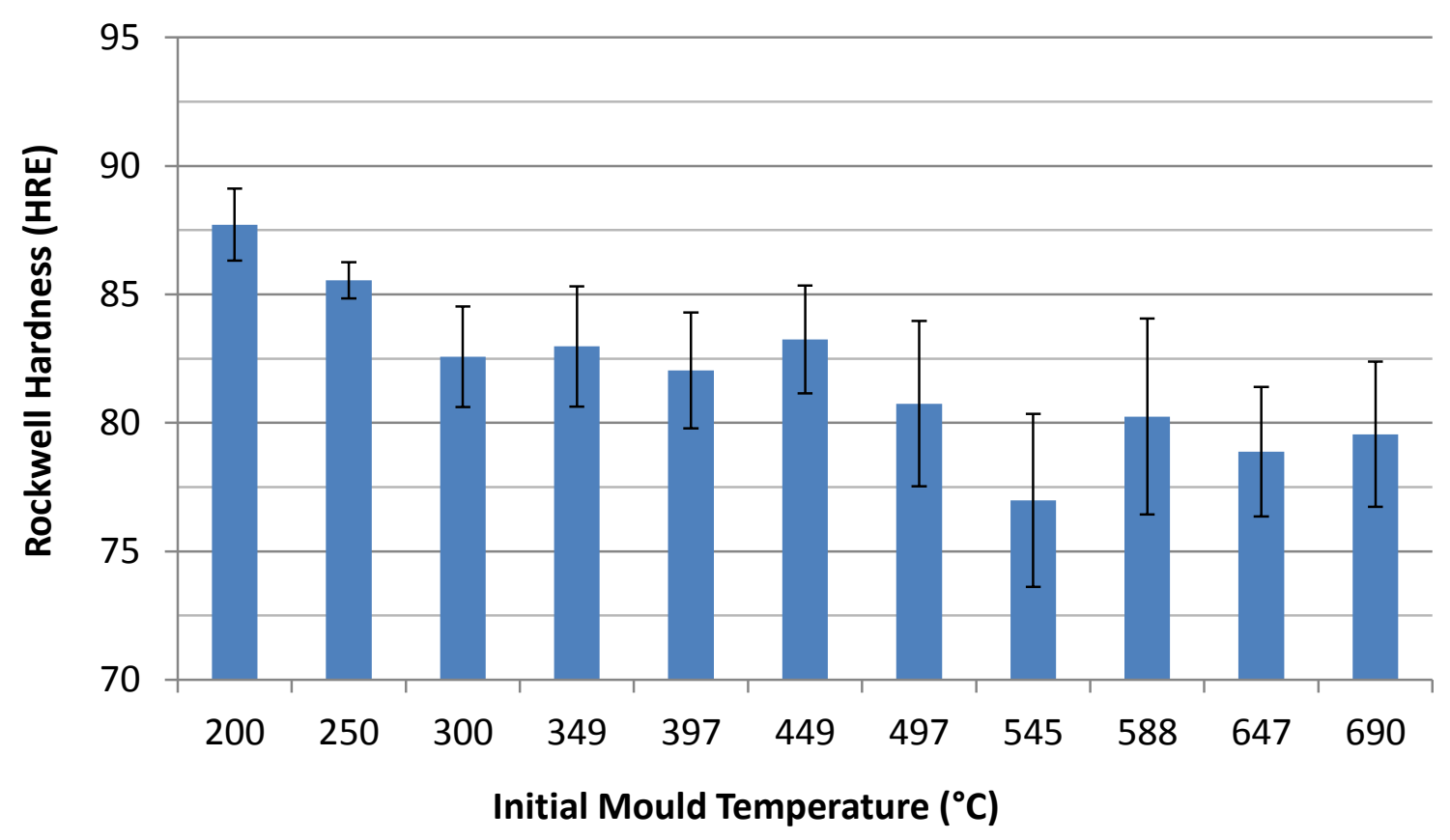

Figure 4-42: Rockwell hardness as a function of initial mould temperature 


\subsection{Thermal Conductivity}

Specific heat was measured on all four microscopy samples per casting, and the average values for the middle and side samples are presented in Figure 4-43 as a function of initial mould temperature (where error bars represent $\pm \sigma$ for two samples). Overall, the specific heat values measured for all samples ranged from about $855 \mathrm{~J} / \mathrm{kg}-\mathrm{K}$ to $885 \mathrm{~J} / \mathrm{kg}-\mathrm{K}$. The accepted specific heat of standard 319 alloy is usually stated in reference databases as $963 \mathrm{~J} / \mathrm{kg}-\mathrm{K}$ at $100{ }^{\circ} \mathrm{C}$ [1]. However, specific heat increases with temperature, and compositional differences between the standard alloy and A319 may account for further deviations [25]. As well, for both casting locations, specific heat steadily decreased as the initial mould temperature increased from $200{ }^{\circ} \mathrm{C}$ to around $449{ }^{\circ} \mathrm{C}$. However, with further increases in mould temperature, specific heat appeared to increase once again, more significantly for the middle samples. This trend corresponds to the findings of Vázquez-López et al. [33]. Furthermore, specific heat was found to be typically higher in the middle samples than in the side samples. This was likely due to the higher porosity levels in the centres of the castings, since greater amounts of energy are required to raise the temperature of a porous medium to compensate for its volume fraction of air.

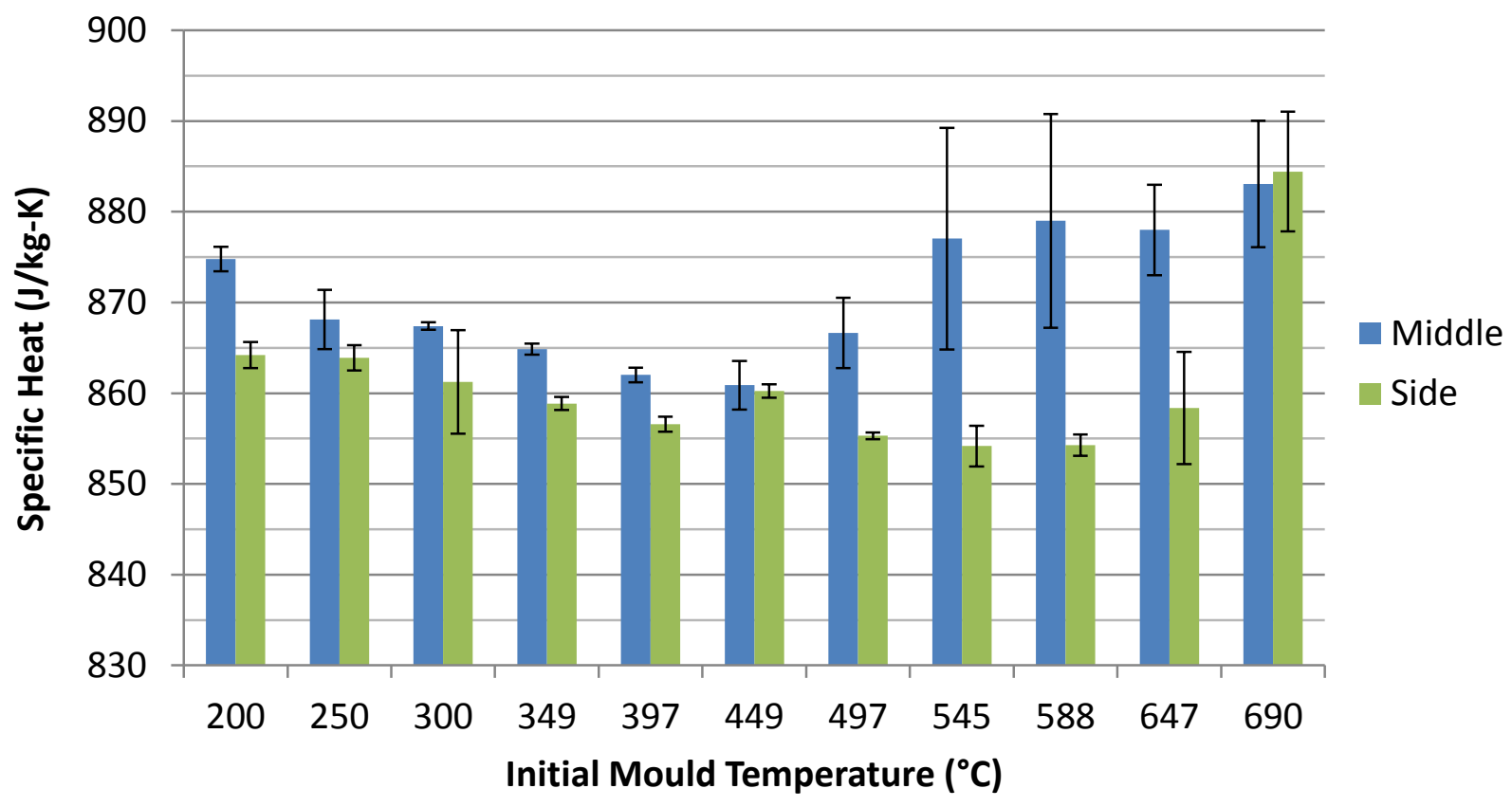

Figure 4-43: Specific heat as a function of casting location and initial mould temperature 
The average volumetric specific heat values for the middle and side samples display a similar trend to that of specific heat as a function of initial mould temperature (Figure 4-44). Yet in this case, the discontinuity in the trend between $449^{\circ} \mathrm{C}$ and $497{ }^{\circ} \mathrm{C}$ is more noticeable. Overall, the volumetric specific heat values measured for all samples ranged from about $2.250 \mathrm{MJ} / \mathrm{m}^{3} \mathrm{~K}$ to about $2.425 \mathrm{MJ} / \mathrm{m}^{3} \mathrm{~K}$. As the product of specific heat and density, volumetric specific heat accounts for porosity differences, and hence the values for the middle and side samples of a given casting were closer than for specific heat. However, in the castings with higher mould temperatures, the middle samples were found to have lower average volumetric specific heats than the respective side samples. Nonetheless, these averages were associated with large standard deviations that mostly overlap with the side samples, corresponding to the large standard deviations in the porosity measurements of the high mould temperature middle samples (Figure 4-35, above).

The average volumetric specific heat values for the side samples were utilized in determining the thermal diffusivity and thermal conductivity of the rods. These values were assumed to be most accurate, given that the measurement surfaces of the side microscopy samples were directly adjacent to the measurement surfaces of the conductivity rods (Figure 3-8, above).

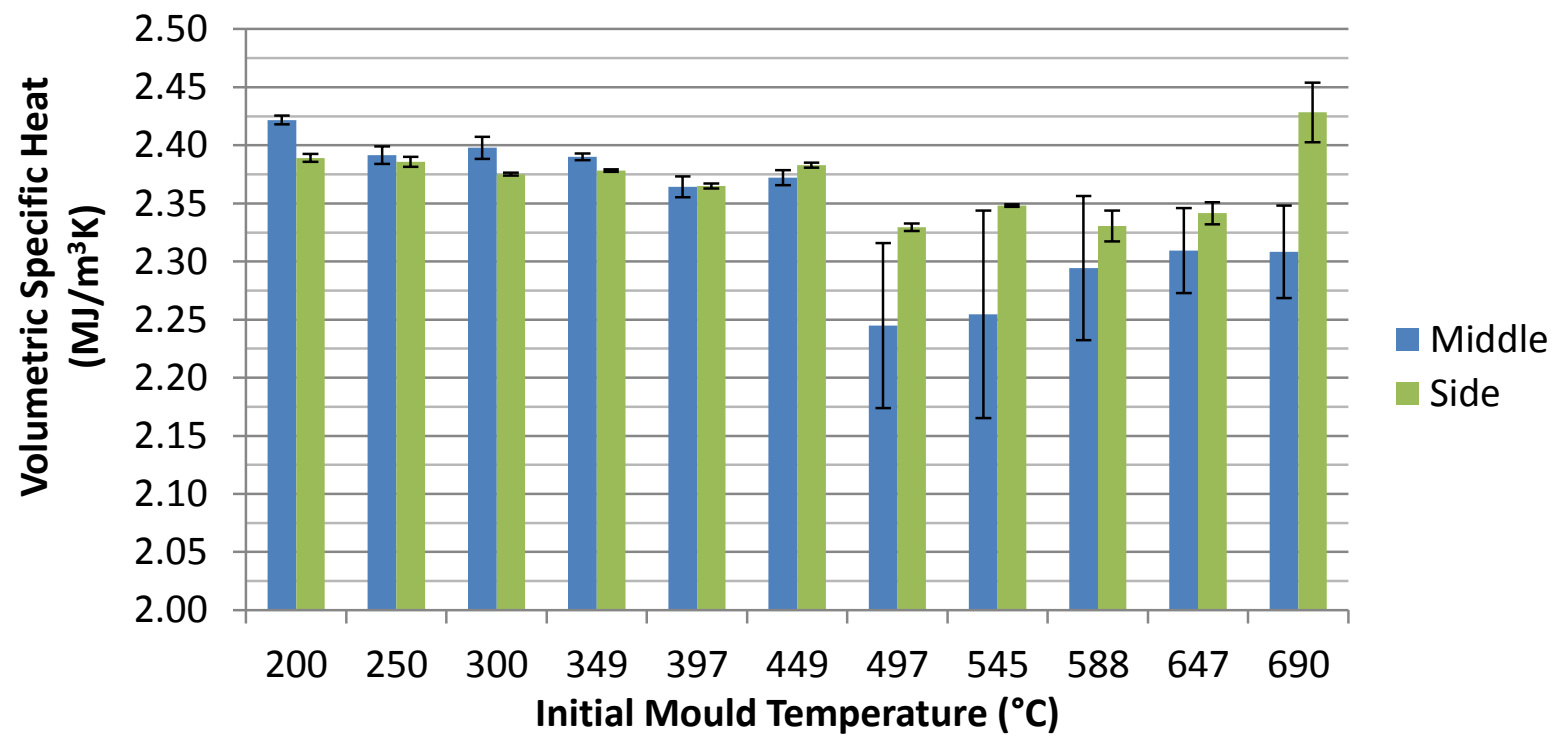

Figure 4-44: Volumetric specific heat as a function of casting location and initial mould temperature 
The resulting thermal diffusivity and thermal conductivity values for each casting condition are presented in Figure 4-45 and Figure 4-46, respectively (where error bars represent $\pm \sigma$ for at least three measurements per sample). In each case, the two thermal properties displayed parabolic behaviours as a function of initial mould temperature. As the initial mould temperature decreased from $690{ }^{\circ} \mathrm{C}$ to $497{ }^{\circ} \mathrm{C}$, diffusivity and conductivity progressively increased to a maximum. However, with further decreases in mould temperature, diffusivity and conductivity steadily decreased to final values slightly lower than those at $690{ }^{\circ} \mathrm{C}$. The values for thermal diffusivity ranged from about $45 \mathrm{~mm}^{2} / \mathrm{s}$ to almost $52 \mathrm{~mm}^{2} / \mathrm{s}$, whereas the values for thermal conductivity ranged from about $108 \mathrm{~W} / \mathrm{m}-\mathrm{K}$ to almost $121 \mathrm{~W} / \mathrm{m}-\mathrm{K}$ for $497{ }^{\circ} \mathrm{C}$ and $200{ }^{\circ} \mathrm{C}$ mould temperatures, respectively. The accepted thermal conductivity of standard 319 alloy is usually stated in reference databases as $109 \mathrm{~W} / \mathrm{m}-\mathrm{K}$ at $25^{\circ} \mathrm{C}$ [1]. While this value is in good agreement with the measured value, the reference value should be used as only a guideline, as it does not consider the influences of cooling rate, porosity, and other process parameters.

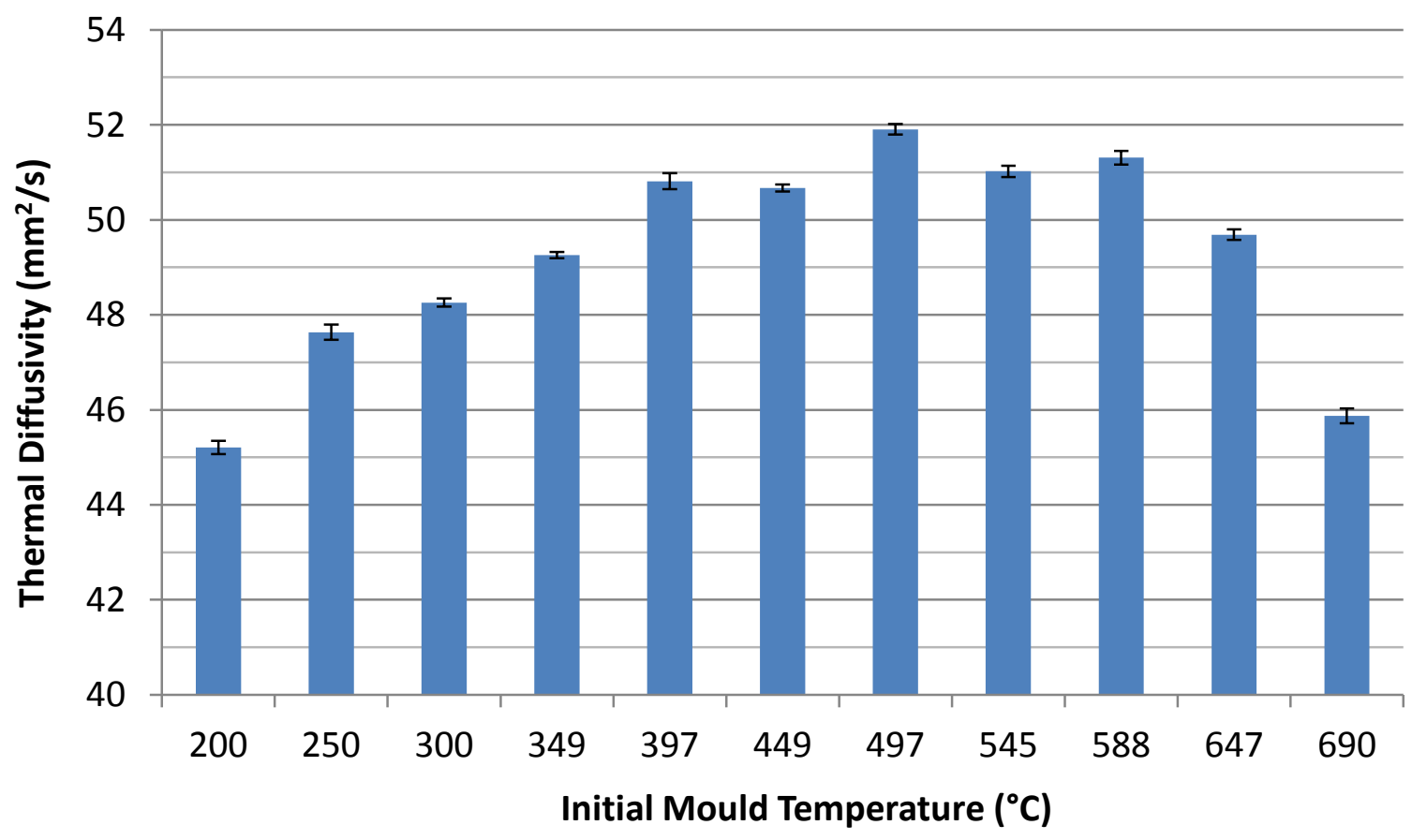

Figure 4-45: Thermal diffusivity as a function of initial mould temperature 


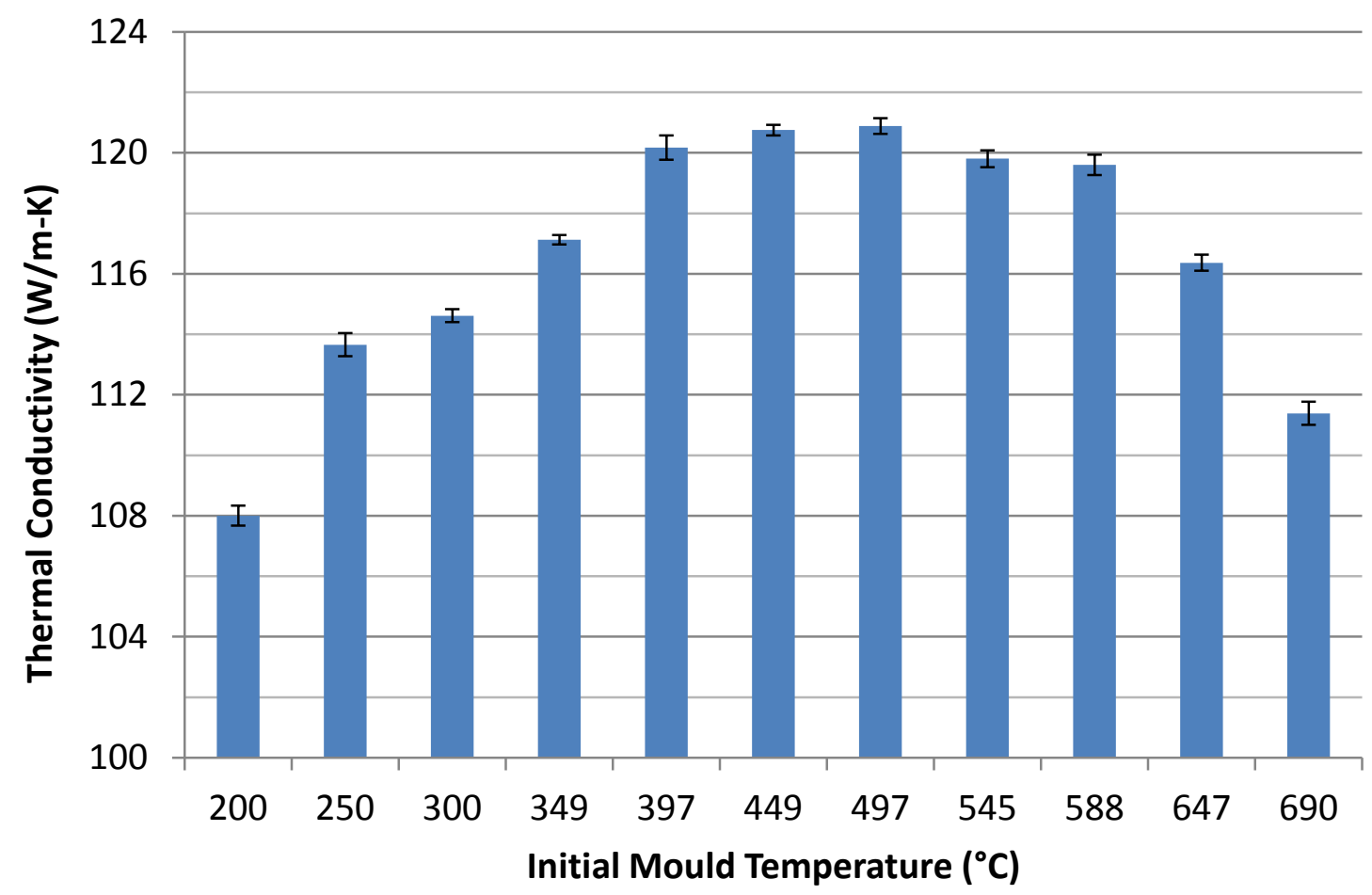

Figure 4-46: Thermal conductivity as a function of initial mould temperature

In Appendix D.3, the thermal conductivity results are plotted as a function of the four solidification parameters, SDAS, and median eutectic Si circular diameter. None of these relationships are easily expressed in an equation, and none of them give evidence to a single factor dominating conductivity. Rather, the parabola-like trend of thermal conductivity is a result of the interaction of multiple competing factors. It has been presented clearly above that decreases in initial mould temperature are associated with increases in primary and total solidification rate and decreases in primary and local solidification time. Also, faster solidification results in a refinement of both the dendritic structure and the secondary phases. Since the area fraction of each phase in the microstructure remains constant, the concentration of dissolved elements in the $\alpha$-Al matrix, and hence its conductivity, can be assumed to be constant. Moreover, the maximum difference in percentage porosity between all the rods is within $1 \%$. While this is not expected to significantly influence the results (Section 2.3.2), it is even less likely that it affected the overall thermal conductivity trend, given that porosity differences between rods from castings with successive mould temperatures are negligible. In the absence of 
compositional differences, the dendritic structure and the morphology of the secondary phases are the only remaining factors that could possibly influence conductivity (Section 2.3).

As discussed in Chapter 2, a refinement in the dendritic structure is associated with increases in grain boundary area, which impedes thermal energy carrier (i.e. electron) flow and reduces thermal conductivity. Yet, this influence is typically negligible in alloys. In contrast, finer secondary phases reduce the probability of carrier collisions, due to the greater number of paths between the phases. This has been observed to effectively improve thermal conductivity. But, based on this, thermal conductivity should continually increase with decreasing mould temperature for all castings.

Consequently, the results of this study provide evidence for another important microstructural consideration. As the primary dendrites decrease in size, the interdendritic regions rich with secondary phases become closer together. Fundamentally, heat transfer is efficient through the conductive $\alpha$-Al dendrites, but are impeded by the secondary phases in the interdendritic regions. Refining the dendritic structure reduces the thermal energy carrier mean free path before colliding with interdendritic phases, thereby reducing thermal conductivity.

Thus, as a result of faster solidification, refinement of the dendritic structure reduces thermal conductivity by decreasing the spacing of interdendritic regions, whereas refinement of the secondary phases improves thermal conductivity by increasing the spacing of secondary particles within the interdendritic regions. While both phenomena are influential within the entire range of solidification conditions, the parabola-like trend of thermal conductivity indicates a transition in the dominant factor:

For the higher initial mould temperature range $\left(690{ }^{\circ} \mathrm{C}\right.$ to $\left.497{ }^{\circ} \mathrm{C}\right)$, the dendrites are very coarse, and so thermal carriers can travel a relatively far distance before reaching an interdendritic regions. As shown in Figure 4-16 above, progressively lower mould temperatures in this range decreases the dendritic size, but not by very much. More importantly, the relative size difference is not very significant when the dendrites are very large. In this case, the refinement in secondary phases is the dominant factor, and the overall thermal conductivity increases with decreasing mould temperature. This process is presented graphically in Figure 4-47. 


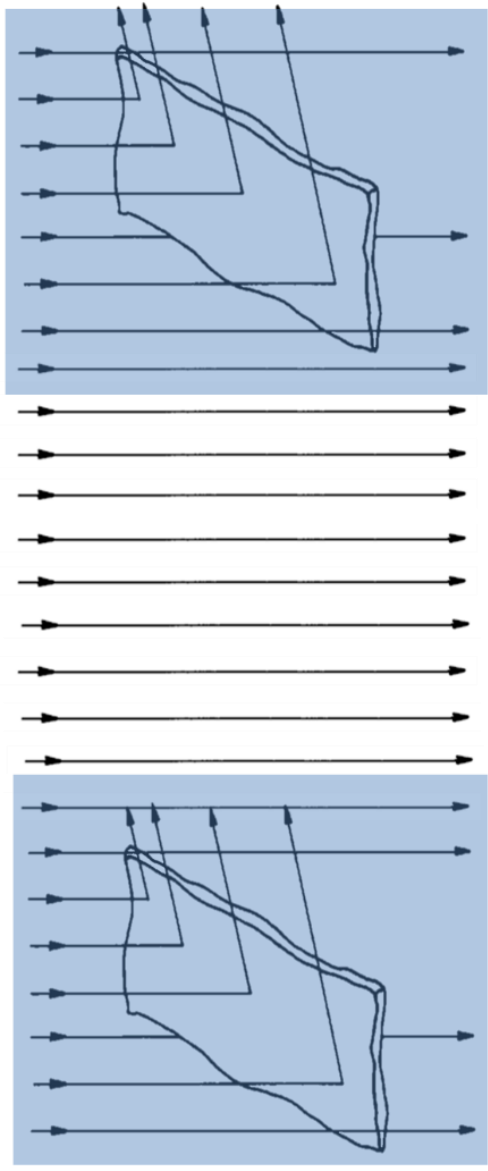

(a)

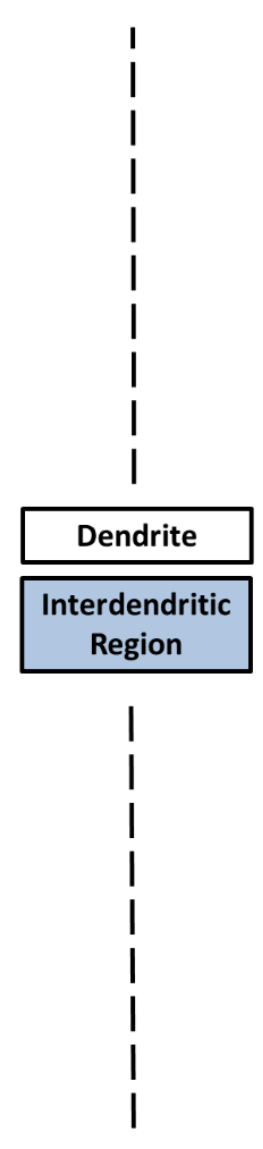

(b)

Figure 4-47: Schematic of heat transfer via electron flow through a dendritic structure with (a) coarse secondary phases and (b) fine secondary phases

On the other hand, for the lower initial mould temperature range $\left(449{ }^{\circ} \mathrm{C}\right.$ to $\left.200{ }^{\circ} \mathrm{C}\right)$, the dendritic structure is finer, and progressively lower mould temperatures causes significant relative dendrite size differences. Still, the secondary phases continue to reduce in size with decreasing mould temperature with a similar slope as for the high mould temperature range (Figure 4-28, above). However, in this range, the benefit of the increased number of flow paths between the phases in the interdendritic regions is negated by the reduction in the mean free path through the dendrites. Hence, the reduction in the spacing between the interdendritic regions is the dominant factor, and the overall thermal conductivity decreases with decreasing mould temperature. This process is presented graphically in Figure 4-48. 


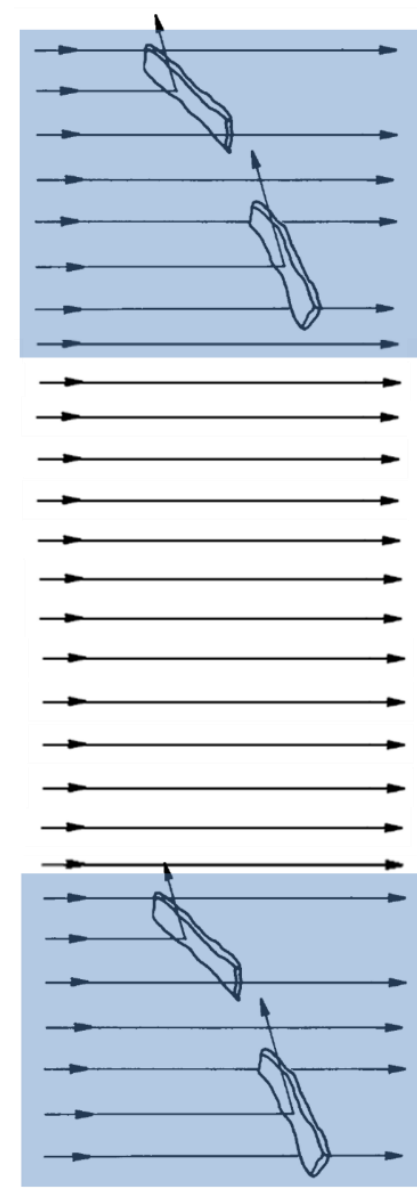

(a)
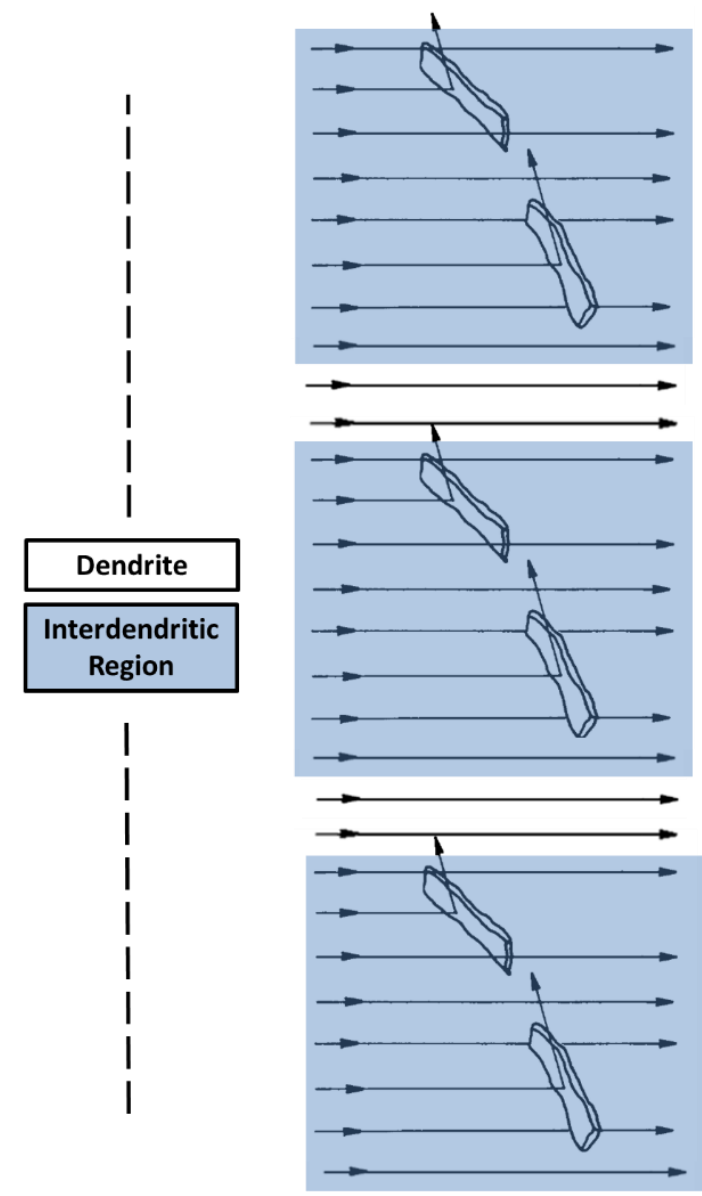

(b)

Figure 4-48: Schematic of heat transfer via electron flow through a dendritic structure with (a) coarse dendrites (b) fine dendrites

Finally, the transition range in initial mould temperature (from $497{ }^{\circ} \mathrm{C}$ to $449^{\circ} \mathrm{C}$ ) is a little more complex. In this range, the most significant absolute decrease was observed for both average SDAS $(79 \mu \mathrm{m}$ to $56 \mu \mathrm{m})$ and median eutectic Si circular diameter (10.3 $\mu \mathrm{m}$ to $4.7 \mu \mathrm{m})$. Given that the thermal conductivity for these two mould temperatures was almost identical at $121 \mathrm{~W} / \mathrm{m}-\mathrm{K}$, it appears that there is a perfect balance of the two predominant competing phenomena. Nonetheless, this explanation does not account for the change in Fe-bearing phases to include the $\beta$ phase at the $449{ }^{\circ} \mathrm{C}$ mould temperature. Since all phases were similarly refined with decreasing mould temperature, but the relative amounts of either the Chinese-script $\alpha$ phase 
or the needle-like $\beta$ phase were relatively constant in either the higher or lower mould temperature ranges, the change does not detract from the thermal conductivity mechanisms proposed. Yet, further research is required to determine the influence of the differing Fe-bearing phases on the transition mould temperature range. 


\section{Chapter 5: CONCLUSIONS}

This study systematically investigated the influence of solidification on the thermal conductivity of A319 aluminum alloy over a wide range of solidification rates. Direct correlations between four solidification parameters, microstructure, porosity, mechanical properties, and thermal conductivity were developed. This analysis contributed to the developed theory of thermal conductivity, with quantitative data supporting a novel perspective of two dominating factors related to solidification. Furthermore, it was determined that there is a critical solidification condition to attain the maximum thermal conductivity in A319 alloy, and it did not coincide with the condition for maximum mechanical properties. Even though tangible changes in both mechanical and thermal properties can be realized through manipulation of solidification, their respective improvements are achieved through different mechanisms. Therefore, it is important to optimize the solidification parameters to produce aluminum castings that combine high strength and high thermal conductivity. This will enable the manufacture of lightweight powertrain components with enhanced properties that are subjected to reduced thermal stresses and allow for higher operating temperatures, promoting better fuel efficiency and conservation of the environment.

The following major conclusions can be drawn from this research:

1. Decreasing the initial mould preheating temperature resulted in an increase in primary and total solidification rate and a decrease in primary and local solidification time. However, the solidification parameters did not noticeably affect the temperatures of the liquidus, Al-Si eutectic, and solidus points.

2. By comparing the experimental and simulated cooling curves, the convective heat transfer coefficient between the A319 alloy and the H13 permanent mould was estimated to be approximately $6000 \mathrm{~W} / \mathrm{m}^{2} \mathrm{~K}$.

3. Increasing solidification rate (or decreasing solidification time) resulted in a decrease in average SDAS. This relationship is captured most clearly by local solidification time, for which the trend is linear.

4. The solidification parameters did not affect the area fraction of any secondary phases. 
5. Increasing solidification rate (or decreasing solidification time) resulted in a refinement of the eutectic Si phases, but no significant change in their aspect ratio or sphericity. This relationship is captured most clearly between median eutectic Si circular diameter and local solidification time, for which the trend is linear.

6. Increasing solidification rate (or decreasing solidification time) resulted in a refinement of both the eutectic and blocky morphologies of $\mathrm{Al}_{2} \mathrm{Cu}$. However, no change in the relative amounts of either phase was noticeable.

7. The Fe/Mn ratio for all castings was 1.94 . For primary solidification rates about 0.25 ${ }^{\circ} \mathrm{C} / \mathrm{s}$ and less, the compact, Chinese-script $\alpha-\mathrm{Al}_{15}(\mathrm{Fe}, \mathrm{Mn})_{3} \mathrm{Si}_{2}$ phase dominated the microstructure. However, for primary solidification rates about $2{ }^{\circ} \mathrm{C} / \mathrm{s}$ and greater, at least half of the $\mathrm{Fe}$ intermetallics formed as the needle-like $\beta-\mathrm{Al}_{5} \mathrm{FeSi}$ phase. The remaining $\alpha$ phase appeared more blocky and fragmented, attributed to reduced diffusion rates. In either case, increasing solidification rate (or decreasing solidification time) resulted in a refinement of the Fe-bearing phases. No gradual transition from $\alpha$ to $\beta$ phase was observed.

8. There were high percentages of interdendritic shrinkage porosity in the slow solidifying castings (primary solidification rates about $0.25^{\circ} \mathrm{C} / \mathrm{s}$ and less), most significantly in the centres of the castings. In contrast, the percentage porosity in the fast solidifying castings (primary solidification rates about $2{ }^{\circ} \mathrm{C} / \mathrm{s}$ and greater) was relatively low and evenly distributed, and it was found to be predominantly the result of microporosity segregated to the complex $\mathrm{Al}_{2} \mathrm{Cu}$ eutectic regions. In either range of solidification rates, percentage porosity was unaffected by a change in solidification parameters.

9. Both ultimate tensile strength and Rockwell hardness improved with increasing solidification rate (or decreasing solidification time). This was attributed to the impediment of dislocation movement achieved by a finer dendritic structure, which is associated with greater grain boundary area, and a refinement of the hard $\mathrm{Al}_{2} \mathrm{Cu}$ particles. As well, a reduction in size of the acicular eutectic Si particles reduces their harm as stress concentrators.

10. Increasing solidification rate (or decreasing solidification time) resulted in decreases in specific heat to a minimum around a $2{ }^{\circ} \mathrm{C} / \mathrm{s}$ primary solidification rate, followed by increases. As well, specific heat increased with percentage porosity. 
11. For primary solidification rates about $0.25{ }^{\circ} \mathrm{C} / \mathrm{s}$ and less, thermal conductivity was found to steadily increase with increasing solidification rate (or decreasing solidification time) up to a maximum value. Then for primary solidification rates about $2{ }^{\circ} \mathrm{C} / \mathrm{s}$ and greater, thermal conductivity was found to steadily decrease with increasing solidification rate (or decreasing solidification time) to a minimum value. This was attributed to the balance of two competing phenomena. First, the refinement of secondary phases improves conductivity by decreasing the probability of thermal energy carriers colliding with the phases. Second, and novel to this research, it was suggested that refinement of the dendritic structure reduces conductivity by decreasing the spacing of the interdendritic regions. This corresponds to a reduction of the thermal energy carrier mean free path through the conductive dendrite before possible collisions with interdendritic phases. Consequently, for relatively coarse dendrites, conductivity increased with increasing solidification rate, since the influence of the secondary phase refinement was more significant than that of the dendritic refinement. In contrast, for relatively fine dendrites, conductivity decreased with increasing solidification rate, since the influence of the dendritic refinement was more significant than that of the secondary phase refinement.

12. By comparing the minimum and maximum measured values in the studied range, manipulating the solidification conditions alone can produce up to $12 \%$ improvements in thermal conductivity for this alloy. 


\section{Chapter 6: RECOMMENDATIONS FOR FUTURE WORK}

This thesis gives evidence to the complex and competing phenomena influencing thermal conductivity in A319 aluminum alloy. Future experiments and analysis are recommended to further enhance the current knowledge of the metallurgical factors affecting thermal conductivity, specifically with regard to the typical process parameters utilized in the automotive industry. Some recommendations include:

1. Thermal conductivity measurements of A319 castings with the same range of solidification rates as in the present study, but with slightly increased Mn additions to completely suppress the $\beta-\mathrm{Al}_{5} \mathrm{FeSi}$ for the entire range. This would remove the change in Fe-bearing phase morphology as a variable.

2. Hot isostatic pressing (HIP) A319 samples cast at various solidification rates to remove porosity as a variable for more accurate thermal conductivity values.

3. Investigation of the effect of chemical grain refinement on thermal conductivity of A319.

4. Development of a specific relationship between thermal and electrical conductivity for A319 in between room temperature and its solidus temperature.

5. Investigation of the effect of eutectic $\mathrm{Si}$ modification via $\mathrm{Sr}$ additions on thermal conductivity of A319 for varying solidification rates.

6. In-situ evaluation of the influence of solution heat treatment times and temperatures on A319 thermal conductivity.

7. In-situ evaluation of the influence of aging heat treatment times and temperatures on A319 thermal conductivity.

8. Comprehensive study of the interactions of solidification rate, eutectic Si modification, and heat treatment of $\mathrm{A} 319$, and the determination of their combined influence on thermal conductivity. 


\section{APPENDIX A: AL-SI-CU TERNARY PHASE DIAGRAM}

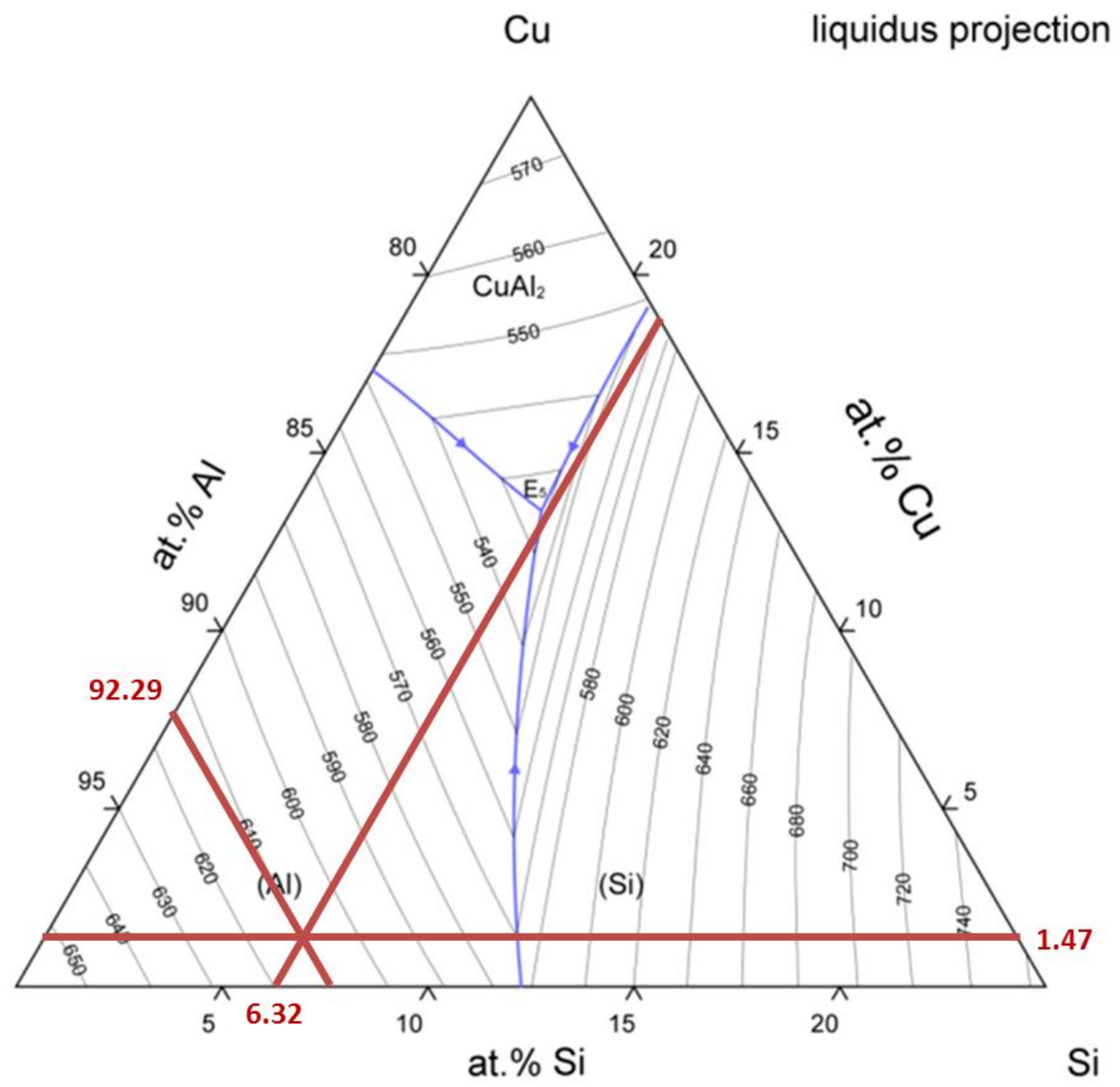

Figure A-1: Aluminum-silicon-copper ternary phase diagram (liquidus projection) [43] 


\section{APPENDIX B: ENGINEERING DRAWINGS}

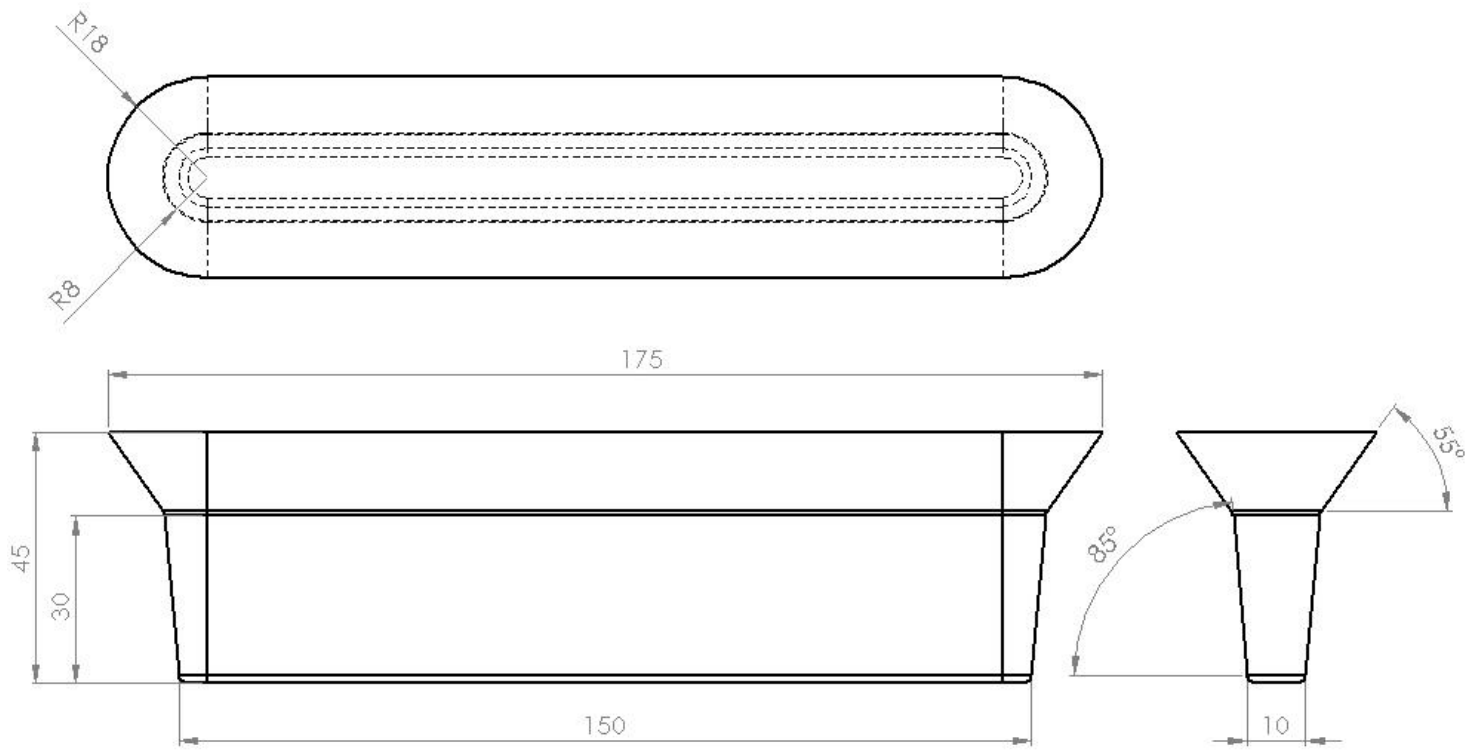

Figure B-1: Casting geometry (units in mm)
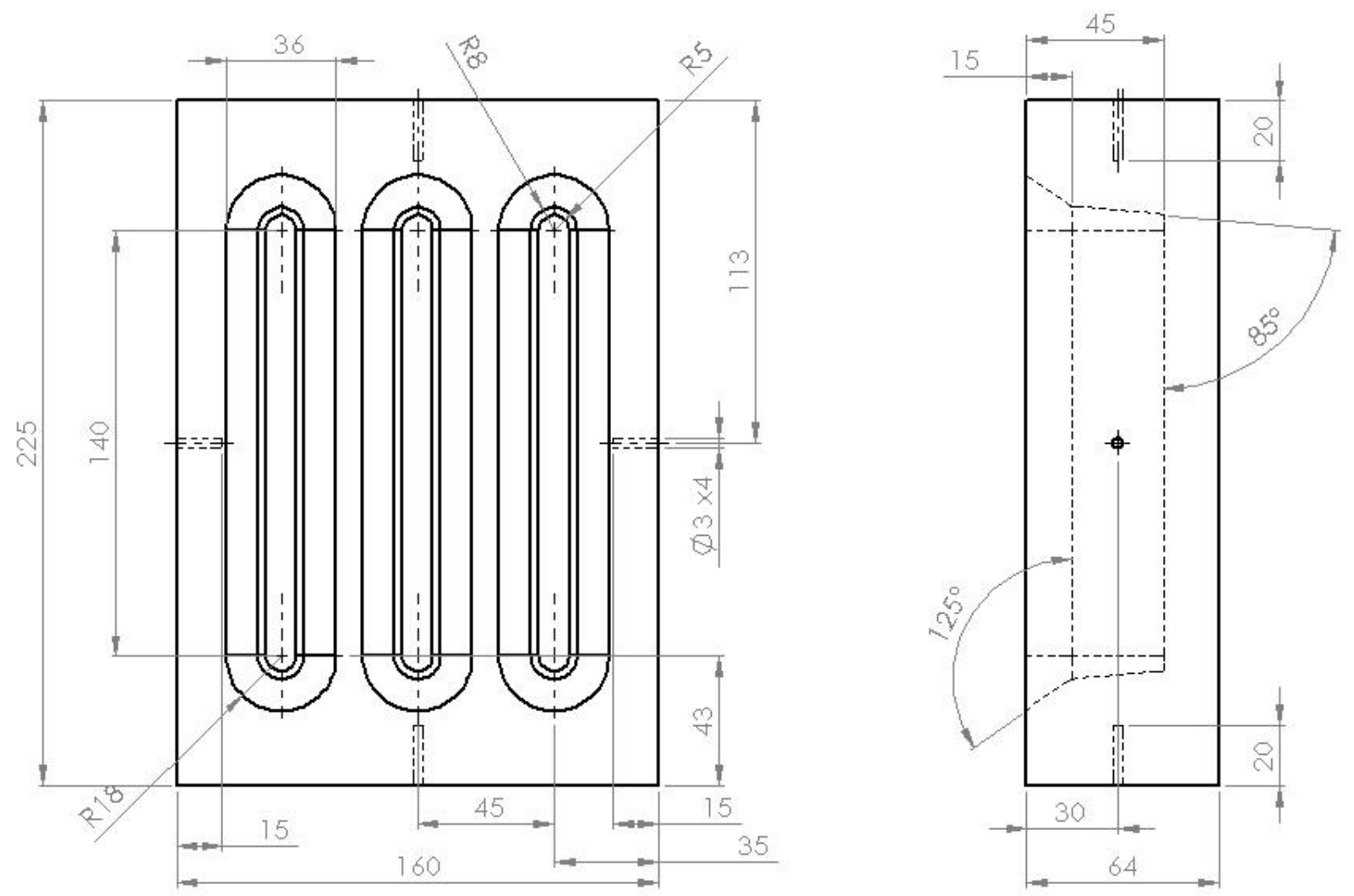

Figure B-2: Permanent mould geometry, omitting $1.6 \mathrm{~mm}$ radius fillets on all internal corners for clarity (units in $\mathbf{~ m m}$ ) 


\section{APPENDIX C: COOLING CURVES}

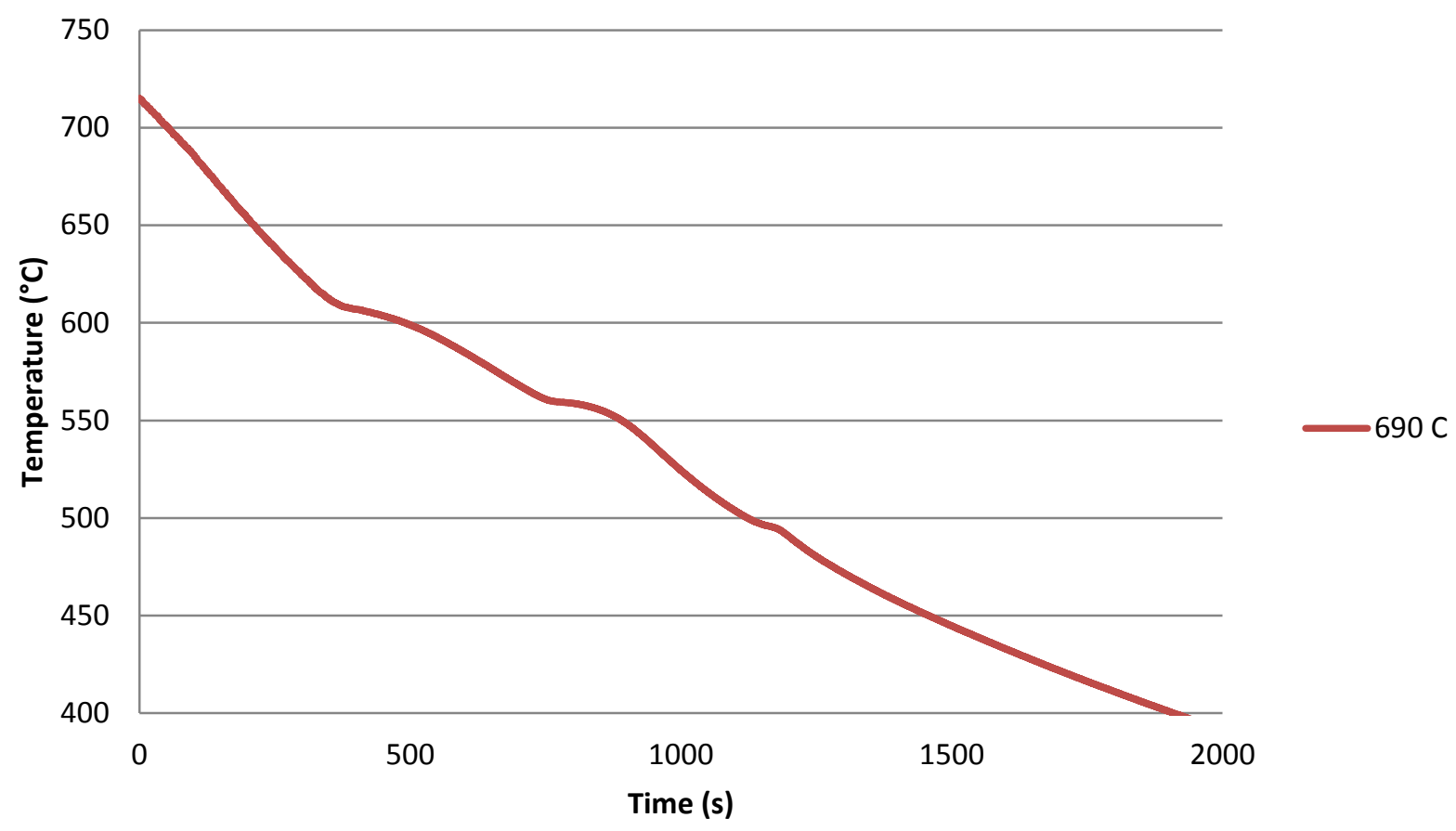

Figure C-1: A319 alloy cooling curve for $690{ }^{\circ} \mathrm{C}$ initial mould temperature 


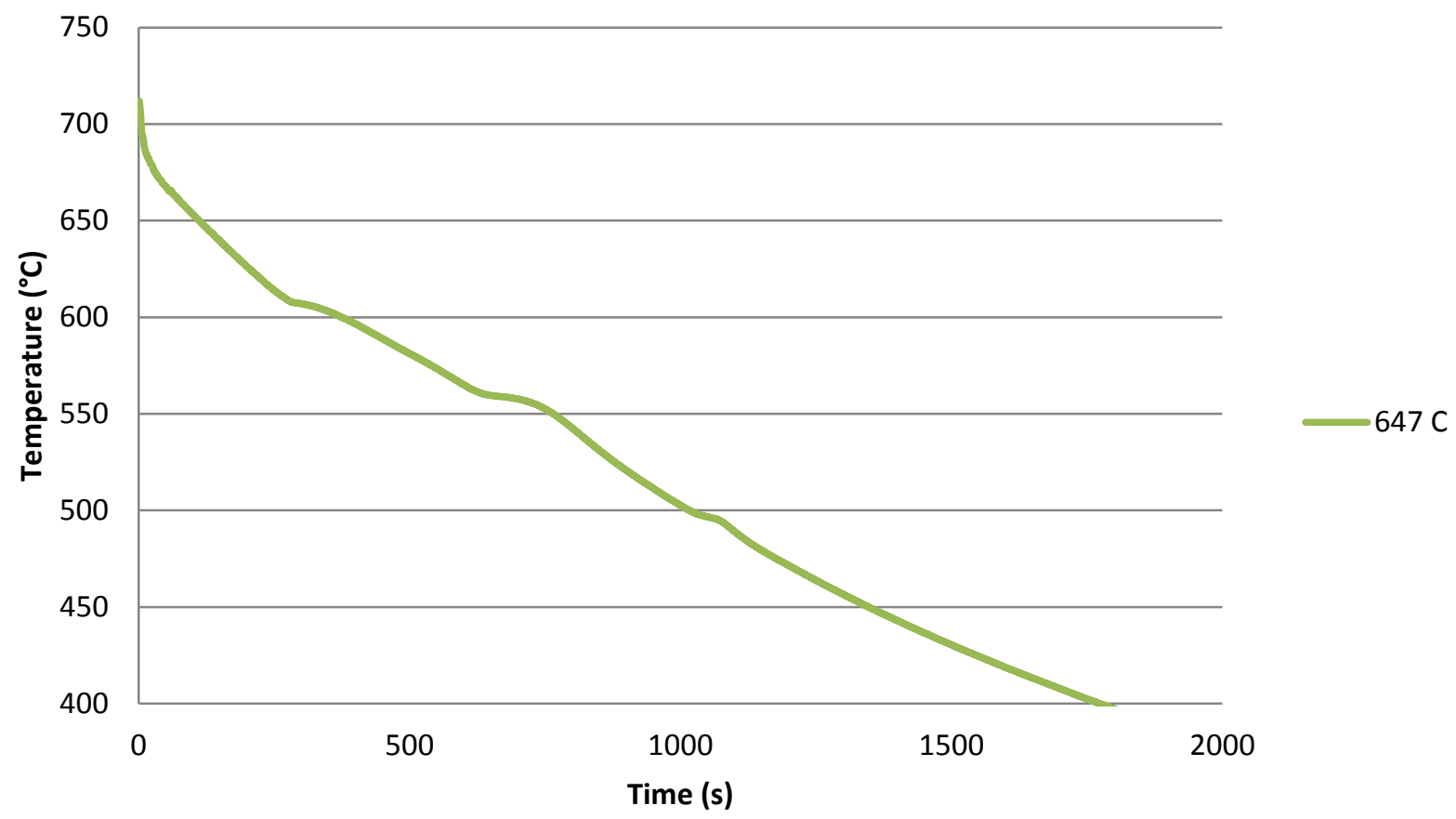

Figure C-2: A319 alloy cooling curve for $647^{\circ} \mathrm{C}$ initial mould temperature

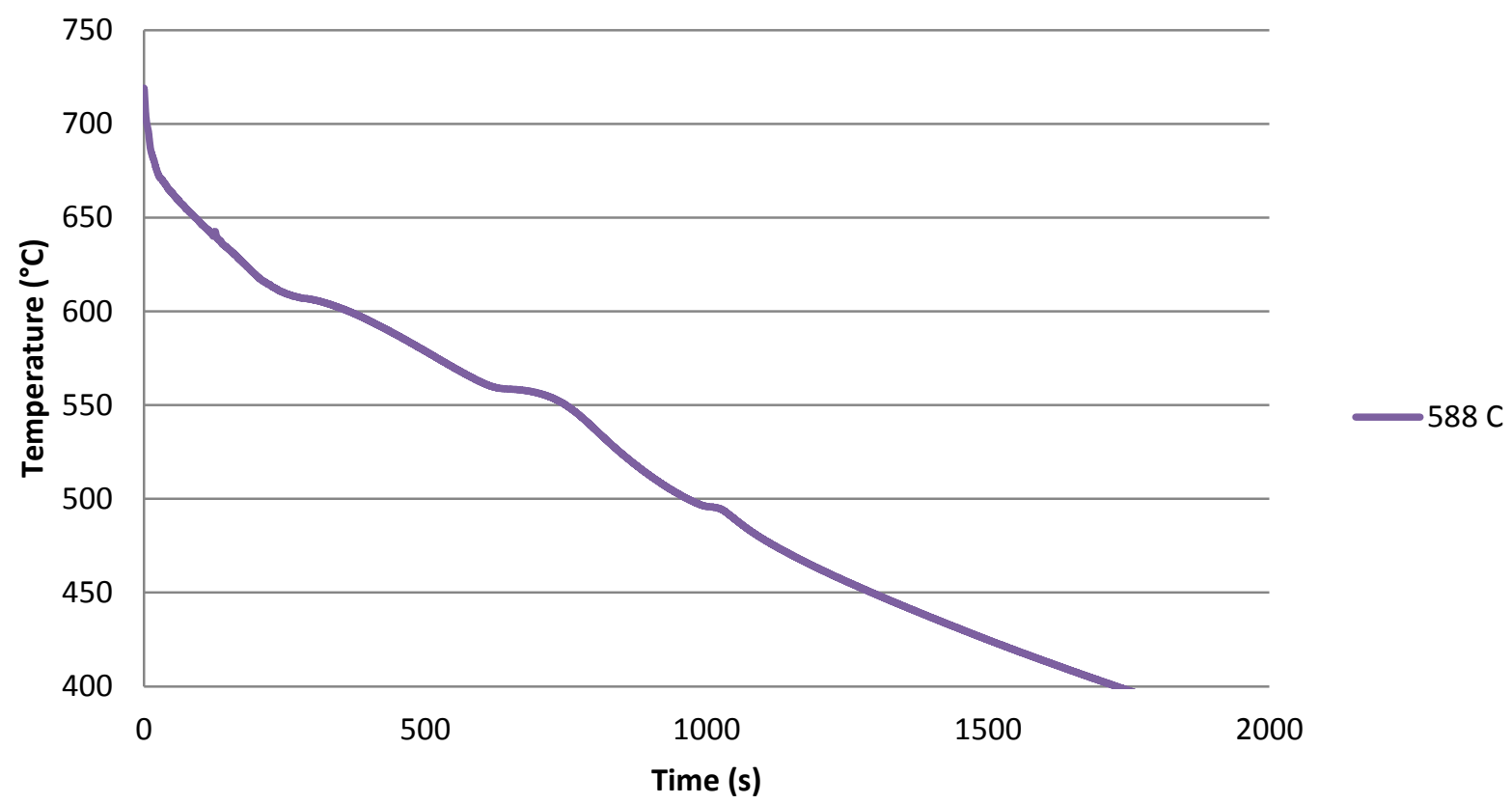

Figure C-3: A319 alloy cooling curve for $588{ }^{\circ} \mathrm{C}$ initial mould temperature 


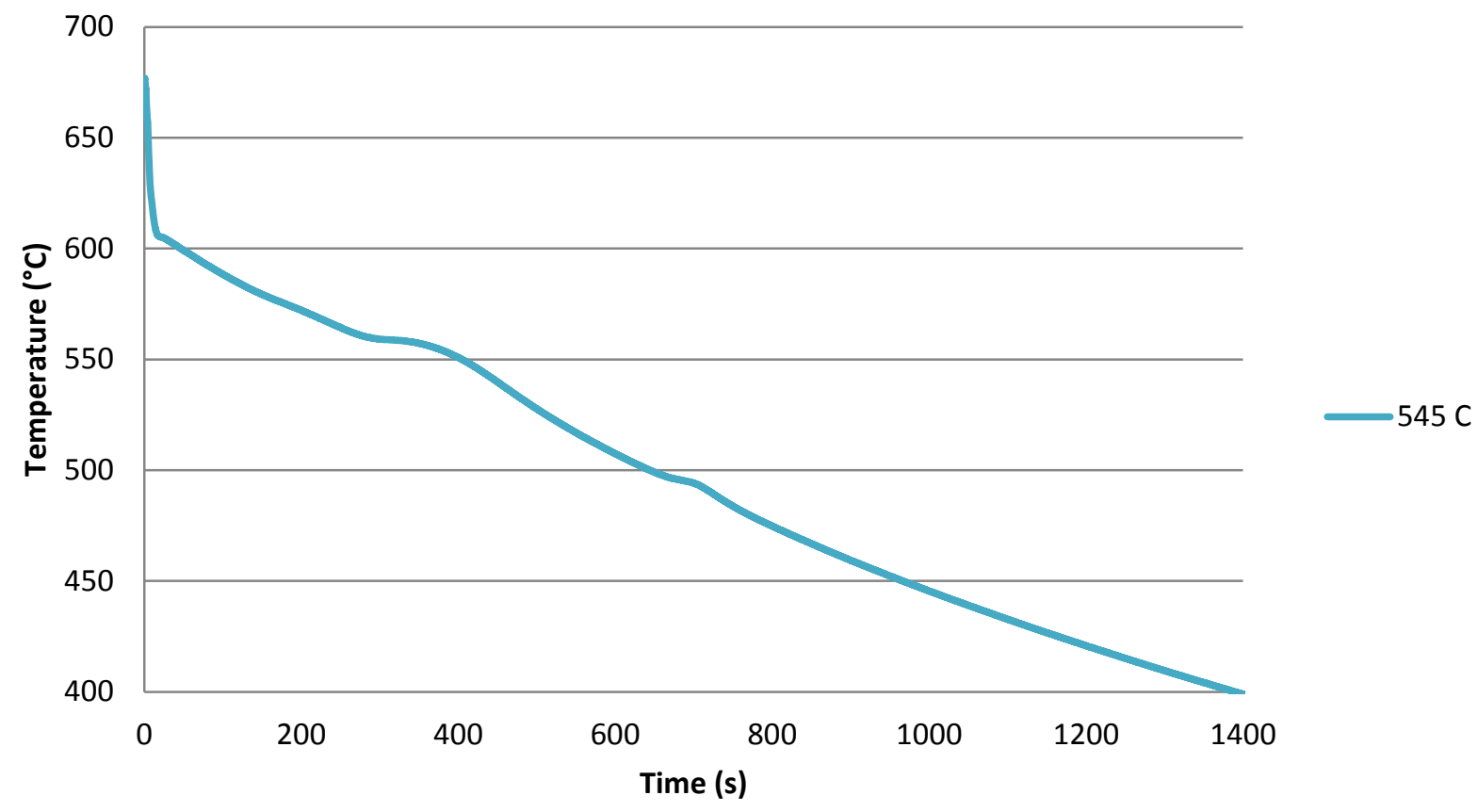

Figure C-4: A319 alloy cooling curve for $545{ }^{\circ} \mathrm{C}$ initial mould temperature

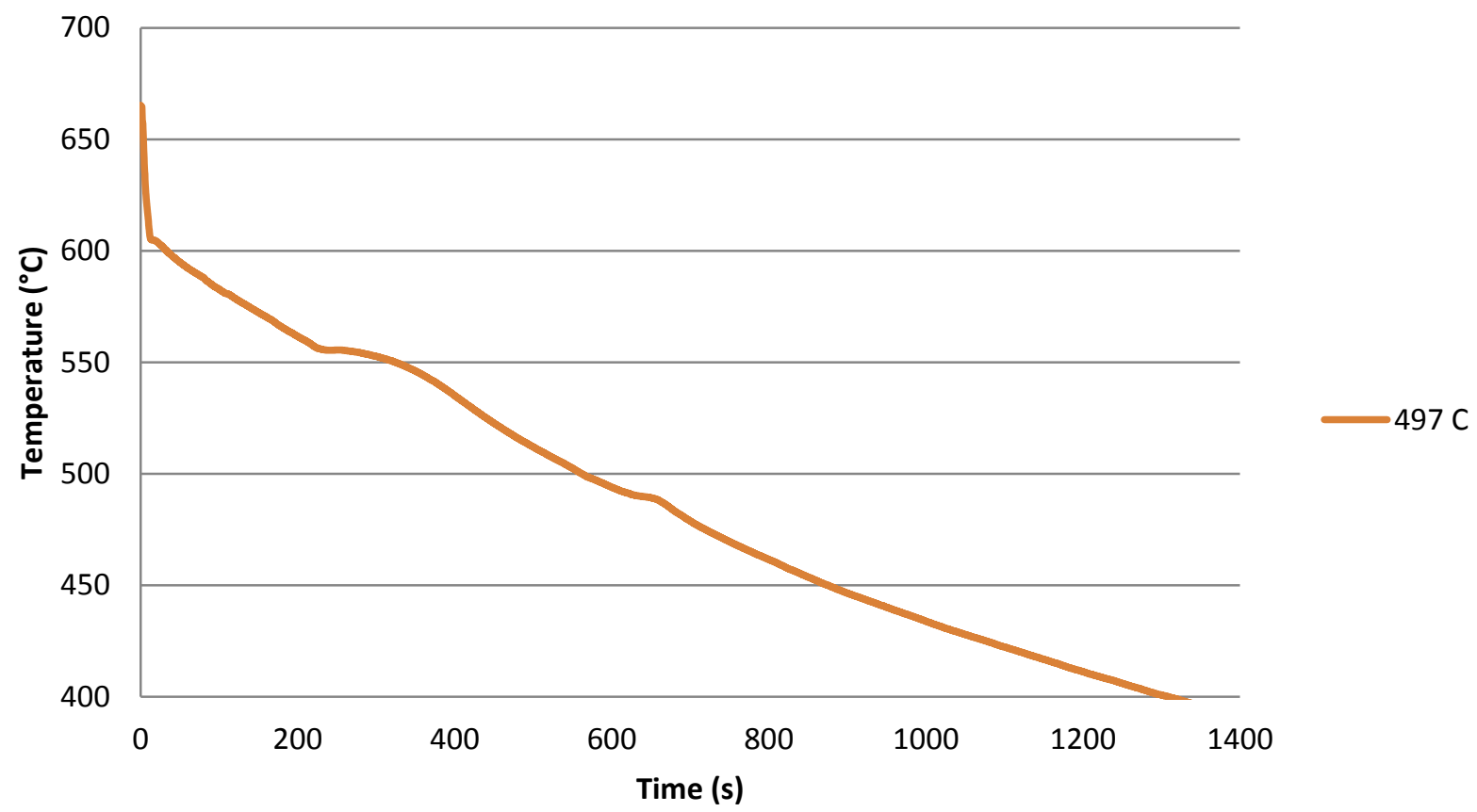

Figure C-5: A319 alloy cooling curve for $497{ }^{\circ} \mathrm{C}$ initial mould temperature 


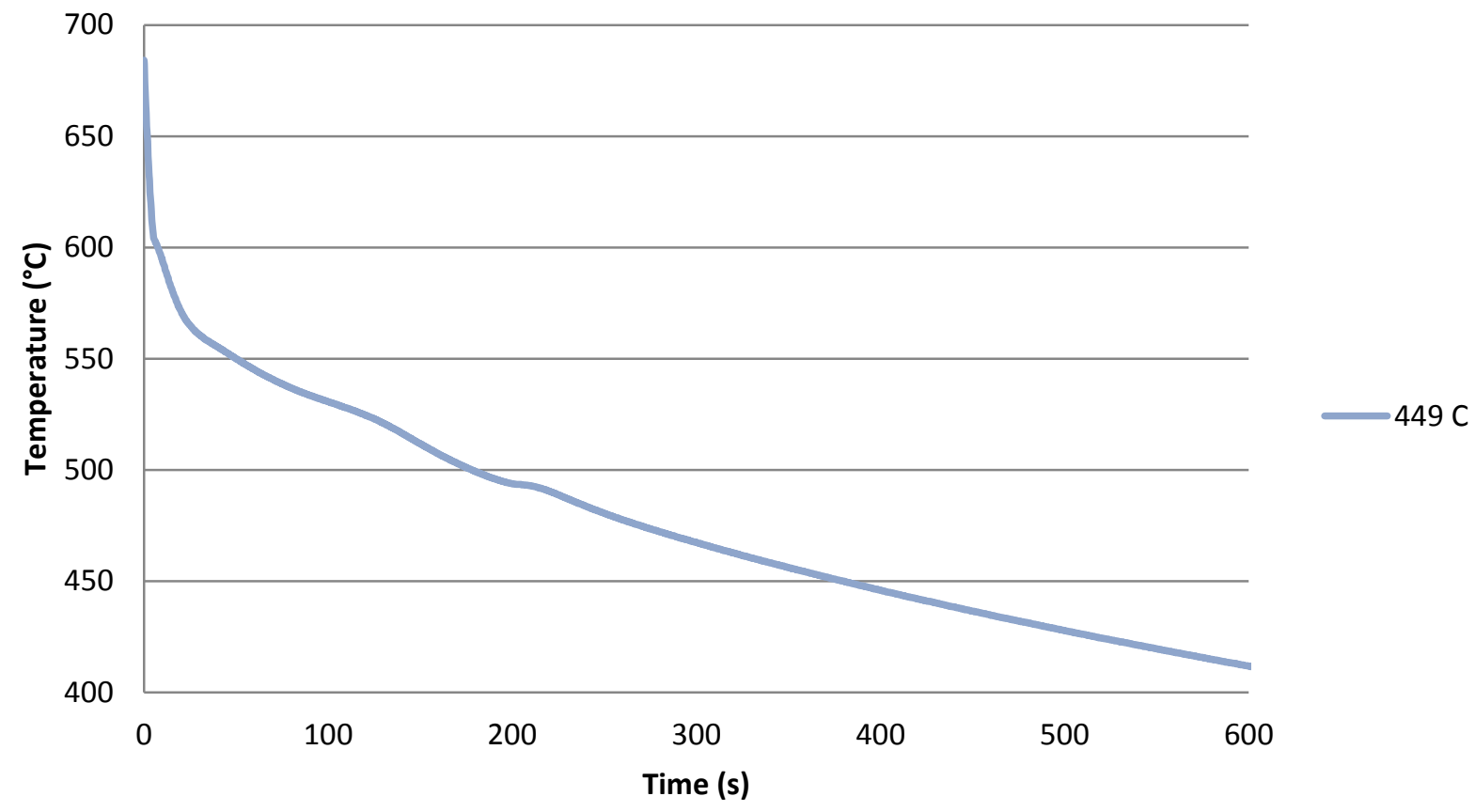

Figure C-6: A319 alloy cooling curve for $449^{\circ} \mathrm{C}$ initial mould temperature

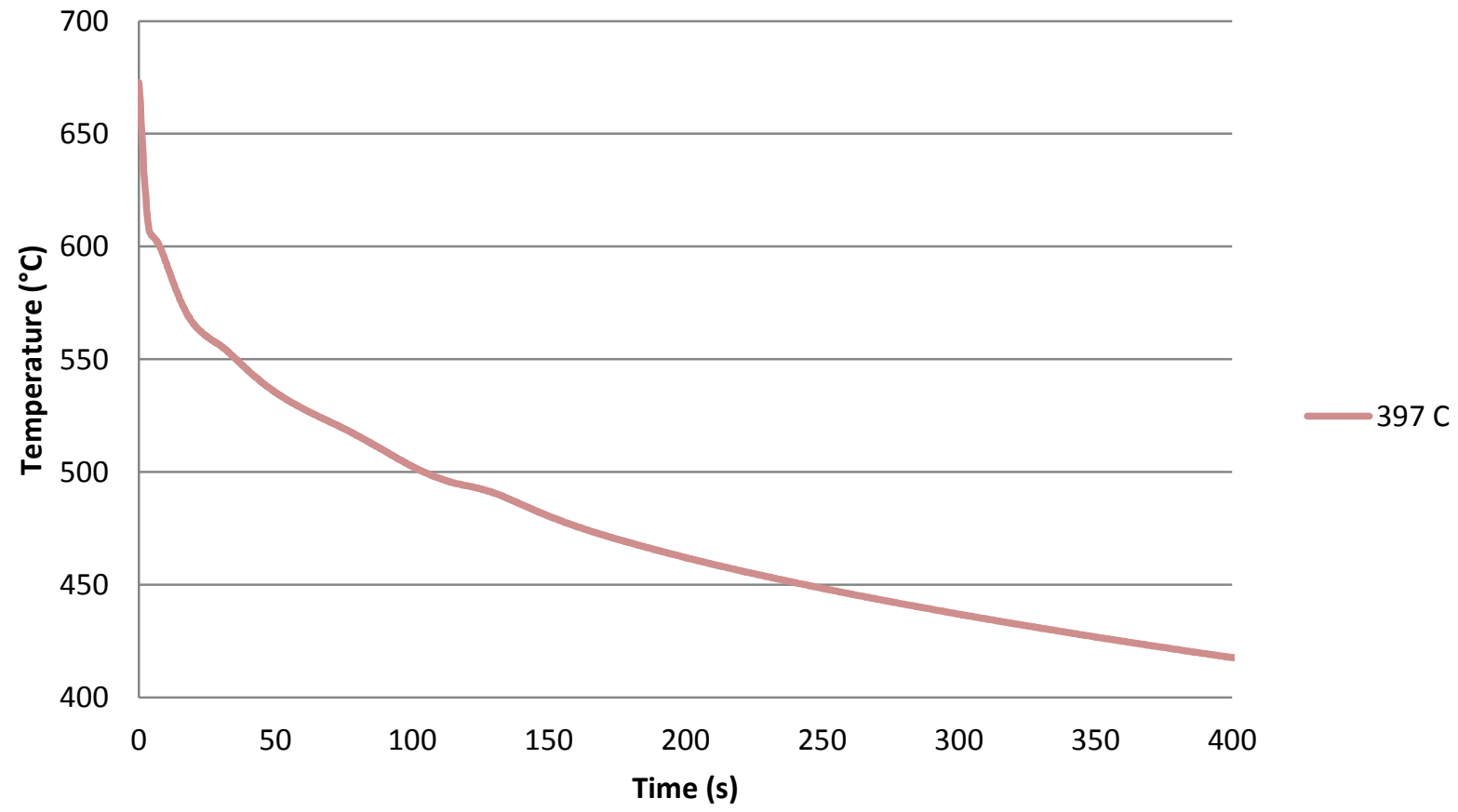

Figure C-7: A319 alloy cooling curve for $397^{\circ} \mathrm{C}$ initial mould temperature 


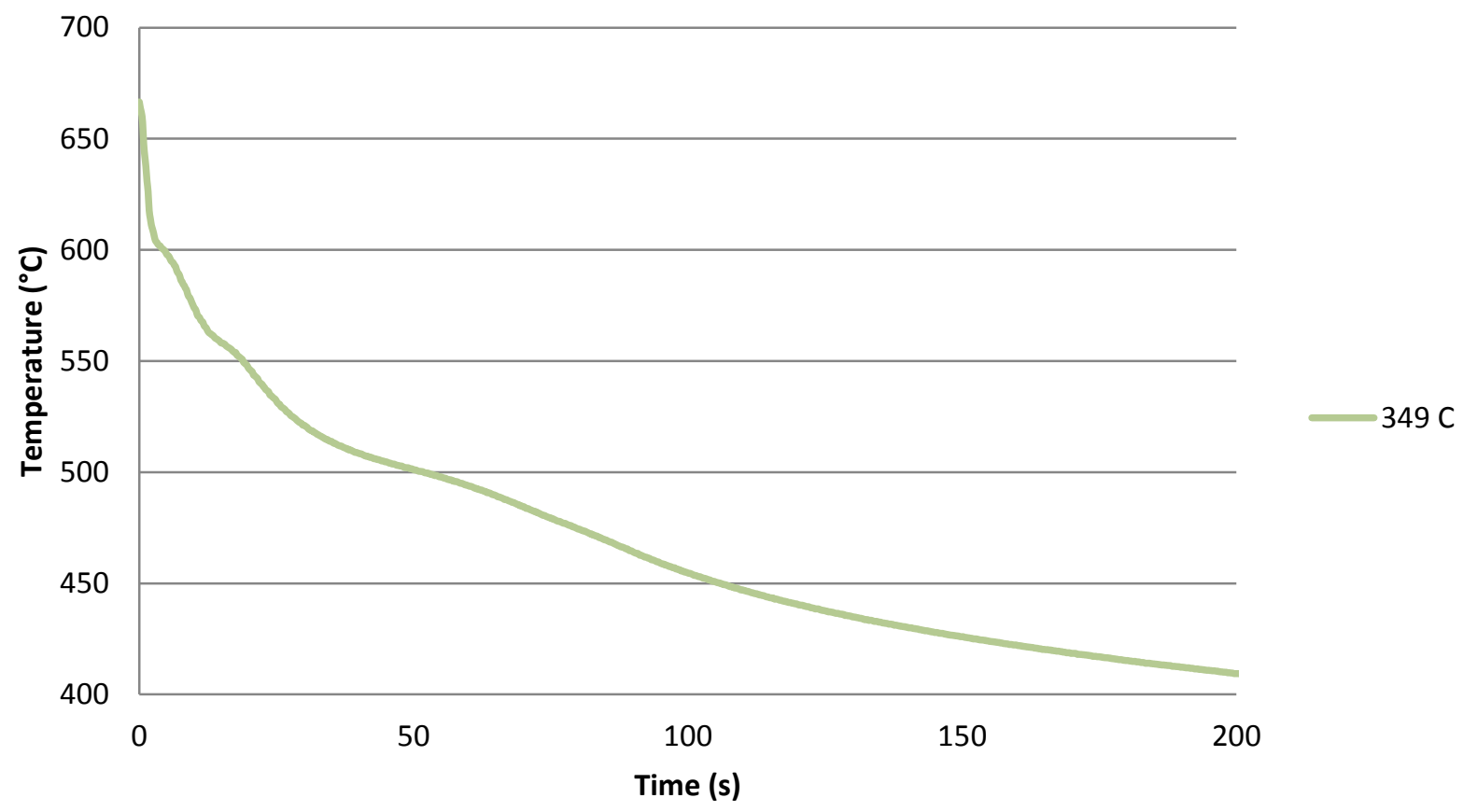

Figure C-8: A319 alloy cooling curve for $349^{\circ} \mathrm{C}$ initial mould temperature

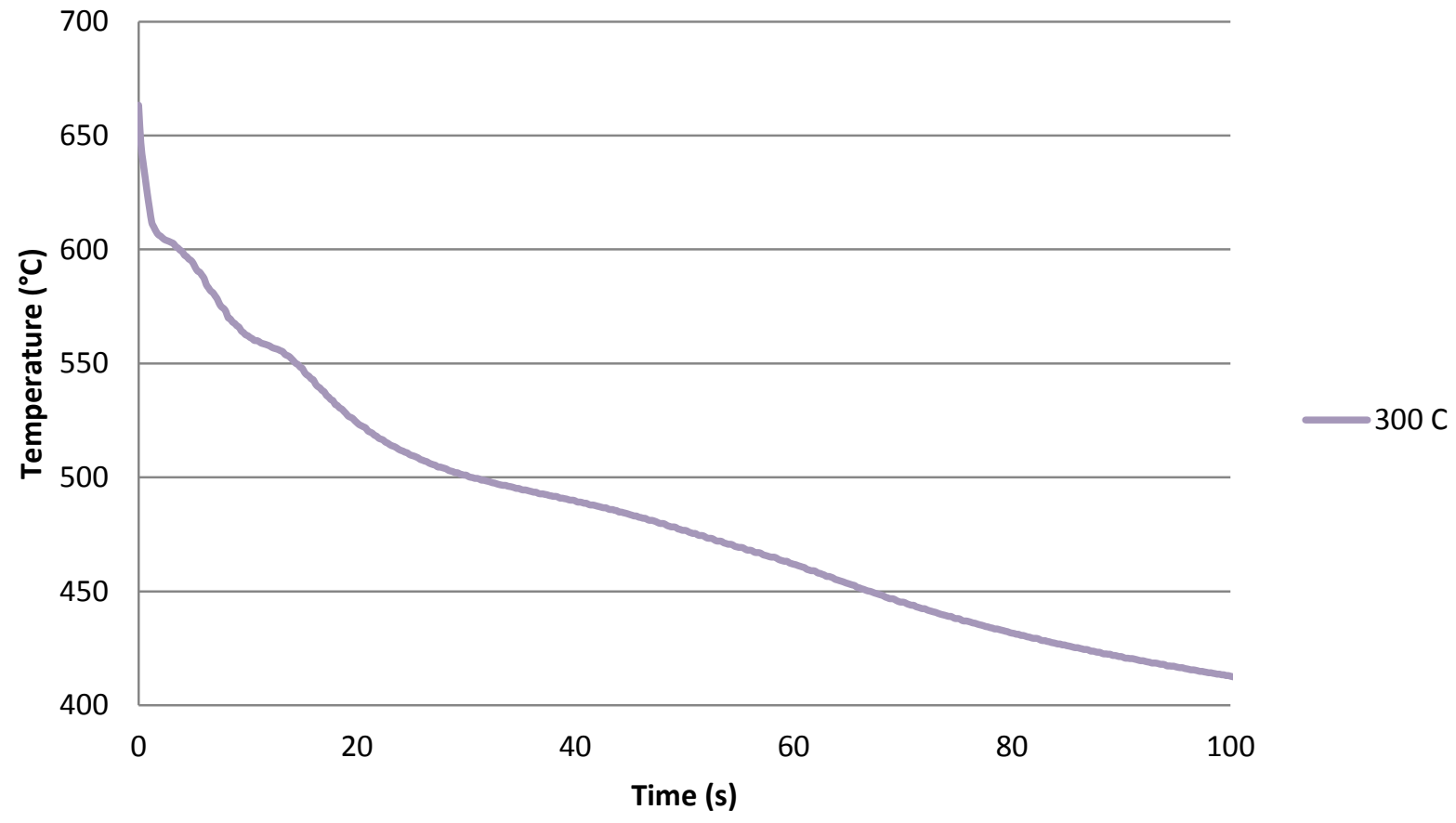

Figure C-9: A319 alloy cooling curve for $300{ }^{\circ} \mathrm{C}$ initial mould temperature 


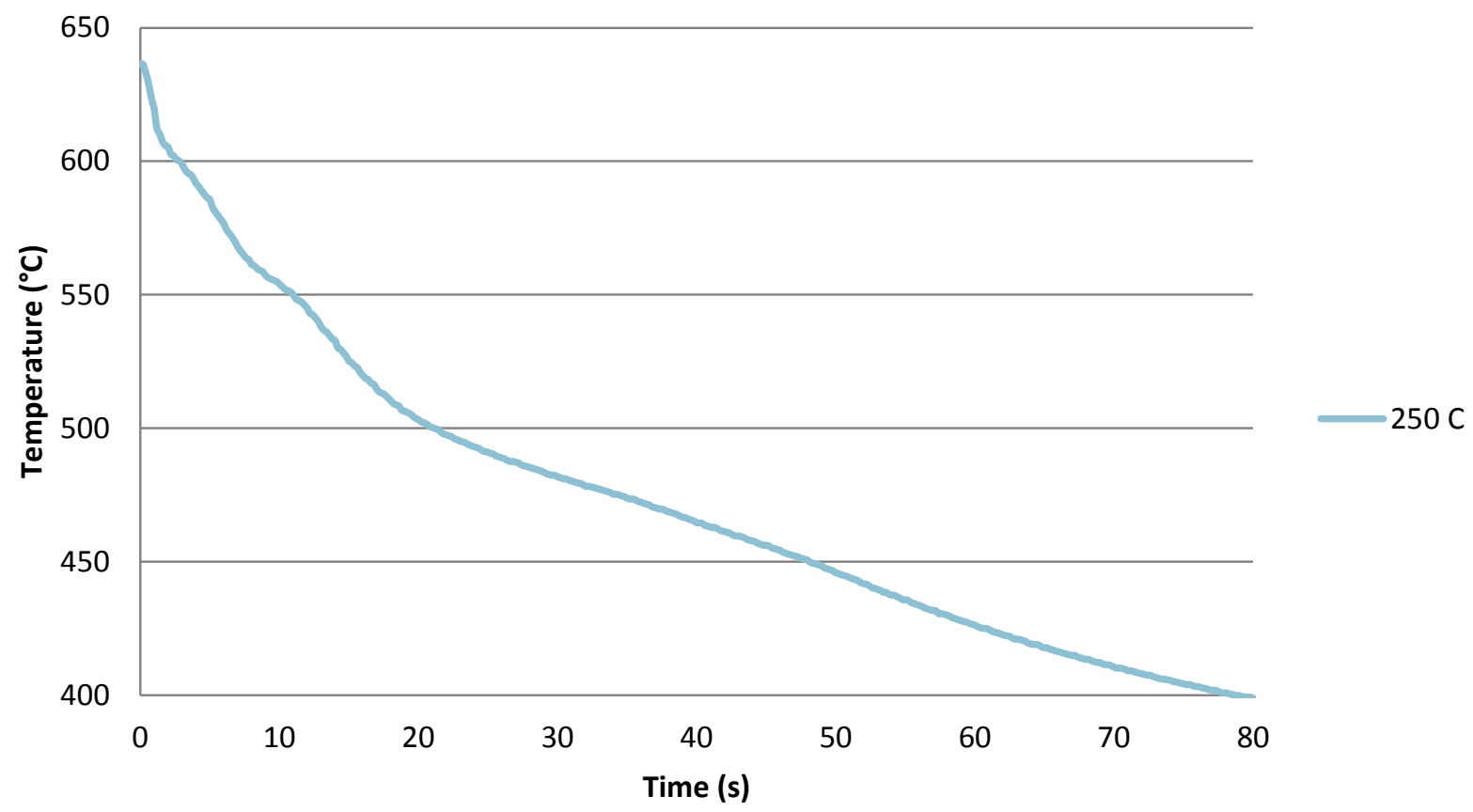

Figure C-10: A319 alloy cooling curve for $250{ }^{\circ} \mathrm{C}$ initial mould temperature

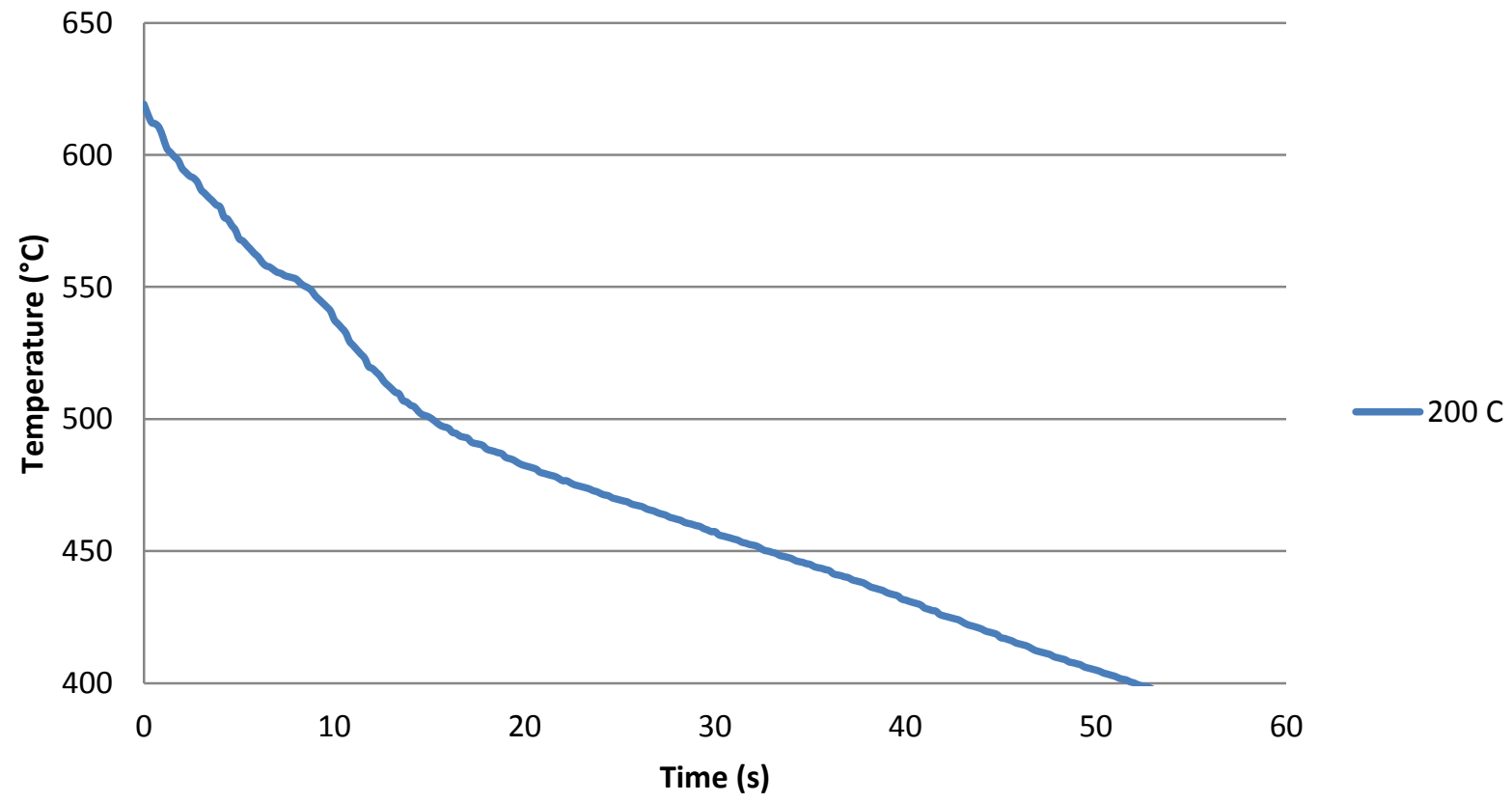

Figure C-11: A319 alloy cooling curve for $200{ }^{\circ} \mathrm{C}$ initial mould temperature 


\section{APPENDIX D: ADDITIONAL RELATIONSHIPS}

\section{D.1. Ultimate Tensile Strength}

As per the discussion in Section 4.4, the treadlines featured in the following graphs only relate to data points from castings with initial mould temperatures less than $450{ }^{\circ} \mathrm{C}$. The castings at higher initial mould temperatures contain higher percentages of porosity, so it is not possible to accurately describe a trend through the entire range of the tensile data.

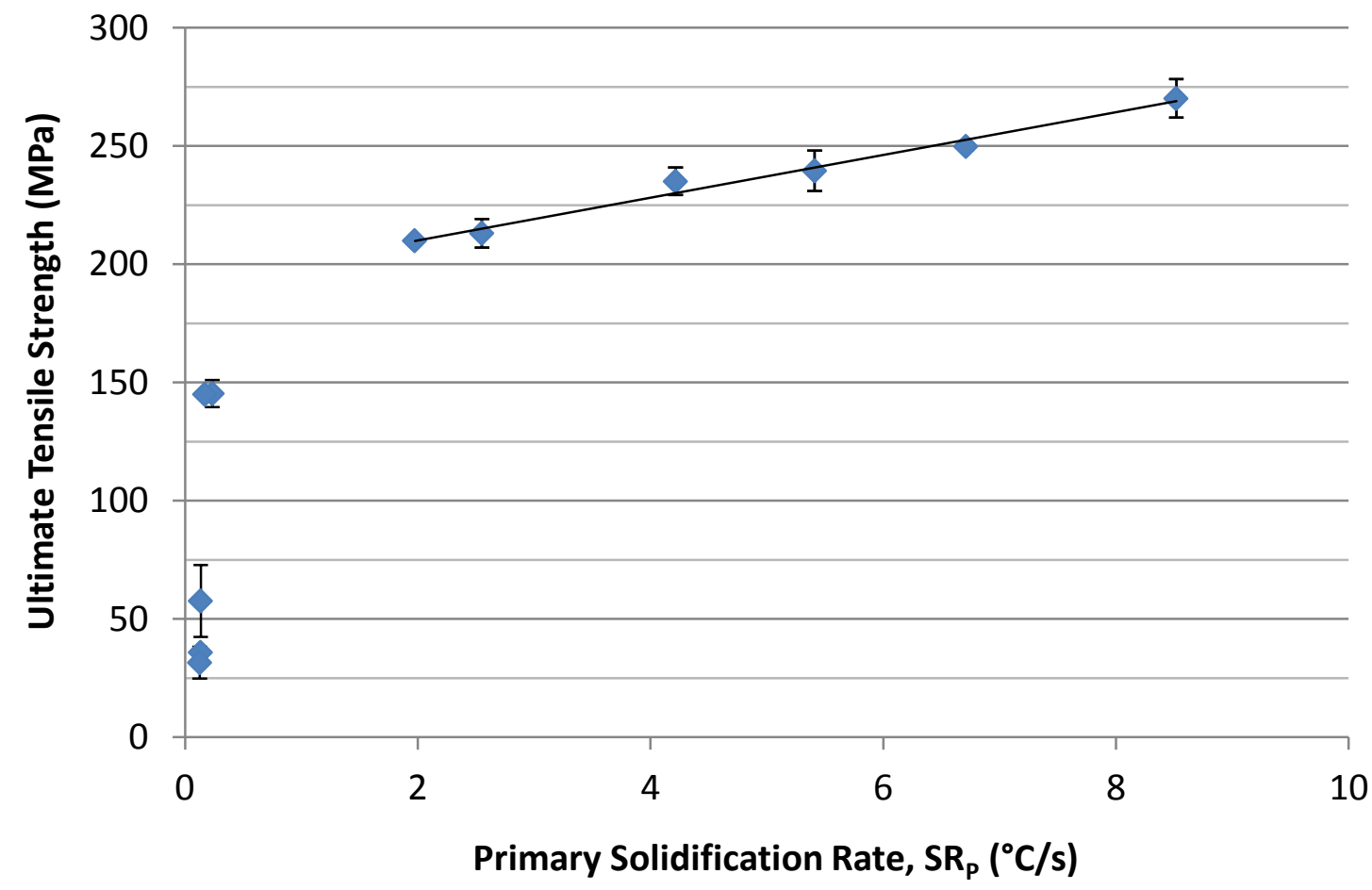

Figure D-1: Ultimate tensile strength as a function of primary solidification rate 


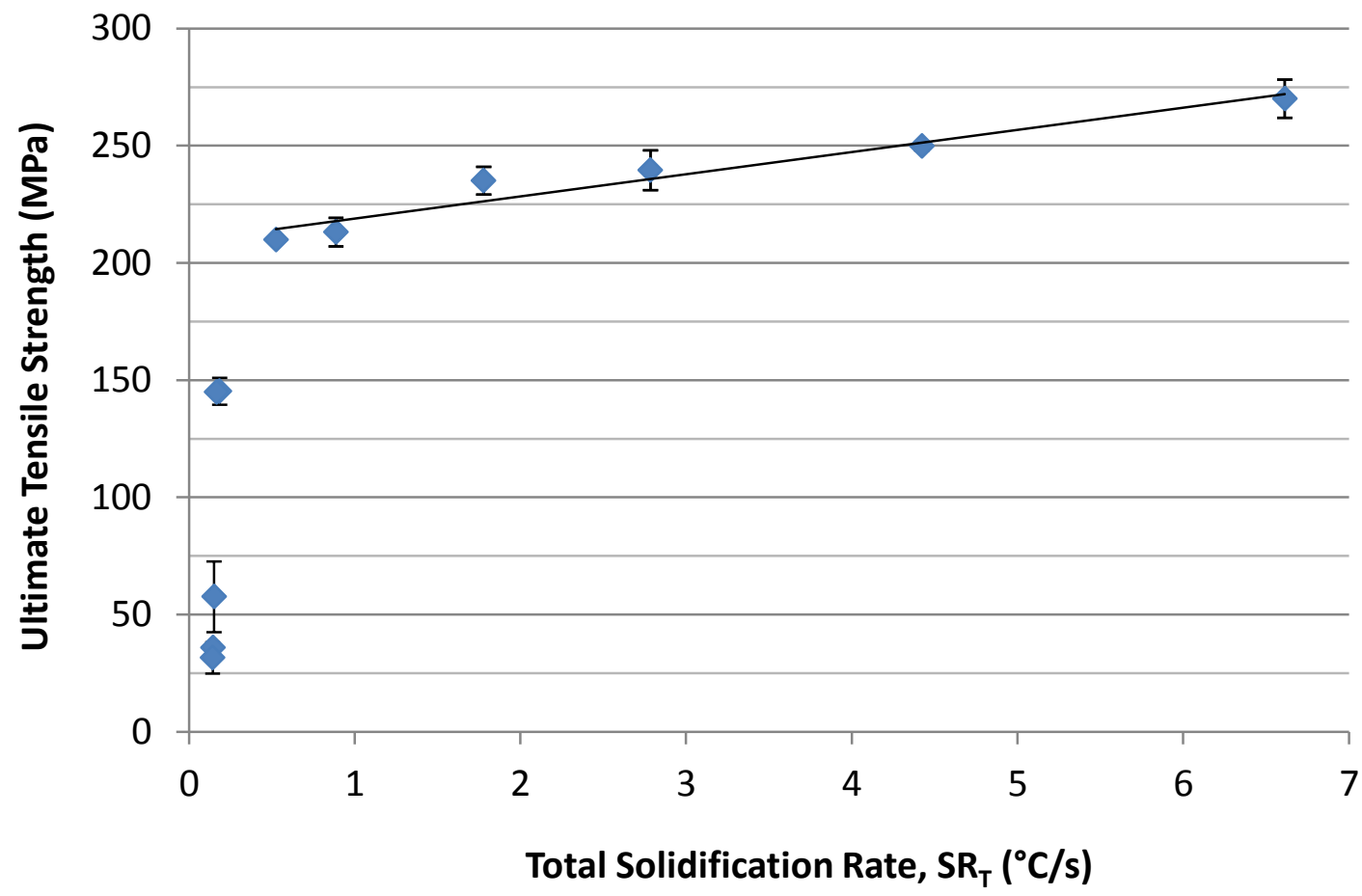

Figure D-2: Ultimate tensile strength as a function of total solidification rate

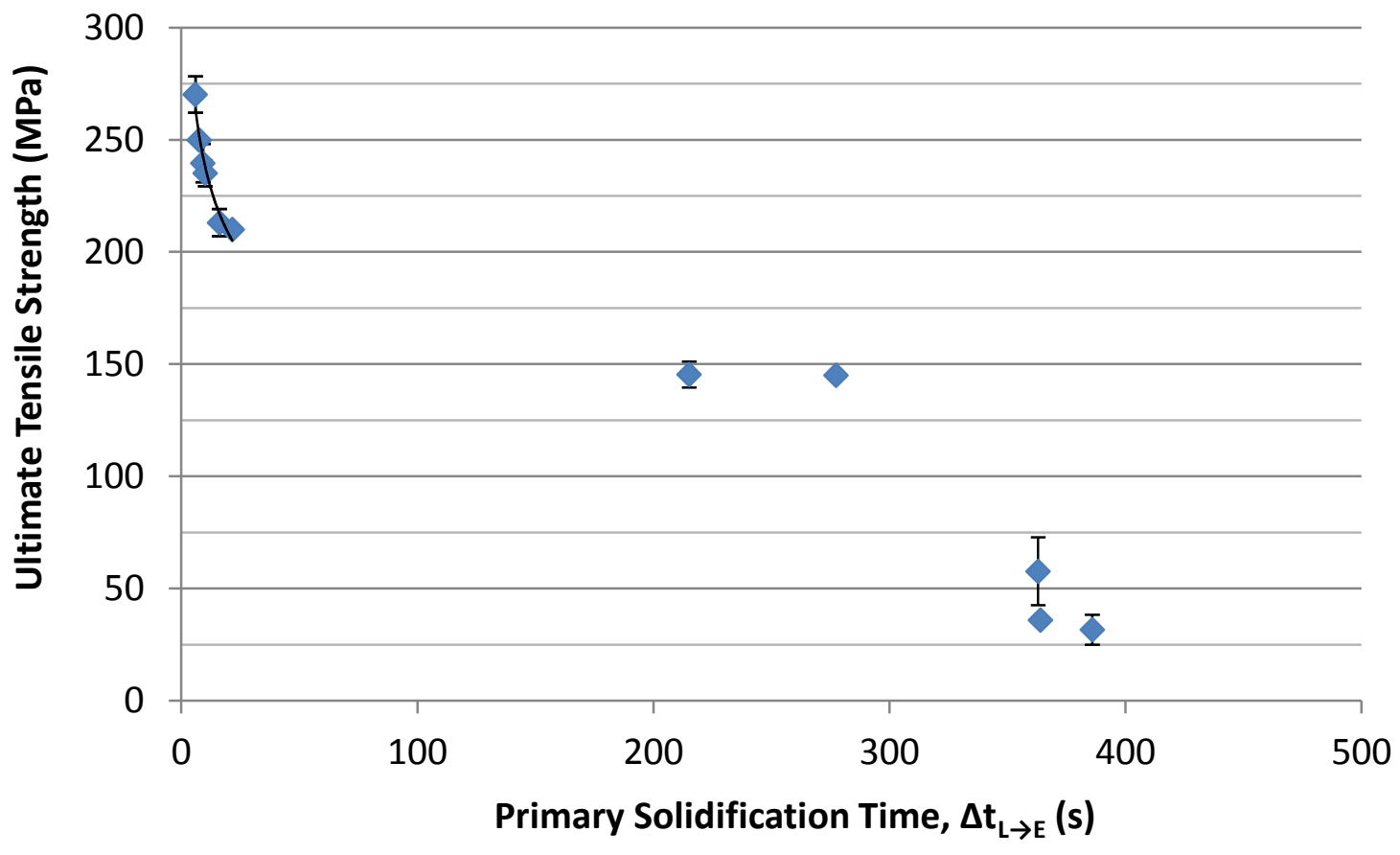

Figure D-3: Ultimate tensile strength as a function of primary solidification time 


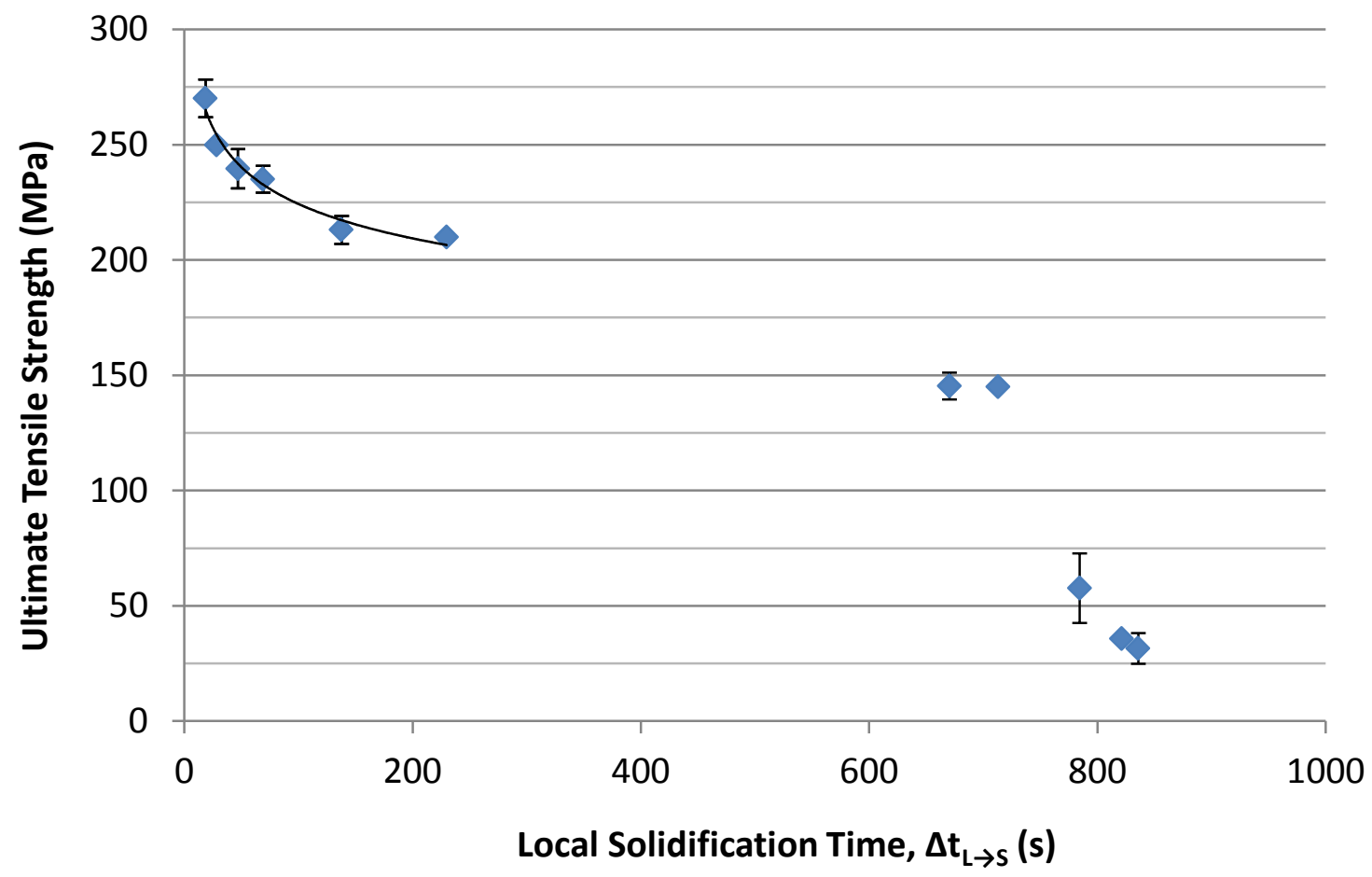

Figure D-4: Ultimate tensile strength as a function of local solidification time

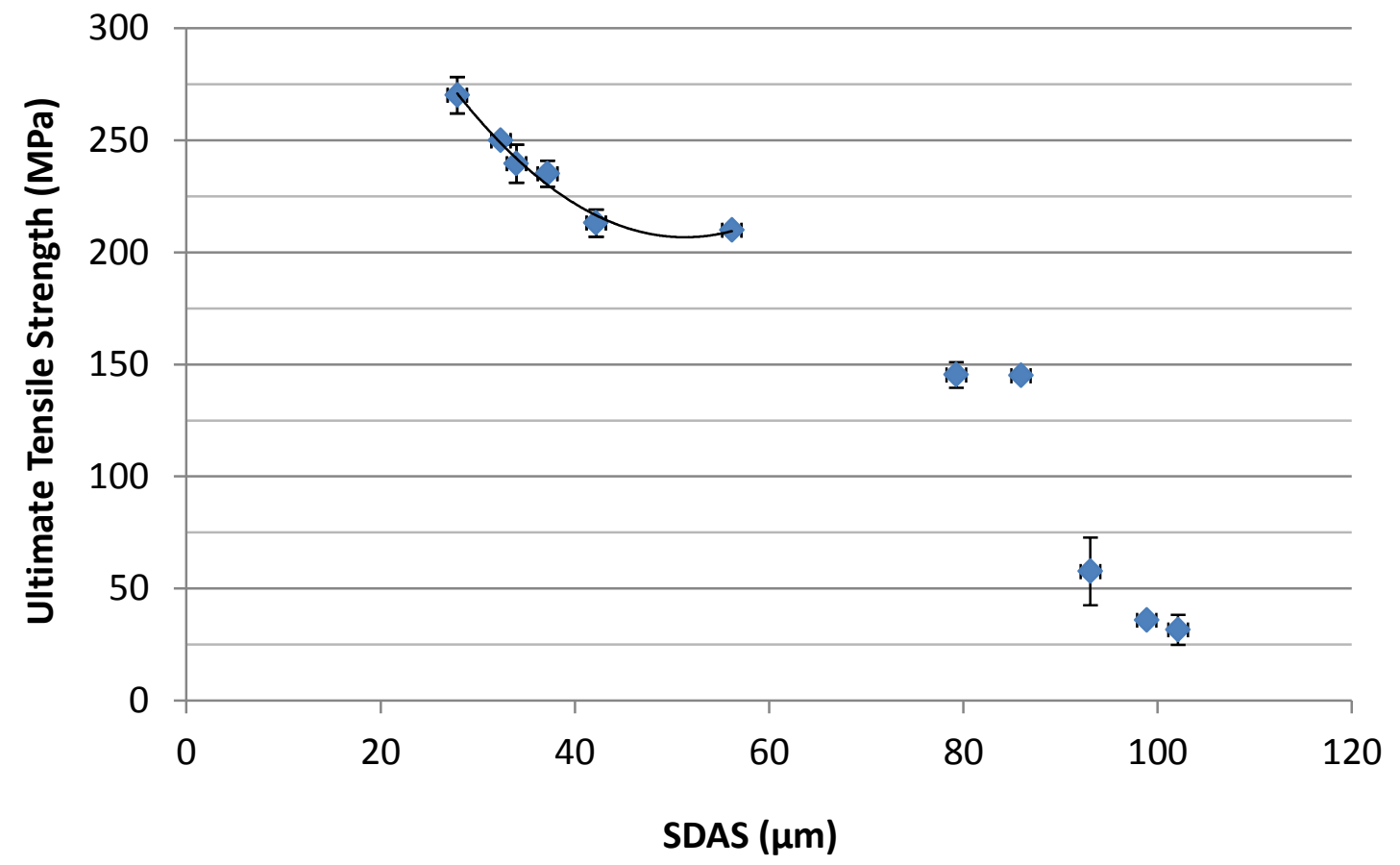

Figure D-5: Ultimate tensile strength as a function of secondary dendrite arm spacing 


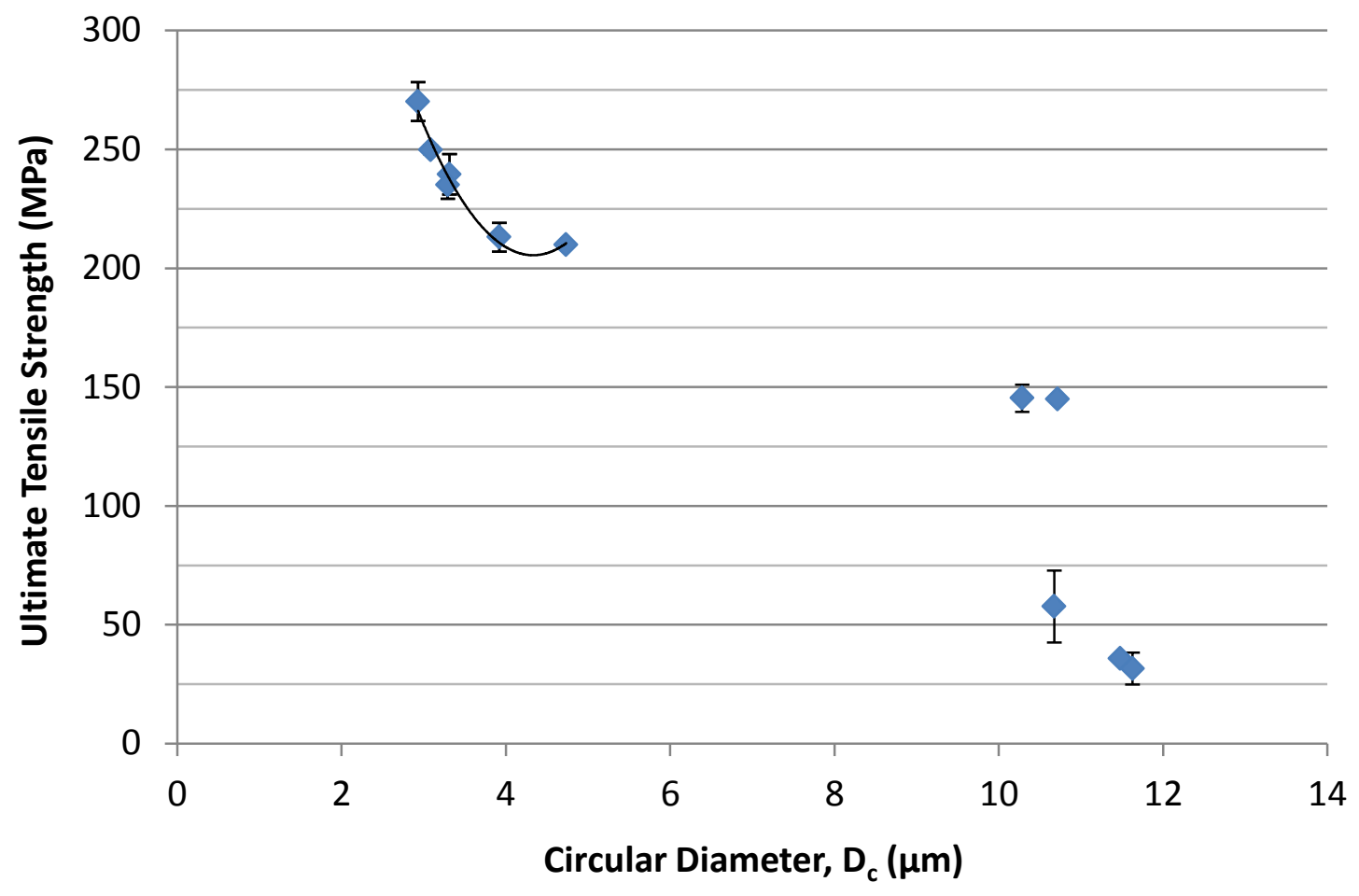

Figure D-6: Ultimate tensile strength as a function of median eutectic Si circular diameter 


\section{D.2. Rockwell Hardness}

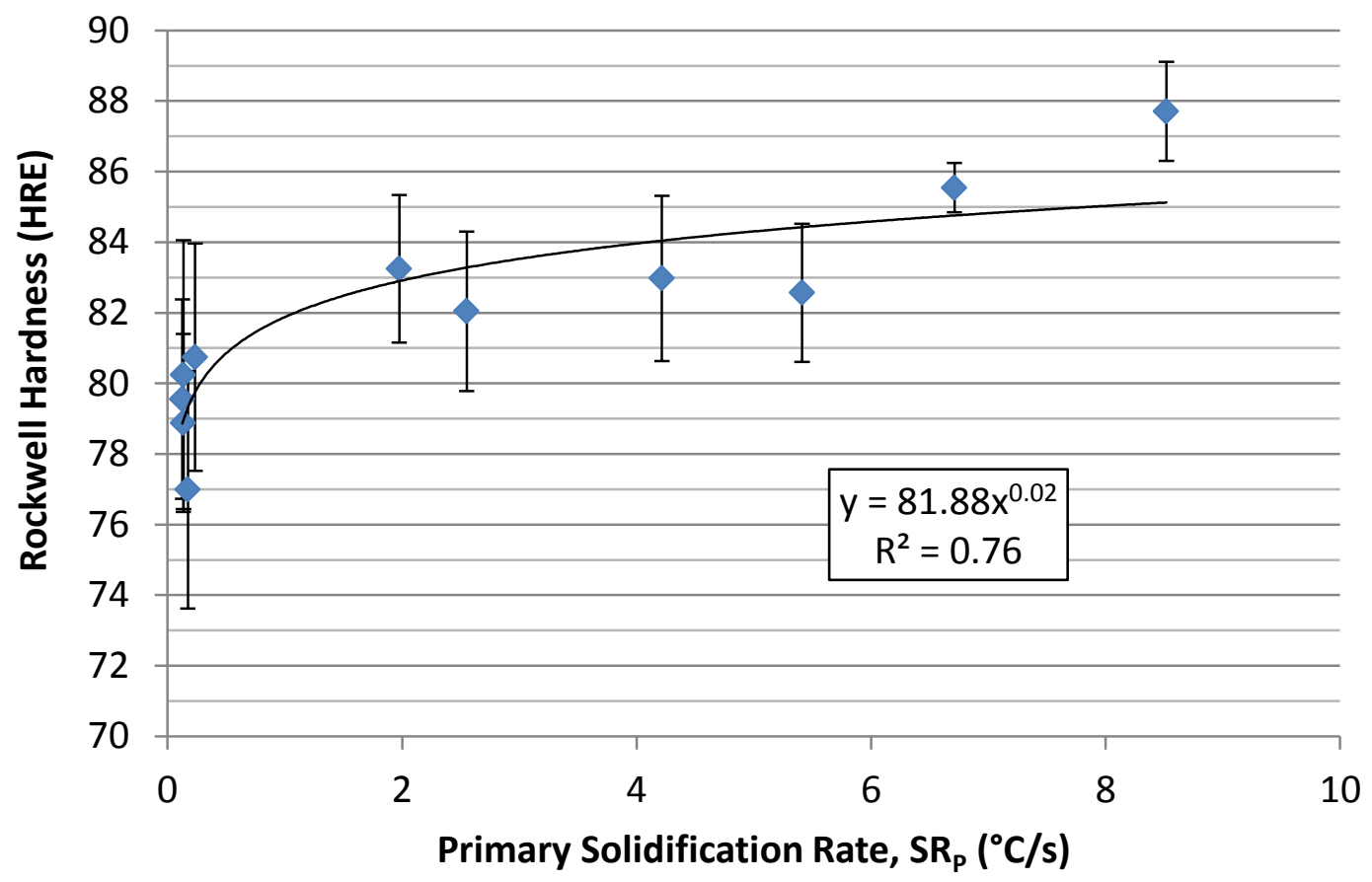

Figure D-7: Rockwell hardness as a function of primary solidification rate 


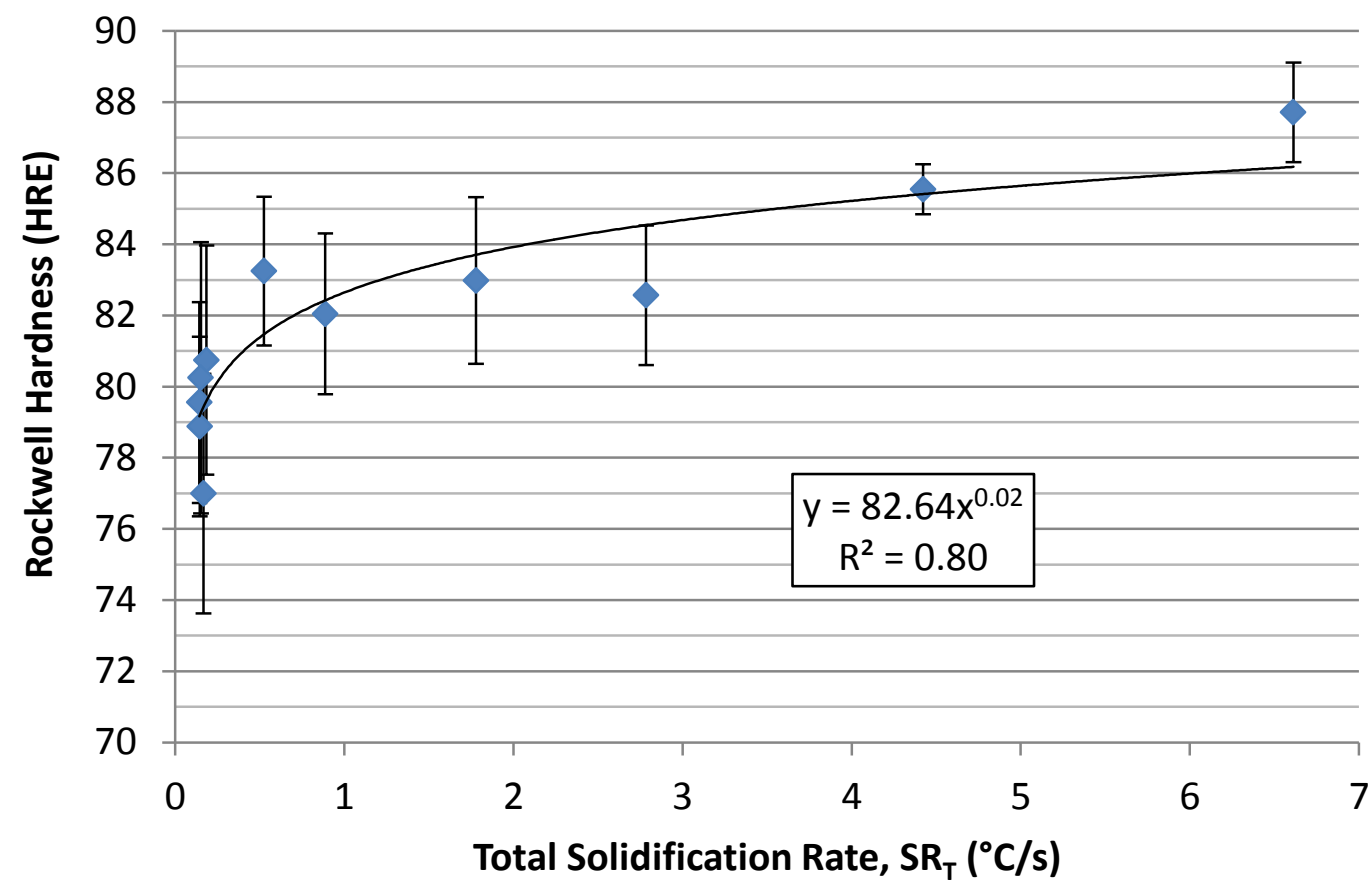

Figure D-8: Rockwell hardness as a function of total solidification rate

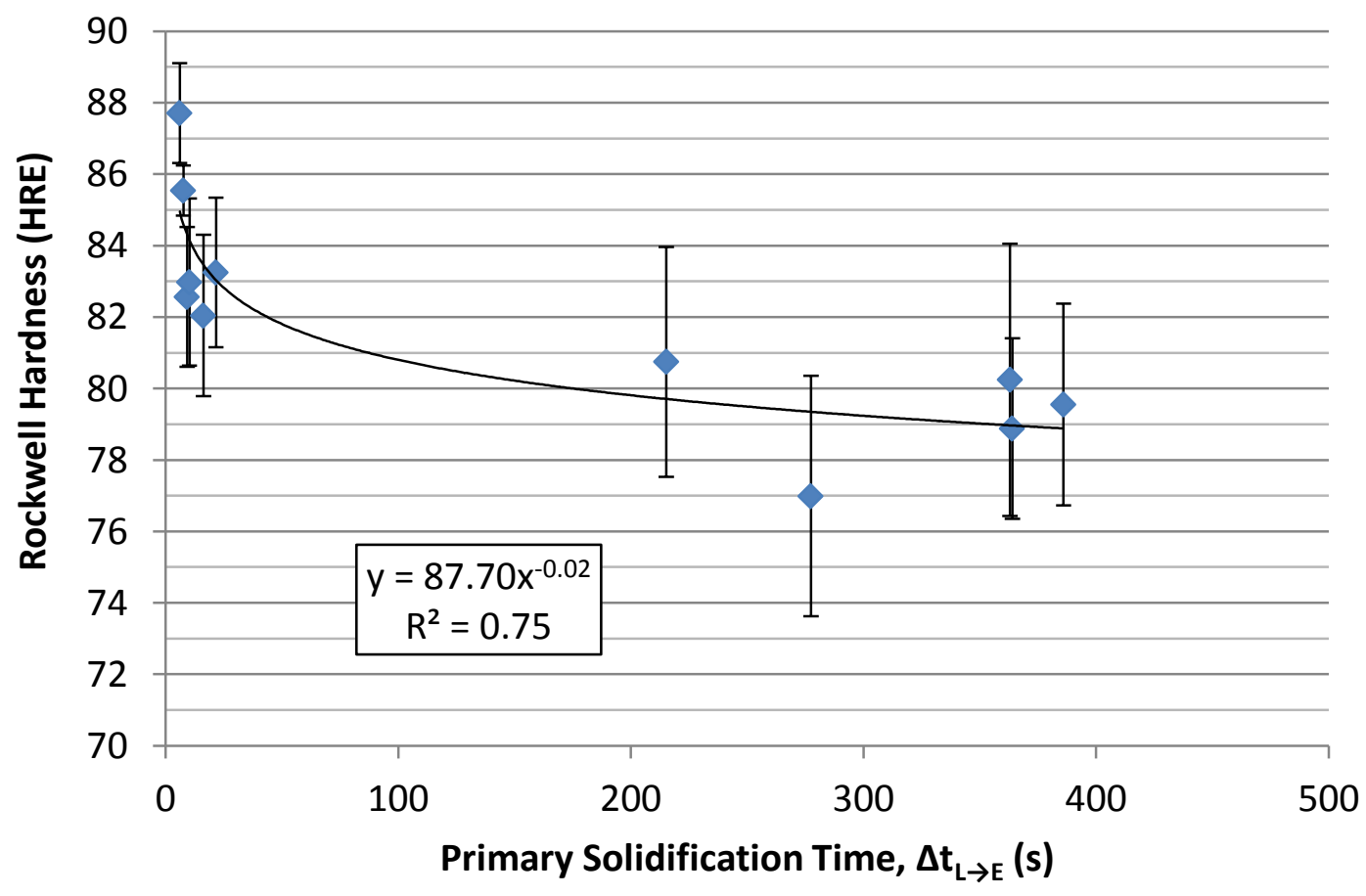

Figure D-9: Rockwell hardness as a function of primary solidification time 


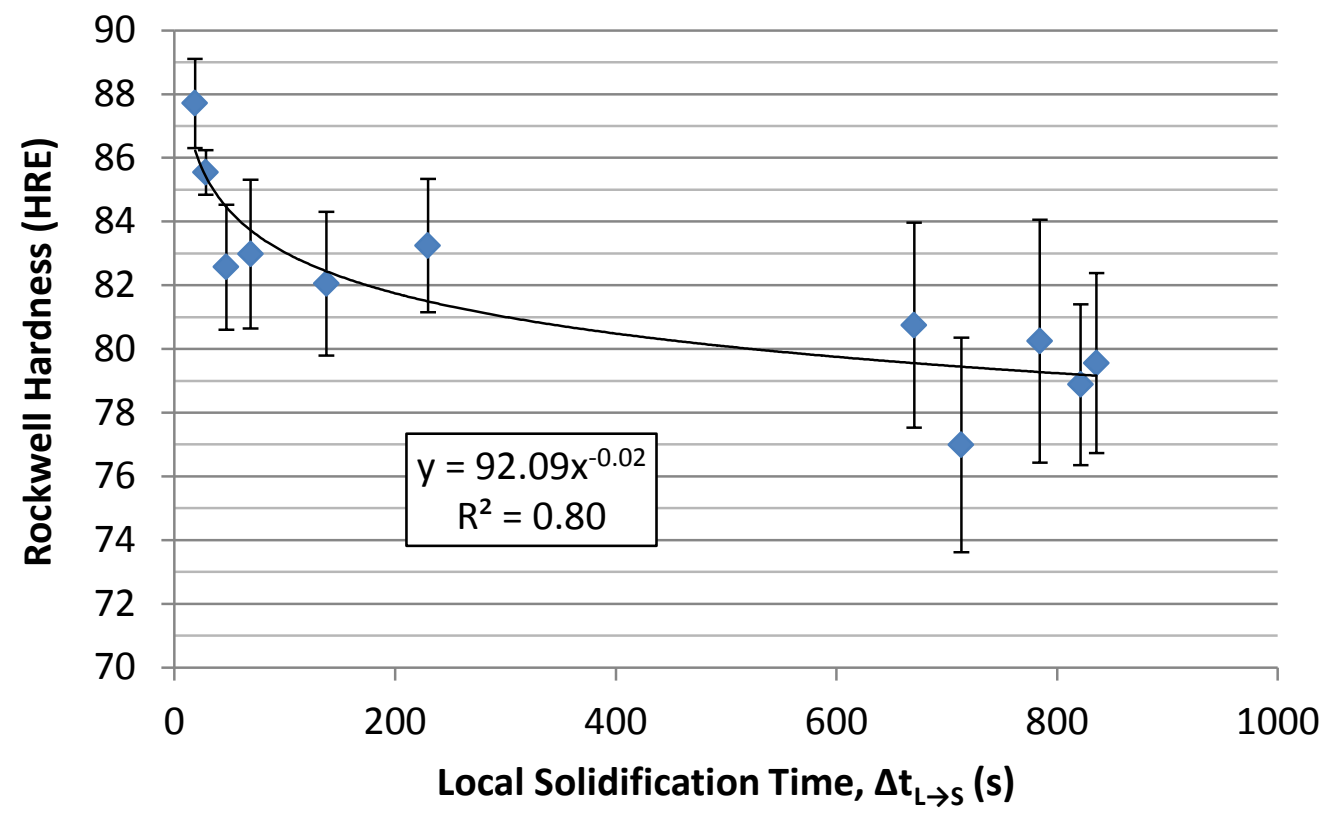

Figure D-10: Rockwell hardness as a function of local solidification time

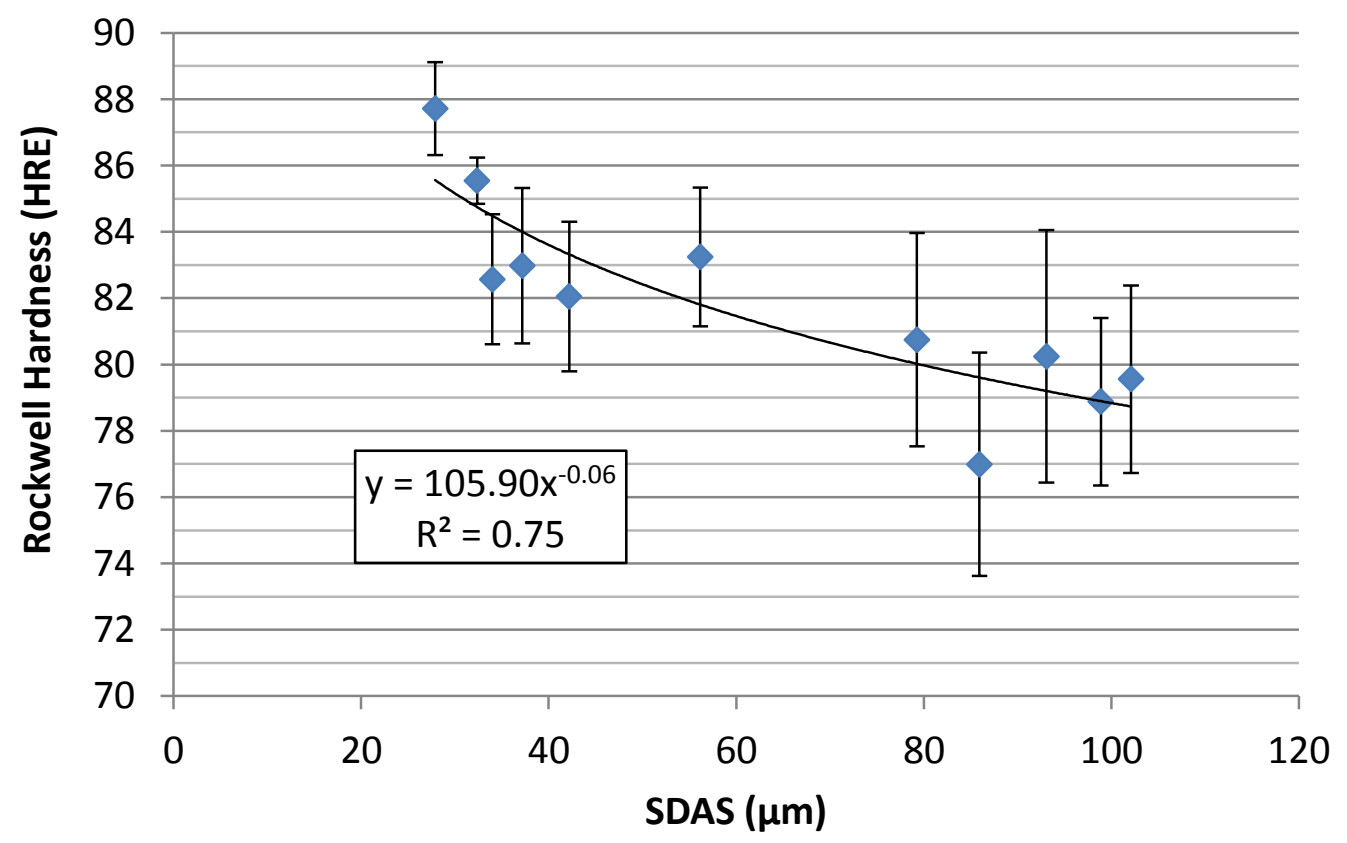

Figure D-11: Rockwell hardness as a function of secondary dendrite arm spacing 


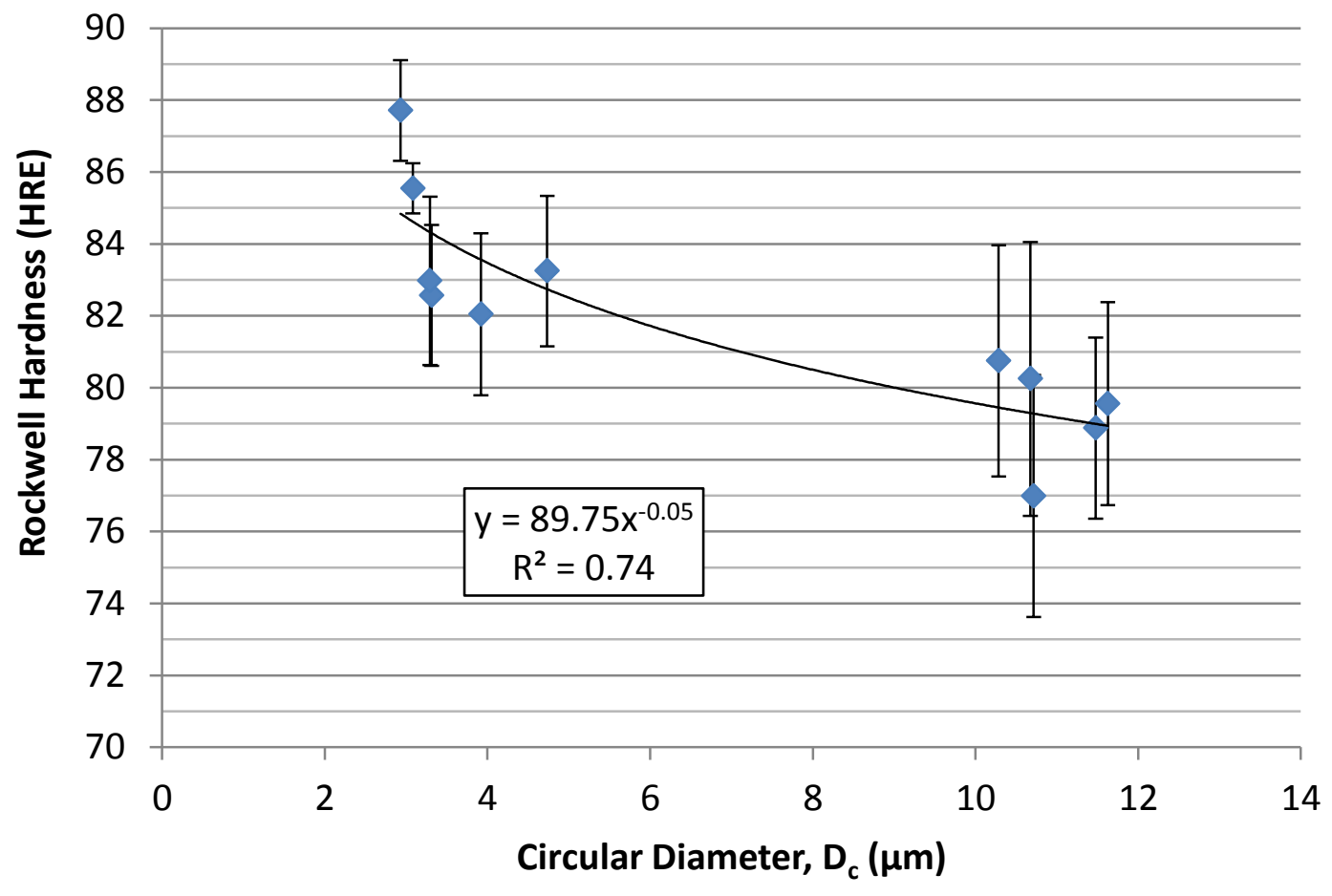

Figure D-12: Rockwell hardness as a function of median eutectic Si circular diameter 


\section{D.3. Thermal Conductivity}

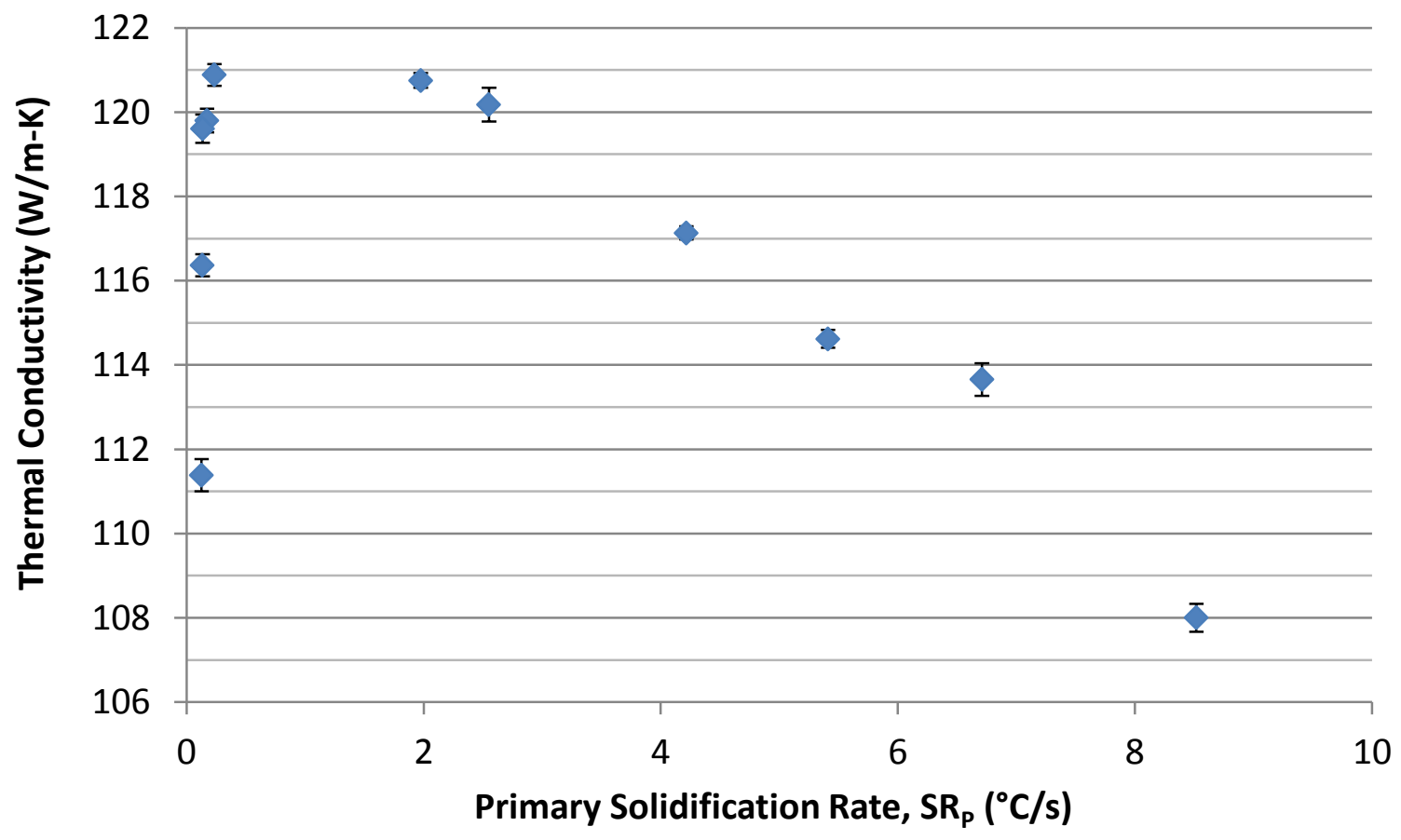

Figure D-13: Thermal conductivity as a function of primary solidification rate 


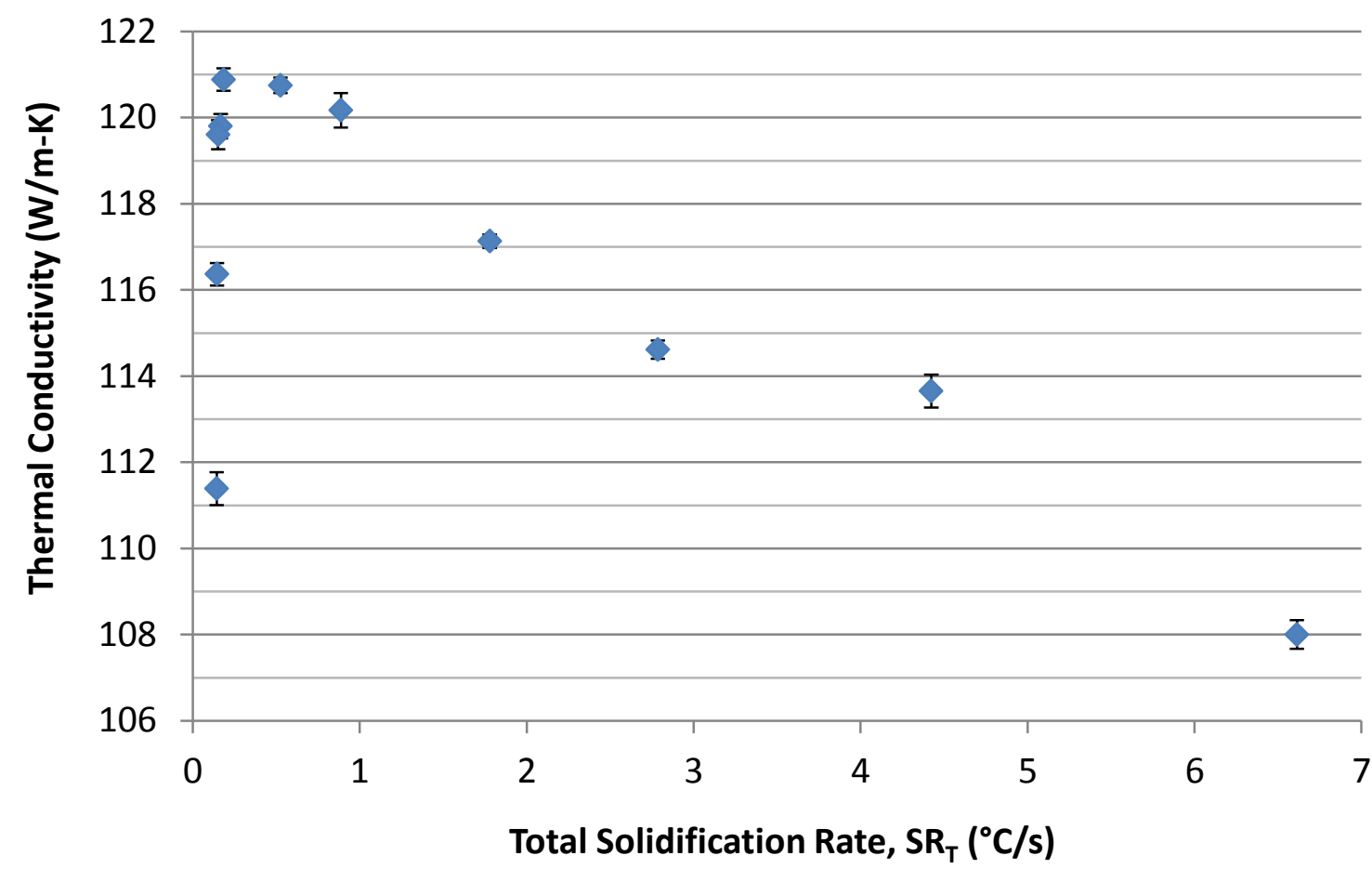

Figure D-14: Thermal conductivity as a function of total solidification rate

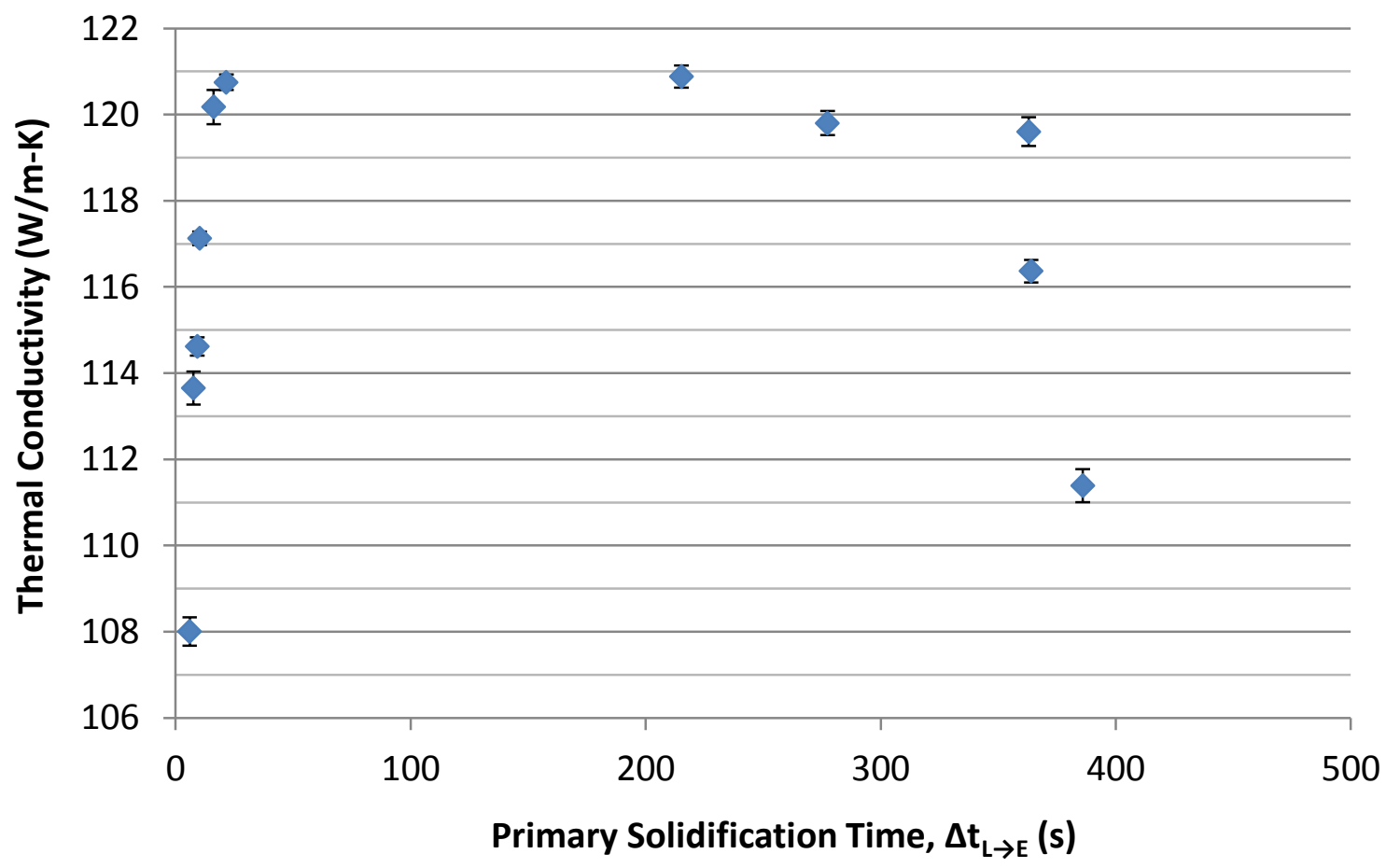

Figure D-15: Thermal conductivity as a function of primary solidification time 


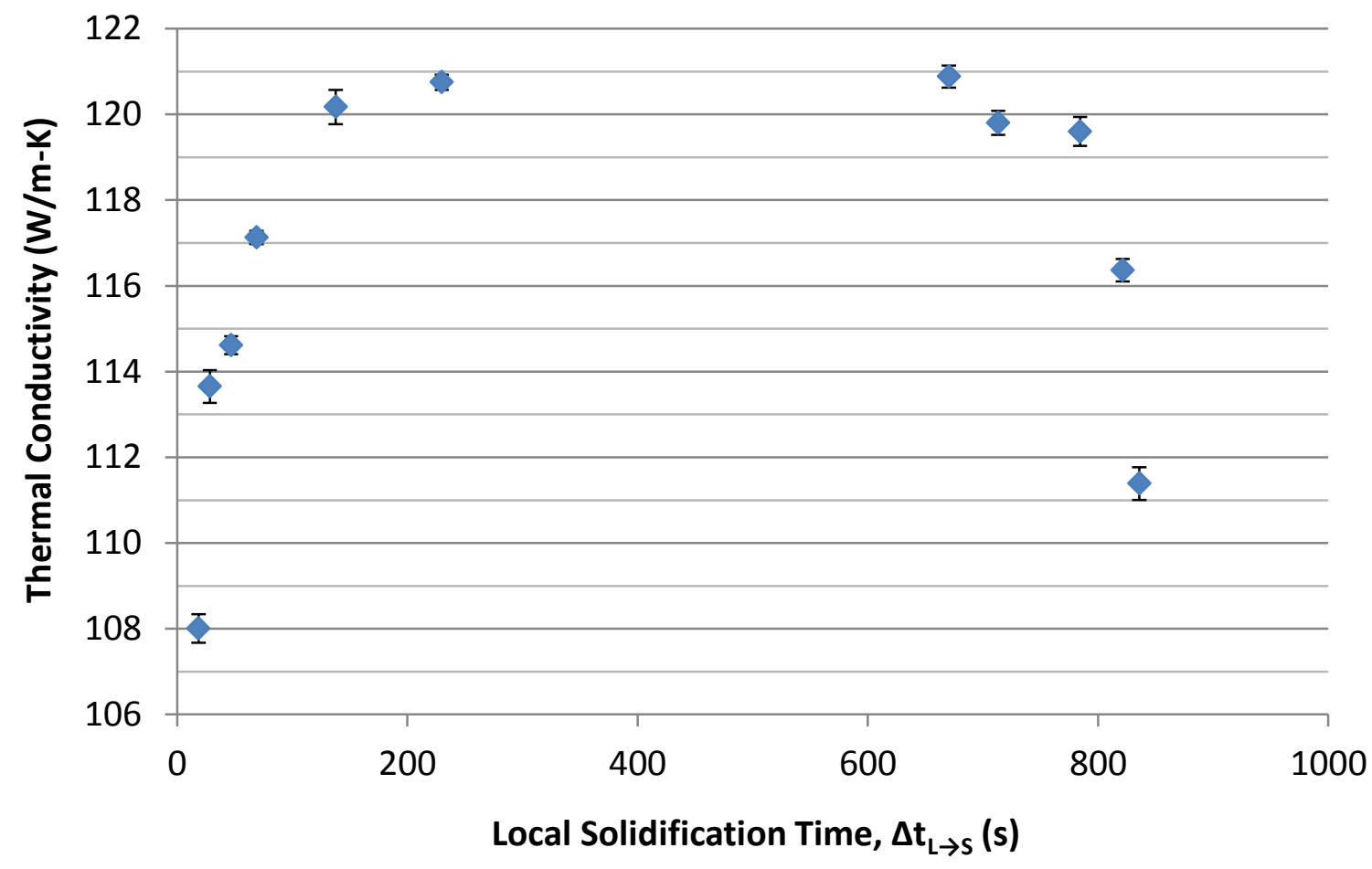

Figure D-16: Thermal conductivity as a function of local solidification time

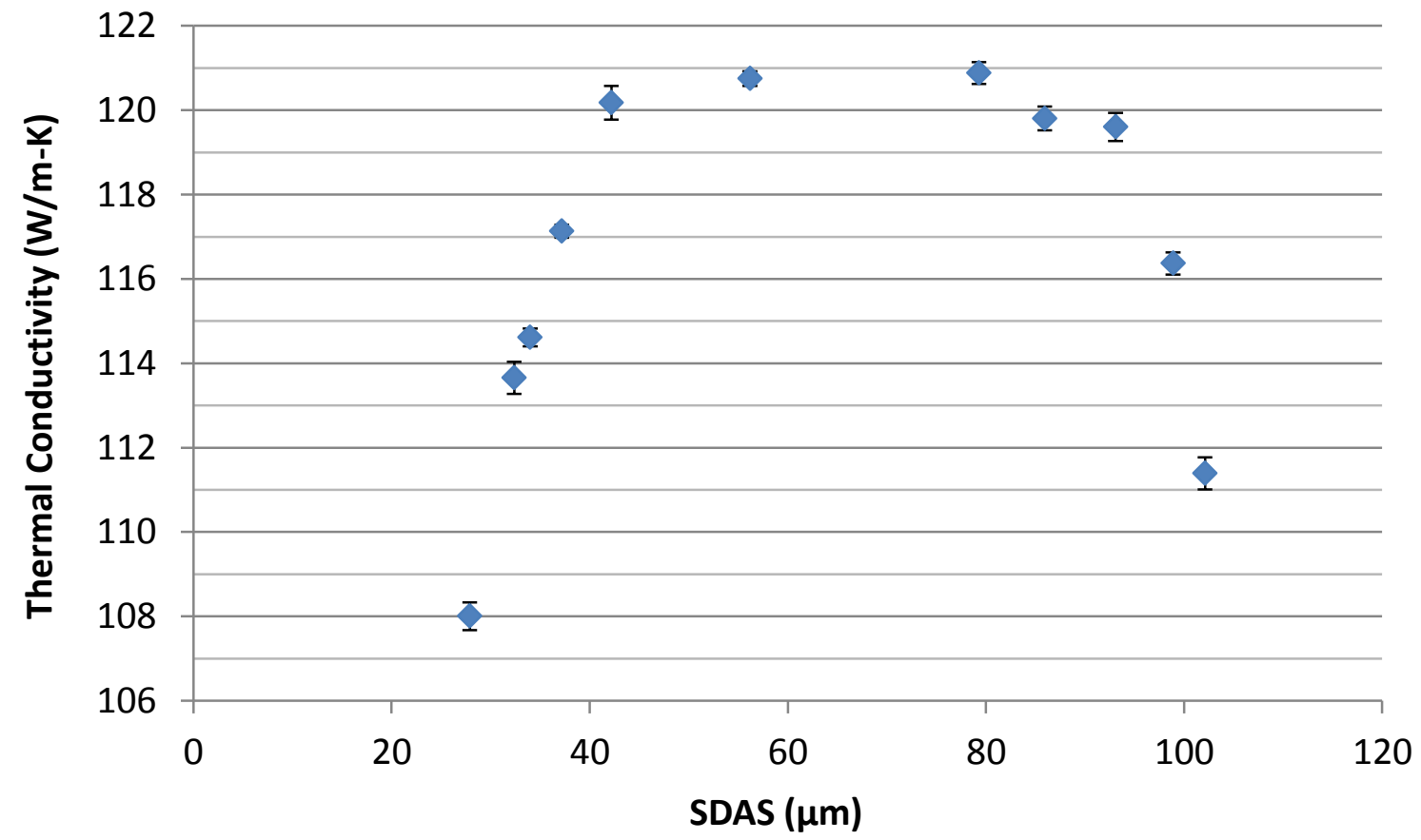

Figure D-17: Thermal conductivity as a function of secondary dendrite arm spacing 


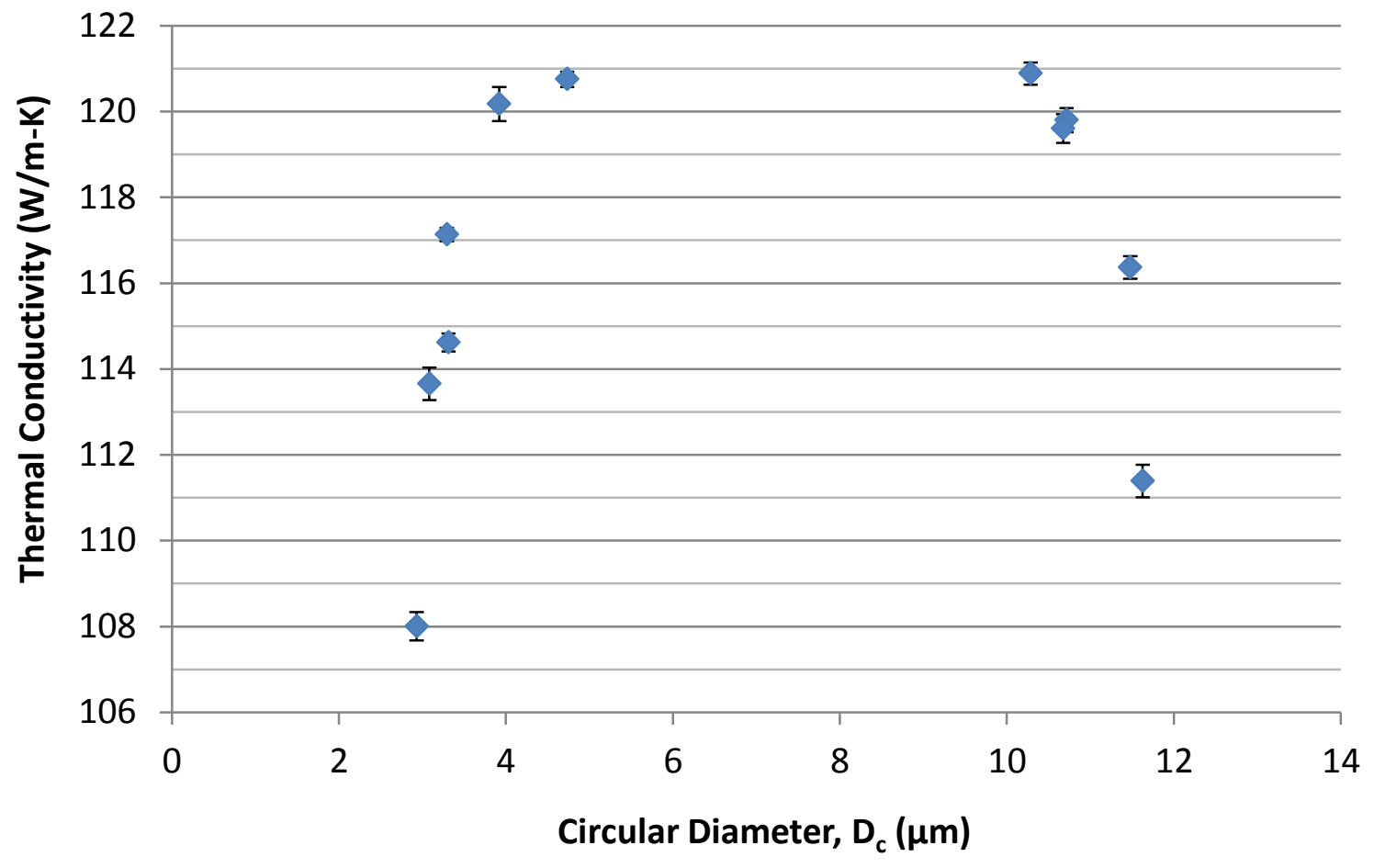

Figure D-18: Thermal conductivity as a function of median eutectic Si circular diameter 


\section{REFERENCES}

[1] J. Davis, Ed., ASM Specialty Handbook: Aluminum and Aluminum Alloys, Materials Park: ASM International, 1993.

[2] L. Arnberg and L. Backerud, Solidification Characteristics of Aluminum Alloys, Volume 3: Dendrite Coherency, S. Thomas, Ed., Des Plaines, Illinois: American Foundrymen's Society, Inc., 1996.

[3] Z. Li, A. Samuel, F. Samuel, C. Ravindran and S. Valtierra, "Effect of Alloying Elements on the Segregation and Dissolution of $\mathrm{CuAl}_{2}$ Phase in Al-Si-Cu Alloys," Journal of Materials Science, vol. 38, pp. 1203-1218, 2003.

[4] S. Hegde and K. Prabhu, "Modification of eutectic silicon in Al-Si alloys," Journal of Materials Science, vol. 43, pp. 3009-3027, 2008.

[5] G. Sigworth, "The modification of Al-Si casting alloys: Important practical and theoretical aspects," AFS Transactions, vol. 116, pp. 115-139, 2008.

[6] G. Sigworth, "Determining grain size and eutectic modification in aluminum alloy castings," Modern Casting, vol. 77, pp. 23-25, 1987.

[7] M. Djurdjevic, H. Jiang and J. Sokolowski, "On-line prediction of aluminum-silicon eutectic modification level using thermal analysis," Materials Characterization, vol. 46, pp. 31-38, 2001.

[8] L. Lasa and J. Rodriguez-Ibabe, "Evolution of the Main Intermetallic Phases in Al-Si-CuMg Casting Alloys during Solution Heat Treatment," Journal of Materials Science, vol. 39, pp. 1343-1355, 2004.

[9] L. Narayanan, F. Samuel and J. Gruzleski, "Crystallization Behavior of Iron-Containing Intermetallic Compounds in 319 Aluminum Alloy," Metallurgical and Materials 
Transactions A, vol. 25, pp. 1761-1773, 1994.

[10] R. Albonetti, "Porosity and Intermetallic Formation in Lost Foam Casting of 356 Alloy," M.E.Sc. Thesis, University of Western Ontario, London, 2000.

[11] J. Hwang, H. Doty and M. Kaufman, "The Effects of Mn Additions on the Microstructure and Mechanical Properties of Al-Si-Cu Casting Alloys," Materials Science and Engineering A, vol. 488, pp. 496-504, 2008.

[12] W. Callister, Materials Science and Engineering: An Introduction, 8th ed., Wiley, 2010.

[13] D. Gloria and J. Gruzleski, "Time as a Control Parameter in Determination of Grain Size of 319 Al-Si-Cu Foundry Alloy," AFS Transactions, vol. 107, pp. 419-424, 1999.

[14] J. Gruzleski, Microstructure Development During Metalcasting, Des Plaines: American Foundrymen's Society, Inc., 2000.

[15] D. Porter and K. Easterling, Phase Transformations in Metals and Alloys, 2nd ed., Boca Raton: CRC Press, 1992.

[16] G. Vander Voort, Ed., "Metallography and Microstructures," in ASM Handbook, vol. 9, Materials Park, ASM International, 2004.

[17] Y. Shi, Q. Xu, R. Chen, B. Liu, Q. Wu and H. Yang, "A microstructure-strength calculation model for predicting tensile strength of AlSi7Mg alloy castings," in 2nd World Congress on Integrated Computational Materials Engineering, Somerset, 2013.

[18] R. Sharma, Phase Transformations in Materials, New Delhi: CBS Publishers and Distributors, 2002.

[19] V. Gerold, "Precipitation Hardening," in Dislocations in Solids, Amsterdam, North-Holland Publishing Company, 1979, p. 222.

[20] N. Tenekedjiev, H. Mulazimoglu, B. Closset and J. Gruzleski, Microstructures and Thermal Analysis of Strontium-Treated Aluminum-Silicon Alloys, S. Thomas, Ed., Des Plaines, 
Illinois: American Foundrymen's Society, Inc. , 1995.

[21] F. Samuel, P. Ouellet, A. Samuel and H. Doty, "Effect of Mg and Sr Additions on the Formation of Intermetallics in Al-6 wt pet Si-3.5 wt pet Cu-(0.45) to (0.8) wt pet Fe 319type Alloys," Metallurgical and Materials Transactions A, vol. 29, no. 12, pp. 2871-2884, 1998.

[22] M. Djurdjevic, W. Kierkus, G. Byczynski, T. Stockwell and J. Sokolowski, "Modeling of Fraction Solid for 319 Aluminum Alloy," AFS Transactions, vol. 107, pp. 173-179, 1999.

[23] P. Ólafsson, R. Sandström and Å. Karlsson, "Comparison of experimental, calculated and observed values for electrical and thermal conductivity of aluminiums alloys," Journal of Materials Science, vol. 32, pp. 4383-90, 1997.

[24] M. Mulazimoglu, R. Drew and J. Gruzleski, "Electrical conductivity of aluminium-rich AlSi-Mg alloys," Journal of Materials Science Letters, vol. 8, pp. 297-300, 1989.

[25] R. Lumley, N. Deeva, R. Larsen, J. Gembarovic and J. Freeman, "The Role of Alloy Composition and T7 Heat Treatment in Enhancing Thermal Conductivity of Aluminum High Pressure Diecastings," Metallurgical and Materials Transactions A, vol. 44A, pp. 1074-1086, 2013.

[26] F. Stadler, H. Antrekowitsch, W. Fragner, H. Kaufmann, E. Pinatel and P. Uggowitzer, "The effect of main alloying elements on the physical properties of Al-Si foundry alloys," Materials Science \& Engineering A, vol. 560, pp. 481-491, 2013.

[27] M. Mulazimoglu, R. Drew and J. Gruzleski, "The Electrical Conductivity of Cast Al-Si Alloys in the Range 2 to 12.6 Wt Pct Silicon," Metallurgical Transactions A, vol. 20A, pp. 383-389, 1989.

[28] C. Ho, M. Ackerman, K. Wu, S. Oh and T. Havill, "Thermal Conductivity of Ten Selected Binary Alloy Systems," Journal of Physical and Chemical Reference Data, vol. 7, no. 3, pp. 959-1177, 1978. 
[29] A. Manzano Ramirez, F. Espinoza Beltran, J. Yanez-Limon, Y. Vorobiev and J. GonzalezHernandez, "Effects of porosity on the thermal properties of a 380-aluminum alloy," Journal of Materials Research, vol. 14, no. 10, pp. 3901-3906, 1999.

[30] D. Argo, R. Drew and J. Gruzleski, "A Simple Electrical Conductivity Technique for Measurement of Modification and Dendrite Arm Spacing in Al-Si Alloys," AFS Transactions, vol. 95, pp. 455-464, 1987.

[31] B. Closset, K. Pirie and J. Gruzleski, "Comparison of Thermal Analysis and Electrical Resistivity in Microstructure Evaluation of Al-Si Foundry Alloys," AFS Transactions, vol. 92, pp. 123-133, 1984.

[32] M. Mulazimoglu, R. Drew and J. Gruzleski, "Solution Treatment Study of Cast Al-Si Alloys by Electrical Conductivity," Canadian Metallurgical Quarterly, vol. 28, no. 3, pp. 251-258, 1989.

[33] C. Vázquez-López, A. Calderón, M. Rodríguez, E. Velasco, S. Cano, R. Colás and S. Valtierra, "Influence of dendrite arm spacing on thermal conductivity of an aluminumsilicon casting alloy," Journal of Materials Research, vol. 15, no. 1, pp. 85-91, 2000.

[34] H. Oger, B. Closset and J. Gruzleski, "Characterization of the Eutectic Microstructure in AlSi Foundry Alloys by Electrical Resistivity," AFS Transactions, vol. 91, pp. 17-20, 1983.

[35] Hot Disk AB, "Hot Disk Thermal Constants Analyser Instruction Manual," Göteborg, 2015.

[36] T. Log and S. Gustafsson, "Transient plane source (TPS) technique for measuring thermal transport properties of building materials," Fire and Materials, vol. 19, pp. 43-49, 1995.

[37] M. Gustavsson, N. Saxena, E. Karawacki and S. Gustafsson, "Specific Heat Measurements with the Hot Disk Thermal Constants Analyser," Thermal Conductivity, vol. 23, pp. 56-65, 1996.

[38] "ASTM B557: Standard Test Methods for Tension Testing Wrought and Cast Aluminum," ASTM International, West Conshohocken, 2014. 
[39] D. Lide, Ed., CRC Handbook of Chemistry and Physics, 70th ed., Boca Raton: CRC Press, 1990.

[40] M. Pariona and A. Mossi, "Numerical Simulation of Heat Transfer during the Solidification of Pure Iron in Sand and Mullite Molds," Journal of the Brazilian Society of Mechnical Sciences and Engineering, vol. 27, no. 4, pp. 399-406, 2005.

[41] C. Paul and P. Venugopal, "Modelling of Interfacial Heat Transfer Coefficient and Experimental Verification for Gravity Die Casting of Aluminium Alloys," International Journal of Mechanical Engineering and Technology, vol. 1, no. 1, pp. 253-274, 2010.

[42] E. Vandersluis, A. Lombardi, C. Ravindran, A. Bois-Brochu, F. Chiesa and R. MacKay, "Factors influencing thermal conductivity and mechanical properties in 319 Al alloy cylinder heads," Materials Science and Engineering A, vol. 648, pp. 401-411, 2015.

[43] H. Lukas, "Aluminum-Copper-Silicon," in Ternary Alloys, vol. 5, G. Effenberg and G. Petzow, Eds., Weinheim Germany, VCH Verlagsgesellschaft, 1992, pp. 11-21. 